GÖTTINGER ZENTRUM

FÜR BIODIVERSITÄTSFORSCHUNG UND ÖKOLOGIE

- Göttingen Centre for Biodiversity ANd ECology -

\title{
Herb layer characteristics, fly communities and trophic interactions along a gradient of tree and herb diversity in a temperate deciduous forest
}

\author{
Dissertation zur Erlangung des Doktorgrades der \\ Mathematisch-Naturwissenschaftlichen Fakultäten der \\ Georg-August-Universität Göttingen
}

\author{
vorgelegt von \\ Mag. rer. nat. \\ Elke Andrea Vockenhuber \\ aus \\ Wien
}

Göttingen, Juli, 2011 
Referent: Prof. Dr. Teja Tscharntke

Korreferent: Prof. Dr. Stefan Vidal

Tag der mündlichen Prüfung: 16.08.2011 


\section{CONTENTS}

Chapter 1: General Introduction..........................................................................................5

Effects of plant diversity on ecosystem functioning and higher trophic levels ................................................... 6

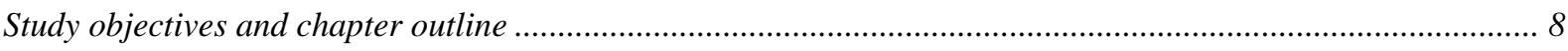

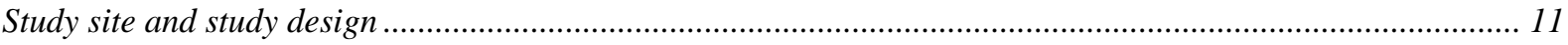

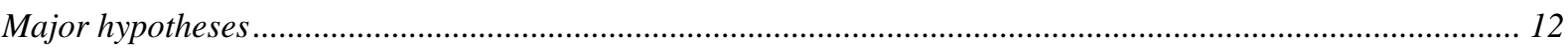

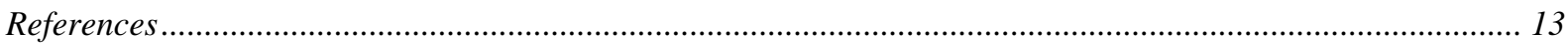

Chapter 2: Tree diversity and environmental context predict herb species richness and cover in Germany's largest connected deciduous forest ...................................................... 16

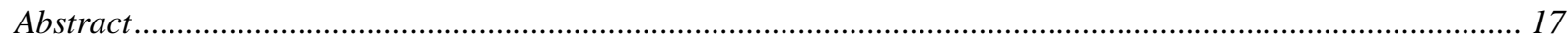

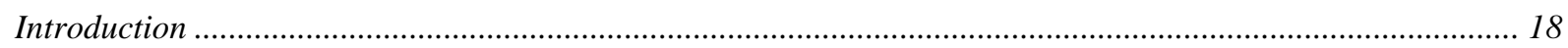

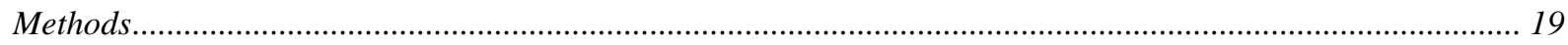

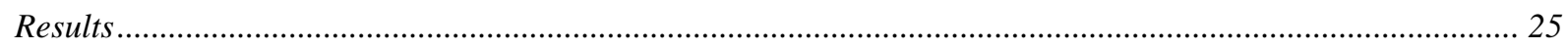

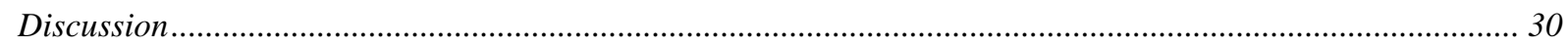

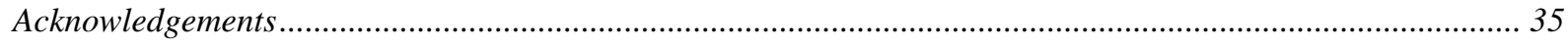

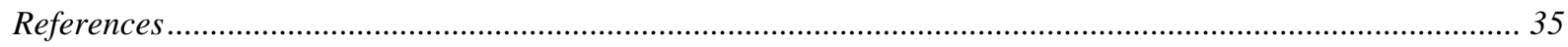

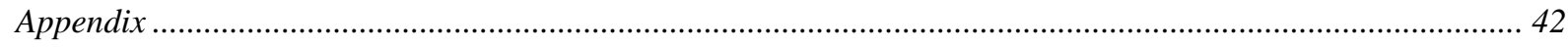

Chapter 3: Richness, abundance, and community composition of flies (Diptera) across a tree and herb diversity gradient ..................................................................................................... 57

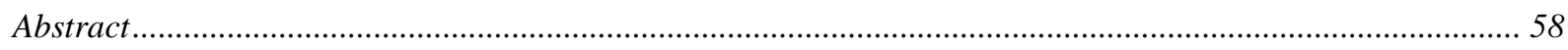

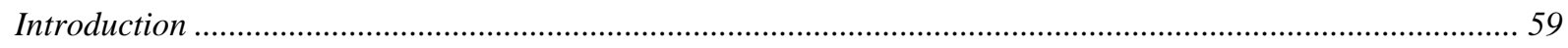

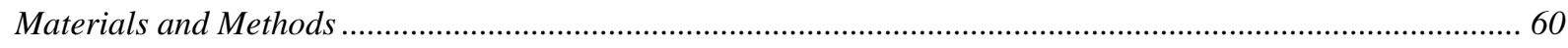

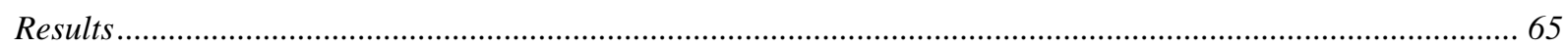

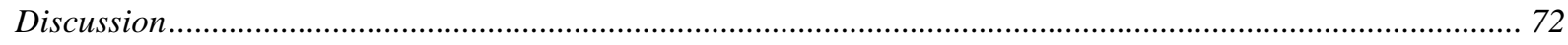

Acknowledgements ............................................................................................................................. 77

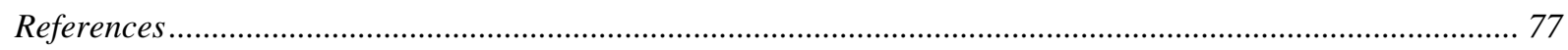

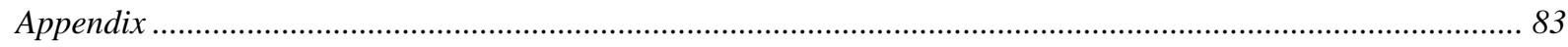


Chapter 4: Herbivory, seed production and seed predation in forest herbs along a tree

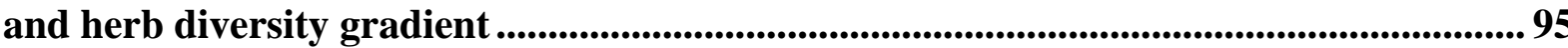

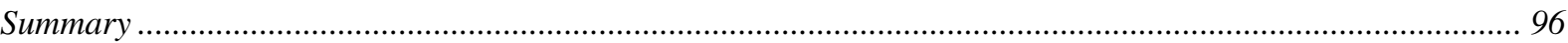

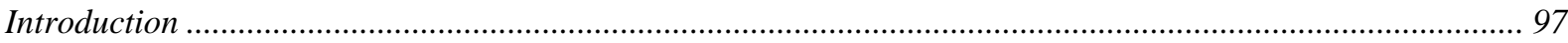

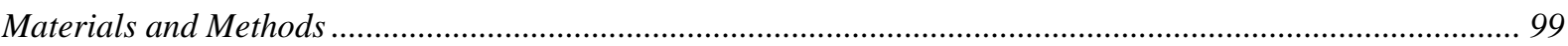

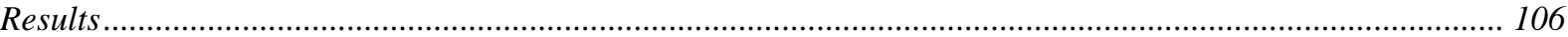

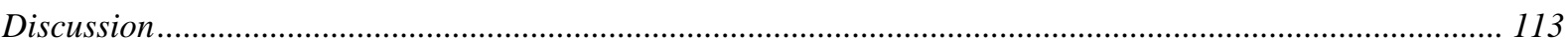

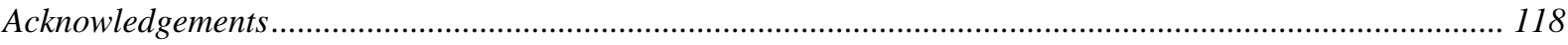

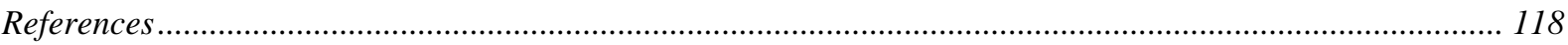

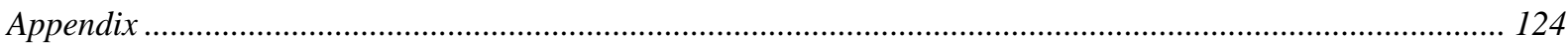

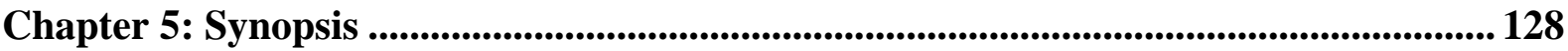

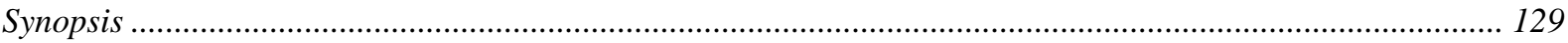

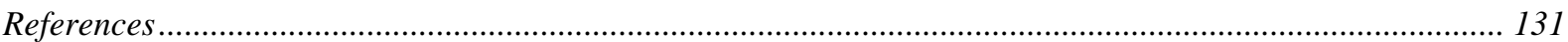

Summary .......................................................................................................................................... 132

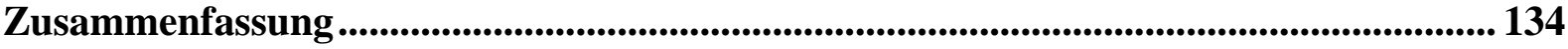

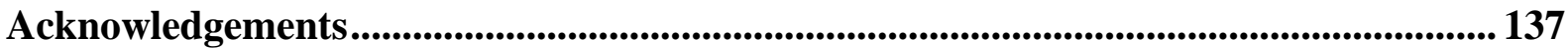

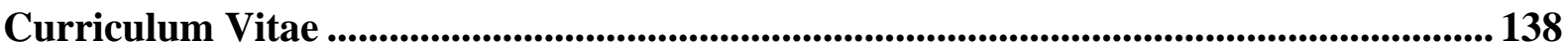

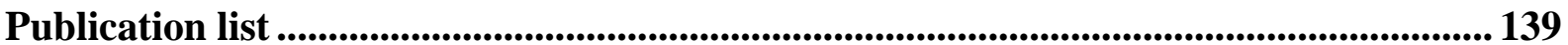

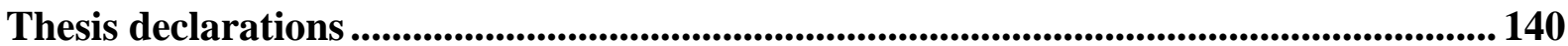


CHAPTER 1

\section{General Introduction}

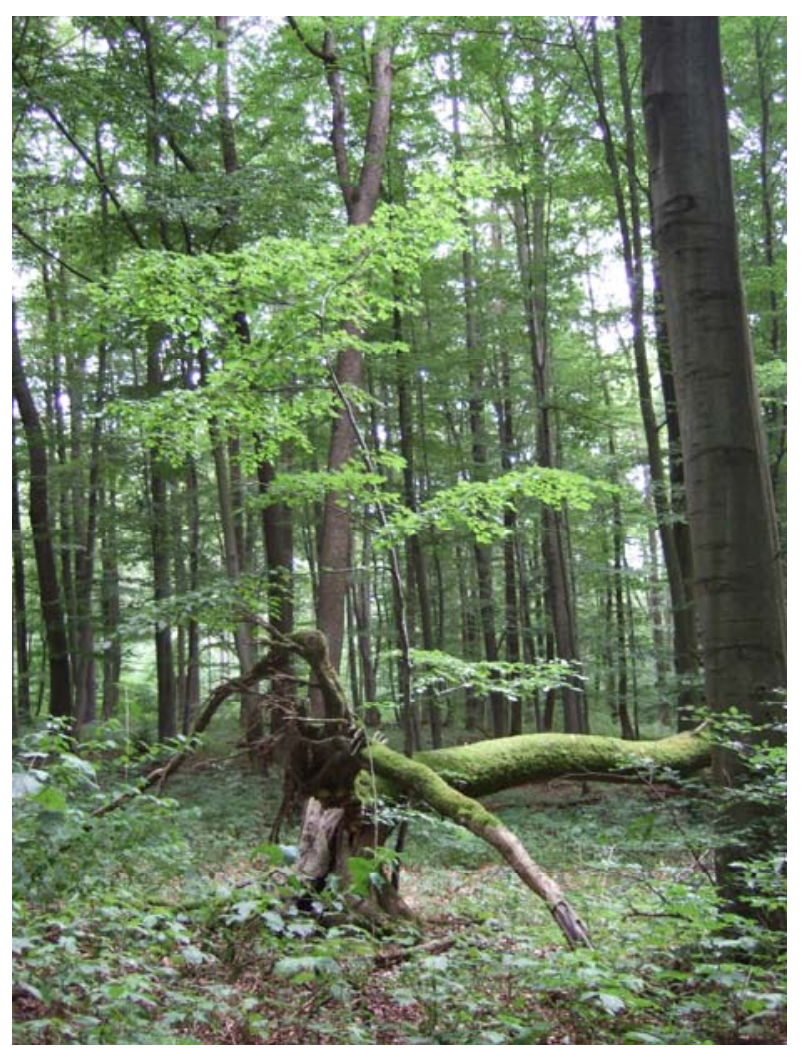




\section{Effects of plant diversity on ecosystem functioning and higher trophic levels}

In the light of human-induced biodiversity loss, it is crucial to understand how changing biodiversity alters processes and components of ecosystems. Much research effort has gone into the field of biodiversity - ecosystem functioning relationships, and it was discovered that biodiversity can play a major role for ecosystem processes and properties such as biomass production, nutrient retention and ecosystem stability (Hooper et al. 2005). In many studies, the focus lies on the diversity of plants due to their vital role as primary producers. Biodiversity effects are generally ascribed to two potential mechanisms (Cardinale et al. 2011): (1) Due to differences in functional traits, different species exhibit complementarity in their resource requirements and adaptations to environmental conditions (niche differentiation). Therefore, combinations of species can exploit the resource space more effectively than communities of the same species. (2) Species-rich communities are more likely to contain species with particularly important traits that contribute disproportionally to ecosystem processes (sampling or selection effect). While this effect was first considered as an artefact in biodiversity experiments based on artificially assembled plant communities, some ecologists argue that it is also relevant in natural ecosystems because community composition can in part depend on stochastic processes (Hooper et al. 2005).

Plant diversity not only affects ecosystem processes, but also communities of higher trophic level organisms, for instance arthropods associated with plants (Haddad et al. 2009). In particular, herbivore diversity has been shown to increase with increasing plant diversity (Scherber et al. 2010). It is not surprising that herbivores, a trophic group closely tied to plants, respond strongest to a greater variety of different feeding resources, considering that many herbivorous species show some degree of feeding specialisation. However, also polyphagous herbivores may benefit from diverse vegetation due to positive effects of dietary mixing (Schuldt et al. 2010). Albeit fewer studies exist on links between plant diversity and saprophagous taxa, saprophages may also be influenced because a higher number of plant species increases the heterogeneity of plant litter and carbon substrates entering the ground, e.g. via root exudates (Hooper et al. 2000). As for predators and parasitoids, they may benefit from a greater variety and abundance of prey and host species in diverse plant communities (Russell 1989). In addition, the higher structural complexity that often goes along with with higher plant diversity has been shown to enhance diversity and abundance of insect taxa from various trophic groups, possibly due to a greater availability of spaces for sheltering, eggdeposition and over-wintering (Strong et al. 1984). 
Multitrophic interactions between plants and invertebrates, such as herbivory, pollination and seed predation, can have pronounced impacts on plant performance and population dynamics (Crawley 1997). However, little is known on how these interactions are modified by varying levels of plant diversity. In the case of pollination, several studies suggest that plant diversity is positively linked to the diversity and abundance of pollinators and may thus enhance pollination success (Ebeling et al. 2008; Ghazoul 2006). As for herbivory, previous studies have yielded contrasting results, with positive, negative or no relationship recorded between plant diversity and the amount of herbivore damage. Early theory predicts increased herbivory in plant monocultures compared to mixed stands because plants are structurally or chemically masked from herbivores in mixed stands (resource concentration hypothesis) and/or natural enemies have higher populations in mixed stands and can therefore more effectively control herbivores (enemies hypothesis) (Root 1973). However, the relevance of these theories for natural ecosystems is debatable considering that they only apply to specialist herbivores and that monospecific stands of only one plant species are fairly rare in natural systems. Indeed, rates of herbivore damage may also increase with increasing plant diversity because of more diverse and abundant herbivore communities in diverse settings (Prieur-Richard et al. 2002).

The majority of studies on the relationship between plant diversity and the diversity of higher trophic levels or multitrophic interaction have been conducted in grassland ecosystems. Forests ecosystems, on the other hand, have rarely been considered, although forests house most of the planet's biodiversity (Klenner et al. 2009). While most of aboveground plant structures in grassland communities are freshly produced every year, trees build up forest biomass over hundred years or more. Therefore, effects caused by differences between tree species can become more pronounced over time (Scherer-Lorenzen et al. 2005). Moreover, forests are characterised by a higher complexity due to their greater biomass and organization into different layers. Several studies have shown lower rates of herbivory in more diverse forest stands (Jactel and Brockerhoff 2007), but these studies mostly involved comparisons between monocultures and two- or three-species stands. Recently, longer gradients of tree diversity are also employed (Schuldt et al. 2010; Sobek et al. 2009).

The herb layer represents a crucial, yet understudied element of forest ecosystems. It generally encompasses most of a forest's plant diversity (especially in temperate regions), plays an important role in nutrient cycling and provides habitat for many forest-dwelling animals (Gilliam 2007; Whigham 2004). Nevertheless, studies on insect communities in the herb layer, or on interactions between insects and herb layer plants, are quite rare, and hardly any studies exist on plant diversity effects in the herb layer. Herb layer and tree layer show 
close linkages, with the canopy composition strongly influencing light availability, litter layer characteristics and soil moisture on the ground (Barbier et al. 2008). Therefore, it is also feasible that tree diversity affects herb layer characteristics such as plant diversity and vegetation cover. Indeed, previous studies found a positive relationship between the diversity of the two forest strata (Mölder et al. 2008).

\section{Study objectives and chapter outline}

This thesis is focused on plant diversity effects in the herb layer of a temperate deciduous forest. First, we explored possible linkages between the diversity of the tree and the herb layer. In this study, we also assessed the relative importance of a possible tree diversity effect on herb layer characteristics compared to influences of abiotic environmental variables (chapter 2). Furthermore, we investigated how the vegetational diversity of tree and herb layer influences the community characteristics of flies (Diptera) (chapter 3). Finally, we studied plant-invertebrate interactions in the herb layer along a tree and herb diversity gradient (chapter 4).

We started off by looking at determinants of herb layer diversity. While several abiotic variables such as soil $\mathrm{pH}$ and light availability have been identified as important drivers of herb layer characteristics, also the presence of specific canopy species can strongly impact the vegetation on the ground (Barbier et al. 2008). Here we investigated how the diversity of the tree layer is associated with diversity and cover of the herb layer. In doing so, we separately assessed effects on several functional groups of herb layer plants (forbs, grasses, tree saplings) which may differ in their responses to tree diversity. 


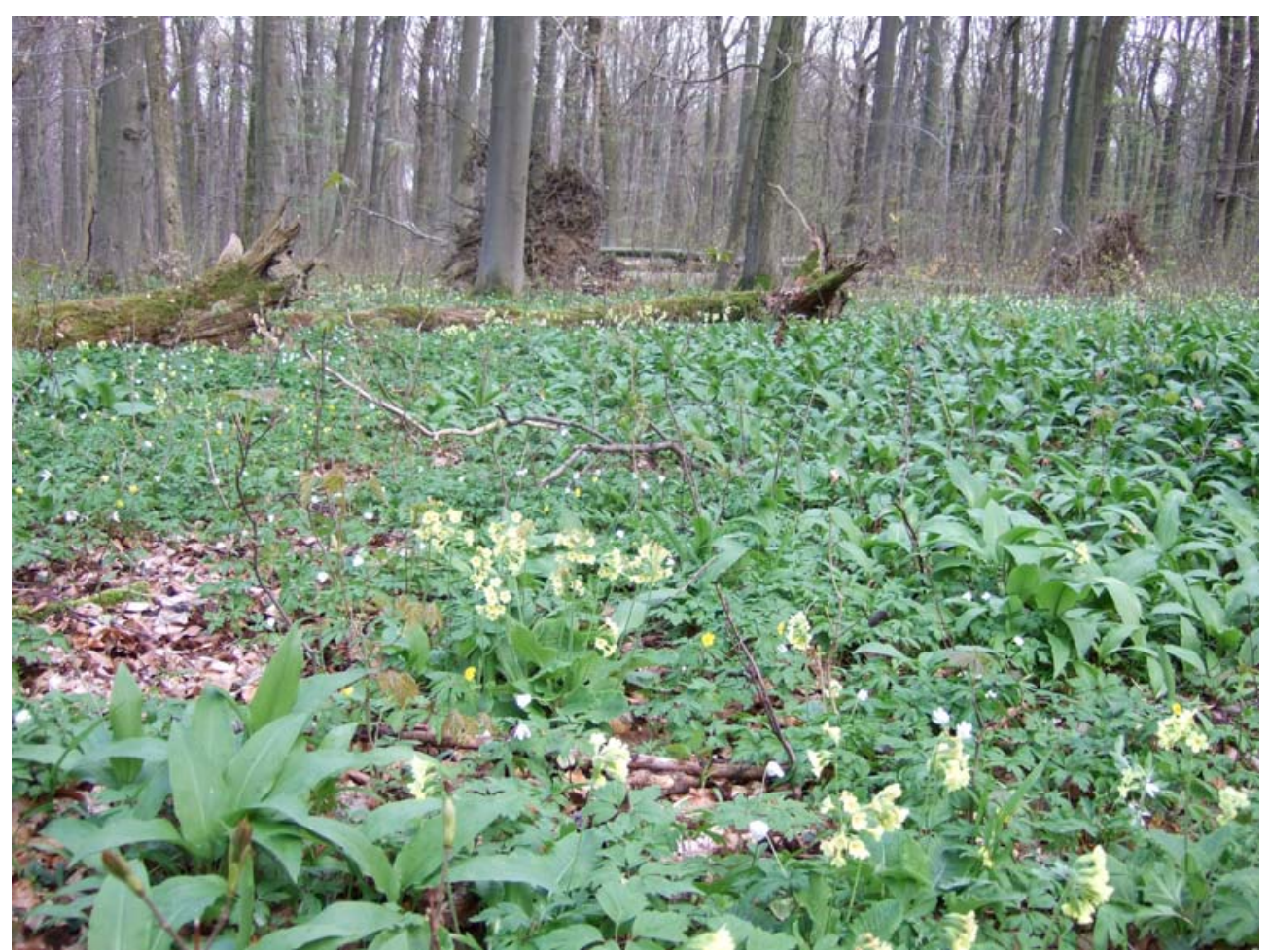

Fig. 1. Herb layer in the Hainich National Park in spring 2010.

Next, we focused on one particular insect taxon, namely flies, to study plant diversity effects on insect community characteristics in the herb layer. Flies are a ubiquitous and highly diverse insect taxon that fulfils many important ecological functions, for example as herbivores, predators, parasitoids and saprophages (Allgood et al. 2009; Oosterbroek 2007). Nevertheless, flies are often over-looked in ecological studies, probably partly because the identification of this species-rich group often poses difficulties. Particularly in the herb layer of temperate forest, very few studies have focused on habitat requirements of flies or on factors influencing fly community characteristics. In this thesis we used this under-studied insect taxon to explore relationships between the diversity of different forest strata and insect diversity, abundance and community composition. As it has been shown that not only plant diversity, but also plant biomass and structural complexity can enhance insect diversity, we also assessed the importance of vegetation cover for fly communities. 

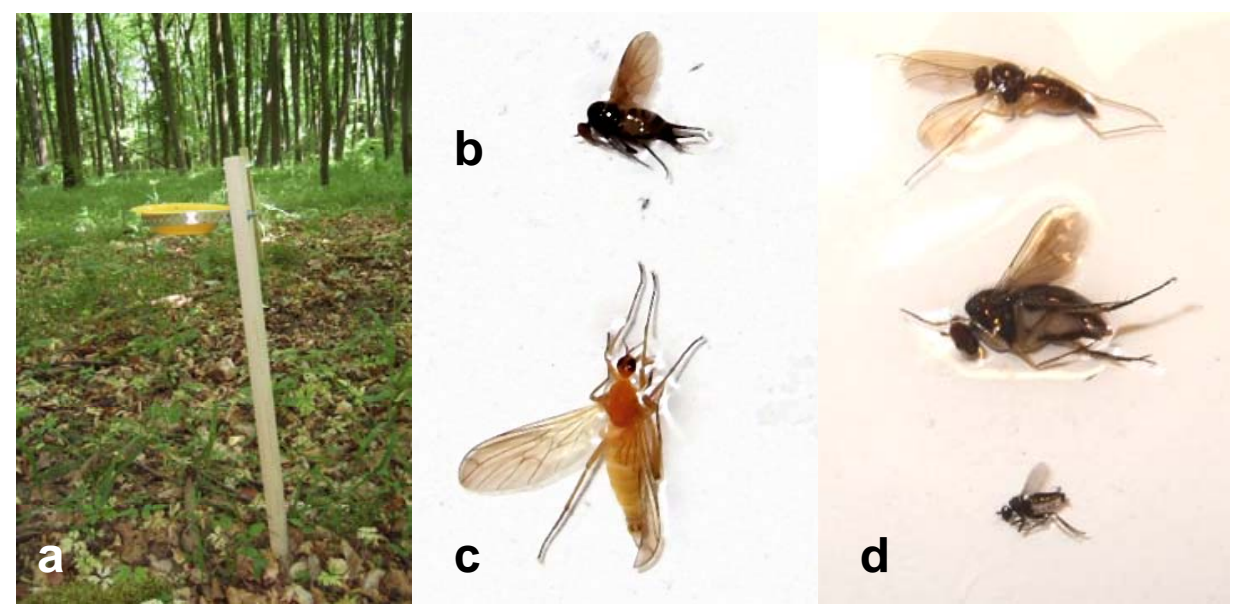

Fig. 2. (a) Yellow pan trap used for fly sampling. The most abundant fly families in samples were (b) Phoridae, (c) Empididae and (d) Dolichopodidae.

Finally, we brought together the plant and the insect side of this thesis by studying plantinvertebrate interactions in the herb layer. Trophic interactions can play an important role for the performance of herb layer plants, but little is known on how plant diversity may modify these interactions. We addressed this research gap by studying the performance of individuals of two common forest herbs (Lathyrus vernus and Primula elatior) which were experimentally added to forest plots (phytometer approach). This allowed an assessment of herbivory and pollination, two important trophic interactions, along a gradient of herb and tree diversity. Additionally we used a seed removal experiment to study effects of tree and herb diversity on seed predation and to identify dominant seed predator groups.
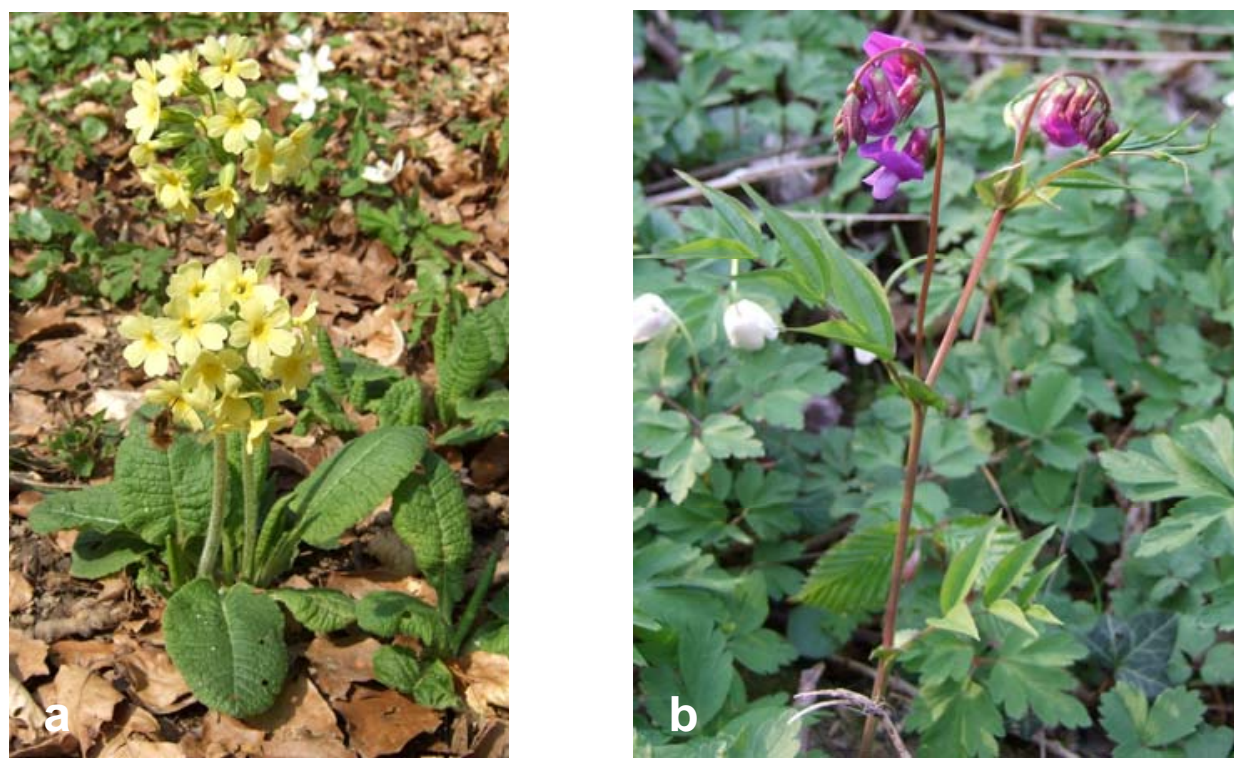

Fig. 3. Study species in the phytometer experiment. (a) Primula elatior (b) Lathyrus vernus 


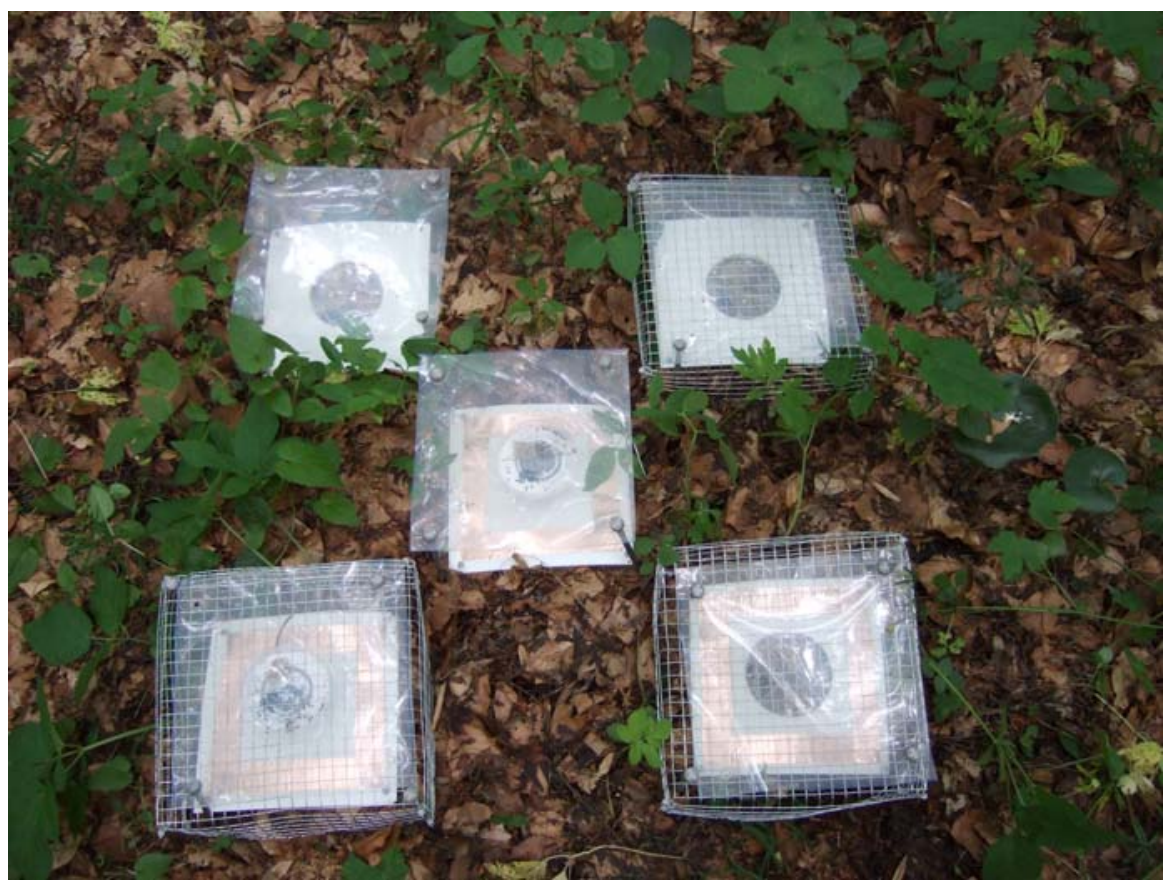

Fig. 4. Seed predation experiment with various predator exclusion treatments.

\section{Study site and study design}

This study was carried out in the framework of the Research Training Group 1086 "The role of biodiversity for biogeochemical cycles and biotic interactions in temperate deciduous forests". Over the course of nine years, this project aims to investigate effects of tree diversity on a variety of ecosystem processes, for instance carbon sequestration, nutrient and water turnover, nitrate leaching and below- and aboveground biotic interactions. An extensive list of investigated variables can be found in Leuschner et al. (2009).

The project is based on research sites in the Hainich National Park in Thuringia (central Germany), which encompasses near-natural temperate deciduous forest. Formerly a military training ground, the area became a National Park in 1997. The Hainich forest covers an area of approximately 16.000 hectares, of which 7.500 hectares have national park status. This makes it the largest connected area of deciduous forest in Germany. The research sites of the Research Training Group are located in two sub-areas (Lindig and Thiemsburg, distance approximately $1.5 \mathrm{~km}$ ) in the south-east of the National Park, near the village of Weberstedt. Due to differences in historic land ownership and management practises, the forest in this area forms a mosaic of stands differing in tree diversity, ranging from nearly monospecific beech stands to species-rich stands with up to nine broad-leaved tree species (Leuschner et al. 2009). The study area has held deciduous forest for at least 200 years and represents ancient 
woodland as defined by Wulf (2003). Investigated forest stands have been essentially unmanaged for 40 years.

In the second phase of the Research Training Group, 100 study plots were selected based on all possible one-, two- and three-species combinations of the five tree species Fagus sylvatica L., Acer pseudoplatanus L., Fraxinus excelsior L., Carpinus betulus L., and Tilia sp., which represent the dominant tree species in the study area (Leuschner et al. 2009). Three tree individuals of a certain combination formed a "tree cluster". The 25 possible combinations included five one-species, ten two-species and ten three-species clusters. Every combination of tree species was replicated twice in the Lindig location and twice in the Thiemsburg location, yielding a total of 100 tree clusters. An area of $4 \mathrm{~m}^{2}$ at the centre of the triangle formed by the three tree individuals of a cluster represented the study plot. The experiments performed for this thesis (e.g. herb layer vegetation surveys, insect sampling, exposure of phytometer plants) were conducted on these central plots. However, for calculations of a cluster's tree diversity, we incorporated all trees growing in a radius of 20 metres around the cluster centre instead of only considering the three trees forming the cluster. While the smaller scale of three tree individuals served the needs of several subgroups investigating small-scale belowground processes, the larger scale of tree diversity within a $20 \mathrm{~m}$ radius was more appropriate for studying highly mobile flying insects.

\section{Major hypotheses}

We examined the following hypotheses:

(1) Herb layer diversity and cover increase with increasing tree diversity (chapter 2)

(2) Fly diversity and abundance increase with increasing tree and herb diversity (chapter 3)

(3) Trophic interactions are modified tree and herb diversity (chapter 4)

o Herbivory increases with increasing tree and herb diversity

o Pollination-dependent seed production increases with increasing tree and herb diversity

o Seed predation increases with increasing tree and herb diversity 


\section{References}

Allgood DW, Miller DA, Kalcounis-Rueppell MC (2009) Influence of Intensive Pine Management on Dipteran Community Structure in Coastal North Carolina. Environmental Entomology 38:657-666

Barbier S, Gosselin F, Balandier P (2008) Influence of tree species on understory vegetation diversity and mechanisms involved - A critical review for temperate and boreal forests. Forest Ecology and Management 254:1-15

Cardinale BJ et al. (2011) The functional role of producer diversity in ecosystems. American Journal of Botany 98:572-592

Crawley M (1997) Plant Ecology, 2nd edn. Blackwell Science, Oxford

Ebeling A, Klein AM, Schumacher J, Weisser WW, Tscharntke T (2008) How does plant richness affect pollinator richness and temporal stability of flower visits? Oikos $117: 1808-1815$

Ghazoul J (2006) Floral diversity and the facilitation of pollination. Journal of Ecology 94:295-304

Gilliam FS (2007) The ecological significance of the herbaceous layer in temperate forest ecosystems. Bioscience 57:845-858

Haddad NM, Crutsinger GM, Gross K, Haarstad J, Knops JMH, Tilman D (2009) Plant species loss decreases arthropod diversity and shifts trophic structure. Ecology Letters 12:1029-1039

Hooper DU et al. (2000) Interactions between aboveground and belowground biodiversity in terrestrial ecosystems: Patterns, mechanisms, and feedbacks. Bioscience 50:10491061

Hooper DU et al. (2005) Effects of biodiversity on ecosystem functioning: A consensus of current knowledge. Ecological Monographs 75:3-35

Jactel H, Brockerhoff EG (2007) Tree diversity reduces herbivory by forest insects. Ecology Letters 10:835-848

Klenner W, Arsenault A, Brockerhoff EG, Vyse A (2009) Biodiversity in forest ecosystems and landscapes: A conference to discuss future directions in biodiversity management for sustainable forestry. Forest Ecology and Management 258:S1-S4

Leuschner C, Jungkunst HF, Fleck S (2009) Functional role of forest diversity: Pros and cons of synthetic stands and across-site comparisons in established forests. Basic and Applied Ecology 10:1-9 
Mölder A, Bernhardt-Römermann M, Schmidt W (2008) Herb-layer diversity in deciduous forests: Raised by tree richness or beaten by beech? Forest Ecology and Management $256: 272-281$

Oosterbroek P (2007) The European families of the Diptera. KNNV Publishing, Utrecht

Prieur-Richard AH, Lavorel S, Linhart YB, Dos Santos A (2002) Plant diversity, herbivory and resistance of a plant community to invasion in Mediterranean annual communities. Oecologia 130:96-104

Root RB (1973) Organization of a plant-arthropod association in simple and diverse habitats fauna of collards (Brassica oleracea). Ecological Monographs 43:95-120

Russell EP (1989) Enemies hypothesis - a review of the effect of vegetational diversity on predatory insects and parasitoids. Environmental Entomology 18:590-599

Scherber C, Eisenhauer, N, Weisser, WW, Schmid, B, Voigt, W, Fischer, M, Schulze, ED, Roscher, C, Weigelt, A, Allan, E, Bessler, H, Bonkowski, M, Buchmann, N, Buscot, F, Clement, LW, Ebeling, A, Engels, C, Halle, S, Kertscher, I, Klein, AM, Koller, R, Konig, S, Kowalski, E, Kummer, V, Kuu, A, Lange, M, Lauterbach, D, Middelhoff, C, Migunova, VD, Milcu, A, Muller, R, Partsch, S, Petermann, JS, Renker, C, Rottstock, T, Sabais, A, Scheu, S, Schumacher, J, Temperton, VM, Tscharntke, T (2010) Bottom-up effects of plant diversity on multitrophic interactions in a biodiversity experiment. Nature 468:553-556

Scherer-Lorenzen M, Körner C, Schulze ED (2005) The functional significance of tree diversity: a synthesis. In: Scherer-Lorenzen M, Körner C, Schulze ED (eds) Forest diversity and function. Temperate and boreal systems. Springer, Berlin

Schuldt A, Baruffol, M, Bohnke, M, Bruelheide, H, Hardtle, W, Lang, AC, Nadrowski, K, von Oheimb, G, Voigt, W, Zhou, HZ, Assmann, T (2010) Tree diversity promotes insect herbivory in subtropical forests of south-east China. Journal of Ecology 98:917926

Sobek S, Scherber C, Steffan-Dewenter I, Tscharntke T (2009) Sapling herbivory, invertebrate herbivores and predators across a natural tree diversity gradient in Germany's largest connected deciduous forest. Oecologia 160:279-288

Strong DR, Lawton JH, Southwood TRE (1984) Insects on Plants: Community Patterns and Mechanisms. Blackwell Scientific, Oxford

Whigham DE (2004) Ecology of woodland herbs in temperate deciduous forests. Annual Review of Ecology Evolution and Systematics 35:583-621 
Wulf M (2003) Preference of plant species for woodlands with differing habitat continuities.

Flora 198:444-460 


\section{CHAPTER 2}

\section{Tree diversity and environmental}

context predict herb species richness and cover in Germany's largest connected deciduous forest

E. A. Vockenhuber, C. Scherber, C. Langenbruch, M. Meißner, D. Seidel, T. Tscharntke

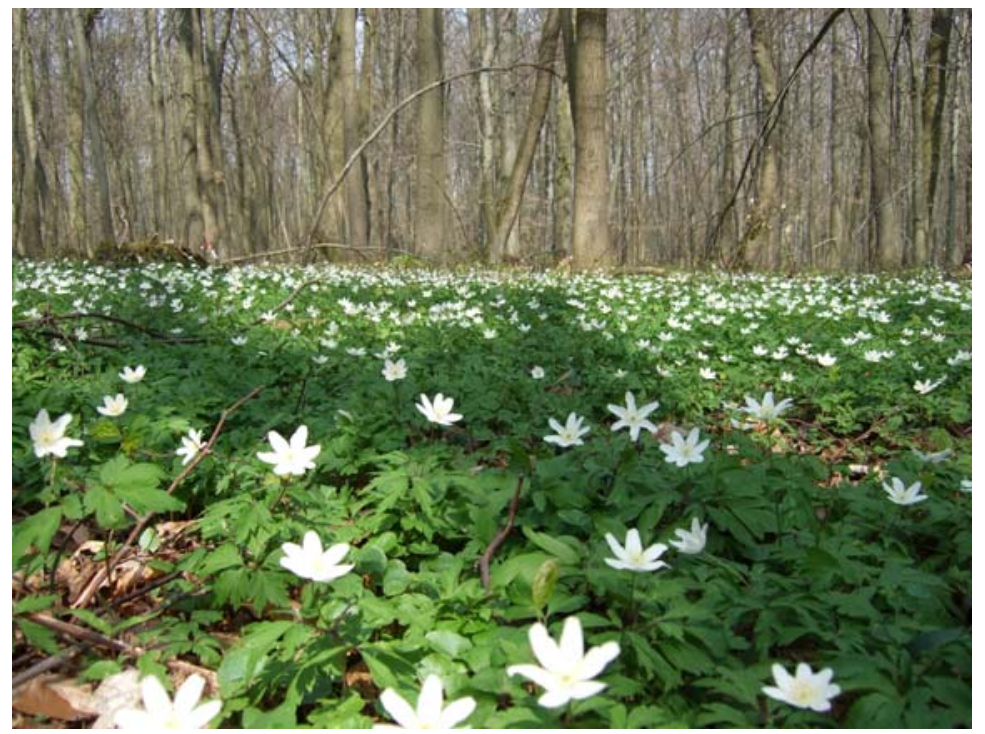

\section{Published in:}

Vockenhuber, E., Scherber, C., Langenbruch, C., Meißner, M., Seidel, D. \& Tscharntke, T. (2011) Tree diversity and environmental context predict herb species richness and cover in Germany's largest connected deciduous forest. Perspectives in Plant Ecology Evolution and Systematics, 13, 111-119. 


\begin{abstract}
In temperate deciduous forests, the herb layer contributes most to total vascular plant species richness. The diversity of the tree layer can influence herb layer diversity by modifying resource availability and environmental conditions relevant to herb layer plants. Here, we explore the relationship between tree layer diversity and herb layer species richness and cover. Also, we address the question how different environmental factors that are potentially modified by the tree layer influence herb layer characteristics. Our study area is located in the Hainich National Park, one of the largest continuous stretches of broad-leaved deciduous forest in Central Europe. We recorded herb and tree layer composition on 79 plots selected along a tree diversity gradient ranging from two to nine tree species. In addition, canopy cover, soil $\mathrm{pH}$, mass of the humus layer, soil $\mathrm{C}: \mathrm{N}$ ratio, soil moisture and distance to the forest edge were determined. We used generalized least squares models to analyse effects of tree diversity, environmental variables, and spatial plot positions on herb layer species richness and cover. Species richness and cover of the herb layer increased with increasing tree diversity. In addition, both species richness and cover showed a negative response to increasing canopy cover and mass of the humus layer. Herb layer species richness was also positively related to increasing soil $\mathrm{pH}$ and the distance to the forest edge. The proportion of forbs increased with increasing tree diversity, whereas the proportion of tree saplings decreased and the proportion of graminoids was not affected. The proportion of true forest species increased with increasing canopy cover. We conclude that forest stands with a high tree diversity feature a more diverse herb layer and a higher herb cover. Furthermore, the environmental variables humus layer mass, light availability and $\mathrm{pH}$ also strongly affect herb layer species richness and cover.
\end{abstract}

Keywords: understorey diversity, herbaceous layer, Fagus sylvatica, canopy cover, humus layer, $\mathrm{pH}$ 


\section{Introduction}

In temperate deciduous forests, the herb layer holds most of the total vascular plant diversity, comprising up to 90 percent of all plant species of the forest (Whigham, 2004; Gilliam, 2007). Although the herb layer makes up only a small proportion of the total forest biomass, it contributes substantially to energy flow and nutrient cycling (Yarie, 1980; Gilliam, 2007). Spring ephemeral herbs can act as nutrient sinks during spring when nutrient uptake by trees is low and deciduous forests experience the annual maximal loss of nutrients due to leaching (Peterson and Rolfe, 1982; Mabry et al., 2008). Herb foliage has a higher nutrient content than tree foliage and decomposes twice as rapidly (Muller, 2003), resulting in increased nutrient cycling (Gilliam, 2007).

Higher tree layer diversity might enhance herb layer diversity either by increasing environmental heterogeneity (Beatty, 2003) or by creating environmental conditions that are favourable to a greater number of herb species. While linkages between the diversity of the herb and tree layer have been commonly reported (Gilliam, 2007; Barbier et al., 2008), most studies so far compared herb layer diversity between forest types with only a few dominant tree species or between different monospecific stands, in particular conifer vs. broad-leaved forests. Little is known on how the diversity of the tree layer affects herb layer diversity across a wider gradient of broad-leaved tree species richness (Scherer-Lorenzen et al., 2007), though some results point towards a positive relationship between tree and herb layer diversity (Barbier et al., 2008; Mölder et al., 2008). In Europe, national forest programmes increasingly aim at enhancing forest biological diversity; however, research on ecosystem consequences of these biodiversity changes is still in its infancy.

A number of factors have been identified as determinants of herb layer diversity, for instance soil pH (Borchsenius et al., 2004; Hofmeister et al., 2009), nutrient availability (Small and McCarthy, 2005; Van Calster et al., 2008), soil moisture (Qian et al., 1997; Lenière and Houle, 2006), mass of the litter layer (Gazol and Ibáñez, 2009; Kooijman, 2010), light availability (Härdtle et al., 2003; Tinya et al., 2009), and distance to the forest edge (Harper et al., 2005; Gonzalez et al., 2009). Changes in tree layer diversity can modify these factors because tree species differ in canopy structure, litter quality, and physiological characteristics (van Oijen et al., 2005; Guckland et al., 2009; Jacob et al., 2009; Wulf and Naaf, 2009). In Central Europe, broad-leaved forests are usually dominated by Fagus sylvatica L., a highly competitive tree species characterized by crowns with low light transmissibility and lowdegradable litter with an acidifying effect on the soil (Ellenberg and Leuschner, 2010; 
Neirynck et al., 2000). Forests with high tree diversity show lower proportions of $F$. sylvatica and an increase in other broad-leaved tree species and might therefore be more suitable to a range of herb layer plants which do not tolerate conditions created by F. sylvatica (Mölder et al., 2008).

Here, we use a near-natural temperate deciduous forest system to study how tree diversity and environmental factors shape species richness and cover of the herb layer. We look separately at different plant functional groups and life forms to investigate group-specific responses. Furthermore, we analyse effects on the proportion of true forest species, because herbaceous species that are closely tied to forests may differ in their habitat requirements from plants that are only occasionally found under closed canopies (Burke et al., 2008). The Hainich National Park offers optimal conditions to study tree diversity effects; with its mixture of forest stands differing in tree diversity, it provides both the complexity of a natural forest ecosystem and a wide gradient in broad-leaved tree species diversity (Leuschner et al., 2009). We focus on the following questions:

(1) How are species richness and cover of the herb layer related to the diversity of the tree layer?

(2) Which environmental factors affect herb layer species richness and cover and what is their relative importance?

(3) How do the proportions of different plant functional groups and life forms respond to gradients of tree diversity and environmental variables?

(4) Which variables determine the proportion of true forest species in the herb layer?

\section{Methods}

\section{Study area and study sites}

We conducted our study in the Hainich National Park (Thuringia, Germany), near the village of Weberstedt $\left(51^{\circ} 05^{\prime} 28^{\prime}\right.$ 'N, $10^{\circ} 31^{\prime} 24^{\prime}$ 'E). The Hainich forest covers approximately 16,000 ha of wooded area, one of the largest continuous stretches of deciduous forest in Central Europe. The southern part of the Hainich forest has been subject to only very extensive management for over the past 40 years, becoming a military training ground in 1964 and a national park in 1997. Historic harvesting practises included coppicing systems and selective cutting (Mölder et al., 2006). Some areas (for instance the Lindig location, see below) still feature structural characteristics of a coppice-with-standards forest. All investigated forest 
stands hold deciduous forest for at least 200 years (Mölder, 2009). With this level of stand continuity, they represent ancient forest stands as defined by Wulf (2003). The median age of the canopy trees does not differ widely between different parts of the study area (79 to 117 years, see Mölder, 2009; our plots are located in close vicinity to the larger plots described by Mölder). Climatic conditions are subatlantic with continental influence; the mean annual temperature is $7.7^{\circ} \mathrm{C}$, mean annual precipitation amounts to $630 \mathrm{~mm}$ (Gauer and Aldinger, 2005). The research area is situated at an elevation of approximately $350 \mathrm{~m}$ a.s.1. The predominant soil type is (stagnic) Luvisol developed from Triassic limestone as bedrock with partial loess cover (Leuschner et al., 2009).

The dominant tree species are Fagus sylvatica L., Tilia platyphyllos Scop., Tilia cordata Mill., and Fraxinus excelsior L. The species Carpinus betulus L., Acer campestre L., Acer platanoides L., Acer pseudoplatanus L., Prunus avium L., Sorbus torminalis (L.) Crantz, Quercus robur L., Quercus petraea Liebl. and Ulmus glabra Huds. are found less frequently. Dominant forest communities include the Galio odorati-Fagetum Sougnez et Thill 1959, the Hordelymo-Fagetum Kuhn 1937, and the Stellario-Carpinetum Oberd. 1957 (Mölder et al., 2006). Due to historic differences in forest ownership and management, adjacent forest stands show different levels of tree diversity while still exhibiting comparable climatic and edaphic conditions (Leuschner et al., 2009).

In spring 2008, we selected $\mathrm{N}=100$ plots of differing tree diversity ("tree clusters"; see Leuschner et al., 2009) arranged in two locations (each $\mathrm{N}=50$ ), Lindig and Thiemsburg (distance between locations approximately $1.5 \mathrm{~km}$ ) (Appendix A). Plot selection was based on a priori combinations of tree species (Leuschner et al., 2009; not considered here). Plots were circular in shape (radius $20 \mathrm{~m}$ ), and plot centres were on average $60 \mathrm{~m}$ apart. 21 plots were excluded because they were surrounded by deer fences, leaving 36 plots at the Thiemsburg location, and 43 plots at the Lindig location (see Appendix A). Distances from the plot centres to the nearest forest edge were determined using maps and subsequently used for analyses. The mean distance to the forest edge was $387 \mathrm{~m}$; excluding the plot with the smallest distance to the edge $(17 \mathrm{~m})$ from analyses did not change results substantially. All plots were located at least $20 \mathrm{~m}$ away from forest paths, a distance that should be sufficient to avoid effects on the herb layer since it has been shown that the impact of forest paths on the vegetation extends less than 5-10 $\mathrm{m}$ into the surrounding forest (e.g. Avon et al., 2010). As the study area is located in a National Park, visitors are not allowed to walk off-track. Triassic limestone (Upper Muschelkalk) forms the soil parent material for all plots (Preußische Geologische Landesanstalt, 1905). To establish that initial soil properties were comparable 
between plots with different tree diversity, we tested for correlations between soil properties $(\mathrm{pH}, \mathrm{C}: \mathrm{N}$ content, clay content) of deeper soil horizons (10-20 cm depth) that are rarely modified by tree species (Augusto et al., 2003; Hagen-Thorn et al., 2004). C:N ratio and clay content of the deeper soil horizon were not correlated with tree diversity ( $\mathrm{C}: \mathrm{N}$ ratio: Spearman rank correlation coefficient $=0.05, \mathrm{P}=0.69$; clay content: Spearman rank correlation coefficient $=0.11, \mathrm{P}=0.34$ ), while $\mathrm{pH}$ showed only a weak positive correlation (Spearman rank correlation coefficient $=0.28, \mathrm{P}=0.01)$.

\section{Herb layer measurements}

Herb layer species richness and cover were recorded within two 1 x $1 \mathrm{~m}$ subplots near the plot centre in June 2008 and 2009. Vegetation survey plots of $1 \mathrm{~m}^{2}$ area have been previously used in studies on herb layer diversity patterns (van Oijen et al., 2005; Macdonald and Fenniak, 2007; Takafumi and Hiura, 2009) and are well suited to this type of studies since linkages between overstorey and understorey are often most easily detectable at small scales (Gilliam and Roberts, 2003). We estimated percentage cover of each vascular plant species present. All plants with a height $<70 \mathrm{~cm}$ were considered as belonging to the herb layer. The herb layer species richness per plot was calculated as the cumulative sum of different herb layer species over subplots and years. Mean cover values per subplot and year were used to calculate herb layer cover.

We assigned herb layer plant species to ecological groups based on three criteria:

(i) Functional group (forbs, graminoids, tree saplings, shrubs, vines, ferns), (ii) life form (phanerophytes, chamaephytes, hemicryptophytes, geophytes, therophytes; following Klotz et al., 2002), and (iii) forest specialisation (true forest species that are closely tied to closed forests vs. indifferent species, following Schmidt et al., 2003) (Appendix B). Tree saplings and vines were not included in the analysis of forest specialisation. Nomenclature of vascular plants follows Wisskirchen and Haeupler (1998).

As herb species richness was recorded in summer only, purely vernal herb species were not considered in this study. However, a comparison between 40 plots for which both spring and summer vegetation surveys were conducted in 2009 revealed a high correlation between the species richness found in spring and in summer (Pearson $r=0.97$ ). Therefore, we are confident that herb species richness data obtained in summer provides adequate information about overall herb species richness within the plots. 


\section{Tree layer measurements}

To measure tree diversity on the plots, we recorded species and diameter at breast height (dbh) of all trees with a $\mathrm{dbh}>6 \mathrm{~cm}$ that were present on the plot (circle with $20 \mathrm{~m}$ radius, area: $1257 \mathrm{~m}^{2}$ ) between April and August 2009. Tree diversity was expressed by the Shannon-Wiener diversity index $\left(H^{\prime}\right)$ based on relative stem area, which incorporates species richness as well as abundances of species (Magurran, 2004). The number of broad-leaved tree species per plot ranged from 2 to 9 species. Dominant species were F. sylvatica (Thiemsburg: 48\%, Lindig 5\%), Tilia sp. (Thiemsburg: 16\%, Lindig: 44\%) and F. excelsior (Thiemsburg: 20\%, Lindig 23\%). No conifers were present. T. cordata/ T. platyphyllos and Q. robur/Q. petraea were recorded on genus level as these species could not be reliably distinguished in the field.

\section{Measurement of abiotic variables}

Canopy cover was used as an indirect measure of the light regime on our study plots (Jennings et al., 1999). All plots were scanned during summer 2008 with a Z+F Imager 5006 terrestrial laser scanner (Zoller und Fröhlich, Wangen, Germany) in a multiple scan design with 5-12 scans per plot, with the laser scanner positioned on the forest floor. The scans were aligned to each other based on 24 artificial targets placed in the plot and merged to only one single 3D-point cloud representing the plot. The virtual space above the plot was then subdivided into volume units of $5 \times 5 \times 5 \mathrm{~cm}$, so-called voxels. If a voxel contained one or more points from the 3D- point cloud, it was considered as "filled". Canopy cover was calculated based on the ratio of the area covered by the projection of the filled voxels onto the ground to the total area $(20 \times 20 \mathrm{~m}$ around the centre of the plot $)$.

The volumetric soil water content was measured with mobile TDR (Time Domain Reflectometry) probes, connected to a circuit analyzer and vertically inserted into the soil to a depth of $30 \mathrm{~cm}$. The soil moisture content was collected at four random locations near the plot centre in April, July, early and late August, and September 2009. To account for the natural heterogeneity of the soils in the research area, a soil specific calibration was conducted in the laboratory on eight undisturbed soil samples, largely following the procedure described in the study by Veldkamp and O'Brien (2000). As measurements from the five sampling dates were highly correlated (Pearson $\mathrm{r}=0.83-0.92$ ), we used mean values across sampling dates for further analyses. 
Soil sampling took place in May 2008. To assess humus layer mass per unit area, a soil sample (20 cm diameter, $0-5 \mathrm{~cm}$ depth of mineral soil) was taken at the plot centre. The humus layer (including litter) was separated from the mineral soil and dried at $60{ }^{\circ} \mathrm{C}$ until constant weight. The stock of humus layer in $\mathrm{kg} \mathrm{m}^{-2}$ was calculated as the quotient of dry matter divided by the sampling area. To record $\mathrm{pH}$ and $\mathrm{C}: \mathrm{N}$ ratio, we took soil samples (6.4 $\mathrm{cm}$ diameter, $0-10 \mathrm{~cm}$ depth) at three locations near the plot centre. The soil samples were dried at $40{ }^{\circ} \mathrm{C}$ until constant weight and passed through a $2 \mathrm{~mm}$ sieve. Soil $\mathrm{pH}$ was measured in a suspension with $\mathrm{H}_{2} \mathrm{O}_{\text {bidest }}\left(10 \mathrm{~g}\right.$ of soil, $25 \mathrm{ml}$ of $\mathrm{H}_{2} \mathrm{O}$ ). Organic carbon and total nitrogen were measured from the mineral soil by an automated $\mathrm{C}$ and $\mathrm{N}$ analyser (Heraeus Elementar Vario EL, Hanau, Germany) after being ground and weighted into tin ships (all samples were free of carbonates); subsequently, the $\mathrm{C}: \mathrm{N}$ ratio was calculated.

Explanatory variables are summarized in Table 1.

Table 1: Summary statistics (mean, standard deviation, range) and description of explanatory variables. SD = standard deviation. Units of variables indicated in brackets.

\begin{tabular}{|c|c|c|c|c|c|}
\hline Variable name & Description & Mean & SD & Minimum & Maximum \\
\hline Location & $\begin{array}{l}\text { Locations Lindig and Thiemsburg, factor with } \\
\text { two levels }\end{array}$ & & - & - & - \\
\hline Tree diversity & Shannon-Wiener diversity index H' of trees & 1.28 & 0.33 & 0.27 & 2 \\
\hline $\begin{array}{l}\text { Distance forest } \\
\text { edge }\end{array}$ & Distance to the nearest forest edge (m) & 387 & 212 & 17 & 830 \\
\hline Canopy cover & $\begin{array}{l}\text { Area of ground covered by vertical projection } \\
\text { of canopy, arcsine square-root transformed for } \\
\text { analyses (\%) }\end{array}$ & 90.7 & 4.2 & 69.1 & 96.4 \\
\hline $\begin{array}{l}\text { Humus layer } \\
\text { mass }\end{array}$ & Mass of the humus layer per unit area $\left(\mathrm{kg} \mathrm{m}^{-2}\right)$ & 0.05 & 0.04 & 0.002 & 0.18 \\
\hline $\mathrm{pH}$ & Soil $\mathrm{pH}$ in depth of $0-10 \mathrm{~cm}$ & 5.35 & 0.65 & 4.05 & 6.98 \\
\hline $\mathrm{C}: \mathrm{N}$ ratio & $\begin{array}{l}\text { Carbon-to-nitrogen ratio of soil in depth of } 0- \\
10 \mathrm{~cm}\end{array}$ & 13.72 & 0.99 & 11.88 & 18.36 \\
\hline Soil moisture & Volumetric soil water content $(\%)$ & 32.71 & 2.84 & 17.88 & 54.69 \\
\hline
\end{tabular}

\section{Data analysis}

We analysed species richness and cover of the total herb layer as well as cover and relative proportion of forbs, graminoids and tree saplings separately using generalized least squares (gls) models fit by maximum likelihood (Pinheiro and Bates, 2000). Proportions of true forest 
species and different plant life forms were also analysed using gls models. Explanatory variables were weakly to moderately correlated, with $\mathrm{pH}$ and soil moisture showing the strongest correlation (Spearman rank correlation coefficient $=0.59$ ). All other explanatory variables had a Spearman rank correlation coefficient $<0.5$. We did not include the proportion of F. sylvatica, the most dominant tree species, into our main analyses because it was strongly correlated with several environmental variables. However, we present linear models containing only tree diversity and the proportion of F. sylvatica as explanatory variables in Appendix $\mathrm{C}$ so that the importance of the species identity effect of $F$. sylvatica can be evaluated. Data on percentage cover and species richness were arcsine square-root and log transformed, respectively. All explanatory variables were standardized to zero mean and unit variance before analyses. Tree saplings were excluded from the herb layer data for analysis of total herb layer species richness and cover because these species are not independent from the explanatory variable "tree layer diversity". Diagnostic plots were used to check for homoscedasticity, normality of errors, and outliers.

We tested for spatial autocorrelation in our analyses by plotting semivariograms of the residuals of our full models (Appendix D). Semivariograms show how quickly spatial autocorrelation falls off with increasing distance. If semivariograms indicated spatial autocorrelation, we corrected for the spatial correlation structure of the errors by including a spatial correlation parameter into our models that incorporates the $\mathrm{x} / \mathrm{y}$ coordinates of the plots (Pinheiro and Bates, 2000).

To incorporate the considerable uncertainty inherent in selecting one single "best" model, we applied multi-model inference and model averaging, a method where statistical inference is based on an entire set of models (Burnham and Anderson, 2002). Based on a full model that included all explanatory variables as main effects, models with all combinations of explanatory variables were fitted and ranked according to their AICc values (Akaike's Information Criterion, corrected for small sample sizes, Burnham and Anderson, 2002). Firstorder interactions with location and quadratic terms of explanatory variables were included in the full model if indicated by previous data exploration. We calculated Akaike weights (AICcw) and the differences in AICc $(\triangle \mathrm{AICc})$ for all models. $\triangle \mathrm{AICc}$ represents the differences in AICc between the best model and the remaining models; the AICcw shows the likelihood of a certain model being the best in a set of models, given the data (Burnham and Anderson, 2002). Models with a $\triangle \mathrm{AICc} \leq 2$ entered the set of best models. From this set of top models, we calculated model averaged parameter estimates and unconditional standard errors weighted by model AICcw (Burnham and Anderson, 2002; Wielgoss et al., 2010). To 
determine the relative importance of explanatory variables, we used $\sum \mathrm{AICc} w$, the sum of Akaike weights of the set of top models in which the variable appeared. Variables with a larger value of $\sum \mathrm{AICc} w$ (which varies between 0 and 1) are considered to be more important since variables with $\sum \mathrm{AICc} w$ values close to 1 appear in all well-supported models.

All analyses were carried out using R, version 2.12.0 (R Development Core Team, 2009). Model averaging was carried out with the MuMIn package (version 0.13.17). Information about models (AICc, $\triangle \mathrm{AICc}, \mathrm{AICc}$ ) included in the top set of models for each separate analysis can be found in Appendix E.

\section{Results}

Species richness and cover of total herb layer

In total, 74 different plant species were recorded in the herb layer during this study (Appendix B). Plant species richness of the herb layer varied between 1 and 27 species per plot, with a mean \pm standard deviation of $11 \pm 6$ species (including tree saplings: 2-32 species, mean $=15$ \pm 6 ). The cover of the herb layer ranged from 0.1 to $56.8 \%$ with a mean of $16.7 \pm 12.4 \%$ (including tree saplings: $3-61.7 \%$, mean $=26.3 \pm 4.3 \%$ ).

The species richness of the herb layer increased with increasing tree diversity (Fig. 1, Table 2). Herb layer species richness was also positively related to the distance from forest edge, while it decreased with increasing humus layer mass and canopy cover. Soil pH and herb layer species richness showed a positive relationship. The quadratic $\mathrm{pH}$ term received high support as well (Table 2), indicating a hump-shaped relationship between soil $\mathrm{pH}$ and herb layer species. Humus layer mass, $\mathrm{pH}$ and tree diversity had the highest sum of Akaike weights ( $\mathrm{SAICc} w)$ and therefore the highest importance in explaining species richness of the herb layer (Fig. 2a). Canopy cover (0.90), distance to the forest edge (0.81) and location (0.81) also received high $\sum \mathrm{AICc} w$ values, while $\mathrm{C} / \mathrm{N}$ ratio $(0.38)$ and soil moisture $(0.17)$ were of low importance. In a separate analysis with only tree diversity and the proportion of $F$. sylvatica as explanatory variables, the model including both variables had the best explanatory power (lowest AICc) (Appendix C). 


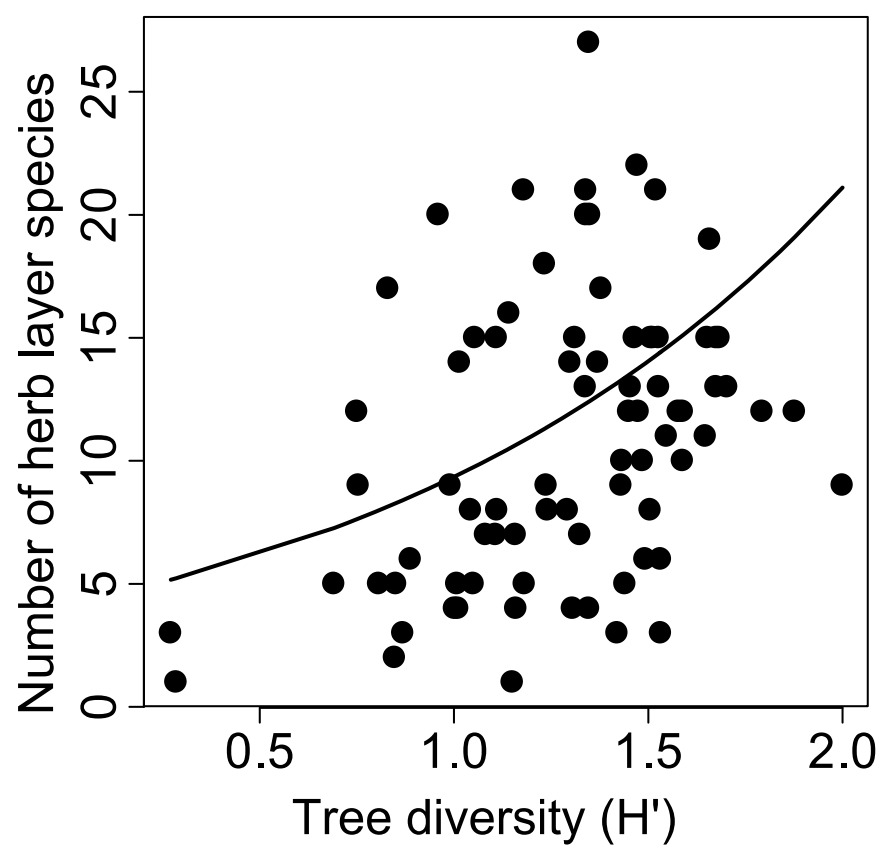

Figure 1: Relationship between tree diversity (Shannon-Wiener Index H') and herb layer species richness on 79 study plots in the Hainich National Park. The line shows the prediction based on model averaged estimates (Table 2), points are observations.

Herb layer cover increased with increasing tree diversity, whereas canopy cover and humus layer mass had a negative influence. Humus layer mass had the highest $\sum$ AICcw (1), followed by tree diversity (0.93) and canopy cover (0.91) (Fig. 2b). There was weaker evidence for an effect of location (0.54) or distance to the forest edge (0.40). Soil $\mathrm{pH}(0.33)$ and soil moisture (0.14) received little support. The $\mathrm{C}: \mathrm{N}$ ratio did not enter any models in the top set. When only tree diversity and the proportion of $F$. sylvatica were used as explanatory variables, the model containing only the proportion of F. sylvatica had the best fit (Appendix C). 
Table 2: Multi-model averaged coefficients and unconditional standard errors of parameters determining herb layer species richness and cover as well as the proportion of true forest species. ":" denotes a two-way interaction. Treatment contrasts were used: (Intercept) represents the mean for "Lindig"; parameter estimates for categorical main effects are differences between means; parameter estimates for numeric main effects and interaction terms are differences between slopes. Negative coefficients for quadratic terms indicate hump-shaped relationships. Herb layer species richness was log transformed, herb layer cover arcsine square-root transformed. All numeric explanatory variables were standardized to zero mean and unit variance.

\begin{tabular}{lccc}
\hline & $\begin{array}{c}\text { Total herb layer species } \\
\text { richness }\end{array}$ & $\begin{array}{c}\text { Total herb layer } \\
\text { cover }\end{array}$ & $\begin{array}{c}\text { Proportion of forest } \\
\text { species }\end{array}$ \\
\hline Intercept) & $2.46 \pm 0.151$ & $0.415 \pm 0.046$ & $0.571 \pm 0.068$ \\
Location Thiemsburg & $-0.402 \pm 0.272$ & $-0.071 \pm 0.088$ & $0.019 \pm 0.082$ \\
Tree diversity & $0.266 \pm 0.068$ & $0.036 \pm 0.02$ & $0.017 \pm 0.027$ \\
Tree diversity & - & - & $0.014 \pm 0.017$ \\
Canopy cover & $-0.118 \pm 0.07$ & $-0.034 \pm 0.02$ & $0.046 \pm 0.021$ \\
Humus layer & $-0.221 \pm 0.09$ & $-0.064 \pm 0.022$ & $-0.079 \pm 0.026$ \\
pH & $0.228 \pm 0.092$ & $0.008 \pm 0.014$ & $0.007 \pm 0.012$ \\
pH ${ }^{2}$ & $-0.086 \pm 0.057$ & - & - \\
Distance forest edge & $0.242 \pm 0.159$ & $0.03 \pm 0.041$ & $-0.037 \pm 0.076$ \\
C:N ratio & $0.047 \pm 0.069$ & - & $-0.005 \pm 0.009$ \\
Soil moisture & $-0.019 \pm 0.037$ & $0.002 \pm 0.005$ & $0.001 \pm 0.003$ \\
Location:tree diversity & - & - & $-0.021 \pm 0.035$ \\
Location:distance forest edge & - & - & $0.183 \pm 0.105$ \\
\hline
\end{tabular}


a)

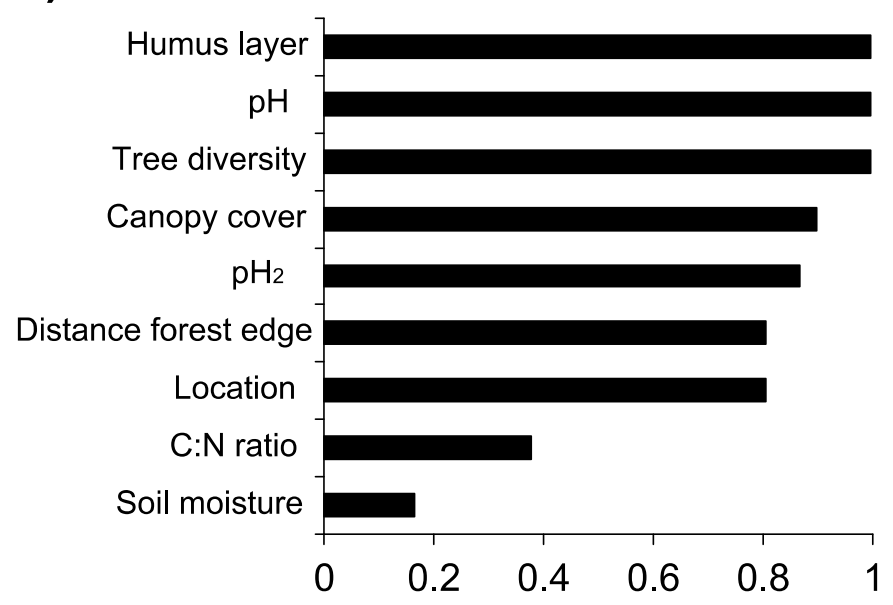

$\sum \mathrm{AICCW}$

b)

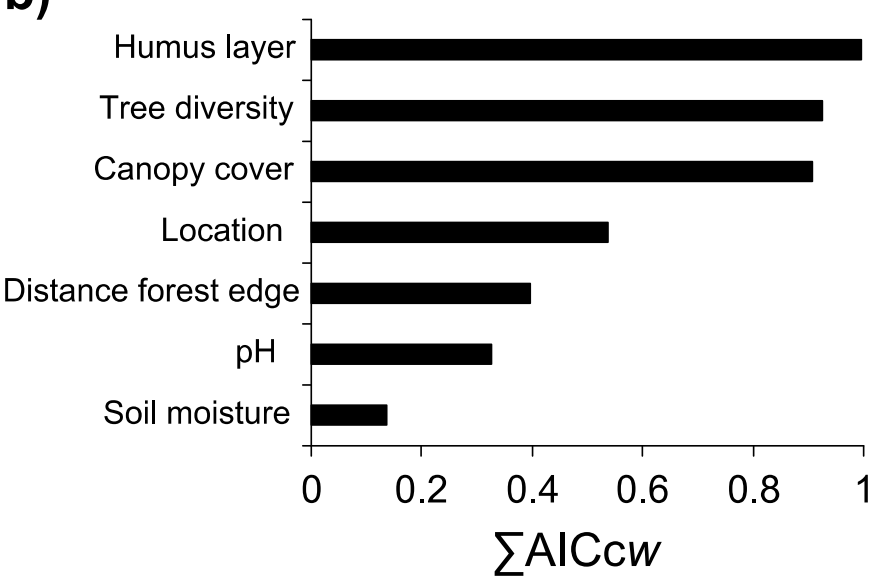

Figure 2: Relative importance of environmental variables in explaining variation in (a) species richness and (b) cover of the herb layer. Variables are ranked in order of the sum of their Akaike weights ( $\left.\sum \mathrm{AICc} w\right)$. Tree saplings were excluded from analysis of total herb layer species richness and cover because these species are not independent from the explanatory variable "tree diversity". $\mathrm{pH}^{2}$ denotes the quadratic term of the variable $\mathrm{pH}$.

\section{Proportion and cover of functional groups}

We focused our analyses on forbs (59.5\% of all herb layer species), graminoids (16.2\%), and tree saplings $(14.9 \%)$, because ferns $(4.1 \%)$, shrubs $(4.1 \%)$, and vines $(1.4 \%)$ did not contain sufficient species for analyses. The proportion of forbs as well as forb cover were positively influenced by tree diversity and $\mathrm{pH}$ (Table 3). Also, the proportion of forbs was negatively related to the $\mathrm{C} / \mathrm{N}$ ratio, while the forb cover responded negatively to increasing canopy cover and humus layer. In contrast to forbs, relative proportion and cover of graminoids did not respond to tree diversity (Table 3). Proportion of graminoids increased with increasing distance to the forest edge and decreased with increasing $\mathrm{pH}$ and humus layer mass. Graminoid cover was negatively associated with canopy cover and also increased with distance to the forest edge, but only at the Lindig location. The proportion of tree saplings was negatively influenced by tree diversity and $\mathrm{pH}$, but increased when the humus layer mass was higher (Table 3). Tree sapling cover responded negatively to increasing soil $\mathrm{pH}$ and positively to the distance to the forest edge. 
Table 3: Multi-model averaged coefficients and unconditional standard errors of parameters determining proportion and cover of forbs, graminoids and tree saplings. ":” denotes a two-way interaction. Treatment contrasts were used: (Intercept) represents the mean for "Lindig"; parameter estimates for categorical main effects are differences between means; parameter estimates for numeric main effects and interaction terms are differences between slopes. The response variable "cover" was arcsine square-root transformed for all functional groups. All numeric explanatory variables were standardized to zero mean and unit variance.

\begin{tabular}{|c|c|c|c|c|c|c|}
\hline & \multicolumn{2}{|c|}{ Forbs } & \multicolumn{2}{|c|}{ Graminoids } & \multicolumn{2}{|c|}{ Tree saplings } \\
\hline & Proportion & Cover & Proportion & Cover & Proportion & Cover \\
\hline (Intercept) & $0.498 \pm 0.029$ & $0.344 \pm 0.032$ & $0.153 \pm 0.024$ & $0.195 \pm 0.027$ & $0.314 \pm 0.032$ & $0.343 \pm 0.041$ \\
\hline $\begin{array}{l}\text { Location } \\
\text { Thiemsburg }\end{array}$ & $-0.009 \pm 0.019$ & $-0.029 \pm 0.045$ & $-0.028 \pm 0.042$ & $-0.069 \pm 0.037$ & $0.038 \pm 0.056$ & $-0.112 \pm 0.079$ \\
\hline Tree diversity & $0.059 \pm 0.021$ & $0.048 \pm 0.02$ & $-0.005 \pm 0.009$ & - & $-0.048 \pm 0.016$ & $-0.002 \pm 0.004$ \\
\hline Canopy cover & - & $-0.042 \pm 0.02$ & $0.001 \pm 0.002$ & $-0.016 \pm 0.012$ & $0.001 \pm 0.003$ & - \\
\hline Humus layer & $-0.004 \pm 0.009$ & $-0.033 \pm 0.025$ & $-0.027 \pm 0.018$ & $-0.002 \pm 0.004$ & $0.052 \pm 0.018$ & - \\
\hline $\mathrm{pH}$ & $0.073 \pm 0.022$ & $0.043 \pm 0.019$ & $-0.015 \pm 0.015$ & - & $-0.084 \pm 0.021$ & $-0.035 \pm 0.015$ \\
\hline $\begin{array}{l}\text { Distance forest } \\
\text { edge }\end{array}$ & $-0.013 \pm 0.021$ & - & $0.032 \pm 0.029$ & $0.09 \pm 0.031$ & $-0.013 \pm 0.022$ & $0.063 \pm 0.041$ \\
\hline $\mathrm{C} / \mathrm{N}$ ratio & $-0.029 \pm 0.023$ & - & $0.001 \pm 0.001$ & $-0.002 \pm 0.004$ & $0.002 \pm 0.004$ & $0.003 \pm 0.007$ \\
\hline Soil moisture & $-0.015 \pm 0.022$ & - & - & - & $0.006 \pm 0.011$ & - \\
\hline $\begin{array}{l}\text { Location:distanc } \\
\text { e forest edge }\end{array}$ & - & - & - & $-0.099 \pm 0.038$ & - & - \\
\hline $\begin{array}{l}\text { Location:canopy } \\
\text { cover }\end{array}$ & - & $0.014 \pm 0.025$ & $-0.004 \pm 0.008$ & - & - & - \\
\hline Location:pH & - & - & - & - & $0.076 \pm 0.029$ & - \\
\hline
\end{tabular}

\section{Proportion of life forms}

Hemicryptophytes represented $48.6 \%$ of all recorded herb layer species, followed by geophytes $(21.6 \%)$, phanerophytes $(20.3 \%)$, therophytes $(2.7 \%)$ and chamaephytes $(2.7 \%)$. Three species (4.1\%) could not be assigned to a life form as they could not be determined to species level. Proportions of hemicryptophytes and geophytes increased with increasing tree diversity, while the proportion of phanerophytes decreased. Different life forms showed contrasting responses to environmental variables and the distance to the forest edge (Appendix F).

\section{Proportion of true forest species}

Plant species that were closely tied to the forest $(\mathrm{K} 1.1+\mathrm{K} 1.2$, see Appendix B) made up 50\% of all herb layer species recorded in the study area, while plants that occurred in forests as well as open vegetation $(\mathrm{K} 2.1+\mathrm{K} 2.2$, see Appendix B) represented 42.9\%. Four species 
could not be assigned to a group as they could not be determined to species level. On average, $67 \pm 18 \%$ of the herb layer species per plot were true forest species. The proportion of true forest species increased with increasing canopy cover and decreased when the mass of the humus layer was high (Table 2). At the Thiemsburg location, the proportion of true forest species increased with increasing distance to the forest edge, while at the Lindig location, the proportion of true forest species was lower at greater distances to the forest edge.

\section{Discussion}

\section{Effects of tree diversity}

We have shown that forest stands with higher tree diversity were characterised by higher herb layer species richness and cover. Previous studies exploring tree diversity effects on the herb layer have shown mixed results: While some studies detected positive relationships between tree and herb layer diversity (Hicks, 1980; Ingerpuu et al., 2003; Mölder et al., 2008), others found no effect (Ewald, 2002; Borchsenius et al., 2004; Houle, 2007). Previously, many studies compared tree stands dominated by conifers to broad-leaved stands, often with the result of reduced herb species richness in the conifer stands (Berger and Puettmann, 2000; Hart and Chen, 2008). Other studies assessed tree diversity effects in forests with only a limited number of different tree species. In contrast, the present study allows inferences on tree diversity effects based on a wide diversity gradient in a purely broad-leaved forest setting.

A comparison between the different functional groups revealed that higher tree diversity went along with an increased proportion of forbs, while graminoids did not respond to tree layer diversity, and the proportion of tree saplings decreased. This might be caused by plant functional groups having different resource requirements and therefore exhibiting contrasting responses in reaction to environmental gradients (Weisberg et al., 2003; Graves et al., 2006; Tinya et al., 2009). High levels of tree diversity apparently create conditions that are more beneficial to forbs than to woody species of the herb layer. This is also shown by the decreasing proportion of phanerophytes with increasing tree diversity, whereas the other two dominant life forms, geophytes and hemicryptophytes, are enhanced.

Tree species can influence the herb layer by changing resource availability and environmental conditions in lower forest layers (Barbier et al., 2008). If dominant tree species create conditions that are unsuitable for many herbs, a more diverse canopy where the dominant tree 
species are less abundant might affect conditions on the ground in such a way that herb diversity and cover are enhanced. In the Hainich forest, secondary tree species occurring on more diverse sites include F. excelsior, A. platyphyllos and Tilia sp., species which may improve litter quality and light availability on the ground compared to stands dominated by $F$. sylvatica (Norden, 1994; Neirynck et al., 2000), thus leading to a higher diversity of herb layer species in these plots. The environmental heterogeneity hypothesis (Huston, 1994) could provide a further explanation for tree diversity effects, implying that a greater tree diversity may lead to higher small-scale heterogeneity of site conditions and consequently to a higher herb diversity. Though plausible, we cannot address this hypothesis as our vegetation survey plots were too small to reliably quantify spatial heterogeneity of environmental conditions.

Half of all plant species in the herb layer of our study area can be classified as species typical of closed forests. This agrees with findings in comparable unmanaged deciduous forests (Mölder et al., 2006) and indicates high continuity of forest cover (Graae and Sunde, 2000). Similar to Mölder et al. (2006), we did not find any evidence that tree diversity plays a substantial role in determining the proportion of true forest species.

\section{Effects of environmental factors}

The mass of the humus layer had particularly high importance in explaining overall species richness and cover of the herb layer. It decreased both species richness and cover. This finding agrees with previous studies which reported negative effects of litter depth, one element of the humus layer, on herb layer diversity or cover (Augusto et al., 2003; Mölder et al., 2008; Gazol and Ibáñez, 2009). A strongly developed humus layer might form a physical barrier that inhibits germination and emergence of herb layer plants (Sydes and Grime, 1981). While some herb layer plants have developed mechanisms to penetrate thick litter layers, others are suppressed (Dzwonko and Gawronski, 2002; Kooijman, 2010). Both forbs and grasses showed a negative response to strongly developed humus layers. In contrast, the proportion of tree saplings increased. Tree saplings might be better adapted to penetrate thick humus layers due to larger seed sizes (Dzwonko and Gawronski, 2002) and might experience less competition from forbs and graminoids in settings with a well-developed humus layer (Facelli and Pickett, 1991). Tree species differ in the decomposability of their litter, affecting the volume of the organic layer. For instance, F. sylvatica forms a thicker organic layer than other broad-leaved tree species (Wulf and Naaf, 2009; Jacob et al., 2010), which could 
contribute to lower herb species numbers on plots with a low tree diversity, i.e. plots dominated by $F$. sylvatica.

Herb layer species richness and cover increased with increasing $\mathrm{pH}$. This finding agrees with numerous studies which documented a positive effect of $\mathrm{pH}$ on herb layer diversity (Lenière and Houle, 2006; Houle, 2007; Kooijman, 2010), with pH often emerging as the main driver of diversity and biomass in the herb layer. Many herb layer species cannot tolerate acidic conditions that lead to $\mathrm{H}^{+}$and $\mathrm{Al}^{3+}$ toxicity (Brunet et al., 1996). In addition, a higher $\mathrm{pH}$ may positively influence nutrient availability for plants: As many plants typical of beech forests preferentially take up $\mathrm{NO}_{3}{ }^{-}$as a nitrogen source, they prefer soils with neutral to slightly basic conditions where nitrifiers are active (Ellenberg and Leuschner, 2010; Härdtle et al., 2003). Comparing the different functional groups shows that proportion and cover of forbs responded positively to higher $\mathrm{pH}$ levels, while proportion and cover of tree saplings decreased. Forbs require more soil nutrients per unit biomass than tree saplings (Graves et al., 2006); therefore they might benefit more strongly than other functional groups from higher $\mathrm{pH}$ levels which favour a higher nutrient availability in the soil. The overstorey can influence soil $\mathrm{pH}$ by modifying the composition of stemflow- and throughfall water, the level of organic acid secretion via the roots and the composition of leaf litter (Augusto et al., 2002; HagenThorn et al., 2004). Fraxinus excelsior, A. platyphyllos and Tilia sp., whose proportions increase with higher tree diversity, are known to produce less acidic topsoil than $F$. sylvatica (Aubert et al. 2004; Guckland et al. 2009).

High levels of canopy cover decreased herb layer species richness as well as cover of the total herb layer, forbs, and graminoids. Similarly, many studies emphasised the positive effect of greater light availability on herb layer diversity (Hart and Chen, 2008; Tinya et al., 2009; Härdtle et al., 2003; Hofmeister et al., 2009). However, others found no effect (Collins and Pickett, 1987; Augusto et al., 2003; Lenière and Houle, 2006). A higher light availability allows the presence of plant species which occur in forests as well as in grassland ecosystems and do not have special adaptations to the low light levels of the forest understorey. As long as these species do not outcompete forest specialists, a net increase in species richness and herb layer cover is to be expected. In accordance with Burke et al. (2008), we found an increasing proportion of true forest species with increasing canopy cover. The light environment in forest stands strongly depends on crown structure and density of the canopy trees (Jennings et al., 1999). In particular, dense canopies of $F$. sylvatica are known for low light transmittance compared to other broadleaved trees (Ellenberg and Leuschner, 2010). 
Distance to the forest edge emerged as another important factor in explaining herb layer species richness. Depending on the type of forest edge considered and the local conditions of the study area, varying responses of the herb layer to the edge distance have been observed, making it difficult to identify general patterns (Murcia, 1995; Harper et al., 2005). Proximity to the forest edge goes along with changes in biotic and abiotic conditions, potentially causing changes in plant community composition such as shifts towards a higher fraction of more light-demanding species and a restriction of forest interior species closer to the edge (Murcia, 1995; Gonzalez et al., 2010). Our results showed an increase of total herb layer species richness with increasing distance to the edge. Apparently, opportunist plant species that might benefit from lighter conditions closer to the forest edge did not play a major role, possibly because all plots except one were located more than $50 \mathrm{~m}$ away from the edge, which is commonly regarded as the maximum distance that edge effects penetrate into the forest (Murcia, 1995). We expected an increase in the proportion of true forest species with increasing distance to the edge; surprisingly, this was only confirmed in the Thiemsburg area. Differences in tree species composition between locations might explain this idiosyncratic response.

Soil moisture did not affect species richness and cover of the total herb layer or of any functional group. Across studies exploring drivers of herb layer diversity, soil moisture often seemed to play a minor role (Borchsenius et al., 2004; Gazol and Ibáñez, 2010; Ingerpuu et al., 2003), though some authors found a positive effect (Lenière and Houle, 2006; Qian et al., 1997; Härdtle et al., 2003). The overall soil moisture content in the Hainich forest may be high enough to rule out limiting effects on herb layer species. The composition of the tree layer can affect soil water availability by tree-species specific differences in the amount of non-intercepted rainwater (throughfall), stemflow and water taken up by the roots (Barbier et al., 2008).

We did not detect an influence of the $\mathrm{C}: \mathrm{N}$ ratio on any herb layer attributes except the proportion of forbs. The C:N ratio can serve as an indicator of substrate quality and nitrogen limitation in forest soils (Currie, 1999; Small and McCarthy, 2005). Thus, it is not surprising that forbs, a functional group with pronounced nutrient requirements, showed a negative response to higher $\mathrm{C}: \mathrm{N}$ ratios. Differences in litter composition between tree species can cause overstorey effects on soil C:N ratios (Augusto et al., 2002). The strength of the herb layer response to variations in the $\mathrm{C}: \mathrm{N}$ ratio might be dependent on the overall $\mathrm{N}$ availability in different forest systems, on the form in which $\mathrm{N}$ is available and whether forests experience $\mathrm{N}$ limitation or rather excess $\mathrm{N}$ levels due to atmospheric deposition. Also, the C:N ratio 
spanned a rather narrow gradient in our study area and generally did not reach levels detrimental to plant growth.

\section{Limitations}

Due to the observational nature of this study we cannot rule out that both tree and herb layer diversity respond to pre-existing abiotic conditions, which could lead to a positive correlation between the diversity of the different forest layers irrespective of a causal relationship. Also, we are not able to disentangle pure tree diversity effects from effects of different tree species which vary in their abundance (dilution gradient, see Scherer-Lorenzen et al., 2007, Nadrowski et al., 2010). Fagus sylvatica, which strongly dominates the species-poor stands, might be mainly responsible for lower herb species numbers because it may create unfavourable soil and light conditions (Graae and Heskjaer, 1997; Barbier et al., 2008; Mölder et al., 2008). When only tree diversity and the proportion of F. sylvatica were used together as explanatory variables, the inclusion of tree diversity did still substantially improve the model explaining herb layer species richness, which suggests a tree diversity effect in addition to the species identity effect of F. sylvatica. However, for herb layer cover, the model containing the proportion of $F$. sylvatica alone received higher support. Future studies in forest types not dominated by F. sylvatica, but still containing a pronounced gradient of tree species richness, would help to shed light on the generality of our results. In spite of these limitations, we believe that comparative studies in established forests such as the Hainich National Park are important for understanding tree diversity effects because they provide representative conditions of (near) natural forest ecosystems at a mature stage. Experiments with planted tree stands often cannot provide the complexity of environmental conditions and processes occurring in old-growth forests, but do allow a better analyses of causal relationships since their design reduces collinearity between tree species diversity and other variables. Therefore, both experimental and observational studies should be used to investigate tree species diversity effects (Leuschner et al., 2009).

Forest management can have strong impacts on the plant species composition of the herb layer. Even though forest use was reduced to a minimum during the past 40 years in our study area, historic differences in forest management might not only have created stands with varying tree diversity, but might also have directly impacted understorey vegetation. This might partly explain contrasting herb layer responses to some environmental factors in the two study areas. 


\section{Conclusions}

In the tree-diversity mosaic of the Hainich National Park, a positive association between diversity of the tree layer and species richness and cover of the herb layer was observed. However, the relative importance of tree diversity in explaining herb layer characteristics was equal or lower to the importance of certain environmental factors. While the variables humus layer mass, canopy cover, $\mathrm{pH}$ and distance to the forest edge were of high relative importance for explaining herb layer species richness and cover, soil moisture and the $\mathrm{C}: \mathrm{N}$ ratio played a smaller role. We conclude that linkages between diversity patterns of tree and herb layer exist, but that controlled biodiversity experiments will be needed to disentangle diversity and species identity effects of the tree layer.

\section{Acknowledgements}

This study was funded by the DFG (German Research Foundation) within the framework of the Research Training Group 'Graduiertenkolleg 1086: The role of biodiversity for biogeochemical cycles and biotic interactions in temperate deciduous forests'. We thank Tobias Wommelsdorf for providing data on tree layer composition and Verena Eißfeller for assistance with soil sampling. Also, we are thankful to Patrick Kabouw, two anonymous reviewers and the subject editor for valuable comments on a previous version of this manuscript.

\section{References}

Aubert, M., Bureau, F., Alard, D., Bardat, J., 2004. Effect of tree mixture on the humic epipedon and vegetation diversity in managed beech forests (Normandy, France). Can. J. For. Res. 34, 233-248.

Augusto, L., Ranger, J., Binkley, D., Rothe, A., 2002. Impact of several common tree species of European temperate forests on soil fertility. Ann. For. Sci. 59, 233-253.

Augusto, L., Dupouey, J.L., Ranger, J., 2003. Effects of tree species on understory vegetation and environmental conditions in temperate forests. Ann. For. Sci. 60, 823-831. 
Avon, C., Bergès, L., Dumas, Y., Dupouey, J., 2010. Does the effect of forest roads extend a few meters or more into the adjacent forest? A study on understory plant diversity in managed oak stands. For. Ecol. Manage. 259, 1546-1555.

Barbier, S., Gosselin, F., Balandier, P., 2008. Influence of tree species on understory vegetation diversity and mechanisms involved - A critical review for temperate and boreal forests. For. Ecol. Manage. 254, 1-15.

Beatty, S.W., 2003. Habitat heterogeneity and maintenance of species in understory communities. In: Gilliam, F.S., Roberts, M.R. (Eds.) The herbaceous layer in forests of eastern North America. Oxford University Press; New York, pp. 177-197.

Berger, A.L., Puettmann, K.J., 2000. Overstory composition and stand structure influence herbaceous plant diversity in the mixed aspen forest of northern Minnesota. Am. Midl. Nat. 143, 111-125.

Borchsenius, F., Nielsen, P.K., Lawesson, J.E., 2004. Vegetation structure and diversity of an ancient temperate deciduous forest in SW Denmark. Plant Ecol. 175, 121-135.

Brunet, J., Falkengren-Grerup, U., Tyler, G., 1996. Herb layer vegetation of south Swedish beech and oak forests - Effects of management and soil acidity during one decade. For. Ecol. Manage. 88, 259-272.

Burke, D.A., Elliott, K.A., Holmes, S.B., Bradley, D., 2008. The effects of partial harvest on the understory vegetation of southern Ontario woodlands. For. Ecol. Manage. 255, 2204-2212.

Burnham, K.P., Anderson, D.R., 2002. Model selection and multimodel inference: a practical information-theoretic approach. Springer, New York.

Collins, B.S., Pickett, S.T.A., 1987. Influence of canopy opening on the environment and herb layer in a northern hardwoods forest. Vegetatio 70, 3-10.

Currie, W.S., 1999. The responsive $\mathrm{C}$ and $\mathrm{N}$ biogeochemistry of the temperate forest floor. Trends Ecol. Evol. 14, 316-320.

Dzwonko, Z., Gawronski, S., 2002. Influence of litter and weather on seedling recruitment in a mixed oak-pine woodland. Ann. Bot. 90, 245-251.

Ellenberg, H., Leuschner, C., 2010. Vegetation Mitteleuropas mit den Alpen in ökologischer, dynamischer und historischer Sicht. 6th ed. Ulmer Verlag, Stuttgart.

Ewald, J., 2002. Multiple controls of understorey plant richness in mountain forests of the Bavarian Alps. Phytocoenologia 32, 85-100. 
Facelli, J.M., Pickett, S.T.A., 1991. Indirect effects of litter on woody seedlings subject to herb competition. Oikos 62, 129-138.

Gauer, J., Aldinger, E., 2005. Waldökologische Naturräume Deutschlands - Forstliche Wuchsgebiete und Wuchsbezirke. Mitt. Ver. forstl. Standortskd. Forstpflanzenzücht. $43,1-324$.

Gazol, A., Ibáñez, R., 2009. Different response to environmental factors and spatial variables of two attributes (cover and diversity) of the understorey layers. For. Ecol. Manage. $258,1267-1274$.

Gazol, A., Ibáñez, R., 2010. Variation of plant diversity in a temperate unmanaged forest in northern Spain: behind the environmental and spatial explanation. Plant Ecol. 207, 111.

Gilliam, F.S., 2007. The ecological significance of the herbaceous layer in temperate forest ecosystems. Bioscience 57, 845-858.

Gilliam, F.S., Roberts, M.R., 2003. Interactions between the herbaceous layer and the overstory canopy of Eastern forests: a mechanism for linkage. In: Gilliam, F.S., Roberts, M.R. (Eds.) The herbaceous layer in forests of eastern North America. Oxford University Press; New York, pp. 198-223.

Gonzalez, M., Deconchat, M., Balent, G., 2009. Woody plant composition of forest layers: the importance of environmental conditions and spatial configuration. Plant Ecol. 201, 305-318.

Gonzalez, M., Ladet, S., Deconchat, M., Cabanettes, A., Alard, D., Balent, G., 2010. Relative contribution of edge and interior zones to patch size effect on species richness: An example for woody plants. For. Ecol. Manage. 259, 266-274.

Graae, B.J., Heskjaer, V.S., 1997. A comparison of understorey vegetation between untouched and managed deciduous forest in Denmark. For. Ecol. Manage. 96, 111123.

Graae, B.J., Sunde, P.B., 2000. The impact of forest continuity and management on forest floor vegetation evaluated by species traits. Ecography 23, 720-731.

Graves, J.H., Peet, R.K., White, P.S., 2006. The influence of carbon-nutrient balance on herb and woody plant abundance in temperate forest understories. J. Veg. Sci. 17, 217-226.

Guckland, A., Jacob, M., Flessa, H., Thomas, F.M., Leuschner, C., 2009. Acidity, nutrient stocks, and organic-matter content in soils of a temperate deciduous forest with different abundance of European beech (Fagus sylvatica L.). J. Plant Nutr. Soil Sci.-Z. Pflanzenernahr. Bodenkd. 172, 500-511. 
Hagen-Thorn, A., Callesen, I., Armolaitis, K., Nihlgard, B., 2004. The impact of six European tree species on the chemistry of mineral topsoil in forest plantations on former agricultural land. For. Ecol. Manage. 195, 373-384.

Härdtle, W., von Oheimb, G., Westphal, C., 2003. The effects of light and soil conditions on the species richness of the ground vegetation of deciduous forests in northern Germany (Schleswig-Holstein). For. Ecol. Manage. 182, 327-338.

Harper, K.A., Macdonald, S.E., Burton, P.J., Chen, J.Q., Brosofske, K.D., Saunders, S.C., Euskirchen, E.S., Roberts, D., Jaiteh, M.S., Esseen, P.A., 2005. Edge influence on forest structure and composition in fragmented landscapes. Conserv. Biol. 19, 768782.

Hart, S.A., Chen, H.Y.H., 2008. Fire, logging, and overstory affect understory abundance, diversity, and composition in boreal forest. Ecol. Monogr. 78, 123-140.

Hicks, D.J., 1980. Intrastand distribution patterns of southern Appalachian cove forest herbaceous species. Am. Midl. Nat. 104, 209-223.

Hofmeister, J., Hosek, J., Modry, M., Rolecek, J., 2009. The influence of light and nutrient availability on herb layer species richness in oak-dominated forests in central Bohemia. Plant Ecol. 205, 57-75.

Houle, G., 2007. Determinants of fine-scale plant species richness in a deciduous forest of northeastern North America. J. Veg. Sci. 18, 345-354.

Huston, M.A., 1994. Biological diversity: the coexistence of species on changing landscapes. Cambridge University Press, Cambridge.

Ingerpuu, N., Vellak, K., Liira, J., Partel, M., 2003. Relationships between species richness patterns in deciduous forests at the north Estonian limestone escarpment. J. Veg. Sci. $14,773-780$.

Jacob, M., Weland, N., Platner, C., Schaefer, M., Leuschner, C., Thomas, F.M., 2009. Nutrient release from decomposing leaf litter of temperate deciduous forest trees along a gradient of increasing tree species diversity. Soil Biol. Biochem. 41, 2122-2130.

Jacob, M., Viedenz, K., Polle, A., Thomas, F.M., 2010. Leaf litter decomposition in temperate deciduous forest stands with a decreasing fraction of beech (Fagus sylvatica). Oecologia 164, 1083-1094.

Jennings, S.B., Brown, N.D., Sheil, D., 1999. Assessing forest canopies and understorey illumination: canopy closure, canopy cover and other measures. Forestry 72, 59-73. 
Klotz, S., Kühn, I., Durka, W., 2002. BIOLFLOR - Eine Datenbank zu biologischökologischen Merkmalen der Gefäßpflanzen in Deutschland. Schriftenreihe für Vegetationskunde 38. Bundesamt für Naturschutz, Bonn.

Kooijman, A., 2010. Litter quality effects of beech and hornbeam on undergrowth species diversity in Luxembourg forests on limestone and decalcified marl. J. Veg. Sci. 21, 248-261.

Lenière, A., Houle, G., 2006. Response of herbaceous plant diversity to reduced structural diversity in maple-dominated (Acer saccharum Marsh.) forests managed for sap extraction. For. Ecol. Manage. 231, 94-104.

Leuschner, C., Jungkunst, H.F., Fleck, S., 2009. Functional role of forest diversity: Pros and cons of synthetic stands and across-site comparisons in established forests. Basic Appl. Ecol. 10, 1-9.

Mabry, C.M., Gerken, M.E., Thompson, J.R., 2008. Seasonal storage of nutrients by perennial herbaceous species in undisturbed and disturbed deciduous hardwood forests. Appl. Veg. Sci. 11, 37-44.

Macdonald, S.E., Fenniak, T.E., 2007. Understory plant communities of boreal mixedwood forests in western Canada: Natural patterns and response to variable-retention harvesting. For. Ecol. Manage. 242, 34-48.

Magurran, A.E., 2004. Measuring biological diversity. Blackwell Science, Oxford.

Mölder, A., Bernhardt-Römermann, M., Schmidt, W., 2006. Forest ecosystem research in Hainich National Park (Thuringia): First results on flora and vegetation in stands with contrasting tree species diversity. Waldökologie online 3, 83-99.

Mölder, A., Bernhardt-Römermann, M., Schmidt, W., 2008. Herb-layer diversity in deciduous forests: Raised by tree richness or beaten by beech? For. Ecol. Manage. 256, 272-281.

Mölder, I., 2009. Diversity and tree neighborhood effects on the growth dynamics of European beech and the stand seed bank in temperate broad-leaved forests of variable tree diversity. $\mathrm{PhD}$ thesis, University of Göttingen.

Muller, R.N., 2003. Nutrient relations of the herbaceous layer in deciduous forest ecosystems. In: Gilliam, F.S., Roberts, M.R. (Eds.) The herbaceous layer in forests of eastern North America. Oxford University Press; New York, pp. 15-37.

Murcia, C., 1995. Edge effects in fragmented forests - implications for conservation. Trends Ecol. Evol. 10, 58-62.

Nadrowski, K., Wirth, C., Scherer-Lorenzen, M., 2010. Is forest diversity driving ecosystem function and service? Curr. Opin. Environ. Sustainability 2, 75-79. 
Neirynck, J., Mirtcheva, S., Sioen, G., Lust, N., 2000. Impact of Tilia platyphyllos Scop., Fraxinus excelsior L., Acer pseudoplatanus L., Quercus robur L. and Fagus sylvatica L. on earthworm biomass and physico-chemical properties of a loamy topsoil. For. Ecol. Manage. 133, 275-286.

Norden, U., 1994. Influence of tree species on acidification and mineral pools in deciduous forest soils of South Sweden. Water Air Soil Pollut. 76, 363-381.

Peterson, D.L., Rolfe, G.L., 1982. Nutrient dynamics of herbaceous vegetation in upland and floodplain forest communities. Am. Midl. Nat. 107, 325-339.

Pinheiro, J.C., Bates, D.M., 2000. Mixed-effects models in S and S-PLUS. Springer, New York.

Preußische Geologische Landesanstalt (Hg.), 1905. Geologische Karte von Preußen und den Thüringischen Staaten $1: 25000$, Henningsleben. Sheet 56 (old) $=4929$ (new). Berlin.

Qian, H., Klinka, K., Sivak, B., 1997. Diversity of the understory vascular vegetation in 40 year-old and old-growth forest stands on Vancouver Island, British Columbia. J. Veg. Sci. 8, 773-780.

R Development Core Team, 2009. R: A Language and Environment for Statistical Computing. Vienna, Austria: R Foundation for Statistical Computing http://www.Rproject.org.

Scherer-Lorenzen, M., Schulze, E.D., Don, A., Schumacher, J., Weller, E., 2007. Exploring the functional significance of forest diversity: A new long-term experiment with temperate tree species (BIOTREE). Perspect. Plant Ecol. Evol. Syst. 9, 53-70.

Schmidt, M., Ewald, J., Fischer, A., von Oheimb, G., Kriebitzsch, W.U., Schmidt, W., Ellenberg, H., 2003. Liste der typischen Waldgefäßpflanzen Deutschlands. Mitt. Bundesforsch.anst. Forst- Holzwirtsch. 212, 1-34.

Small, C.J., McCarthy, B.C., 2005. Relationship of understory diversity to soil nitrogen, topographic variation, and stand age in an eastern oak forest, USA. For. Ecol. Manage. $217,229-243$

Sydes, C., Grime, J.P., 1981. Effects of tree leaf litter on herbaceous vegetation in deciduous woodland: I. Field investigations. J. Ecol. 69, 237-248.

Takafumi, H., Hiura, T., 2009. Effects of disturbance history and environmental factors on the diversity and productivity of understory vegetation in a cool-temperate forest in Japan. For. Ecol. Manage. 257, 843-857. 
Tinya, F., Marialigeti, S., Kiraly, I., Nemeth, B., Odor, P., 2009. The effect of light conditions on herbs, bryophytes and seedlings of temperate mixed forests in Örség, Western Hungary. Plant Ecol. 204, 69-81.

van Calster, H., Baeten, L., Verheyen, K., De Keersmaeker, L., Dekeyser, S., Rogister, J.E., Hermy, M., 2008. Diverging effects of overstorey conversion scenarios on the understorey vegetation in a former coppice-with-standards forest. For. Ecol. Manage. $256,519-528$

van Oijen, D., Feijen, M., Hommel, P., den Ouden, J., de Waal, R., 2005. Effects of tree species composition on within-forest distribution of understorey species. Appl. Veg. Sci. 8, 155-166.

Veldkamp, E., O'Brien, J.J., 2000. Calibration of a frequency domain reflectometry sensor for humid tropical soils of volcanic origin. Soil Sci. Soc. Am. J. 64, 1549-1553.

Weisberg, P.J., Hadorn, C., Bugmann, H., 2003. Predicting understorey vegetation cover from overstorey attributes in two temperate mountain forests. Forstwiss. Cent.bl. 122, 273286.

Whigham, D.E., 2004. Ecology of woodland herbs in temperate deciduous forests. Annu. Rev. Ecol. Evol. Syst. 35, 583-621.

Wielgoss, A., Tscharntke, T., Buchori, D., Fiala, B., Clough, Y., 2010. Temperature and a dominant dolichoderine ant species affect ant diversity in Indonesian cacao plantations. Agr. Ecosyst. Environ. 135, 253-259.

Wisskirchen, R., Haeupler, H., 1998. Standardliste der Farn- und Blütenpflanzen Deutschlands. Ulmer, Stuttgart.

Wulf, M., 2003. Preference of plant species for woodlands with differing habitat continuities. Flora 198: 444-460.

Wulf, M., Naaf, T., 2009. Herb layer response to broadleaf tree species with different leaf litter quality and canopy structure in temperate forests. J. Veg. Sci. 20, 517-526.

Yarie, J., 1980. The role of understory vegetation in the nutrient cycle of forested ecosystems in the mountain hemlock biogeoclimatic zone. Ecology 61, 1498-1514. 


\section{Appendix}

\section{Appendix A}

The two study locations, Thiemsburg and Lindig (a). Plots are shown as filled blue dots on the detailed map of the Thiemsburg (b) and Lindig (c) location.

(a)

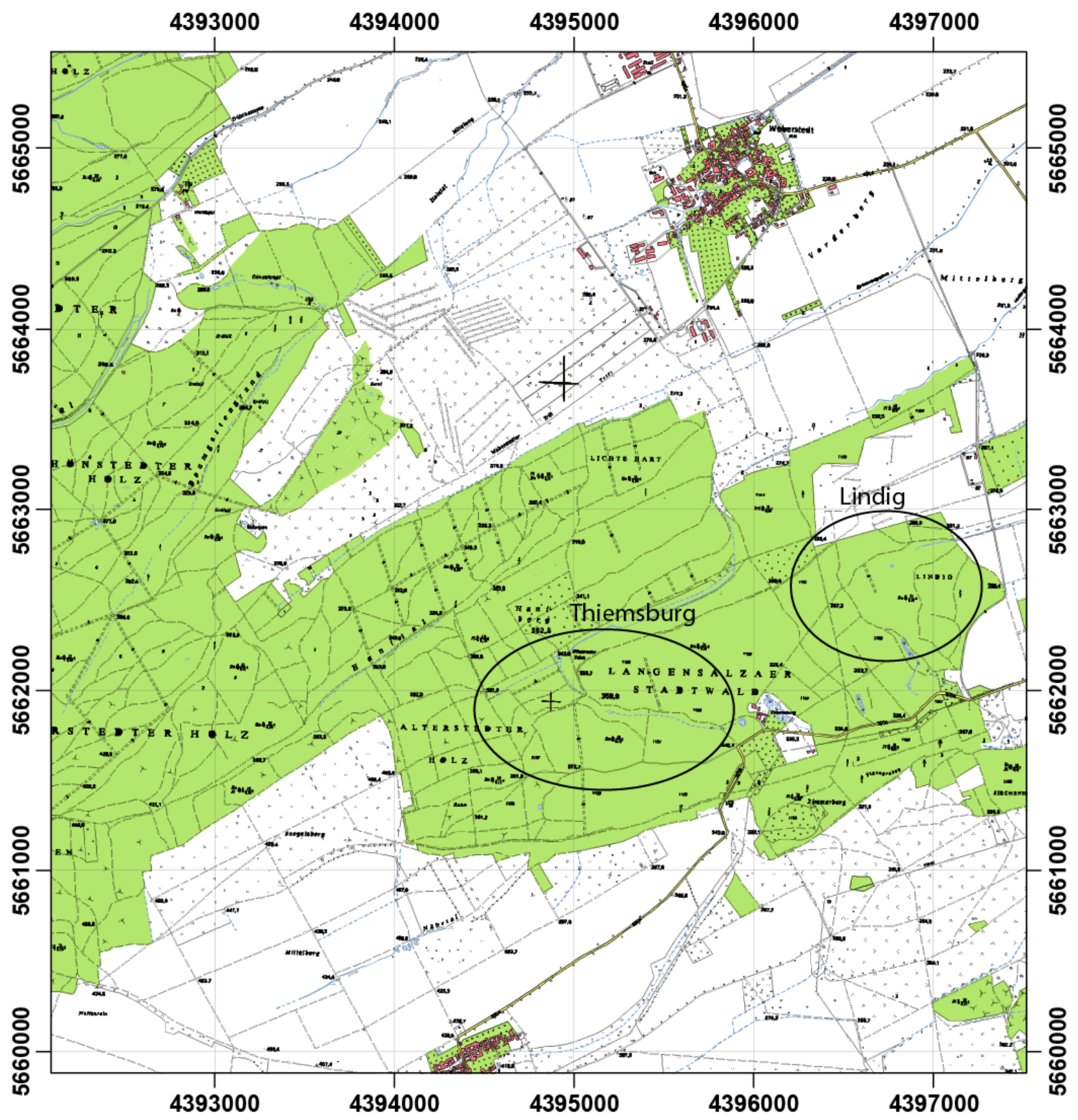

(b) Thiemsburg 


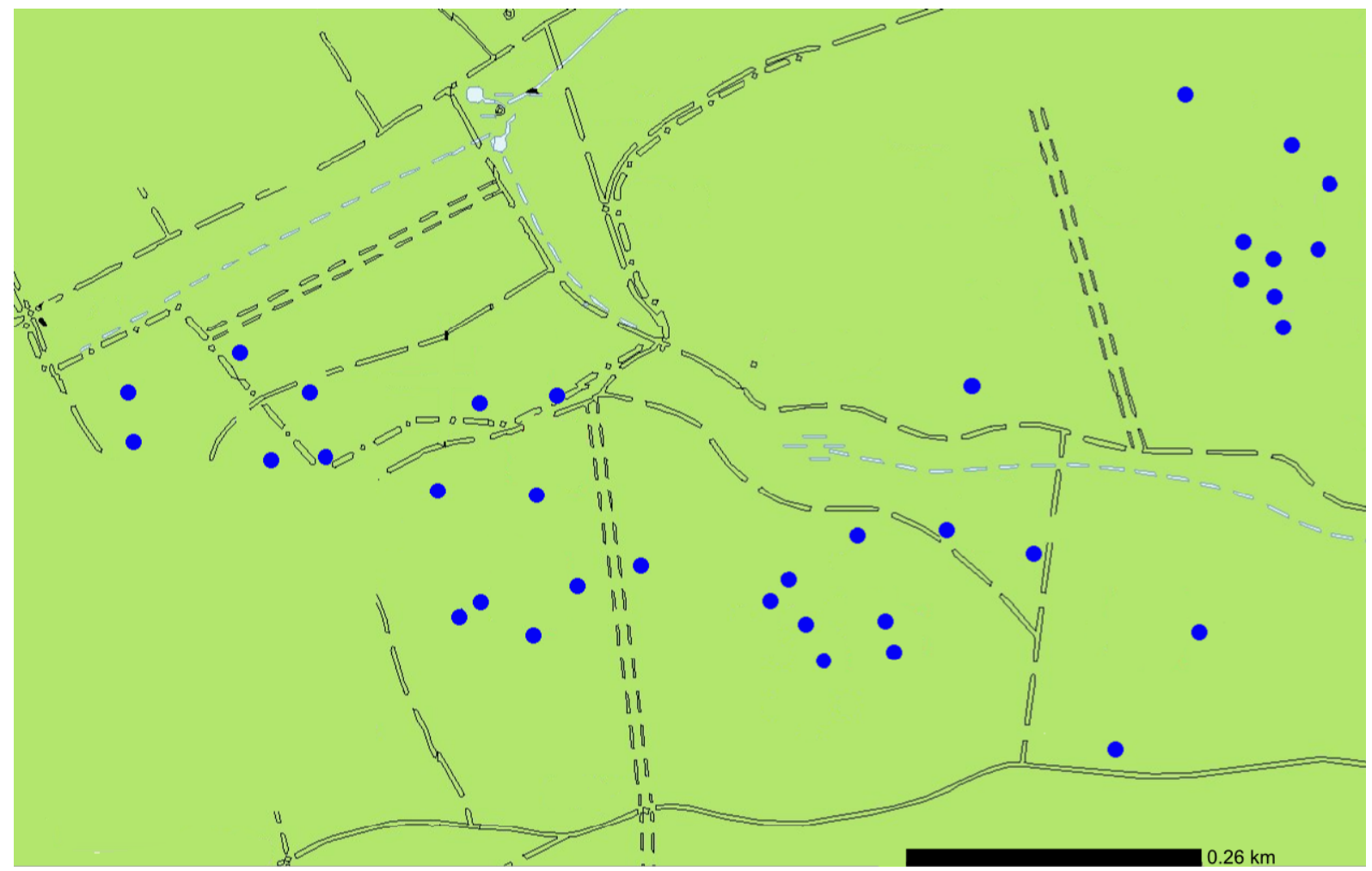

(c) Lindig

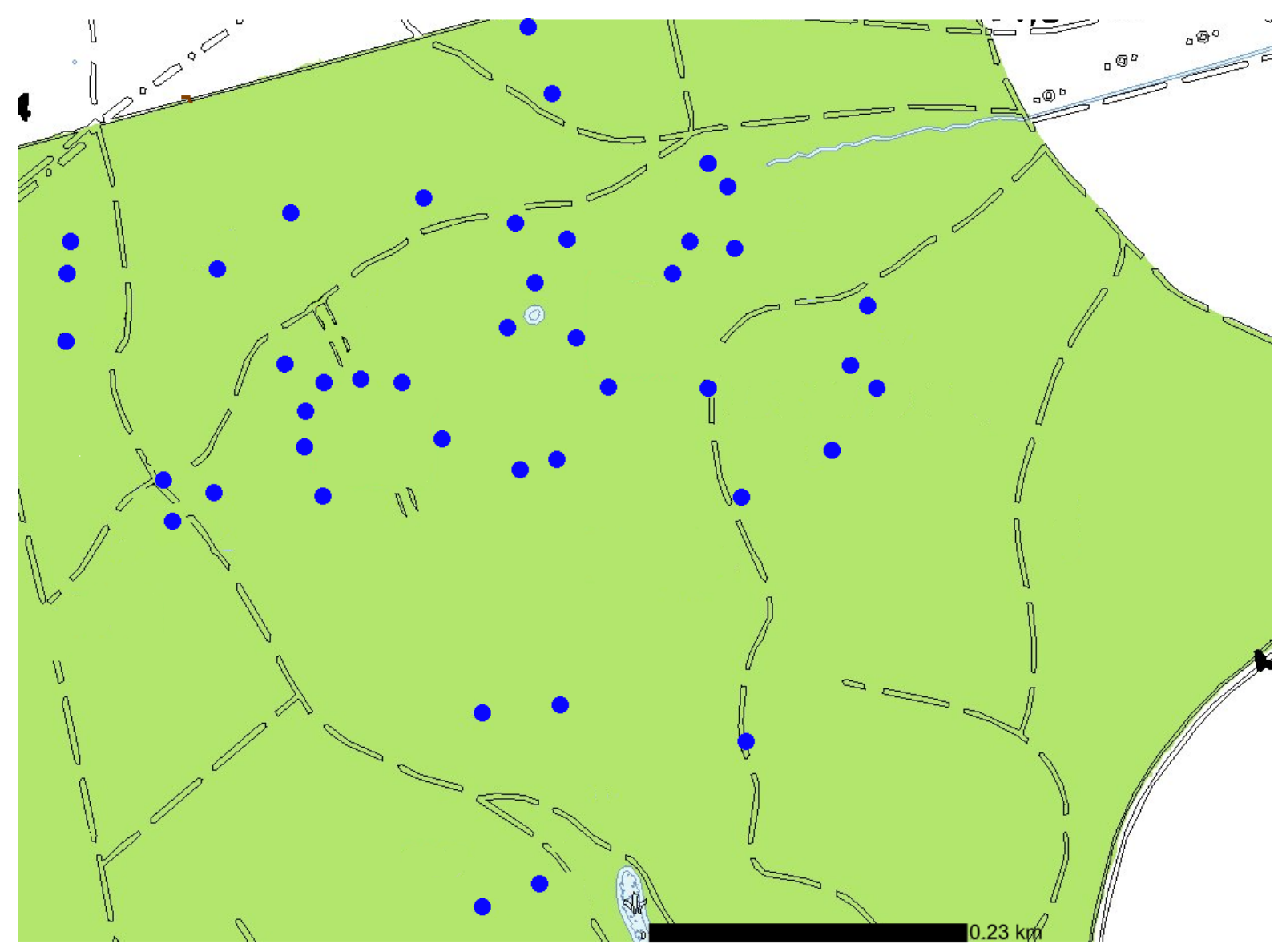

Appendix B 
List of all recorded herb layer plant species with information on functional group, forest specialisation, and life form. $\mathrm{K}=$ herb layer, $\mathrm{S}=$ shrub layer, $\mathrm{B}=$ tree layer, $\mathrm{K} 1.1$ : closely tied to forests, mainly in closed forests, $\mathrm{K}$ 1.2: closely tied to forests, mainly in forest clearings and forest fringes, $\mathrm{S}+\mathrm{K} 2.1$ : occurring in forest as well as open vegetation, $\mathrm{K} 2.2$ : partly in forest, mainly in open vegetation; based on Schmidt et al. (2003). Assignment to life form based on Klotz et al. (2002). One forb species and two graminoid species are not listed as they could not be determined to species and no forest specialisation type or life form could be assigned.

\begin{tabular}{|c|c|c|c|}
\hline Species & $\begin{array}{l}\text { Functional } \\
\text { group }\end{array}$ & $\begin{array}{c}\text { Forest } \\
\text { specialisation }\end{array}$ & Life form \\
\hline Athyrium filix-femina & fern & K2.1 & hemicryptophyte \\
\hline Dryopteris dilatata & fern & K2.1 & hemicryptophyte \\
\hline Dryopteris filix-mas & fern & $\mathrm{K} 1.1$ & hemicryptophyte \\
\hline Aconitum lycoctonum & forb & K2.1 & hemicryptophyte \\
\hline Aegopodium podagraria & forb & $\mathrm{K} 2.1$ & hemicryptophyte \\
\hline Ajuga reptans & forb & K2.1 & hemicryptophyte \\
\hline Alliaria petiolata & forb & $\mathrm{K} 1.2$ & hemicryptophyte \\
\hline Allium ursinum & forb & K1.1 & geophyte \\
\hline Anemone nemorosa & forb & K2.1 & geophyte \\
\hline Arctium nemorosum & forb & $\mathrm{K} 1.2$ & hemicryptophyte \\
\hline Arum maculatum agg. & forb & K1.1 & geophyte \\
\hline Asarum europaeum & forb & K1.1 & hemicryptophyte \\
\hline Campanula trachelium & forb & K1.1 & hemicryptophyte \\
\hline Cardamine pratensis s.1. & forb & K2.1 & hemicryptophyte \\
\hline Circaea lutetiana & forb & K1.1 & geophyte \\
\hline Convallaria majalis & forb & K2.1 & geophyte \\
\hline Dactylorhiza maculata & forb & K2.1 & geophyte \\
\hline Fragaria vesca & forb & $\mathrm{K} 2.1$ & hemicryptophyte \\
\hline Galium aparine & forb & $\mathrm{K} 2.1$ & therophyte \\
\hline Galium sylvaticum & forb & K1.1 & geophyte \\
\hline Geranium robertianum s.str. & forb & $\mathrm{K} 2.1$ & therophyte \\
\hline Geum urbanum & forb & $\mathrm{K} 2.1$ & hemicryptophyte \\
\hline Heracleum sphondylium & forb & $\mathrm{K} 2.2$ & hemicryptophyte \\
\hline Hieracium murorum & forb & K2.1 & hemicryptophyte \\
\hline Lamium galeobdolon s.str. & forb & K1.1 & chamaephyte \\
\hline Lathyrus vernus & forb & K1.1 & geophyte \\
\hline Lilium martagon & forb & $\mathrm{K} 2.1$ & geophyte \\
\hline Listera ovata & forb & K2.1 & geophyte \\
\hline
\end{tabular}




\begin{tabular}{|c|c|c|c|}
\hline Maianthemum bifolium & forb & K1.1 & geophyte \\
\hline Mercurialis perennis & forb & K1.1 & geophyte \\
\hline Oxalis acetosella & forb & K1.1 & geophyte \\
\hline Paris quadrifolia & forb & K1.1 & geophyte \\
\hline Phyteuma spicatum & forb & $\mathrm{K} 2.1$ & hemicryptophyte \\
\hline Polygonatum multiflorum & forb & K1.1 & geophyte \\
\hline Primula elatior & forb & $\mathrm{K} 2.1$ & hemicryptophyte \\
\hline Pulmonaria officinalis & forb & K1.1 & hemicryptophyte \\
\hline Ranunculus auricomus agg. & forb & $\mathrm{K} 2.1$ & hemicryptophyte \\
\hline Ranunculus lanuginosus & forb & $\mathrm{K} 1.1$ & hemicryptophyte \\
\hline Sanicula europaea & forb & $\mathrm{K} 1.1$ & hemicryptophyte \\
\hline Senecio ovatus & forb & $\mathrm{K} 1.2$ & geophyte \\
\hline Solidago virgaurea & forb & $\mathrm{K} 2.1$ & hemicryptophyte \\
\hline Stachys sylvatica & forb & $\mathrm{K} 1.1$ & hemicryptophyte \\
\hline Stellaria holostea & forb & K1.1 & chamaephyte \\
\hline Urtica dioica & forb & $\mathrm{K} 2.1$ & hemicryptophyte \\
\hline Vicia sepium & forb & $\mathrm{K} 2.1$ & hemicryptophyte \\
\hline Viola reichenbachiana & forb & K1.1 & hemicryptophyte \\
\hline Brachypodium sylvaticum & graminoid & K1.1 & hemicryptophyte \\
\hline Bromus ramosus s.str. & graminoid & K1.1 & hemicryptophyte \\
\hline Calamagrostis arundinacea & graminoid & K2.1 & hemicryptophyte \\
\hline Carex sylvatica & graminoid & K1.1 & hemicryptophyte \\
\hline Dactylis polygama & graminoid & K1.1 & hemicryptophyte \\
\hline Deschampsia cespitosa s.str. & graminoid & K2.1 & hemicryptophyte \\
\hline Hordelymus europaeus & graminoid & K1.1 & hemicryptophyte \\
\hline Milium effusum & graminoid & $\mathrm{K} 1.1$ & hemicryptophyte \\
\hline Poa nemoralis & graminoid & $\mathrm{K} 2.1$ & hemicryptophyte \\
\hline Crataegus laevigata & shrub & $\mathrm{S} 2.1$ & phanerophyte \\
\hline Euonymus europaea & shrub & S2.1 & phanerophyte \\
\hline Lonicera periclymenum & shrub & $\mathrm{S} 2.1$ & phanerophyte \\
\hline Acer campestre & tree sapling & $\mathrm{B}$ & phanerophyte \\
\hline Acer platanoides & tree sapling & $\mathrm{B}$ & phanerophyte \\
\hline Acer pseudoplatanus & tree sapling & $\mathrm{B}$ & phanerophyte \\
\hline Carpinus betulus & tree sapling & $\mathrm{B}$ & phanerophyte \\
\hline Fagus sylvatica & tree sapling & $\mathrm{B}$ & phanerophyte \\
\hline Fraxinus excelsior & tree sapling & B & phanerophyte \\
\hline Populus sp. & tree sapling & B & phanerophyte \\
\hline Prunus avium & tree sapling & B & phanerophyte \\
\hline Quercus sp. & tree sapling & B & phanerophyte \\
\hline Tilia sp. & tree sapling & $\mathrm{B}$ & phanerophyte \\
\hline
\end{tabular}


Ulmus glabra

tree sapling

$\mathrm{B}$

phanerophyte

Hedera helix

vine

$\mathrm{B}$

phanerophyte

\section{Appendix C}

Model selection table of linear models containing total herb layer species richness (a) or total herb layer cover (b) as response variable and tree diversity and/or the proportion of Fagus sylvatica on the study plots as explanatory variables. AICc: Akaike's Information Criterion corrected for small sample sizes, a lower AICc indicates a better model fit; $\triangle \mathrm{AICc}$ : differences in AICc between the best model and the remaining models in a set; AICcw (Akaike weight): likelihood of a certain model being the best in a set of models.

\begin{tabular}{lccc}
\hline a) Total herb layer species richness & & & \\
& AICc & $\Delta \mathrm{AICc}$ & $\mathrm{AICc} w$ \\
& & & \\
Tree diversity + Proportion beech & 138 & 0 & 0.836 \\
Proportion beech & 141.3 & 3.3 & 0.161 \\
Tree diversity & 149.1 & 11.2 & 0.003 \\
Null model & 166.4 & 28.5 & 0 \\
\hline
\end{tabular}

\begin{tabular}{lccc}
\hline b) Total herb layer cover & & & \\
\hline & AICc & $\Delta$ AICc & AICc $w$ \\
Proportion beech & -64.8 & 0 & 0.695 \\
Tree diversity + Proportion beech & -63.1 & 1.7 & 0.302 \\
Tree diversity & -53.8 & 11 & 0.003 \\
Null model & -48.5 & 16.2 & 0 \\
\hline
\end{tabular}




\section{Appendix D}

Semivariograms of residuals of full models fitted to analyse species richness and cover of the total herb layer, proportion and cover of forbs, graminoids and tree saplings, proportion of plant life forms, and proportion of true forest species. A spatial correlation parameter incorporating $\mathrm{x} / \mathrm{y}$ coordinates of plots was incorporated into gls models to accommodate for spatial autocorrelation except in the case of total herb layer species richness, graminoid cover, and the proportions of all life forms, where semivariograms indicated no substantial spatial autocorrelation.

Total herb layer species richness:

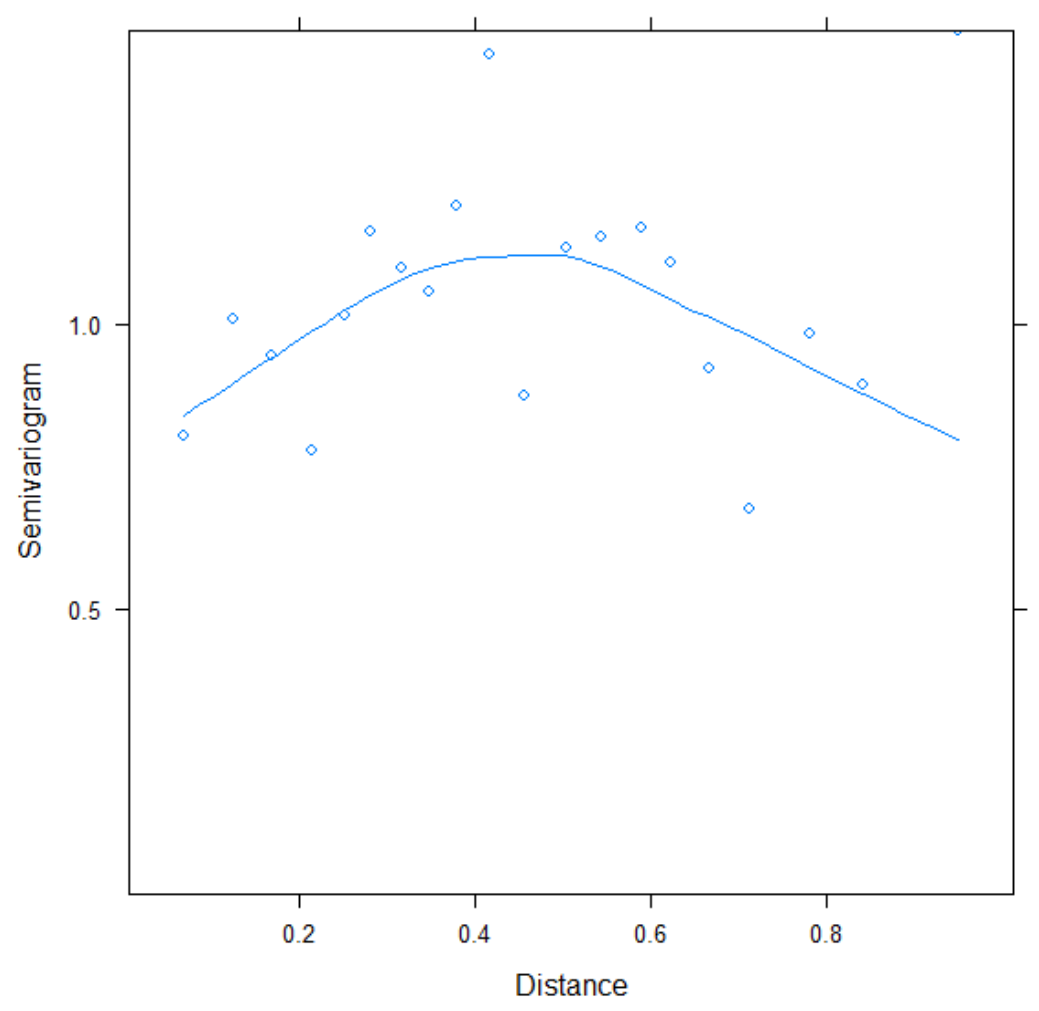


Total herb layer cover:

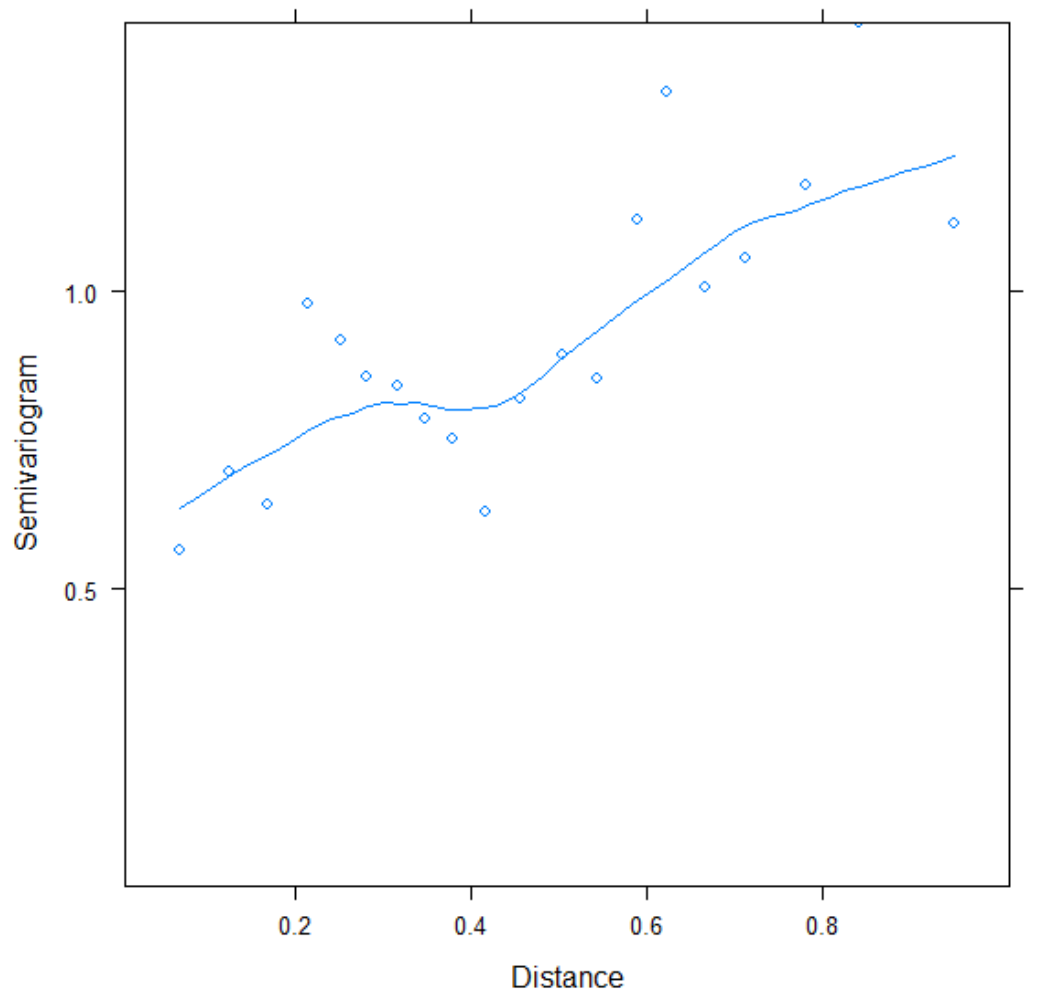

Proportion forbs:

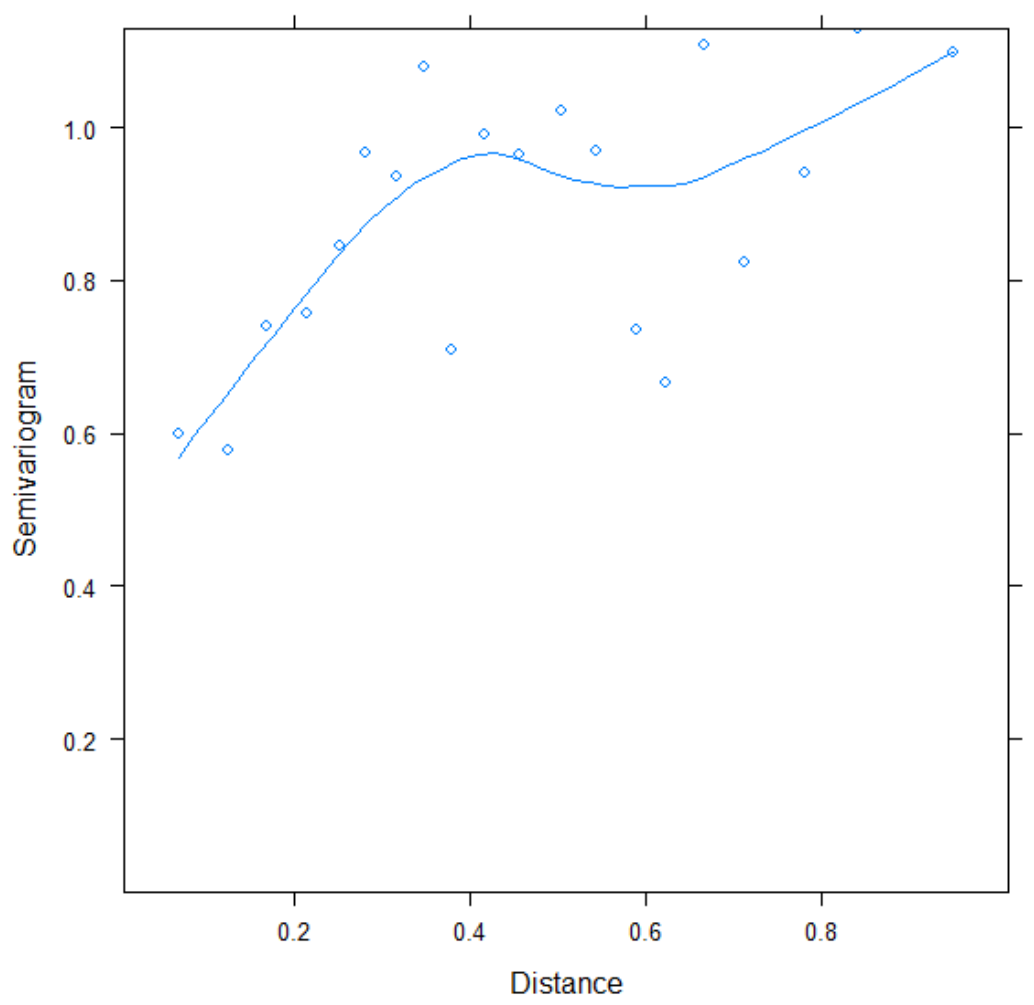


Forb cover:

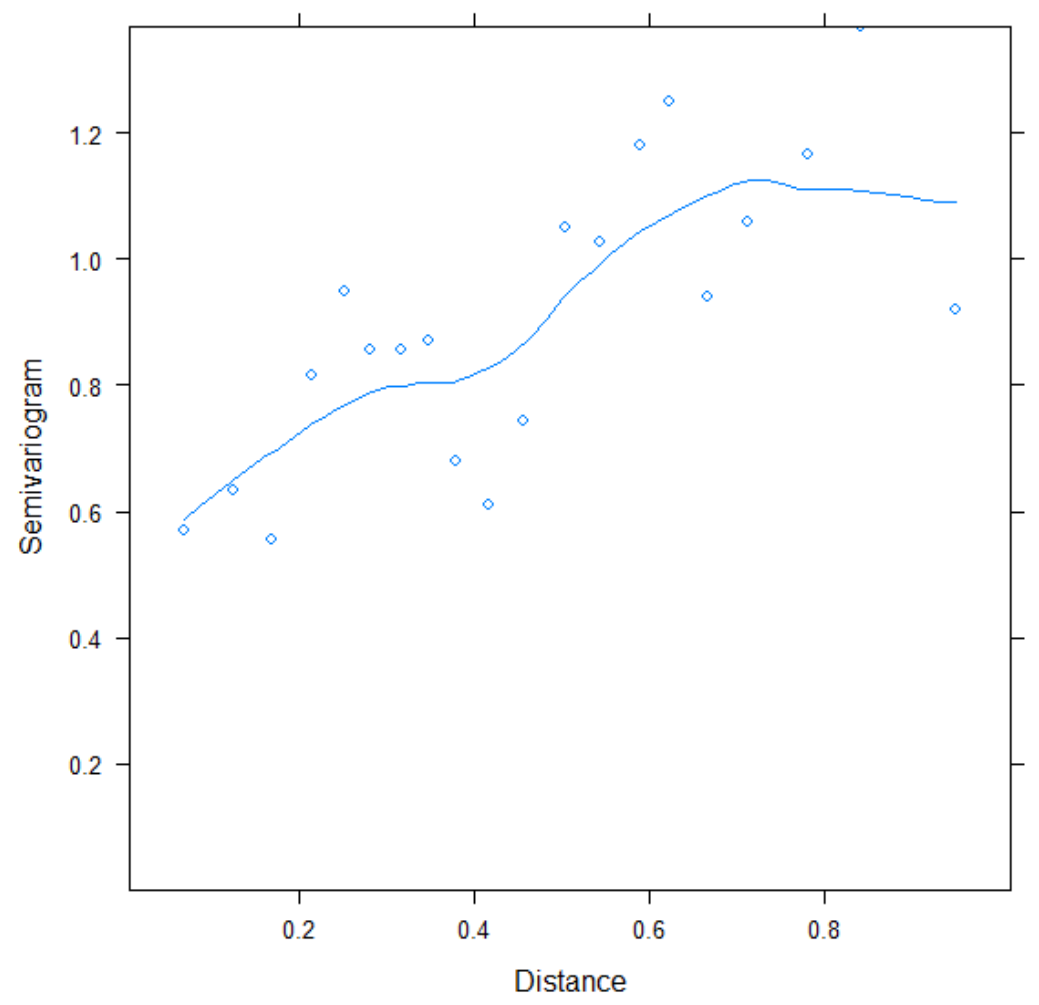

Proportion graminoids:

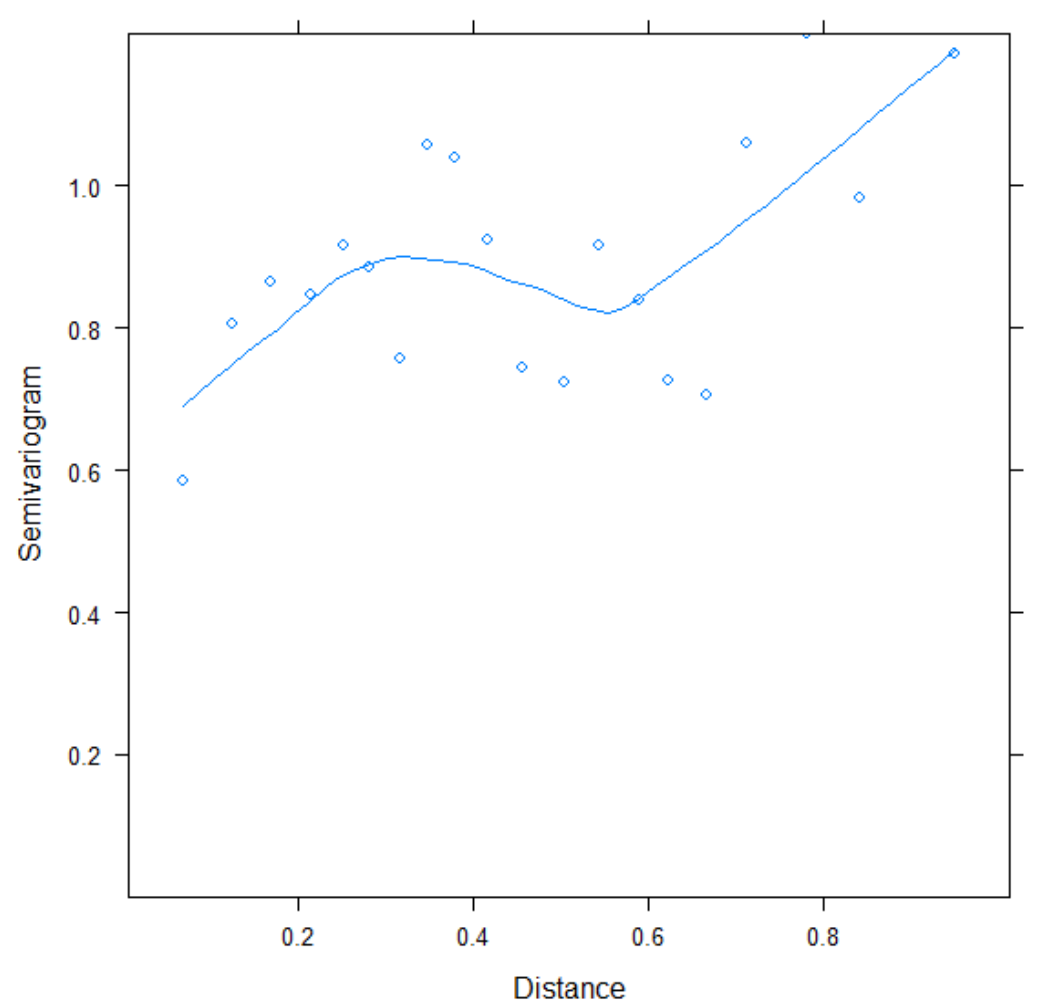


Graminoid cover:

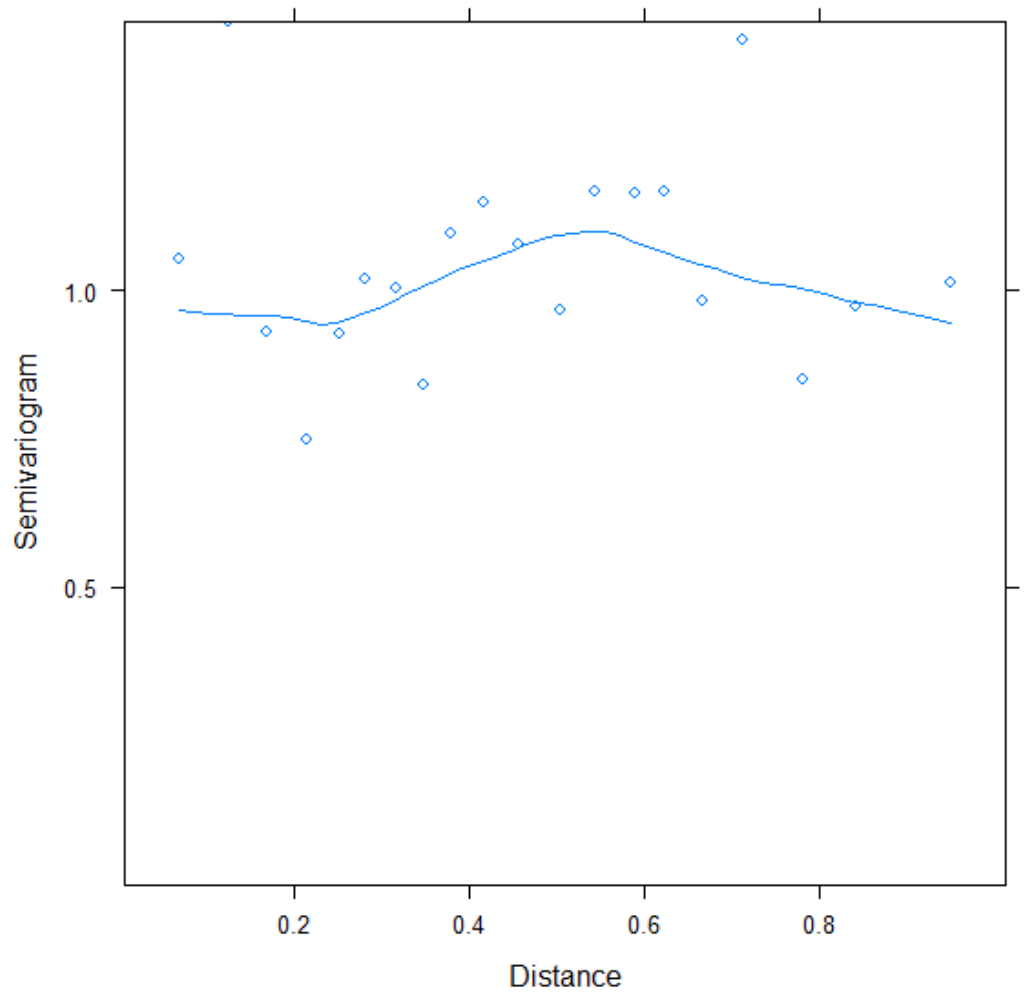

Proportion tree saplings:

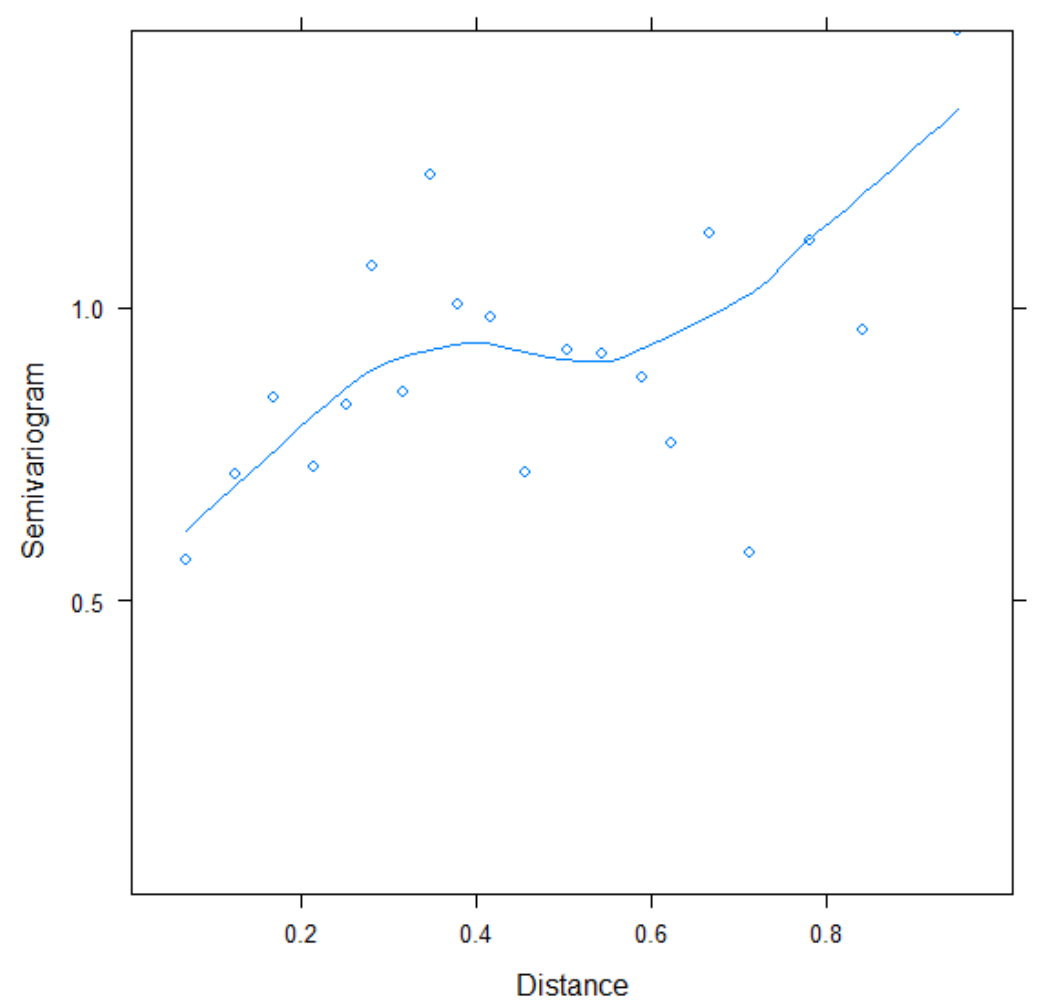


Tree sapling cover:

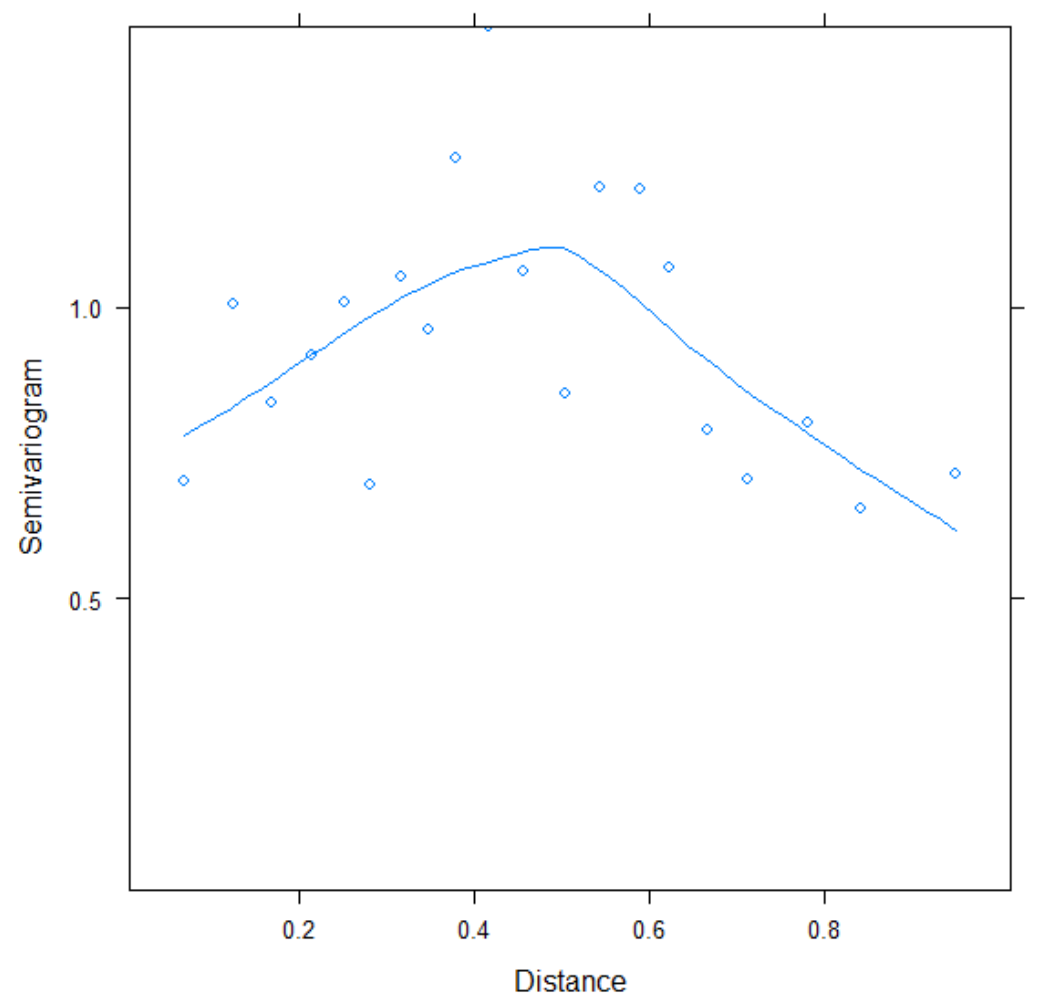

Proportion of true forest species:

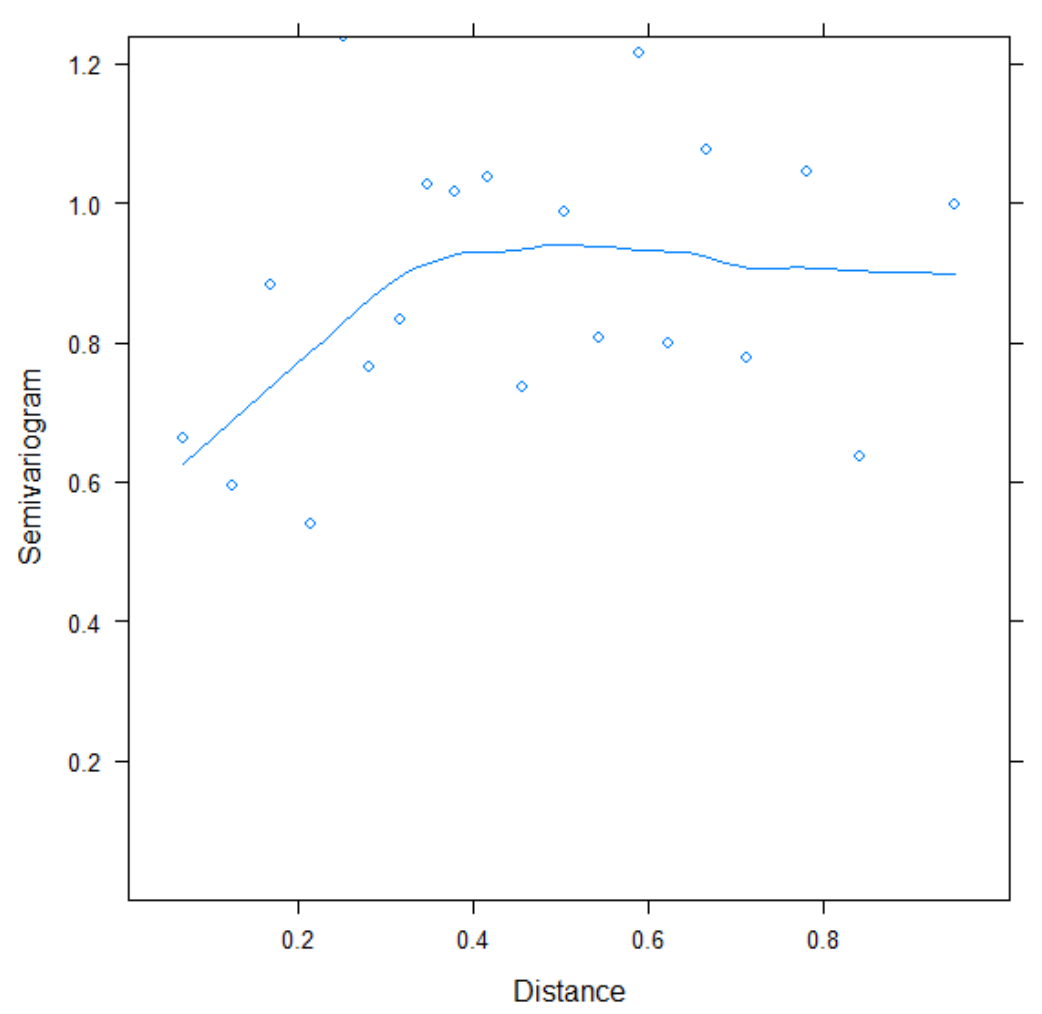


Proportion geophytes:

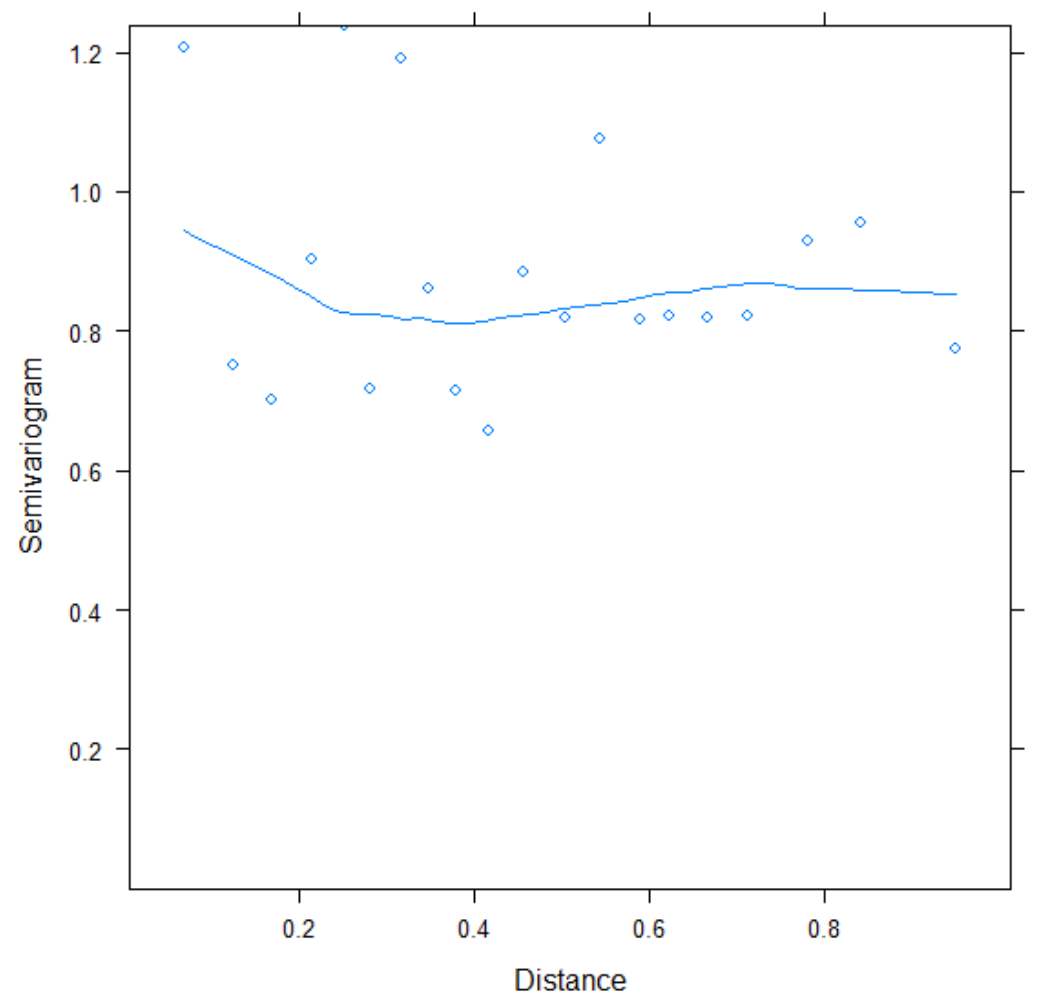

Proportion hemicryptophytes:

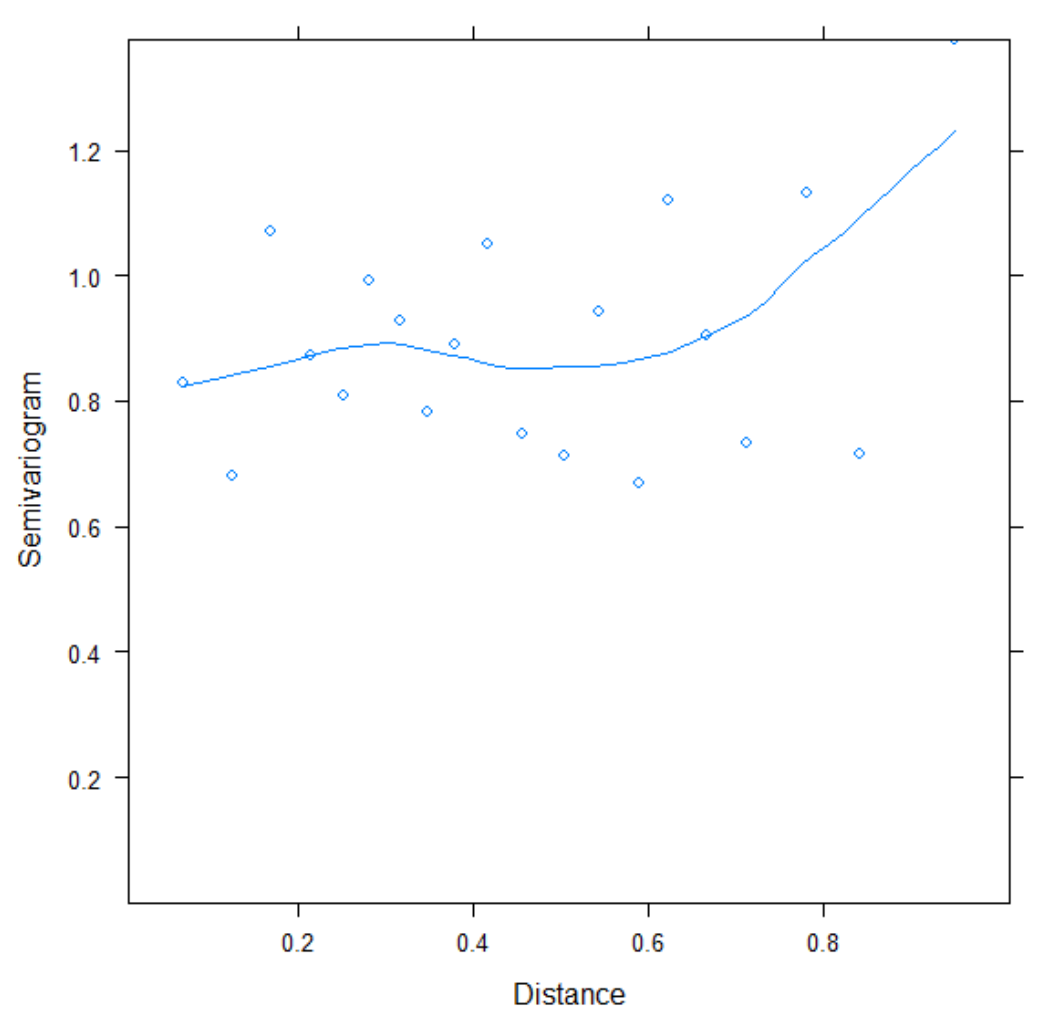


Proportion phanerophytes:

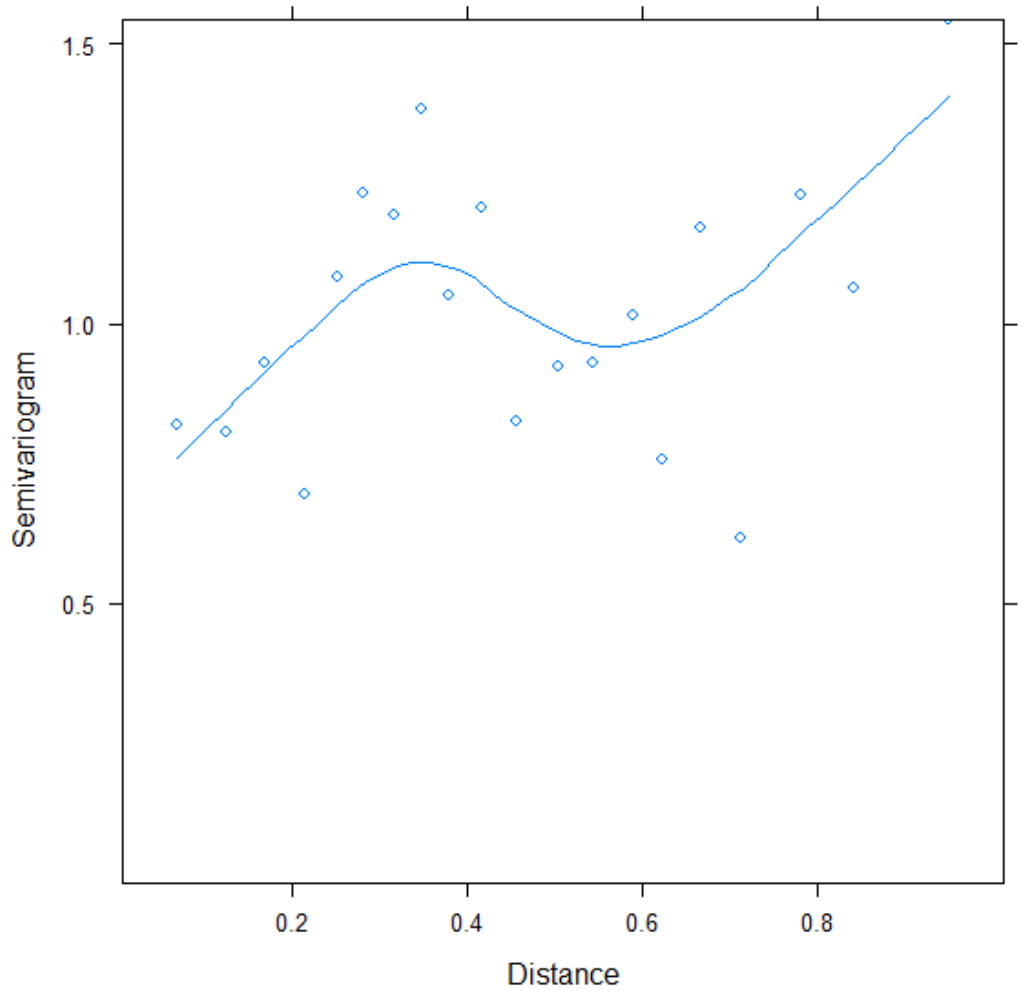




\section{Appendix E}

Multi-model inference summary statistics for the best model subset $(\triangle \mathrm{AICc}<2)$ explaining total herb layer species richness (SR), total herb layer cover, proportion of forbs, forb cover, proportion of graminoids, graminoid cover, proportion of tree saplings, tree sapling cover, proportion of true forest species, proportion of geophytes, proportion of hemicryptophytes, and proportion of phanerophytes. Several models include a spatial correlation parameter (see Appendix E). Tree H': tree diversity expressed as Shannon-Wiener index, Tree $\mathrm{H}^{\prime}{ }^{2}$ : quadratic tree diversity term, $\mathrm{LOC}=$ location, $\mathrm{pH}^{2}$ : quadratic $\mathrm{pH}$ term, $\mathrm{CC}$ : canopy cover, HLM: humus layer mass, C/N: Carbon-to-nitrogen ratio, SM: soil moisture, DIST: distance to forest edge, $\mathrm{K}$ : number of parameters in model, AICc: Akaike's Information Criterion corrected for small sample sizes, $\triangle \mathrm{AICc}$ : difference in AICc, AICcw: Akaike weight ; "1" indicates that a variable was present in the model; “:” signifies a two-way interaction.

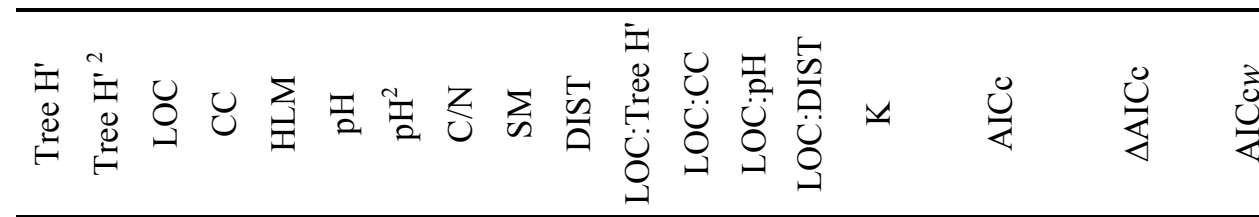

\begin{tabular}{cccccccccccccccccc}
\hline \multicolumn{1}{c}{ Total herb layer $\boldsymbol{S R}$} \\
1 & 0 & 1 & 1 & 1 & 1 & 1 & 1 & 0 & 1 & 0 & 0 & 0 & 0 & 10 & 123.64 & 0 & 0.22 \\
1 & 0 & 1 & 1 & 1 & 1 & 1 & 0 & 0 & 1 & 0 & 0 & 0 & 0 & 9 & 123.74 & 0.1 & 0.21 \\
1 & 0 & 0 & 1 & 1 & 1 & 1 & 0 & 0 & 0 & 0 & 0 & 0 & 0 & 7 & 123.96 & 0.32 & 0.19 \\
1 & 0 & 1 & 1 & 1 & 1 & 1 & 1 & 1 & 1 & 0 & 0 & 0 & 0 & 11 & 124.17 & 0.53 & 0.17 \\
1 & 0 & 1 & 1 & 1 & 1 & 0 & 0 & 0 & 1 & 0 & 0 & 0 & 0 & 8 & 124.71 & 1.07 & 0.13 \\
1 & 0 & 1 & 0 & 1 & 1 & 1 & 0 & 0 & 1 & 0 & 0 & 0 & 0 & 8 & 125.28 & 1.64 & 0.1 \\
\multicolumn{1}{|c}{ Total herb layer cover } & & & & & & & & & & & & \\
1 & 0 & 0 & 1 & 1 & 0 & 0 & 0 & 0 & 0 & 0 & 0 & 0 & 0 & 6 & -81.23 & 0 & 0.16 \\
1 & 0 & 0 & 1 & 1 & 1 & 0 & 0 & 0 & 0 & 0 & 0 & 0 & 0 & 7 & -81.07 & 0.16 & 0.15 \\
1 & 0 & 1 & 1 & 1 & 0 & 0 & 0 & 0 & 1 & 0 & 0 & 0 & 0 & 8 & -80.99 & 0.24 & 0.14 \\
1 & 0 & 1 & 1 & 1 & 1 & 0 & 0 & 0 & 1 & 0 & 0 & 0 & 0 & 9 & -80.4 & 0.83 & 0.11 \\
1 & 0 & 1 & 0 & 1 & 0 & 0 & 0 & 0 & 1 & 0 & 0 & 0 & 0 & 7 & -79.98 & 1.25 & 0.09 \\
1 & 0 & 1 & 1 & 1 & 1 & 0 & 0 & 0 & 0 & 0 & 0 & 0 & 0 & 8 & -79.74 & 1.49 & 0.08 \\
1 & 0 & 0 & 1 & 1 & 0 & 0 & 0 & 1 & 0 & 0 & 0 & 0 & 0 & 7 & -79.71 & 1.52 & 0.08 \\
0 & 0 & 0 & 1 & 1 & 0 & 0 & 0 & 0 & 0 & 0 & 0 & 0 & 0 & 5 & -79.5 & 1.73 & 0.07 \\
1 & 0 & 1 & 1 & 1 & 0 & 0 & 0 & 1 & 1 & 0 & 0 & 0 & 0 & 9 & -79.44 & 1.79 & 0.07 \\
1 & 0 & 1 & 1 & 1 & 0 & 0 & 0 & 0 & 0 & 0 & 0 & 0 & 0 & 7 & -79.43 & 1.8 & 0.07 \\
Proportion forbs & & & & & & & & & & & & & \\
1 & 0 & 0 & 0 & 0 & 1 & 0 & 1 & 0 & 1 & 0 & 0 & 0 & 0 & 7 & -72.47 & 0 & 0.21 \\
1 & 0 & 0 & 0 & 0 & 1 & 0 & 1 & 0 & 0 & 0 & 0 & 0 & 0 & 6 & -71.85 & 0.62 & 0.16 \\
1 & 0 & 0 & 0 & 0 & 1 & 0 & 0 & 1 & 0 & 0 & 0 & 0 & 0 & 6 & -71.43 & 1.04 & 0.13 \\
1 & 0 & 1 & 0 & 0 & 1 & 0 & 1 & 0 & 0 & 0 & 0 & 0 & 0 & 7 & -71.41 & 1.06 & 0.13 \\
1 & 0 & 0 & 0 & 0 & 1 & 0 & 1 & 1 & 0 & 0 & 0 & 0 & 0 & 7 & -71.32 & 1.15 & 0.12 \\
1 & 0 & 0 & 0 & 0 & 1 & 0 & 1 & 1 & 1 & 0 & 0 & 0 & 0 & 8 & -70.75 & 1.72 & 0.09 \\
1 & 0 & 0 & 0 & 1 & 1 & 0 & 0 & 1 & 0 & 0 & 0 & 0 & 0 & 7 & -70.74 & 1.73 & 0.09 \\
1 & 0 & 0 & 0 & 1 & 1 & 0 & 1 & 0 & 0 & 0 & 0 & 0 & 0 & 7 & -70.52 & 1.95 & 0.08
\end{tabular}




\section{Forb cover}

$\begin{array}{cccccccccccccccccc}1 & 0 & 0 & 1 & 1 & 1 & 0 & 0 & 0 & 0 & 0 & 0 & 0 & 0 & 7 & -72.77 & 0 & 0.41 \\ 1 & 0 & 1 & 1 & 1 & 1 & 0 & 0 & 0 & 0 & 0 & 0 & 0 & 0 & 8 & -71.56 & 1.21 & 0.22 \\ 1 & 0 & 1 & 1 & 1 & 1 & 0 & 0 & 0 & 0 & 0 & 1 & 0 & 0 & 9 & -71.38 & 1.39 & 0.2 \\ 1 & 0 & 0 & 1 & 0 & 1 & 0 & 0 & 0 & 0 & 0 & 0 & 0 & 0 & 6 & -71.03 & 1.74 & 0.17\end{array}$

\section{Proportion graminoids}

$\begin{array}{llllllllllllllllll}0 & 0 & 1 & 0 & 1 & 1 & 0 & 0 & 0 & 1 & 0 & 0 & 0 & 0 & 7 & -145.29 & 0 & 0.15 \\ 0 & 0 & 0 & 0 & 1 & 1 & 0 & 0 & 0 & 1 & 0 & 0 & 0 & 0 & 6 & -145.14 & 0.15 & 0.14 \\ 1 & 0 & 0 & 0 & 1 & 1 & 0 & 0 & 0 & 1 & 0 & 0 & 0 & 0 & 7 & -144.28 & 1.01 & 0.09 \\ 0 & 0 & 0 & 0 & 0 & 0 & 0 & 0 & 0 & 0 & 0 & 0 & 0 & 0 & 3 & -144.06 & 1.23 & 0.08 \\ 0 & 0 & 1 & 1 & 1 & 1 & 0 & 0 & 0 & 1 & 0 & 1 & 0 & 0 & 9 & -143.90 & 1.39 & 0.07 \\ 1 & 0 & 1 & 0 & 1 & 1 & 0 & 0 & 0 & 1 & 0 & 0 & 0 & 0 & 8 & -143.79 & 1.5 & 0.07 \\ 0 & 0 & 0 & 0 & 1 & 0 & 0 & 0 & 0 & 1 & 0 & 0 & 0 & 0 & 5 & -143.58 & 1.71 & 0.06 \\ 1 & 0 & 0 & 0 & 1 & 1 & 0 & 0 & 0 & 0 & 0 & 0 & 0 & 0 & 6 & -143.51 & 1.78 & 0.06 \\ 0 & 0 & 1 & 0 & 1 & 1 & 0 & 1 & 0 & 1 & 0 & 0 & 0 & 0 & 8 & -143.49 & 1.8 & 0.06 \\ 1 & 0 & 0 & 0 & 1 & 0 & 0 & 0 & 0 & 0 & 0 & 0 & 0 & 0 & 5 & -143.45 & 1.84 & 0.06 \\ 1 & 0 & 0 & 0 & 0 & 0 & 0 & 0 & 0 & 0 & 0 & 0 & 0 & 0 & 4 & -143.42 & 1.87 & 0.06 \\ 0 & 0 & 0 & 0 & 1 & 0 & 0 & 0 & 0 & 0 & 0 & 0 & 0 & 0 & 4 & -143.35 & 1.94 & 0.06 \\ 0 & 0 & 1 & 0 & 1 & 0 & 0 & 0 & 0 & 1 & 0 & 0 & 0 & 0 & 6 & -143.34 & 1.95 & 0.06\end{array}$

\section{Graminoid cover}

$\begin{array}{llllllllllllllllll}0 & 0 & 1 & 1 & 0 & 0 & 0 & 0 & 0 & 1 & 0 & 0 & 0 & 1 & 6 & -157.94 & 0 & 0.43\end{array}$ $\begin{array}{llllllllllllllllll}0 & 0 & 1 & 1 & 0 & 0 & 0 & 1 & 0 & 1 & 0 & 0 & 0 & 1 & 7 & -156.52 & 1.42 & 0.21\end{array}$ $\begin{array}{llllllllllllllllll}0 & 0 & 1 & 1 & 1 & 0 & 0 & 0 & 0 & 1 & 0 & 0 & 0 & 1 & 7 & -156.29 & 1.65 & 0.19\end{array}$ $\begin{array}{llllllllllllllllll}0 & 0 & 1 & 0 & 0 & 0 & 0 & 0 & 0 & 1 & 0 & 0 & 0 & 1 & 5 & -156.17 & 1.77 & 0.18\end{array}$

\section{Proportion tree saplings}

$\begin{array}{cccccccccccccccccc}1 & 0 & 1 & 0 & 1 & 1 & 0 & 0 & 0 & 0 & 0 & 0 & 1 & 0 & 8 & -105.05 & 0 & 0.3 \\ 1 & 0 & 1 & 0 & 1 & 1 & 0 & 0 & 0 & 1 & 0 & 0 & 1 & 0 & 9 & -104.08 & 0.97 & 0.18 \\ 1 & 0 & 1 & 0 & 1 & 1 & 0 & 0 & 1 & 0 & 0 & 0 & 1 & 0 & 9 & -103.82 & 1.23 & 0.16 \\ 1 & 0 & 1 & 0 & 1 & 1 & 0 & 1 & 0 & 0 & 0 & 0 & 1 & 0 & 9 & -103.41 & 1.64 & 0.13 \\ 1 & 0 & 1 & 0 & 1 & 1 & 0 & 0 & 1 & 1 & 0 & 0 & 1 & 0 & 10 & -103.11 & 1.94 & 0.11 \\ 1 & 0 & 1 & 1 & 1 & 1 & 0 & 0 & 0 & 0 & 0 & 0 & 1 & 0 & 9 & -103.09 & 1.96 & 0.11\end{array}$

Tree sapling cover

$\begin{array}{cccccccccccccccccc}0 & 0 & 1 & 0 & 0 & 1 & 0 & 0 & 0 & 1 & 0 & 0 & 0 & 0 & 6 & -99.4 & 0 & 0.42 \\ 0 & 0 & 1 & 0 & 0 & 1 & 0 & 1 & 0 & 1 & 0 & 0 & 0 & 0 & 7 & -98.03 & 1.37 & 0.21 \\ 0 & 0 & 0 & 0 & 0 & 1 & 0 & 0 & 0 & 0 & 0 & 0 & 0 & 0 & 4 & -97.94 & 1.46 & 0.2 \\ 1 & 0 & 1 & 0 & 0 & 1 & 0 & 0 & 0 & 1 & 0 & 0 & 0 & 0 & 7 & -97.46 & 1.94 & 0.16\end{array}$

\section{Proportion of true forest species}

$\begin{array}{cccccccccccccccccc}1 & 1 & 1 & 1 & 1 & 0 & 0 & 0 & 0 & 1 & 0 & 0 & 0 & 1 & 10 & -56.11 & 0 & 0.14 \\ 0 & 0 & 1 & 1 & 1 & 0 & 0 & 0 & 0 & 1 & 0 & 0 & 0 & 1 & 8 & -55.98 & 0.13 & 0.13 \\ 1 & 1 & 1 & 1 & 1 & 0 & 0 & 0 & 0 & 1 & 1 & 0 & 0 & 1 & 11 & -55.33 & 0.78 & 0.09 \\ 1 & 1 & 1 & 1 & 1 & 1 & 0 & 0 & 0 & 1 & 0 & 0 & 0 & 1 & 11 & -55.04 & 1.07 & 0.08 \\ 1 & 0 & 1 & 1 & 1 & 0 & 0 & 0 & 0 & 1 & 1 & 0 & 0 & 1 & 10 & -54.95 & 1.16 & 0.08 \\ 1 & 1 & 1 & 1 & 1 & 1 & 0 & 0 & 0 & 1 & 1 & 0 & 0 & 1 & 12 & -54.73 & 1.38 & 0.07 \\ 1 & 1 & 1 & 1 & 1 & 0 & 0 & 0 & 0 & 1 & 0 & 0 & 0 & 1 & 11 & -54.7 & 1.41 & 0.07 \\ 0 & 0 & 1 & 1 & 1 & 0 & 0 & 1 & 0 & 1 & 0 & 0 & 0 & 1 & 9 & -54.7 & 1.41 & 0.07 \\ 0 & 0 & 0 & 1 & 1 & 0 & 0 & 0 & 0 & 1 & 0 & 0 & 0 & 0 & 6 & -54.66 & 1.45 & 0.07 \\ 0 & 0 & 0 & 1 & 1 & 0 & 0 & 1 & 0 & 1 & 0 & 0 & 0 & 0 & 7 & -54.48 & 1.63 & 0.06 \\ 0 & 0 & 1 & 1 & 1 & 1 & 0 & 0 & 0 & 1 & 0 & 0 & 0 & 1 & 9 & -54.47 & 1.64 & 0.06 \\ 1 & 1 & 1 & 1 & 1 & 0 & 0 & 1 & 0 & 1 & 0 & 0 & 0 & 1 & 11 & -54.35 & 1.76 & 0.06 \\ 1 & 0 & 1 & 1 & 1 & 1 & 0 & 0 & 0 & 1 & 1 & 0 & 0 & 1 & 11 & -54.13 & 1.98 & 0.05 \\ \text { Proportion } & \text { of geophytes } & & & & & & & & & & & & \\ 1 & 0 & 1 & 0 & 1 & 1 & 0 & 0 & 0 & 1 & 0 & 0 & 1 & 1 & 9 & -171.99 & 0 & 0.21 \\ 1 & 0 & 1 & 0 & 1 & 1 & 0 & 1 & 0 & 1 & 0 & 0 & 1 & 1 & 10 & -171.41 & 0.58 & 0.15 \\ 1 & 0 & 0 & 0 & 1 & 1 & 0 & 0 & 0 & 1 & 0 & 0 & 0 & 0 & 6 & -171.18 & 0.81 & 0.14 \\ 1 & 0 & 1 & 0 & 1 & 1 & 0 & 0 & 0 & 1 & 0 & 0 & 0 & 1 & 8 & -171.03 & 0.96 & 0.13\end{array}$




\begin{tabular}{|c|c|c|c|c|c|c|c|c|c|c|c|c|c|c|c|c|c|}
\hline & 0 & 1 & 0 & 1 & 1 & 0 & 1 & 0 & 1 & 0 & 0 & 1 & 0 & 9 & -170.64 & 1.35 & 0.1 \\
\hline & 0 & 1 & 1 & 1 & 1 & 0 & 0 & 0 & 1 & 0 & 0 & 1 & 1 & 10 & -170.45 & 1.54 & 0.1 \\
\hline & 0 & 0 & 0 & 1 & 1 & 0 & 1 & 0 & 1 & 0 & 0 & 0 & 0 & 7 & -170.32 & .67 & 0.09 \\
\hline & 0 & 1 & 1 & 1 & 1 & 0 & 1 & 0 & & & & & & 11 & & 81 & .08 \\
\hline \multicolumn{18}{|c|}{ Proportion of hemicryptophytes } \\
\hline & 0 & 1 & 1 & 1 & 1 & 0 & 0 & 1 & 1 & 0 & 0 & 1 & 0 & 10 & -106.81 & 0 & 0.28 \\
\hline & 0 & 1 & 1 & 1 & 1 & 0 & 0 & 0 & 1 & 0 & 0 & 1 & 0 & 9 & -10 & 0.28 & 0.25 \\
\hline & 0 & 0 & 1 & 1 & 1 & 0 & 0 & 1 & 1 & 0 & 0 & 0 & 0 & 8 & 25 & .56 & 0.21 \\
\hline & 0 & 1 & 1 & 1 & 1 & 0 & 0 & 1 & 1 & 0 & 0 & 0 & 0 & 9 & & 32 & 0.15 \\
\hline & 0 & 1 & 1 & 1 & 1 & 0 & 1 & 1 & & & & & & 11 & & & \\
\hline \multicolumn{18}{|c|}{ Proportion of phanerophytes } \\
\hline & 0 & 0 & 1 & 1 & 1 & 1 & 0 & 1 & 0 & 0 & 0 & $\sigma$ & 0 & 8 & -95.72 & 0 & 0.13 \\
\hline & 0 & 0 & 1 & 0 & 1 & 1 & 0 & 1 & 0 & 0 & 0 & 0 & 0 & 7 & -95.01 & 0.71 & 0.09 \\
\hline & 0 & 0 & 0 & 1 & 1 & 1 & 0 & 1 & 0 & 0 & 0 & 0 & 0 & 7 & -94.74 & 0.98 & 0.08 \\
\hline & 0 & 0 & 1 & 1 & 1 & 0 & 1 & 1 & 0 & 0 & 0 & 0 & 0 & 8 & -94.58 & 1.14 & 0.08 \\
\hline & c & 0 & 1 & 1 & 1 & 1 & 1 & 1 & 0 & 0 & 0 & 0 & 0 & 9 & -94.48 & 1.24 & 0.07 \\
\hline & 0 & 0 & 0 & 1 & 1 & 0 & 1 & 1 & 0 & 0 & 0 & 0 & 0 & 7 & -94.45 & 1.27 & 0.07 \\
\hline & 0 & 1 & 1 & 1 & 1 & 1 & 0 & 0 & 0 & 0 & 0 & 1 & 0 & 9 & -94.42 & 1.3 & 0.07 \\
\hline & 0 & 0 & 1 & 1 & 1 & 0 & 1 & 0 & 0 & 0 & 0 & 0 & 0 & 7 & -94.17 & 1.55 & 0.06 \\
\hline & 0 & 0 & 1 & 0 & 1 & 1 & 1 & 1 & 0 & 0 & 0 & 0 & 0 & 8 & -94.04 & 1.68 & 0.06 \\
\hline & 0 & 0 & 1 & 1 & 1 & 1 & 1 & 0 & 0 & 0 & 0 & 0 & 0 & 8 & -94.04 & 1.68 & 0.06 \\
\hline & 0 & 0 & 1 & 1 & 1 & 0 & 0 & 1 & 0 & 0 & 0 & 0 & 0 & 7 & -94.01 & 1.71 & 0.06 \\
\hline & 0 & 0 & 1 & 0 & 1 & 0 & 1 & 1 & ( & ( & ( & ( & 0 & 7 & -93.95 & 1.77 & 0.06 \\
\hline & 0 & 0 & 0 & 1 & 1 & 1 & 1 & 1 & & ( & ( & & 0 & $\gamma$ & 3.86 & 1.86 & 0.05 \\
\hline & 0 & 0 & 1 & 1 & 1 & 1 & 0 & 0 & & 0 & & & 0 & 7 & -93.81 & 1.91 & 0.05 \\
\hline
\end{tabular}

\section{Appendix F}

Multi-model averaged coefficients and unconditional standard errors of parameters determining the proportion of the three most common plant life forms (geophytes, hemicryptophytes, phanerophytes). “:” denotes a two-way interaction.

\begin{tabular}{lccc}
\hline & Proportion geophytes & Proportion hemicryptophytes & Proportion phanerophytes \\
\hline (Intercept) & $0.117 \pm 0.026$ & $0.428 \pm 0.027$ & $0.331 \pm 0.021$ \\
Location Thiemsburg & $0.012 \pm 0.029$ & $-0.049 \pm 0.052$ & $0.002 \pm 0.005$ \\
Tree diversity & $0.032 \pm 0.011$ & $0.04 \pm 0.015$ & $-0.037 \pm 0.016$ \\
Canopy cover & $0.002 \pm 0.004$ & $-0.03 \pm 0.015$ & $0.023 \pm 0.018$ \\
Humus layer & $0.03 \pm 0.014$ & $-0.069 \pm 0.02$ & $0.03 \pm 0.023$ \\
$\mathrm{pH}$ & $0.031 \pm 0.014$ & $0.046 \pm 0.022$ & $-0.086 \pm 0.027$ \\
$\mathrm{pH}$ & - & - & $0.015 \pm 0.015$ \\
Distance forest edge & $-0.068 \pm 0.032$ & $0.065 \pm 0.028$ & - \\
$\mathrm{C} / \mathrm{N}$ ratio & $-0.007 \pm 0.01$ & $0.002 \pm 0.004$ & $0.013 \pm 0.017$ \\
Soil moisture & - & $-0.028 \pm 0.023$ & $0.029 \pm 0.024$ \\
Location:distance & $0.047 \pm 0.044$ & - & - \\
forest edge & $0.025 \pm 0.024$ & $-0.039 \pm 0.038$ & $0.004 \pm 0.008$ \\
Location:pH & & & \\
\hline
\end{tabular}




\section{CHAPTER 3}

\section{Richness, abundance, and}

community composition of flies

(Diptera) across a tree and herb diversity gradient

E. A. Vockenhuber, T. Tscharntke, A. Stark, C. Scherber

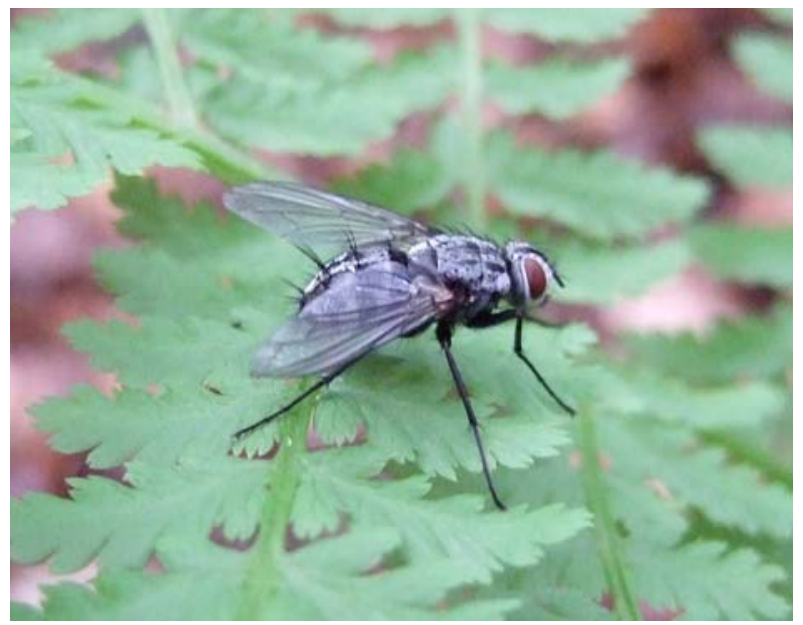




\begin{abstract}
Plant diversity positively affects insect diversity and abundance in grasslands. In more complex forest ecosystems, however, linkages between plant diversity and communities of other biota remain under-studied. We examined how richness and abundance of Diptera, a ubiquitous and species-rich insect order that nevertheless receives little attention in ecological studies, respond to varying levels of tree layer diversity, herb layer diversity, and herb cover. The study was conducted in the Hainich National Park (Central Germany) on 84 plots along a broad gradient of tree diversity (2-9 species) and herb diversity (2-28 species).

Both tree and herb diversity influenced Dipteran abundance, whereas abundances of the locally common taxa Empidoidea and Phoridae responded to herb diversity only. Relationships between Dipteran abundances and tree and herb diversity were positive in the study location dominated by lime, but absent or weakly negative in the beech-dominated location. Dipteran family richness and species richness of Empidoidea and Phoridae did not respond to tree or herb diversity.

Herb cover showed a strong and consistently positive relationship with both Dipteran abundance and family richness. Similarity of herb and tree layer composition resulted also in a more similar Dipteran community, pointing to the role of species identity effects.

We conclude that herb diversity, and to a lesser extent tree diversity, influence Dipteran communities in temperate deciduous forests; however, strength and direction of the relationship are context-dependent and possibly modified by the identity of the dominant tree species. Altogether, herb cover plays a greater role in shaping patterns of Dipteran richness and abundance than plant diversity.
\end{abstract}

Key words: insect diversity, Fagus sylvatica, field layer, temperate forests, understorey 


\section{Introduction}

Vegetation characteristics such as the diversity and productivity of plants strongly shape the terrestrial habitats of most animals. For example, plant diversity has been shown to enhance insect diversity and abundance (Knops et al. 1999; Haddad et al. 2009; Scherber et al. 2010). More diverse plant communities provide a more heterogeneous resource base that allows a greater number of herbivorous insect species to coexist, an effect that can cascade up to higher trophic levels of predators and parasitoids (Hunter and Price 1992; Siemann et al. 1998). Also, higher structural complexity associated with diverse plant communities can positively influence insect diversity and abundance (Lawton 1983; Siemann 1998; Brose 2003).

While these plant-insect diversity relationships have been frequently studied in grassland ecosystems (Siemann et al. 1998; Koricheva et al. 2000; Haddad et al. 2009), little is known on whether these patterns also hold true for forest habitats. Compared to grasslands, forests are characterised by a higher complexity due to an overall higher biovolume and the organisation of the plant community in different layers. Tree and herb layer diversity often show linkages (Barbier et al. 2008; Vockenhuber et al. 2011) and may both affect the structure of insect communities in the forest. Due to this greater spatial complexity, different patterns between plant and insect diversity may be found in forests than in grasslands. So far, studies of tree diversity effects on insect communities have mostly compared stands along a limited diversity gradient (monocultures vs. mixtures containing a small selection of species), often in conifer-dominated plantations. Only few studies used a wider diversity gradient in deciduous settings (Sobek et al. 2009a; 2009b; 2009c). Effects of herb layer characteristics on insect communities have rarely been considered at all (but see Humphrey et al. 1999; Hirao et al. 2009) although the herb layer contains most of a forest's plant diversity (Gilliam 2007). In comparison, the tree layer generally holds less species, but the individual species have a stronger capacity to shape their environment due to their greater biomass. Thus, herb layer and tree layer diversity might differ in their effect on insect communities.

Diptera, a hyper-diverse insect order, represent a major component of all non-marine ecosystems and are often the most abundant animals in temperate habitats (Hughes, Daily \& Ehrlich 2000; Thompson 2009). They fulfil a great variety of ecological functions, acting as predators, parasitoids, herbivores, detritivores and pollinators (Oosterbroek 2007). In spite of their high ecological importance, Diptera are frequently overlooked in ecological studies, even though they may respond differently to changing habitat characteristics than trophically 
more limited insect taxa such as Lepidoptera (Woodcock, Watt \& Leather 2003; Allgood, Miller \& Kalcounis-Rueppell 2009). In particular, the effect of plant diversity on Dipteran diversity has rarely been addressed.

In this study, we explore the effects of both tree layer and herb layer diversity on Dipteran richness and abundance in Germany's largest connected deciduous forest. Plots span a wide diversity gradient of broad-leaved tree species and herb layer plants. We study the richness of the total Dipteran community using family richness as diversity indicator (Baldi 2003). Additionally, we analyze the species richness of two locally abundant Dipteran taxa, the Empidoidea and the Phoridae. While the main focus of the study lies on testing biodiversity effects, we also consider possible effects of plant cover (as a surrogate variable for herb layer productivity) on the Dipteran community. We focus on the following questions:

(1) How do tree and herb layer diversity affect Dipteran richness and abundance?

(2) How does the cover of the herb layer affect Dipteran richness and abundance?

(3) Is the Dipteran community composition influenced by the plant composition of tree or herb layer?

(4) What is the effect of tree and herb layer diversity on different ecological groups of Empidoidea?

\section{Materials and Methods}

\section{Study area}

The study was conducted in the Hainich National Park (Thuringia, Central Germany), near the village of Weberstedt $\left(51^{\circ} 05^{\prime} 28^{\prime \prime} \mathrm{N}, 10^{\circ} 31^{\prime} 24^{\prime \prime} \mathrm{O}\right)$. The Hainich forest encompasses 16000 ha, of which 7500 ha have national park status. Climatic conditions are sub-Atlantic with continental influence; with a mean annual temperature of $7.5^{\circ} \mathrm{C}$ and a mean annual precipitation of $590 \mathrm{~mm}$ (1973 - 2004, Deutscher Wetterdienst). Throughout the study period (2008), the mean daily temperature was $9.5^{\circ} \mathrm{C}$ and annual precipitation was $500.8 \mathrm{~mm}$ (Meteomedia, Germany). The research area is situated at an elevation of approximately $350 \mathrm{~m}$ a.s.1. The predominant soil type is (stagnic) Luvisol developed from Triassic limestone as bedrock with partial loess cover (Leuschner et al. 2009).

Sampled forest stands have essentially been unmanaged since the area became a military training ground in the 1960s and a national park in 1997. All investigated forest stands were mature and held deciduous forest for at least 200 years (Mölder 2009). Dominant tree species 
were Fagus sylvatica L., Tilia platyphyllos Scop., Tilia cordata Mill., and Fraxinus excelsior L. Other species such as Carpinus betulus L., Acer campestre L., Acer platanoides L., Acer pseudoplatanus L., Prunus avium L., Sorbus torminalis (L.) Crantz, Quercus robur L., Quercus petraea Liebl., and Ulmus glabra Huds. were less abundant. The area is exceptionally suitable for studying tree diversity effects because differences in historic forestuse practises (mostly coppicing and selective cutting) have created a small-scale mosaic of stands differing in tree diversity, while exhibiting comparable climatic and edaphic conditions (Leuschner et al. 2009).

\section{Study plots}

In spring 2008, we established 100 plots based on a priori combinations of tree species (Leuschner et al. 2009). Plots were arranged in two locations (each $n=50$ ), Lindig and Thiemsburg (distance between locations approximately $1.5 \mathrm{~km}$ ). In the current study, we defined plots as consisting of a circular area (radius $20 \mathrm{~m}$, area: $1257 \mathrm{~m}^{2}$ ) for tree layer measurements, with herb layer measurements (on $2 \times 1 \mathrm{~m}^{2}$ quadrats) and sampling of Diptera conducted at the plot centre (see below). We included only plots with a minimum distance of $30 \mathrm{~m}$ to improve spatial independence of insect samples. This yielded 84 plots ( 44 plots at the Lindig location and 40 plots at the Thiemsburg location) (Online Resource 1). Plots differed in their tree and herb diversity and herb cover (Table 1). Online Resource 2 gives a summary of abiotic plot characteristics.

Table 1. Summary statistics of the explanatory variables, based on all 84 study plots. Lindig/Thiemsburg represent the two locations used in this study. $\mathrm{SE}=$ standard error.

\begin{tabular}{|c|c|c|c|c|c|c|c|}
\hline \multirow[b]{2}{*}{ Variable (unit) } & \multirow[b]{2}{*}{ Description } & \multicolumn{2}{|c|}{ Overall } & \multicolumn{2}{|c|}{ Lindig } & \multicolumn{2}{|c|}{ Thiemsburg } \\
\hline & & Mean $\pm \mathrm{SE}$ & Range & Mean \pm SE & Range & Mean $\pm \mathrm{SE}$ & Range \\
\hline Herb cover $(\%)$ & $\begin{array}{l}\text { Area of ground } \\
\text { covered by herb } \\
\text { layer }\end{array}$ & $33.6 \pm 2.2$ & $1.8-86.9$ & $42.2 \pm 3.4$ & $7.8-86.9$ & $24.1 \pm 2.0$ & $1.8-47.9$ \\
\hline Herb diversity $\left(\mathrm{H}^{\prime}\right)$ & $\begin{array}{l}\text { Shannon-Wiener } \\
\text { diversity index H' } \\
\text { of herb layer plants }\end{array}$ & $1.81 \pm 0.05$ & $0.56-2.92$ & $1.84 \pm 0.07$ & $0.97-2.92$ & $1.78 \pm 0.07$ & $0.56-2.65$ \\
\hline Tree diversity (H') & $\begin{array}{l}\text { Shannon-Wiener } \\
\text { diversity index H' } \\
\text { of trees }\end{array}$ & $1.26 \pm 0.04$ & $0.27-1.88$ & $1.33 \pm 0.04$ & $0.6-1.79$ & $1.2 \pm 0.06$ & $0.27-1.88$ \\
\hline
\end{tabular}

\section{Vegetation measurements}


Herb layer species richness and cover were recorded on two 1 x $1 \mathrm{~m}$ quadrats in the plot centre in June 2008. We estimated percentage cover of each vascular plant species present. All plants with a height $<1 \mathrm{~m}$ were considered, as this threshold is commonly used to delimit the herb layer (Gilliam 2007). For every pair of quadrats, we pooled the number of plant species present and calculated mean vegetation cover, giving a total of $n=84$ values for herb species richness and cover. The number of herb layer species recorded per plot ranged from 2-28 plant species, herb cover from 2-79\% (Table 1). We calculated plant diversity indices for every plot (see section data analysis). The most common herb layer plant species included A. platanoides, F. excelsior, A. pseudoplatanus, and F. sylvatica (tree saplings), Lamium galeobdolon (L.) L. s. str., Stellaria holostea L., Viola reichenbachiana Boreau, and Primula elatior (L.) Hill (forbs), and the graminoid Hordelymus europaeus (L.) Harz (see Vockenhuber et al. (2011) for a detailed description of the vegetation composition in the study area).

To estimate tree diversity, we recorded all tree species within a $20 \mathrm{~m}$ radius around the plot center (area: $1257 \mathrm{~m}^{2}$ ) with diameter at breast height $(\mathrm{dbh})$ of $>7 \mathrm{~cm}$. In addition, we measured dbh of all trees with circumference tape and calculated the stem area. The number of broad-leaved tree species per plot ranged from two (nearly monospecific F. sylvatica stands) to nine different broad-leaved tree species. No conifers were present. The most dominant species were F. sylvatica (Lindig 5\%, Thiemsburg 48\%), Tilia sp. (Lindig 44\%, Thiemsburg 16\%) and F. excelsior (Lindig 23\%, Thiemsburg 20\%). Tilia cordata/ T. platyphyllos and Q. robur/Q. petraea were recorded on genus level as these species could not be reliably distinguished in the field.

\section{Diptera sampling and processing}

We used both suction sampling and pan traps to sample Diptera with a broad range of habitat requirements. One yellow, one white and one blue plastic pan trap per plot (Fun In A Box Ltd., $5 \mathrm{~cm}$ deep, $15 \mathrm{~cm}$ upper diameter, $8 \mathrm{~cm}$ lower diameter) were mounted on wooden posts at $50 \mathrm{~cm}$ height and arranged $1.5 \mathrm{~m}$ apart in a triangle around the plot centre. Pan trap colours corresponded to the prevailing floral colours in the herb layer. We filled the traps with $200 \mathrm{ml}$ of a $50 \%$ ethylene glycol solution in water with a few drops of unscented dishwashing detergent. Traps were set out in the forest for one week in May and July 2008.

In July 2008, we performed suction sampling at two locations near the centre of each plot, using a leaf blower (Stihl SH56) fitted with a cloth bag at the nozzle to hold the insects. We 
quickly placed a plastic cylinder (basal area: $0.25 \mathrm{~m}^{2}$, height: $0.8 \mathrm{~m}$ ) onto the ground vegetation to prevent insects from escaping, and took a suction sample with a duration of 30 sec within the cage. Insect samples were sorted in the laboratory and stored in $70 \%$ ethanol.

Based on an assessment of Dipteran abundance distributions, we chose the two locally very abundant taxa Empidoidea and Phoridae for a more in-depth look at how different Dipteran groups react to gradients of plant diversity. Both groups encompass species with a variety of different habitat requirements and life history traits (Disney 1994; Delettre et al. 1998). The Empidoidea (particularly the Empididae) include a number of flower-visiting species, with adults depending on nectar or pollen as energy source (Chvála 1983).

All Diptera were identified to family level following Oosterbroek (2007). Empidoidea (including the families Empididae, Hybotidae, Atelestidae, Microphoridae, and Dolichopodidae, following Chvála 1983) and Phoridae were identified to species level (see Online Resource 3 for references of identification keys). All Empidoidea were classified as to whether they were silvicolous species (predominantly inhabiting forests) and whether they were flower-visitors (Online Resource 4). We chose these subcategories because vegetation characteristics might differentially affect silvicolous species or flower visitors due to their particular habitat requirements.

\section{Data analysis}

Tree diversity and herb diversity were expressed by the Shannon-Wiener diversity index (H') based on relative stem area and relative cover, respectively. The Shannon-Wiener diversity index incorporates species richness as well as relative abundances of species (Magurran 2004).

For analyses of total Dipteran family richness and abundance as well as abundances of Empidoidea and Phoridae, we pooled data from pan trapping (both sampling rounds; yellow, white, and blue pan traps) and suction sampling. Species richness of Empidoidea and Phoridae was determined from pan traps only (Phoridae: only from yellow pan traps). Female phorids of the genus Megaselia were not included in the analysis of phorid species richness since their identification to species level is not possible at the time. We excluded plots from analyses where pan traps had been overturned or otherwise damaged during either of the two sampling rounds (see table 2 for final $n$ ).

We used generalized linear models (GLM) with Poisson distribution and log-link to test for relationships between response variables (Table 2) and explanatory variables (Table 1). 
Separate analyses were conducted for total Dipteran family richness and abundance, species richness and abundance of Empidoidea, proportions of flower-visiting Empidoidea and silvicolous Empidoidea, and species richness and abundance of Phoridae, yielding eight models in total. When overdispersion or underdispersion occurred, we corrected standard errors using quasi-GLM models that include a dispersion parameter specifying the relationship between variance and mean (McCullagh and Nelder 1989). First, we fitted a maximal model with the following sequence of terms: log-abundance (only when analysing family or species richness $)+$ location + herb cover + herb diversity + tree diversity + twoway interactions with location. Model simplification was then carried out by dropping each explanatory variable in turn, removing the term that led to the smallest non-significant change in deviance according to F- tests (using the drop1 command in the "stats" package of R), and refitting the model (Zuur et al, 2009). When dropping terms, hierarchy was respected (that is, lower-order terms were never removed if they were present in higher-order interactions).This was continued until all remaining terms were significant (minimal adequate model). To account for effects of sample size on family/species richness data, we additionally performed sequential F-tests on all model terms, where log-transformed abundance data were included before all other explanatory variables (Knops et al. 1999; Sobek et al. 2009b) (Online Resource 5). Log- and square root transformations were applied to abundance and cover data respectively to improve model fit. We checked diagnostic plots for homoscedasticity, normality of residuals, and presence of outliers. All explanatory variables had pairwise Spearman rank correlation coefficients $<0.43$ (Online Resource 6).

Mantel matrix correlation tests were used to check for spatial autocorrelation of all response variables (Legendre and Legendre 1998). A spatial dissimilarity matrix (based on $\mathrm{x} / \mathrm{y}$ coordinates of the plots) and dissimilarity matrices based on each response variable were created using Euclidean distances. We found no significant correlations between the spatial dissimilarity matrix and matrices of any response variable (all $r<0.11$, all $P>0.107,999$ permutations used), indicating that spatial autocorrelation did not pose a significant problem in this study.

To test if similarities in Dipteran community composition are correlated with similarities of the floristic composition of herb and tree layer, we performed Mantel correlation tests on dissimilarity matrices based on Bray-Curtis distance, which quantifies the compositional dissimilarity between plots (Magurran 2004). If we detected a correlation between plot distance and dissimilarity in species composition, partial Mantel tests were used to statistically control for spatial autocorrelation by additionally incorporating the spatial 
distance matrix in calculations. This was however only the case for the analysis of Empidoidea community composition.

We used the bias-corrected version of the Chao estimator to estimate the extrapolated family or species richness per plot (Chao 2005). For all Diptera, mean sampling success (observed species/familiy number out of extrapolated species/family number) was $82 \%$ (range 40-99\%), for Empidoidea 67\% (range 32-97\%), and for Phoridae 73\% (range 28-100\%). Sampling success was not significantly correlated with any explanatory variables except in the case of Phoridae (weak correlation between sampling success and herb diversity, Spearman rank correlation coefficient $=0.24, P=0.04)$.

All analyses were carried out using R, version 2.12.0 (R Development Core Team, 2010).

Table 2. Summary statistics of the response variables. Lindig/Thiemsburg represent the two locations used in this study; $n=$ sample size; prop. = proportion, $\mathrm{SE}=$ standard error.

\begin{tabular}{|c|c|c|c|c|c|c|c|c|c|}
\hline \multirow[t]{2}{*}{ Variable } & \multicolumn{3}{|c|}{ Mean +/- SE } & \multicolumn{3}{|c|}{ Range } & \multicolumn{3}{|c|}{$n$} \\
\hline & Overall & Lindig & Thiemsburg & Overall & Lindig & Thiemsburg & Overall & Lindig & Thiemsburg \\
\hline $\begin{array}{l}\text { Total Dipteran family } \\
\text { richness }\end{array}$ & $24.7 \pm 0.5$ & $26.6 \pm 0.5$ & $22.3 \pm 0.6$ & $16-35$ & $18-35$ & $16-30$ & 70 & 40 & 30 \\
\hline Total Dipteran abundance & $281 \pm 11$ & $292 \pm 15$ & $266 \pm 15$ & $132-643$ & $132-643$ & $144-438$ & 70 & 40 & 30 \\
\hline $\begin{array}{l}\text { Empidoidea species } \\
\text { richness }\end{array}$ & $15.5 \pm 0.6$ & $18.7 \pm 0.7$ & $11.8 \pm 0.5$ & $6-28$ & $6-28$ & $7-17$ & 72 & 39 & 33 \\
\hline Empidoidea abundance & $60 \pm 4$ & $71 \pm 7$ & $45 \pm 4$ & $17-248$ & $17-248$ & $20-116$ & 70 & 40 & 30 \\
\hline $\begin{array}{l}\text { Prop. flower-visiting } \\
\text { Empidoidea }\end{array}$ & $31.3 \pm 1.1$ & $33.6 \pm 1.4$ & $28.6 \pm 1.7$ & $11.11-55.56$ & $12.5-54.55$ & $11.11-55.56$ & 72 & 39 & 33 \\
\hline $\begin{array}{l}\text { Prop. silvicolous } \\
\text { Empidoidea }\end{array}$ & $74.7 \pm 1.1$ & $72.7 \pm 1.5$ & $77.1 \pm 1.5$ & $50-100$ & $50-100$ & $57.14-94.12$ & 72 & 39 & 33 \\
\hline Phoridae species richness & $6.3 \pm 0.3$ & $6.6 \pm 0.5$ & $6 \pm 0.3$ & $2-15$ & $2-15$ & $2-10$ & 77 & 42 & 35 \\
\hline Phoridae abundance & $71 \pm 6$ & $71 \pm 7$ & $71 \pm 9$ & $18-255$ & $24-251$ & $18-255$ & 70 & 40 & 30 \\
\hline
\end{tabular}

\section{Results}

Family richness and abundance of the total Dipteran community

In total, we collected 19641 individuals belonging to 62 families (Online Resource 7) during two rounds of pan trap sampling (yielding $94.5 \%$ of individuals) and one round of suction sampling (yielding 5.5\% of individuals). Between 16 and 35 different families were found per plot (Table 2). Phoridae were by far the most abundant Dipteran family $(25.2 \%$ of individuals), followed by Cecidomyiidae (10.9\%), Dolichopodidae (10.7\%), Sciaridae (8.8\%), Muscidae (5.5\%), Empididae (5.2\%), Hybotidae (5.1\%), Lauxaniidae (4.9\%), and Limoniidae (4.7\%) (Online Resource 7). 
The family richness of Diptera did not respond to herb layer diversity, but increased with increasing herb cover (Fig. 1a, Table 3, Online Resource 5). In contrast, Dipteran abundance was related to herb and tree diversity: Higher herb diversity was positively related to Dipteran abundance, but notably only in the Lindig location (Fig. 2a, interaction herb diversity:location in Table 3, Online Resource 5). Tree diversity, on the other hand, was negatively associated with Dipteran abundance only in the Thiemsburg location, whereas its effect was weakly positive in the Lindig location (Fig. 3, Table 3, Online Resource 5). Herb cover showed a consistently positive relationship with Dipteran abundance (Fig. 1b, Table 3, Online Resource 5). Excluding the plot with the highest Dipteran abundance (643 individuals) did not substantially change results. 
Table 3. Parameter estimates, standard errors, $t$ and $P$ values of terms present in minimal adequate models (quasi-GLM). Family richness and abundance of the total Dipteran community, species richness and abundance of Empidoidea and Phoridae, the proportion of flower-visiting Empidoidea, and the proportion of Empidoidea typical of forests (silvicolous species) were used as response variables. Parameter estimates are on the log-scale. Abundance $(\log )=\log$-transformed Dipteran abundance $($ sample size); location = variable with two factors, study locations Lindig and Thiemsburg; herb cover (sqrt) = square-root transformed percentage of ground on forest plots covered by herb layer; herb diversity = Shannon-Wiener Index H' of herb layer; tree diversity = Shannon-Wiener Index H' of tree layer. Parameters are tested marginally, i.e., in presence of all other terms in the model. The intercept represents the estimate for the Lindig location, for the Thiemsburg location it is the difference between the intercept and the value indicated in the table. Interaction terms are indicated by ":".

\begin{tabular}{|c|c|c|c|c|}
\hline & Estimate & $\mathrm{SE}$ & $t$ & $P$ \\
\hline \multicolumn{5}{|l|}{ Family richness Diptera } \\
\hline Intercept (Lindig) & 2.36 & 0.24 & 9.65 & $<0.001$ \\
\hline Abundance (log) & 0.13 & 0.05 & 2.78 & 0.006 \\
\hline Location (Thiemsburg) & -0.12 & 0.03 & -3.67 & $<0.001$ \\
\hline Herb cover (sqrt) & 0.03 & 0.01 & 3.18 & 0.001 \\
\hline \multicolumn{5}{|l|}{ Abundance Diptera } \\
\hline Intercept (Lindig) & 4.18 & 0.27 & 15.38 & $<0.001$ \\
\hline Location (Thiemsburg) & 1.52 & 0.32 & 4.77 & $<0.001$ \\
\hline Herb cover (sqrt) & 0.07 & 0.02 & 3.57 & $<0.001$ \\
\hline Herb diversity & 0.39 & 0.09 & 4.36 & $<0.001$ \\
\hline Tree diversity & 0.21 & 0.13 & 1.58 & 0.119 \\
\hline Location : herb diversity & -0.48 & 0.15 & -3.19 & 0.002 \\
\hline Location : tree diversity & -0.48 & 0.20 & -2.47 & 0.016 \\
\hline \multicolumn{5}{|l|}{ Species richness Empidoidea } \\
\hline Intercept (Lindig) & 1.64 & 0.19 & 8.48 & $<0.001$ \\
\hline Abundance $(\log )$ & 0.26 & 0.05 & 5.45 & $<0.001$ \\
\hline Location (Thiemsburg) & -0.28 & 0.05 & -5.20 & $<0.001$ \\
\hline Herb cover (sqrt) & 0.03 & 0.01 & 2.12 & 0.038 \\
\hline \multicolumn{5}{|l|}{ Abundance Empidoidea } \\
\hline Intercept (Lindig) & 2.93 & 0.29 & 10.02 & $<0.001$ \\
\hline Location (Thiemsburg) & 0.56 & 0.47 & 1.19 & 0.237 \\
\hline Herb diversity & 0.70 & 0.14 & 4.85 & $<0.001$ \\
\hline Location : herb diversity & -0.52 & 0.24 & -2.12 & 0.038 \\
\hline \multicolumn{5}{|l|}{ Species richness Phoridae } \\
\hline Intercept (Lindig) & 1.13 & 0.14 & 8.24 & $<0.001$ \\
\hline Abundance (log) & 0.24 & 0.04 & 5.50 & $<0.001$ \\
\hline \multicolumn{5}{|l|}{ Abundance Phoridae } \\
\hline Intercept (Lindig) & 3.44 & 0.45 & 7.71 & $<0.001$ \\
\hline Location (Thiemsburg) & 0.16 & 0.74 & 0.21 & 0.831 \\
\hline Herb cover (sqrt) & -0.02 & 0.06 & -0.31 & 0.755 \\
\hline Herb diversity & 0.49 & 0.23 & 2.12 & 0.038 \\
\hline Location : herb cover (sqrt) & 0.26 & 0.11 & 2.40 & 0.020 \\
\hline Location : herb diversity & -0.81 & 0.33 & -2.43 & 0.018 \\
\hline \multicolumn{5}{|c|}{ Prop. flower visiting Empidoidea } \\
\hline Intercept (Lindig) & -1.26 & 0.16 & -7.77 & $<0.001$ \\
\hline Herb cover (sqrt) & 0.08 & 0.03 & 3.32 & 0.001 \\
\hline \multicolumn{5}{|l|}{ Prop. silvicolous Empidoidea } \\
\hline Intercept (Lindig) & 1.70 & 0.18 & 9.33 & $<0.001$ \\
\hline Herb cover (sqrt) & -0.11 & 0.03 & -3.99 & $<0.001$ \\
\hline
\end{tabular}


(a)

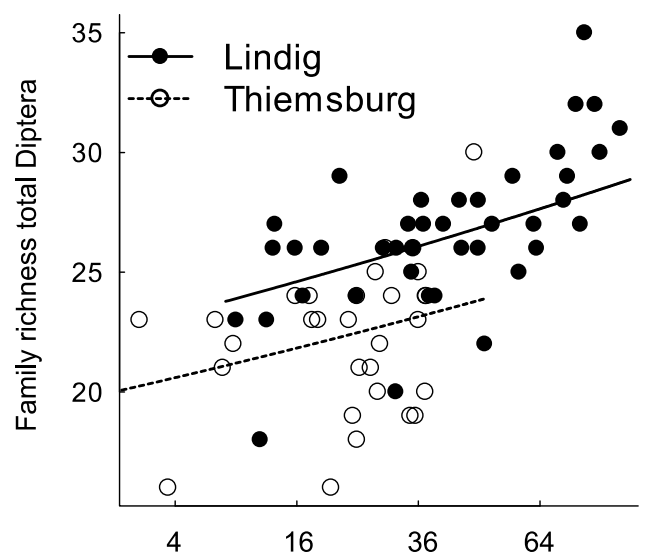

(c)

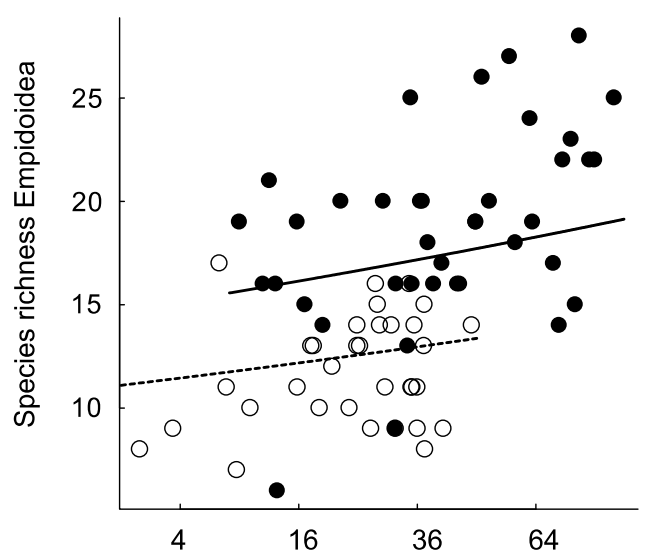

(e)

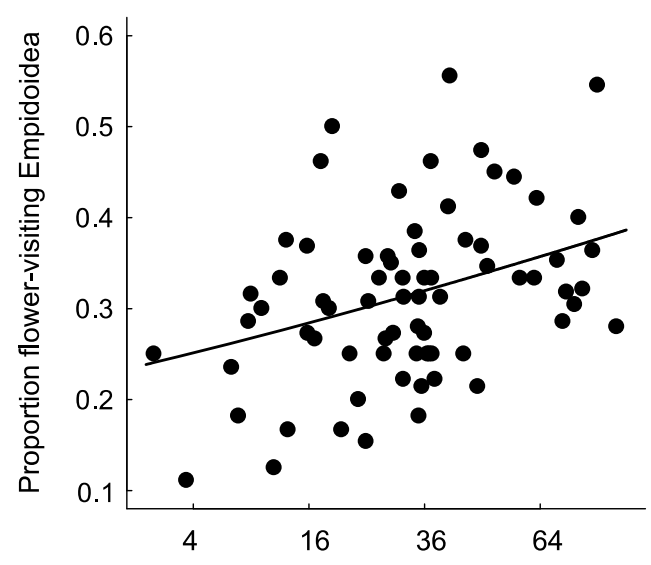

(b)

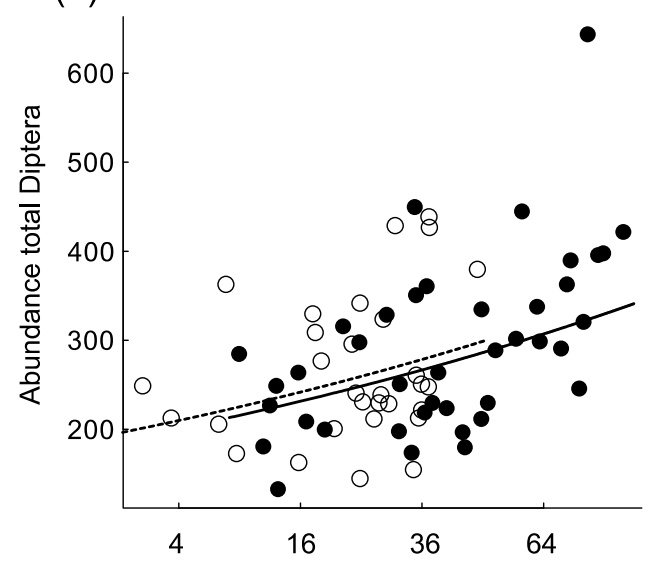

(d)

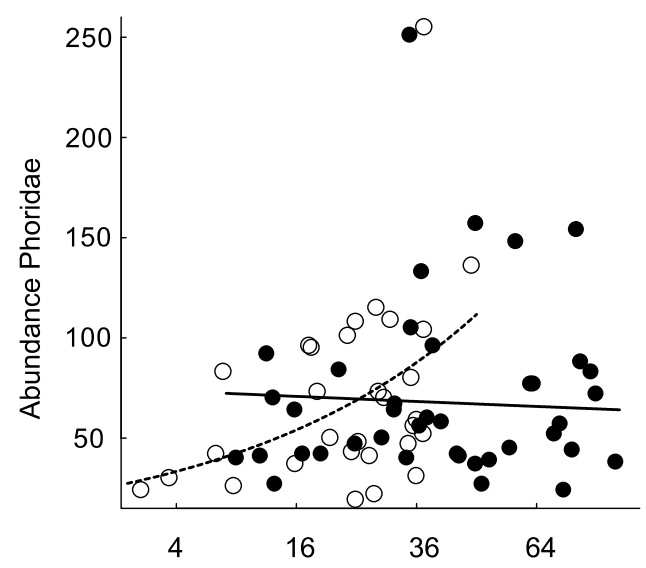

(f)

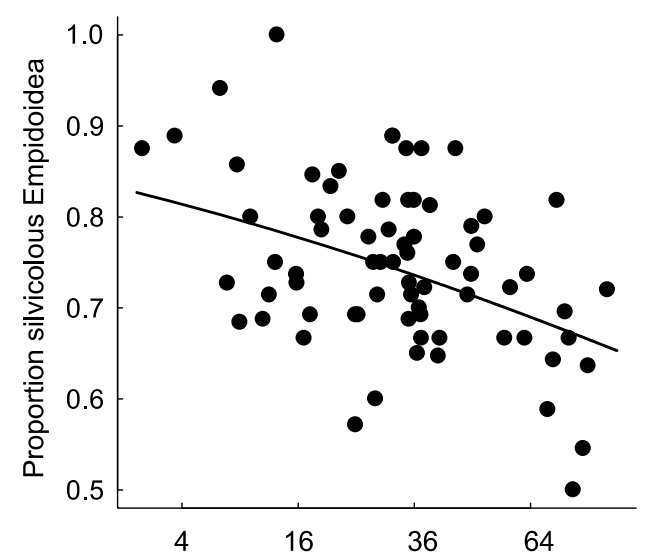

Herb layer cover (\%)

Figure 1. Relationship between herb layer cover (square-root scale) and (a) total Dipteran family richness ( $n=$ $70)$, (b) total Dipteran abundance $(n=70)$, (c) Empidoidea species richness $(n=72)$, (d) Phorid abundance $(n=$ 70 ), (e) proportion of flower-visiting Empidoidea $(n=72)$, and (f) proportion of Empidoidea typical of forests ( $n$ $=72$ ). Curves are based on parameters from fitted minimal adequate generalized linear models (Table 3). Solid line and filled circles denote the Lindig location, dashed line and open circles the Thiemsburg location. For discussion of outliers in b) and d), see results section. 
(a)

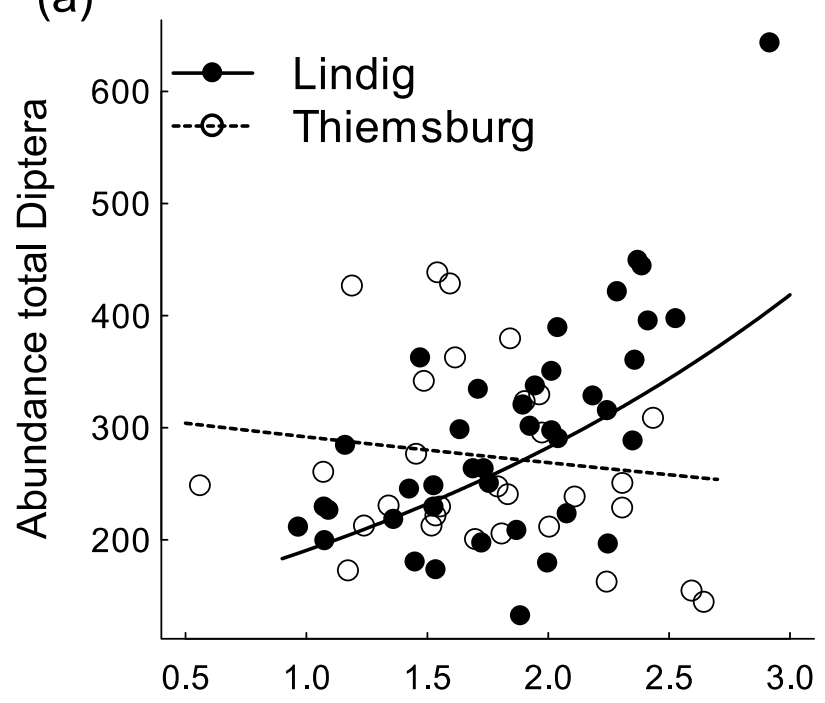

(b)

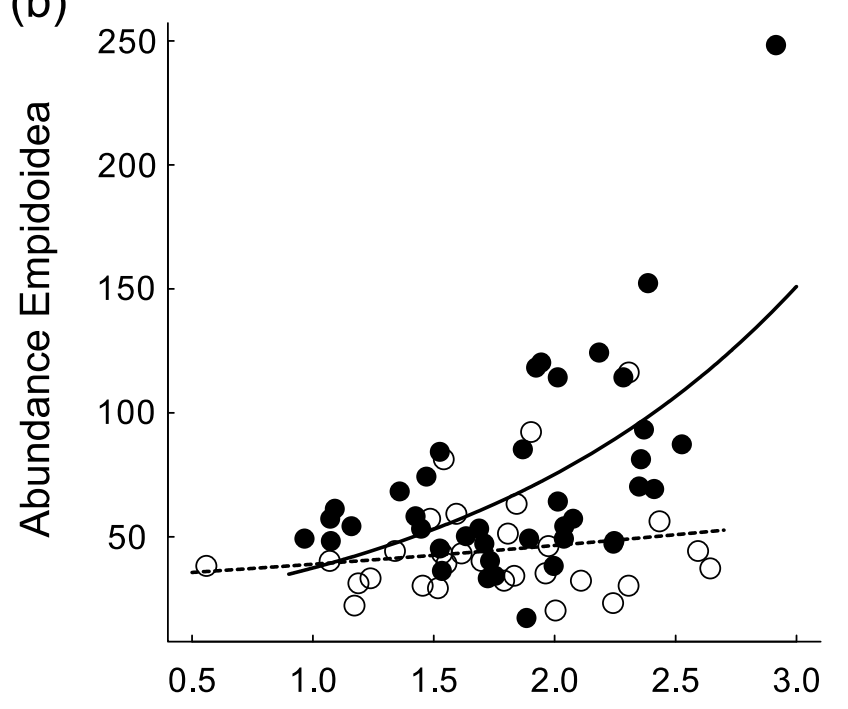

(c)

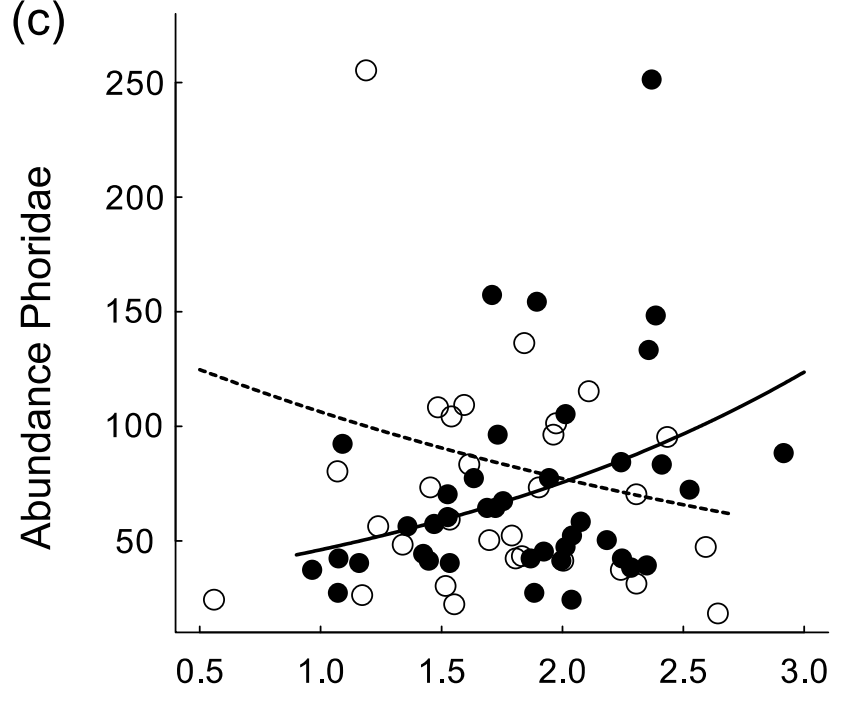

Herb layer diversity $\left(\mathrm{H}^{\prime}\right)$ 


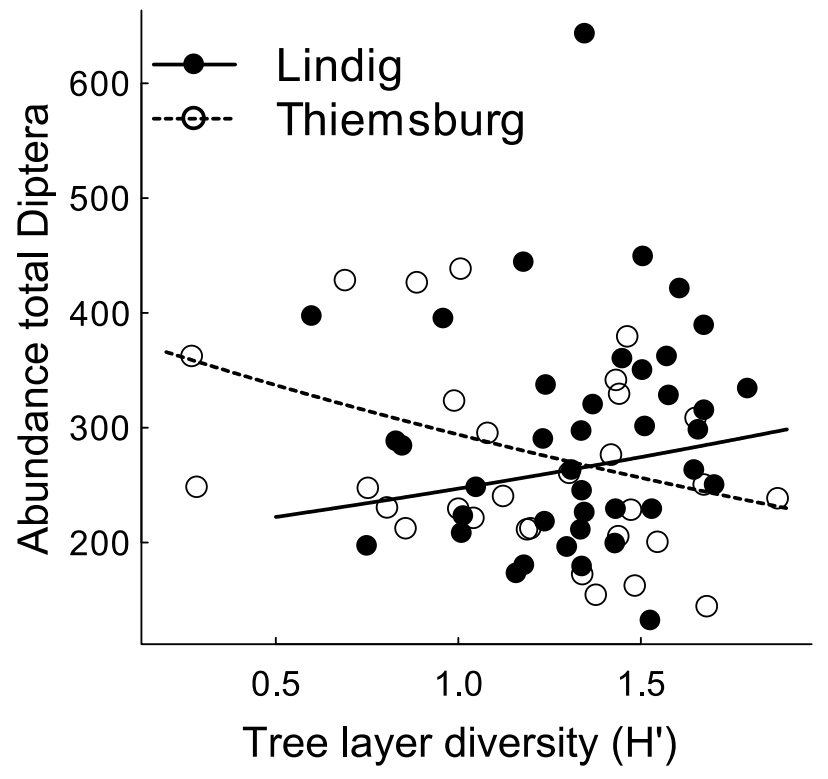

Figure 3. Relationship between tree layer diversity (Shannon-Wiener Index H') and total Dipteran abundance. $N=70$. Solid line and filled circles denote the Lindig location, dashed line and open circles the Thiemsburg location. Curves are based on parameters from fitted minimal adequate generalized linear models (Table 3). For discussion of the outlier, see results section.

Species richness, abundance, and proportions of ecological groups of Empidoidea

Overall, 4182 individuals of Empidoidea were caught. Catches from pan traps, which were determined to species level, yielded 4077 individuals belonging to 99 species (Online Resource 4). About a quarter of all recorded Empidoidea species (26.6\%) were classified as flower visitors, and more than half of all species were silvicolous (54.5\%) (Online Resource 4). Species richness per plot ranged from 6-28 species (Table 2).

Similar to total Dipteran family richness, species richness of Empidoidea was enhanced by increasing herb cover (Fig. 1c, Table 3, Online Resource 5), though the response was weaker in the case of Empidoidea. Empidoidea species richness was also unaffected by herb and tree diversity. Abundance of Empidoidea responded positively to herb diversity in the Lindig location, but showed no response in the Thiemsburg location (Fig. 2b, Table 3, Online Resource 5). If the plot with the highest abundance of Empidoidea (248 individuals, possibly caused by a dancing swarm of Empis aestiva being attracted to a pan trap) was removed as an outlier, herb diversity remained significant $(F=8.27, P=0.005)$, whereas the interaction term was not significant any more. Herb cover and tree diversity did not affect the abundance of Empidoidea. The proportion of species with flower-visiting adults increased with increasing herb cover (Fig. 1e), whereas the proportion of silvicolous species declined (Fig. 1f, Table 3, Online Resource 5). 
In total, we recorded 4955 phorids, of which 2483 individuals were caught in yellow pan traps and analysed to species level. Species richness per plot ranged from 2-15 species (Table 2). Altogether, 78 species were found (Online Resource 8).

Phorid species richness did not respond to any explanatory variable except phorid abundance (i.e. sample size) (Table 3, Online Resource 5). Phorid abundance increased with increasing herb cover at the Thiemsburg location, while remaining unaffected at the Lindig location (Fig. 1d, Table 3, Online Resource 5). Higher herb diversity was associated with higher phorid abundance at the Lindig location, but with lower phorid abundance at the Thiemsburg location (Fig. 2c, Table 3, Online Resource 5). If two plots with exceptionally high phorid abundances (251 and 255 individuals) were omitted as outliers, only herb cover had a marginally significant positive effect on phorid abundance $(F=3.74, P=0.057)$.

\section{Relationship between tree and herb community composition and fly community composition}

Total fly community composition was similar in plots that showed a similar species composition of herb and tree layer (Table 4). This was also true for the community composition of Empidoidea, even after controlling for increasing compositional similarity of Empidoidea communities with increasing spatial proximity of plots. In the case of Phoridae, similarity in phorid community composition was not related to similarity in herb or tree layer community composition.

Table 4. Mantel test matrix correlations between distances in fly community composition, floristic composition of tree and herb layer, and geographic distance. $P$-values were calculated using 999 permutations. Significant $P$ values shown in bold. Partial Mantel tests controlling for geographic distance were used for analyses of Empidoidea since the community composition matrix showed significant spatial autocorrelation.

\begin{tabular}{lccc}
\hline & Geographic distance & Herb layer & Tree layer \\
\hline Diptera & $0.04(P=0.291)$ & $0.16(\boldsymbol{P}=\mathbf{0 . 0 0 3})$ & $0.24(\boldsymbol{P}=\mathbf{0 . 0 0 3})$ \\
Empidoidea & $0.12(\boldsymbol{P}=\mathbf{0 . 0 1})$ & $0.15(\boldsymbol{P}=\mathbf{0 . 0 0 1})$ & $0.23(\boldsymbol{P}=\mathbf{0 . 0 0 1})$ \\
Phoridae & $-0.03(P=0.734)$ & $0.04(P=0.364)$ & $0.1(P=0.061)$ \\
\hline
\end{tabular}




\section{Discussion}

This study shows that plant diversity and vegetation cover in forests determine community characteristics of Diptera, an often-neglected insect taxon. Our findings are especially noteworthy because Diptera are often (falsely) considered unspecialized detritivores with little relationships to aboveground changes (Savage 2002). Tree diversity affected Dipteran community characteristics to a lesser extent than herb diversity. This is not surprising, given that (i) tree canopies are distant to the locations at which flies were sampled and (ii) tree diversity may act on a larger spatial scale than herb diversity. It should be noted that the scope of this study included sampling of adult Diptera only. Larvae, which are often soil-dwelling, may be more strongly influenced by environmental characteristics such as soil moisture, soil $\mathrm{pH}$, and extent of the litter layer (Hövemeyer 1999). However, a higher tree and herb diversity may also potentially affect soil-dwelling larvae via increases in soil and litter layer heterogeneity due to plant-specific root exudates and differences in litter quality.

\section{Effects of herb diversity}

We found that the plant diversity of the herb layer influenced abundance of the total Dipteran community and of the taxa Empidoidea and Phoridae. A diverse herb layer may support higher insect numbers due to a greater variety of (alternative) food sources available for herbivores. Further, higher structural complexity in diverse plant communities may create habitat conditions suitable for holding greater insect numbers, for instance because more structures and surfaces suitable for egg deposition, sheltering, or overwintering are available (Strong et al. 1984). In contrast to our results, Dipteran abundance was not related to herb layer diversity in Scottish woodlands (Woodcock et al. 2003).

Intriguingly, we only found a positive relationship between herb layer diversity and Dipteran abundances in the Lindig location, while there was no effect or even a weakly negative relationship in the Thiemsburg location (see Fig. 2). Thus, the association between herb layer diversity and Dipteran numbers appears location-specific and dependent on certain forest stand characteristics. For instance, the two locations in our study differ in their canopy tree species, with Tilia sp. dominating at the Lindig location and F. sylvatica at the Thiemsburg location. Species identity of canopy trees has the potential to alter herb layer characteristics (Augusto et al. 2003; Barbier et al. 2008) and may affect processes occurring in lower strata, such as the association between herb and insect diversity. At the Thiemsburg location, plots 
with low herb layer diversity feature a high percentage of $F$. sylvatica, a tree species characterised by low light permeability and slowly degrading litter. Consequently, these plots generally have a strongly developed litter layer, which might represent highly suitable habitat for larvae and therefore lead to high abundances of Diptera (Hövemeyer 1992). At the Lindig location, on the other hand, F. sylvatica plays a minor role, and plots of high as well as low herb layer diversity show weakly developed litter layers. In this setting, herb layer diversity may considerably increase Dipteran abundance. In a study on the relationship between plant diversity and the diversity of insect herbivores in moorland ecosystems, Hartley and Jones (2003) also found location-specific responses that depended on the dominant species of the plant community.

In contrast to Dipteran abundance, Dipteran family richness as well as species richness of Empidoidea and Phoridae did not respond to herb diversity. This was surprising, as a positive association between plant and insect diversity is predicted by theory and has frequently been reported by observational as well as experimental studies (Murdoch et al. 1972; Haddad et al. 2009; Woodcock and Pywell 2009; Scherber et al. 2010). However, most studies that show positive effects of plant diversity on insect diversity were conducted in grassland ecosystems. Forest ecosystems display different and more complex habitat characteristics compared to grasslands, conditions under which plant diversity might contribute less to insect diversity patterns. In addition, herbivorous taxa generally react most strongly to changes in plant diversity, whereas plant diversity effects get weaker with increasing trophic level and level of omnivory (Haddad et al. 2009; Scherber et al. 2010). As a consequence, taxa that encompass few herbivores, such as the Diptera, may be less affected. The few studies which analysed the effect of herb layer diversity on insect richness yielded mixed results: In agreement with our findings, parasitoid wasp richness (Sperber et al. 2004; Fraser et al. 2007) and carabid richness (Humphrey et al. 1999) were not found to be affected by herb layer diversity. However, Woodcock et al. (2003) found higher Dipteran species richness with increasing plant species richness in the herb layer, whereas in coniferous plantation forests, syrphid diversity even showed a negative relationship with herb layer diversity (Humphrey et al.1999). 
Responses of the Dipteran community differed strongly between locations, and it is possible that these differences were again caused by the identity of the dominant tree species. Indeed, tree species composition might be a more important driver of insect diversity patterns than tree diversity per se (Riihimaki et al. 2005; Schuldt et al. 2008; Nadrowski et al. 2010).

In previous studies, responses of arthropod communities to variations in tree diversity have been mixed and taxon-dependent. In contrast to our results, richness of parasitoid wasp taxa increased with increasing tree species richness in agroforestry systems (Sperber et al. 2004) and temperate woodlands (Fraser et al. 2007). Similarly, species richness of beetles was higher in stands with higher tree diversity in a near-natural forest (Sobek et al. 2009b), while diversity of spiders, true bugs and cavity-nesting bees was not affected by tree diversity (Schuldt et al. 2008; Sobek et al. 2009a, 2009c). It must be noted that in our study, Diptera were sampled in the herb layer only. By employing traps in the canopy, different conclusions about the importance of tree diversity might be drawn. However, it can still be worthwhile to include tree diversity as an explanatory variable in studies set in the herb layer since the tree layer has the potential to modify herb layer characteristics and thus indirectly affect insect communities in the understorey.

\section{Effects of herb cover}

Herb cover showed a pronounced and consistently positive relationship with both total Dipteran richness and abundance. It is apparently a more important determinant of Dipteran community characteristics than the plant diversity of herb or tree layer. Previous studies also emphasised the greater importance of plant biomass/cover compared with plant diversity for shaping insect species richness or abundance (Koricheva et al. 2000; Haddad et al. 2001; Ober and Hayes 2008; Woodcock and Pywell 2009). According to the More Individuals Hypothesis (Srivastava and Lawton 1998), more productive sites harbour higher insect species richness, since productive sites support bigger populations of each species, making even rare species less extinction prone. A greater herb cover has the potential to support higher insect numbers by providing a greater resource base for herbivores, which can subsequently lead to higher abundances of predators and parasitoids. In addition, insect species richness as well as abundance may be enhanced if a greater herb cover is linked to more complex and extensive assemblage of plant structures that can be utilized by insects. Similar to our results, syrphid richness is enhanced by higher levels of herb cover (Humphrey 
et al. 1999). Bährmann (1984) pointed out that a pronounced vegetation cover (together with the presence of decaying plant material) can enhance the abundances of certain Dipteran taxa in grasslands.

Empidoidea and Phoridae showed a weaker response to herb cover than the total Dipteran community. Species richness of Empidoidea was enhanced by higher herb cover, possibly because predatory species hunting on leaf surfaces (particularly of the family Hybotidae) benefit from the increased structural complexity, or flower-visiting species (predominantly Empididae) profit from the greater abundance of floral resources. Indeed, the percentage of flower-visiting Empidoidea increased with increasing herb cover. In contrast, the percentage of typical forest species in the Empidoidea community was lower at plots with high herb cover. Possibly, these forest specialists have adapted to forest settings characterised by low herb cover, low light availability and thick litter layer, conditions that are usually found in forests dominated by F. sylvatica. Previous studies mentioned a preference of Empidoidea for habitats with well-developed herb layers (Pollet and Grootaert 1987; Meyer and Heydemann 1990), with other environmental factors such as humidity/soil moisture, light intensity, and the availability of dead wood also contributing to diversity patterns of Empidoidea (Pollet and Grootaert 1987; Stark 2008).

Phorid abundance was enhanced by a higher herb cover, though to a small extent and only at the Thiemsburg location. Commonly, phorids engage in leaf-searching behaviour looking for traces of honeydew, moisture, dead insects, or plant sap, thus larger leaf surfaces concomitant with higher herb cover may prove beneficial. Durska (2006) found that phorid communities were influenced by the physical structure of the habitat, but also point out the importance of microclimatic factors, in particular the light regime.

Correlations between plant composition of herb and tree layer and Dipteran community composition

Both herb and tree layer composition were related to the total Dipteran community composition as well as the community composition of Empidoidea: Plots that had a more similar plant community also exhibited a more similar Dipteran community. This shows that apart from diversity and cover, also the presence of certain plant species is an important factor shaping Dipteran communities. Our findings agree with Sääksjärvi et al. (2006), who discovered significant correlations between patterns in parasitoid wasp species composition and plant species composition in a lowland rain forest. It is interesting that tree layer 
composition was more strongly associated with Dipteran community composition than herb layer composition in our study, even though tree diversity played only a minor role in explaining variations of Dipteran richness and abundance. It seems that species identity effects of trees as ecosystem engineers that strongly shape forest habitats might override effects of tree diversity per se. In contrast to the Empidoidea, phorid community composition did not react to herb or tree composition. Similarly, phorid species richness and abundance showed only weak or no responses to tree or herb layer diversity and herb cover. Possibly phorids depend less on the presence of particular plants since flower-visiting behaviour is less common in this family than in the Empidoidea.

\section{Observation vs. experimentation}

Because our study is largely observational, it is of course not possible to infer strong causality, and it might well be possible that the linkage between herb diversity and Dipteran abundances is caused by a common response to a third, unknown factor. However, we used a gradient in tree species richness that was selected a priori, and in that sense our study differs from purely observational approaches. Using such an a priori gradient has proven to be an appropriate approach to biodiversity studies in natural ecosystems (Kahmen et al. 2005; Unsicker et al. 2006).

The influence of confounding factors can be reduced using experimental forest plantations (Scherer-Lorenzen et al. 2007), but conditions in old-growth, natural forests can never be completely recreated in these young plantations (Leuschner et al. 2009).

Another possible caveat of our study is that the tree diversity gradient actually represents a dilution gradient of the species F. sylvatica, which is present in different proportions on nearly all plots (Nadrowski et al. 2010). Thus, plots with low tree diversity are always almost pure stands of $F$. sylvatica, with the typical conditions created by this species, such as low light availability, reduced soil $\mathrm{pH}$, low herb cover, and a thick, slow-decaying litter layer (Ellenberg and Leuschner 2010). As a consequence, it is impossible to completely disentangle the species identity effect of F. sylvatica on Dipteran communities in the herb layer from the effect of tree diversity. Future studies in forests differing in tree diversity, but not dominated by F. sylvatica, could help to test the generality of our results.

\section{Conclusions}


Herb diversity, and to a lesser extent tree diversity, are related to Dipteran community characteristics in Germany's largest connected deciduous forest. While plant diversity effects are not as prominent as in several grassland studies, Dipteran abundance does respond, albeit moderately, to the diversity of tree and herb layer, while Dipteran richness remains unaffected. The fact that the direction of the relationship between Dipteran abundances and tree/herb layer diversity is location-specific and differs between forest stands dominated by different tree species underlines the importance of tree species identity effects, which may override effects of tree diversity per se. Altogether, patterns of Dipteran abundance and richness are better explained by herb cover than by tree or herb diversity. Higher herb cover enhances Dipteran richness and abundance, possibly by providing more biomass, habitat structures, or floral resources for flower-visiting species. The linkages between herb layer characteristics (plant diversity, cover, species composition) and community attributes of a large and ecologically important taxon such as the Diptera indicate that the maintenance of a diverse and well-developed herb layer should be a main concern when managing forest ecosystems.

\section{Acknowledgements}

This study was funded by the German Research Foundation (DFG) within the framework of the Research Training Group 'Graduiertenkolleg 1086: The role of biodiversity for biogeochemical cycles and biotic interactions in temperate deciduous forests'. We thank Sabine Prescher and Gisela Weber for the identification of all Phoridae. Tobias Wommelsdorf provided valuable data on tree layer composition. We are grateful to Verena Eißfeller and other members of the Research Training Group for field assistance, to Mareen Gollnow and Emma Dyson for assisting with the sorting of insect samples, and to Patrick Kabouw for comments that improved this manuscript. The experiments comply with the laws of Germany where they have been conducted.

\section{References}


Allgood DW, Miller DA, Kalcounis-Rueppell MC (2009) Influence of intensive pine management on Dipteran community structure in coastal North Carolina. Environ. Entomol. 38:657-666

Augusto L, Dupouey JL, Ranger J (2003) Effects of tree species on understory vegetation and environmental conditions in temperate forests. Ann. For. Sci. 60:823-831

Bährmann R (1984) Die Zweiflügler (Diptera Brachycera) der Kraut- und Strauchschicht des Leutratales bei Jena/Thüringen - ein ökofaunistischer Vergleich. Zool. Jb. Syst. $111: 175-217$

Baldi A (2003) Using higher taxa as surrogates of species richness: a study based on 3700 Coleoptera, Diptera, and Acari species in Central-Hungarian reserves. Basic Appl. Ecol. 4:589-593

Barbier S, Gosselin F, Balandier P (2008) Influence of tree species on understory vegetation diversity and mechanisms involved - A critical review for temperate and boreal forests. For. Ecol. Manage. 254:1-15

Brose U (2003) Bottom-up control of carabid beetle communities in early successional wetlands: mediated by vegetation structure or plant diversity? Oecologia 135:407-413

Chao A (2005) Species estimation and applications. In: Balakrishnan N, Read CB, Vidakovic B (eds) Encyclopedia of Statistical Sciences, 2nd edn, vol 12. Wiley, New York, pp 7907-7916

Chvála M (1983) The Empidoidea (Diptera) of Fennoscandia and Denmark. II. General Part. The families Hybotidae, Atelestidae and Microphoridae. Fauna Entomol. Scand. 12:1279

Delettre YR, Morvan N, Tréhen P, Grootaert P (1998) Local biodiversity and multi-habitat use in empidoid flies (Insecta : Diptera, Empidoidea). Biodivers. Conserv. 7:9-25

Disney RHL (1994) Scuttle Flies: The Phoridae. Chapman and Hall, London

Durska E (2006) Diversity of the scuttle fly (Diptera : Phoridae) communities in the plantations of moist pine forests of the Bialowieza Primeval Forest and the Tuchola Forest (Poland). Biodivers. Conserv. 15:385-393

Ellenberg H, Leuschner C (2010) Vegetation Mitteleuropas mit den Alpen in ökologischer, dynamischer und historischer Sicht, 6th edn. Ulmer Verlag, Stuttgart

Fraser SEM, Dytham C, Mayhew PJ (2007) Determinants of parasitoid abundance and diversity in woodland habitats. J Appl Ecol 44:352-361

Gilliam FS (2007) The ecological significance of the herbaceous layer in temperate forest ecosystems. Bioscience 57:845-858 
Haddad NM, Crutsinger GM, Gross K, Haarstad J, Knops JMH, Tilman D (2009) Plant species loss decreases arthropod diversity and shifts trophic structure. Ecol. Lett. 12:1029-1039

Haddad NM, Tilman D, Haarstad J, Ritchie M, Knops JMH (2001) Contrasting effects of plant richness and composition on insect communities: A field experiment. Amer. Nat. $158: 17-35$

Hartley SE, Jones TH (2003) Plant diversity and insect herbivores: effects of environmental change in contrasting model systems. Oikos 101:6-17

Hirao T, Murakami M, Kashizaki A (2009) Importance of the understory stratum to entomofaunal diversity in a temperate deciduous forest. Ecol. Res. 24:263-272

Hövemeyer K (1992) Response of Diptera populations to experimentally modified leaf litter input in a beech forest on limestone. Pedobiologia 36:35-49

Hövemeyer K (1999) Diversity patterns in terrestrial dipteran communities. J Anim Ecol $68: 400-416$

Hughes JB, Daily GC, Ehrlich PR (2000) Conservation of insect diversity: a habitat approach. Conserv. Biol. 14:1788-1797

Humphrey J, Hawes C, Peace AJ, Ferris-Kaan R, Jukes MR (1999) Relationships between insect diversity and habitat characteristics in plantation forests. For. Ecol. Manage. $113: 11-21$

Hunter MD, Price PW (1992) Playing Chutes and Ladders : Heterogeneity and the Relative Roles of Bottom-Up and Top- Down Forces in Natural Communities. Ecology 73:724732

Kahmen A, Perner J, Audorff V, Weisser W, Buchmann N (2005) Effects of plant diversity, community composition and environmental parameters on productivity in montane European grasslands. Oecologia 142:606-615

Kaitaniemi P, Riihimaki J, Koricheva J, Vehvilainen H (2007) Experimental evidence for associational resistance against the European pine sawfly in mixed tree stands. Silva Fenn. 41:259-268

Knops JMH et al. (1999) Effects of plant species richness on invasion dynamics, disease outbreaks, insect abundances and diversity. Ecol. Lett. 2:286-293

Koricheva J, Mulder CPH, Schmid B, Joshi J, Huss-Danell K (2000) Numerical responses of different trophic groups of invertebrates to manipulations of plant diversity in grasslands. Oecologia 125:271-282 
Lawton JH (1983) Plant architecture and the diversity of phytophagous insects. Annu. Rev. Entomol. 28:23-39

Legendre P, Legendre L (1998) Numerical ecology, 2nd edn. Elsevier, Amsterdam

Leuschner C, Jungkunst HF, Fleck S (2009) Functional role of forest diversity: Pros and cons of synthetic stands and across-site comparisons in established forests. Basic Appl. Ecol. 10:1-9

Magurran AE (2004) Measuring biological diversity. Blackwell Science, Oxford, UK

McCullagh P, Nelder JA (1989) Generalized linear models, 2nd edn. Chapman and Hall, London

Meyer H, Heydemann B (1990) Faunistisch-ökologische Untersuchungen an Dolichopodiden und Empididen (Diptera - Dolichopodidae u. Empididae, Hybotidae) in Küsten- und Binnenlandbiotopen Schleswig-Holsteins. Faun.-Ökol. Mitt. 6:147-172

Mölder I (2009) Diversity and tree neighborhood effects on the growth dynamics of European beech and the stand seed bank in temperate broad-leaved forests of variable tree diversity. PhD dissertation, University of Göttingen, Göttingen

Murdoch WW, Peterson CH, Evans FC (1972) Diversity and pattern in plants and insects. Ecology 53:819-829

Nadrowski K, Wirth C, Scherer-Lorenzen M (2010) Is forest diversity driving ecosystem function and service? Curr. Opin. Environ. Sustainability 2:75-79

Ober HK, Hayes JP (2008) Influence of forest riparian vegetation on abundance and biomass of nocturnal flying insects. For. Ecol. Manage. 256:1124-1132

Oosterbroek P (2007) The European families of the Diptera. KNNV Publishing, Utrecht

Pollet M, Grootaert P (1987) Ecological data on Dolichopodidae (Diptera) from a woodland ecosystem. I. Colour preference, detailed distribution and comparison of different sampling techniques. Bull. Inst. R. Sci. Nat. Belg., Ent. 57:173-186

Riihimaki J, Kaitaniemi P, Koricheva J, Vehvilainen H (2005) Testing the enemies hypothesis in forest stands: the important role of tree species composition. Oecologia 142:90-97

Sääksjärvi IE et al. (2006) Comparing composition and diversity of parasitoid wasps and plants in an Amazonian rain-forest mosaic. J. Trop. Ecol. 22:167-176

Savage J (2002) Cleaning up the world: Dipteran decomposers. Biodiversity 3:12-15

Scherber C et al. (2010) Bottom-up effects of plant diversity on multitrophic interactions in a biodiversity experiment. Nature 440:6-9 
Scherer-Lorenzen M, Schulze ED, Don A, Schumacher J, Weller E (2007) Exploring the functional significance of forest diversity: A new long-term experiment with temperate tree species (BIOTREE). Perspect. Plant Ecol. Evol. Syst. 9:53-70

Schuldt A, Fahrenholz N, Brauns M, Migge-Kleian S, Platner C, Schaefer M (2008) Communities of ground-living spiders in deciduous forests: Does tree species diversity matter? Biodivers. Conserv. 17:1267-1284

Siemann E (1998) Experimental tests of effects of plant productivity and diversity on grassland arthropod diversity. Ecology 79:2057-2070

Siemann E, Tilman D, Haarstad J, Ritchie M (1998) Experimental tests of the dependence of arthropod diversity on plant diversity. Am. Nat. 152:738-750

Sobek S, Goßner MM, Scherber C, Steffan-Dewenter I, Tscharntke T (2009a) Tree diversity drives abundance and spatiotemporal $\beta$-diversity of true bugs (Heteroptera). Ecol. Entomol. 34:772-782

Sobek S, Steffan-Dewenter I, Scherber C, Tscharntke T (2009b) Spatiotemporal changes of beetle communities across a tree diversity gradient. Divers. Distrib. 15:660-670

Sobek S, Tscharntke T, Scherber C, Schiele S, Steffan-Dewenter I (2009c) Canopy vs. understory: Does tree diversity affect bee and wasp communities and their natural enemies across forest strata? For. Ecol. Manage. 258:609-615

Sperber C, Nakayama K, Valverde M, Neves F (2004) Tree species richness and density affect parasitoid diversity in cacao agroforestry. Basic Appl. Ecol. 5:241-251

Srivastava DS, Lawton JH (1998) Why more productive sites have more species: An experimental test of theory using tree-hole communities. Am. Nat. 152:510-529

Stark A (2008) Species of the genus Oedalea Meigen, 1820 (Diptera: Hybotidae): An element of the canopy fauna in European forests? In: Floren A, Schmidl J (eds) Canopy arthropod research in Europe. Bioform entomology, Nürnberg, pp 105-117

Strong DR, Lawton JH, Southwood TRE (1984) Insects on Plants: Community Patterns and Mechanisms. Blackwell Scientific, Oxford

Thompson FC (2009) Nearctic Diptera: Twenty years later. In: Pape T, Bickel D, Meier R (eds) Diptera Diversity: Status, Challenges and Tools. Brill, Leiden, pp 3-46

Unsicker SB, Baer N, Kahmen A, Wagner M, Buchmann N, Weisser WW (2006) Invertebrate herbivory along a gradient of plant species diversity in extensively managed grasslands. Oecologia 150:233-246

Vockenhuber, E., Scherber, C., Langenbruch, C., Meißner, M., Seidel, D. \& Tscharntke, T. (2011) Tree diversity and environmental context predict herb species richness and 
cover in Germany's largest connected deciduous forest. Perspectives in Plant Ecology Evolution and Systematics, 13, 111-119.

Woodcock BA, Pywell RF (2009) Effects of vegetation structure and floristic diversity on detritivore, herbivore and predatory invertebrates within calcareous grasslands. Biodivers. and Conserv. 19:81-95

Woodcock BA, Watt AD, Leather SR (2003) Influence of management type on Diptera communities of coniferous plantations and deciduous woodlands. Agric. Ecosyst. Environ. 95:443-452 


\section{Appendix}

\section{Online Resource 1}

The two study locations, Thiemsburg and Lindig (a). Plots are shown as blue circles on the detailed maps of the Lindig (b) and Thiemsburg (c) location.

(a)






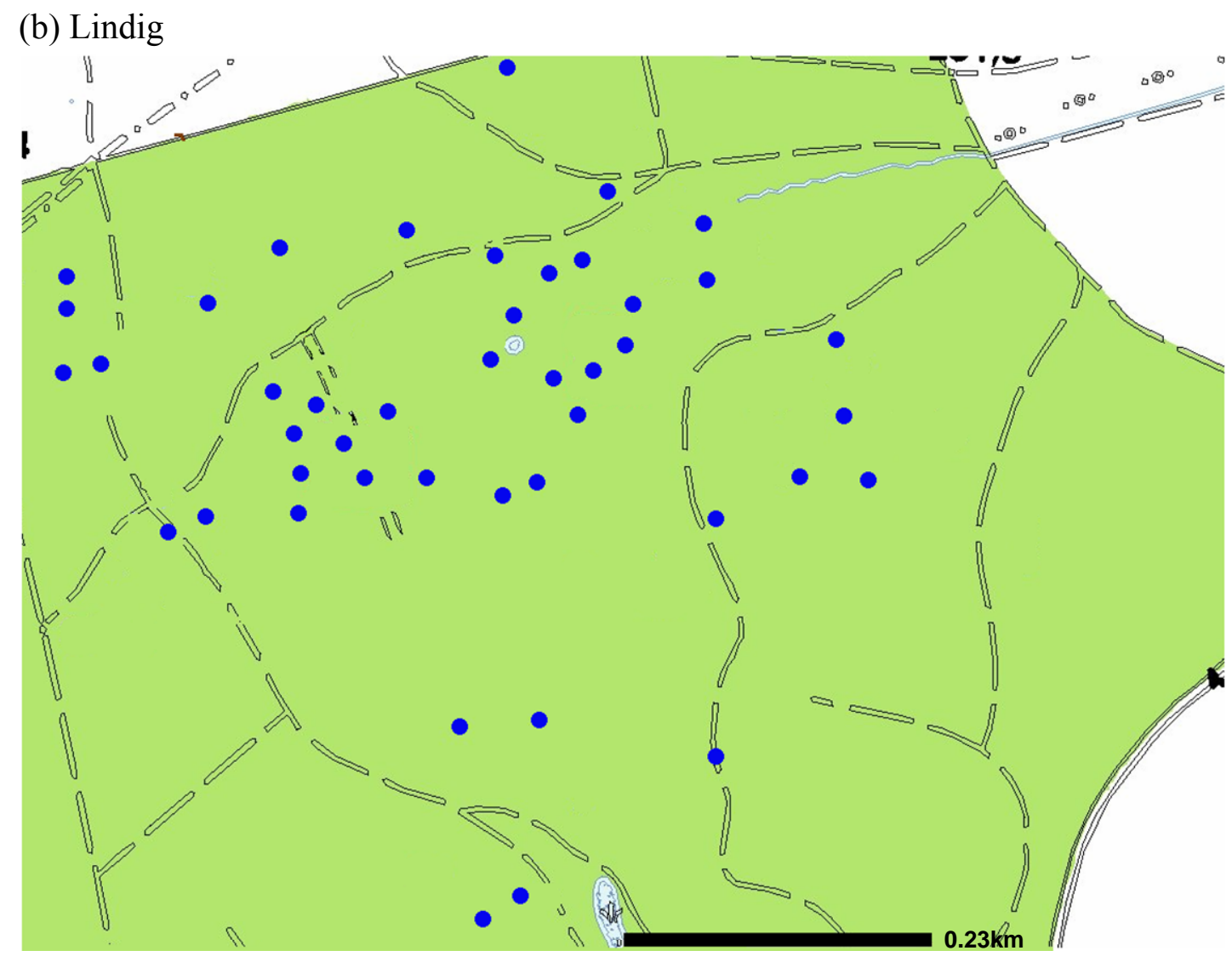

(c) Thiemsburg

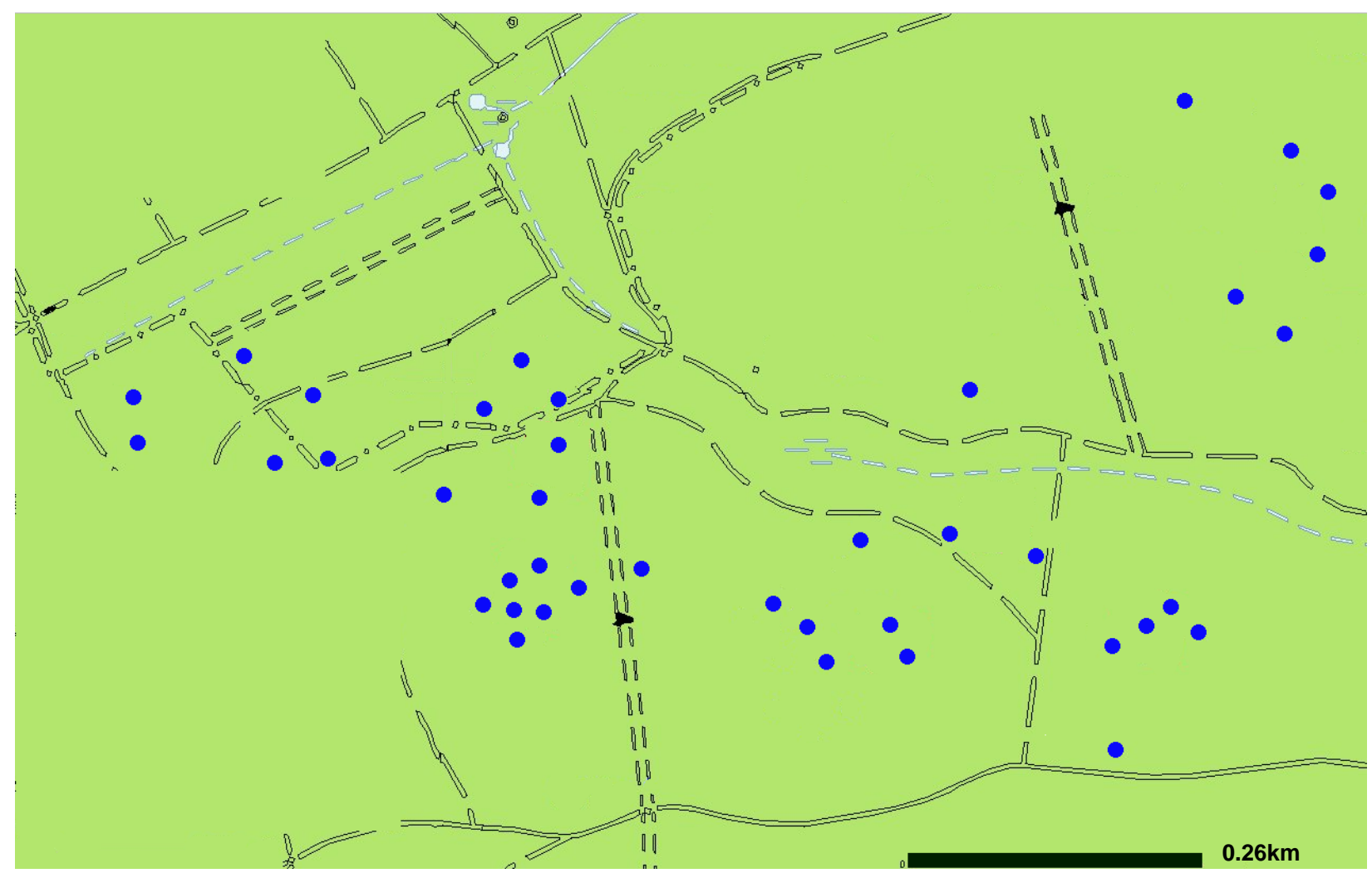




\section{Online Resource 2}

Summary of abiotic plot characteristics of all 84 study plots (overall) and of plots located in the two different study regions (Lindig/Thiemsburg). Canopy-cover: Area of ground covered by vertical projection of canopy; soil $\mathrm{pH}$ : soil $\mathrm{pH}$ in depth of $0-10 \mathrm{~cm}$; humus layer mass: mass per unit area of the humus layer; soil moisture: volumetric soil water content.

\begin{tabular}{lcccccc}
\hline & \multicolumn{2}{c}{ Overall } & \multicolumn{2}{c}{ Lindig } & \multicolumn{2}{c}{ Thiemsburg } \\
Variable (unit) & Mean $\pm \mathrm{SE}$ & Range & Mean $\pm \mathrm{SE}$ & Range & Mean \pm SE & Range \\
\hline Canopy cover (\%) & $90.2 \pm 0.5$ & $69.1-96.4$ & $88.3 \pm 0.9$ & $69.1-94.8$ & $92.3 \pm 0.3$ & $87.9-96.6$ \\
Soil pH & $5.33 \pm 0.07$ & $4.05-6.98$ & $5.32 \pm 0.1$ & $4.05-6.96$ & $5.34 \pm 0.08$ & $4.57-6.98$ \\
Humus layer mass $\left(\mathrm{g} \mathrm{m}^{-2}\right)$ & $51.6 \pm 4.5$ & $2.5-180.1$ & $34 \pm 4.8$ & $2.5-128$ & $70.9 \pm 6.6$ & $4-180.1$ \\
Soil moisture (\%) & $25.5 \pm 0.3$ & $18.9-35.3$ & $24.5 \pm 0.4$ & $18.9-29.4$ & $26.7 \pm 0.5$ & $21.6-35.3$ \\
\hline
\end{tabular}

\section{Online Resource 3}

\section{Identification of Phoridae followed:}

Disney, R.H.L. (1983) Scuttle Flies - Diptera Phoridae (except Megaselia). Handbooks for the Identification of British Insects 10(6), 1-81. Royal Entomological Society of London.

Disney, R.H.L. (1989) Scuttle Flies - Diptera Phoridae Genus Megaselia. Handbooks for the Identification of British Insects 10(8), 1-155. Royal Entomological Society of London.

Schmitz, H. (1938 - 1958) 33.Phoridae. Die Fliegen der paläarktischen Region Vol. IV (ed Lindner, E.), pp. 1-512. E. Schweizerbart'sche Verlagsbuchhandlung, Stuttgart.

Schmitz, H., Beyer, E. (1965 -1974) 33.Phoridae. Die Fliegen der paläarktischen Region Vol. IV (ed Lindner, E.), pp. 513-608. E. Schweizerbart'sche Verlagsbuchhandlung, Stuttgart.

Schmitz, H., Delage, A. (1974 -1981) 33.Phoridae. Die Fliegen der paläarktischen Region Vol. IV (ed Lindner, E.), pp. 609-712. E. Schweizerbart'sche Verlagsbuchhandlung, Stuttgart.

Zaitsev, V.F. (1988) 47.Family Phoridae. Insects of the European part of the USSR Vol. V (ed BeyBienko, G.Ya.), pp. 1156-1233. Amerind Publishing, New Delhi.

\section{Identification of Empidoidea followed:}

Chvála, M. (1975) The Tachydromiinae (Dipt. Empididae) of Fennoscandia and Denmark. Fauna Entomologica Scandinavica, 3. Scandinavian Science Press, Copenhagen.

Chvála, M. (1983) The Empidoidea (Diptera) of Fennoscandia and Denmark. II. Fauna Entomologica Scandinavica, 12. Scandinavian Science Press, Copenhagen. 
Chvála, M. (1994) The Empidoidea (Diptera) of Fennoscandia and Denmark. III. Genus Empis. Fauna entomologica scandinavica, 29. E. J. Brill, Leiden, New York, Köln.

Collin, J.E. (1961) Empididae. British Flies, Vol. 6. University Press, Cambridge.

Grootaert, P. \& Chavála, M. (1992) Monograph of the genus Platypalpus (Diptera: Empidoidea, Hybotidae) of the Mediterranean region and the Canary Islands. Acta Universitatis Carolinae Biologica, 36: 3-226.

Engel, O. (1938-1956) Empididae. Die Fliegen der paläarktischen Region Vol. IV(4) (ed Lindner, E.), pp. 1-639. E. Schweizerbart'sche Verlagsbuchhandlung, Stuttgart.

\section{Online Resource 4}

List of Empidoidea species collected with pan traps (blue, yellow, white) in the herb layer of the Hainich National Park. $n=$ number of individuals; flower-visitor: species where adults are known to visit flowers; silvicolous: species that predominantly inhabit forests.

\begin{tabular}{|c|c|c|c|c|}
\hline Species & flower-visitor & silvicolous & $n$ & Rel. Proportion $(\%)$ \\
\hline \multicolumn{5}{|l|}{ Atelestidae } \\
\hline Atelestus dissonans Collin, 1961 & $\bullet$ & - & 27 & 0.66 \\
\hline \multicolumn{5}{|l|}{ Empididae } \\
\hline Empis (Coptophlebia) albinervis Meigen, 1822 & - & - & 5 & 0.12 \\
\hline Empis (Euempis) ciliata Fabricius, 1787 & $\bullet$ & $\bullet$ & 1 & 0.02 \\
\hline Empis (Euempis) tessellata Fabricius, 1794 & $\bullet$ & & 22 & 0.54 \\
\hline Empis (Kritempis) livida Linnaeus, 1758 & $\bullet$ & & 157 & 3.85 \\
\hline Empis (Leptempis) grisea Fallén, 1816 & $\bullet$ & & 4 & 0.10 \\
\hline Empis (Lissempis) nigritarsis Meigen, 1804 & $\bullet$ & - & 1 & 0.02 \\
\hline Empis (Xanthempis) lutea Meigen, 1804 & $\bullet$ & $\bullet$ & 127 & 3.12 \\
\hline Empis (Xanthempis) stercorea Linnaeus, 1761 & $\bullet$ & $\bullet$ & 5 & 0.12 \\
\hline Empis (Xanthempis) trigramma Wiedemann, 1822 & $\bullet$ & $\bullet$ & 31 & 0.76 \\
\hline Empis s. str. aestiva Loew, 1867 & $\bullet$ & & 199 & 4.88 \\
\hline Empis s. str. albopilosa De Meijere, 1935 & $\bullet$ & - & 10 & 0.25 \\
\hline Empis s. str. caudatula Loew, 1867 & $\bullet$ & & 7 & 0.17 \\
\hline Empis s. str. chioptera Meigen, 1804 & $\bullet$ & & 4 & 0.10 \\
\hline Empis s. str. nigripes Fabricius, 1794 & $\bullet$ & $\bullet$ & 3 & 0.07 \\
\hline Empis s. str. nuntia Meigen, 1838 & $\bullet$ & $\bullet$ & 82 & 2.01 \\
\hline Empis s. str. pennipes Linnaeus, 1758 & $\bullet$ & $\bullet$ & 21 & 0.52 \\
\hline Empis s. str. planetica Collin, 1927 & $\bullet$ & $\bullet$ & 9 & 0.22 \\
\hline Empis s. str. pseudoprodromus Collin, 1969 & $\bullet$ & & 262 & 6.43 \\
\hline Hilara anglodanica Lundbeck, 1913 & & & 2 & 0.05 \\
\hline Hilara bohemica Straka, 1976 & & & 1 & 0.02 \\
\hline Hilara cornicula Loew, 1873 & & & 20 & 0.49 \\
\hline Hilara galactoptera Strobl, 1910 & & $\bullet$ & 26 & 0.64 \\
\hline Hilara lasiochira Strobl, 1892 & & $\bullet$ & 1 & 0.02 \\
\hline Hilara litorea (Fallén, 1816) & & & 1 & 0.02 \\
\hline Iteaphila nitida & - & - & 1 & 0.02 \\
\hline Phyllodromia melanocephala (Fabricius, 1794) & & & 3 & 0.07 \\
\hline Rhamphomyia (Aclonempis) longipes (Meigen, 1804) & - & - & 2 & 0.05 \\
\hline Rhamphomyia (Holoclera) flava (Fallén, 1816) & $\bullet$ & $\bullet$ & 1 & 0.02 \\
\hline \multicolumn{5}{|l|}{ Hybotidae } \\
\hline Allanthalia pallida (Zetterstedt, 1838) & - & $\bullet$ & 2 & 0.05 \\
\hline
\end{tabular}


Bicellaria nigrita Collin, 1926

Drapetis assimilis (Fallén, 1815)

Drapetis fumipennis Strobl, 1906

Drapetis parilis Collin, 1926

Elaphropeza ephippiata (Fallén, 1815)

Euthyneura albipennis (Zetterstedt, 1842)

Euthyneura myrtilli Macquart, 1836

Hybos culiciformis (Fabricius, 1775)

Hybos femoratus (Müller, 1776)

Leptopeza flavipes (Meigen, 1820)

Oedalea stigmatella Zetterstedt, 1842

Oedalea tibialis Macquart, 1827

Oedalea zetterstedti Collin, 1926

Oropezella sphenoptera (Loew, 1873)

Platypalpus aeneus (Macquart, 1823)

Platypalpus aristatus (Collin, 1926)

Platypalpus aurantiacus (Collin, 1926)

Platypalpus balticus Kovalev, 1971

Platypalpus calceatus (Meigen, 1822)

Platypalpus candicans (Fallén, 1815)

Platypalpus cf. unicus (Collin, 1961)

Platypalpus cothurnatus Macquart, 1827

Platypalpus exilis (Meigen, 1822)

Platypalpus laticinctus Walker, 1851

Platypalpus longiseta (Zetterstedt, 1842)

Platypalpus luteus (Meigen, 1804)

Platypalpus major (Zetterstedt, 1842)

Platypalpus mikii (Becker, 1890)

Platypalpus minutus (Meigen, 1804)

Platypalpus niveiseta (Zetterstedt, 1842)

Platypalpus pallidiventris (Meigen, 1822)

Platypalpus pectoralis (Fallén, 1815)

Platypalpus spec. nov.

Symballophthalmus fuscitarsis (Zetterstedt, 1859)

Tachypeza nubila (Meigen, 1804)

Trichina elongata Haliday, 1833

Microphoridae

Microphor holosericeus Loew, 1867

Dolichopodidae

Achalcus melanotrichus Mik, 1878

Argyra grata Loew, 1857

Campsicnemus curvipes (Fallén, 1823)

Chrysotimus flaviventris (von Roser, 1840)

Chrysotus angulicornis Kowarz, 1874

Chrysotus blepharosceles Kowarz, 1874

Chrysotus cupreus (Macquart, 1827)

Chrysotus laesus (Wiedemann, 1817)

Diaphorus oculatus (Fallén, 1823)

Dolichopus arbustorum Stannius, 1831

Dolichopus linearis Meigen, 1824

Dolichopus longicornis Stannius, 1831

Dolichopus nigricornis Meigen, 1824 
Lamprochromus strobli Parent, 1925

Medetera abstrusa Thuneberg, 1955

Medetera acanthura Negrobov \& Thuneberg, 1970

Medetera flavipes Meigen, 1824

Medetera takagii Negrobov, 1970

Medetera tristis (Zetterstedt, 1838)

Micromorphus albipes (Zetterstedt, 1843)

Nematoproctus distendens (Meigen, 1824)

Neurigona quadrifasciata (Fabricius, 1781)

Poecilobothrus nobilitatus (Linnaeus, 1767)

Rhaphium commune (Meigen, 1824)

Rhaphium crassipes (Meigen, 1827)

Sciapus platypterus (Fabricus, 1805)

Syntormon bicolorellus (Zetterstedt, 1843)

Teuchophorus signatus (Zetterstedt, 1849)

$1 \quad 0.02$

$\begin{array}{lll}-\quad 21 & 0.52\end{array}$

$4 \quad 0.10$

$\begin{array}{ll}25 & 0.61\end{array}$

$5 \quad 0.12$

Xanthochlorus ornatus (Haliday, 1832)

0.02

0.02

0.22

0.32

0.22

0.05

11.99

0.02

0.02

0.07 


\section{Online Resource 5}

Sequential ANOVA table for quasi-GLM models analysing family richness and abundance of the total Dipteran community, species richness and abundance of Empidoidea and Phoridae, the proportion of flower-visiting Empidoidea, and the proportion of Empidoidea typical of forests (silvicolous species). Only terms remaining in minimum adequate models are shown. F-tests were used to assess the overall significance of terms if added sequentially to a null model containing only the intercept. Abundance $(\log )=\log$-transformed fly abundance; location = variable with two factors, study locations Lindig and Thiemsburg; herb cover (sqrt) $=$ square-root transformed percentage of ground on forest plots covered by herb layer; herb diversity = Shannon-Wiener Index H' of herb layer; tree diversity = Shannon-Wiener Index $\mathrm{H}^{\prime}$ of tree layer. Interaction terms are indicated by “:”.numDF = numerator degrees of freedom; denDF $=$ denominator degrees of freedom.

\begin{tabular}{|c|c|c|c|c|c|}
\hline Response variables & Explanatory variables & numDF & denDF & $F$ value & $P$ value \\
\hline \multirow[t]{3}{*}{ Family richness Diptera } & Abundance (log) & 1 & 68 & 34.72 & $<0.001$ \\
\hline & Location & 1 & 67 & 39.09 & $<0.001$ \\
\hline & Herb cover (sqrt) & 1 & 66 & 11.11 & 0.001 \\
\hline \multirow[t]{6}{*}{ Abundance Diptera } & Location & 1 & 68 & 2.64 & 0.109 \\
\hline & Herb cover (sqrt) & 1 & 67 & 26.25 & $<0.001$ \\
\hline & Herb diversity & 1 & 66 & 2.91 & 0.093 \\
\hline & Tree diversity & 1 & 65 & 3.84 & 0.055 \\
\hline & Location : herb diversity & 1 & 64 & 16.92 & $<0.001$ \\
\hline & Location : tree diversity & 1 & 63 & 6.10 & 0.016 \\
\hline \multirow[t]{3}{*}{ Species richness Empidoidea } & Abundance $(\log )$ & 1 & 70 & 104.79 & $<0.001$ \\
\hline & Location & 1 & 69 & 37.39 & $<0.001$ \\
\hline & Herb cover (sqrt) & 1 & 68 & 4.53 & 0.037 \\
\hline \multirow[t]{3}{*}{ Abundance Empidoidea } & Location & 1 & 68 & 18.21 & $<0.001$ \\
\hline & Herb diversity & 1 & 67 & 20.24 & $<0.001$ \\
\hline & Location : herb diversity & 1 & 66 & 4.49 & 0.038 \\
\hline Species richness Phoridae & Abundance $(\log )$ & 1 & 75 & 29.22 & $<0.001$ \\
\hline \multirow[t]{5}{*}{ Abundance Phoridae } & Location & 1 & 68 & $<0.01$ & 0.998 \\
\hline & Herb cover (sqrt) & 1 & 67 & 3.68 & 0.059 \\
\hline & Herb diversity & 1 & 66 & 0.25 & 0.620 \\
\hline & Location : herb cover (sqrt) & 1 & 65 & 3.45 & 0.068 \\
\hline & Location : herb diversity & 1 & 64 & 6.00 & 0.017 \\
\hline Prop. flower visiting Empidoidea & Herb cover (sqrt) & 1 & 70 & 11.10 & 0.001 \\
\hline Prop. silvicolous Empidoidea & Herb cover (sqrt) & 1 & 70 & 16.20 & $<\mathbf{0 . 0 0 1}$ \\
\hline
\end{tabular}




\section{Online Resource 6}

Spearman rank correlations of response (Dipteran richness) and explanatory variables for analyses of total fly community, Empidoidea and Phoridae.

\section{Total Dipteran community}

\begin{tabular}{lccccc}
\hline Overall & $\begin{array}{c}\text { Dipteran } \\
\text { richness }\end{array}$ & $\begin{array}{c}\text { Dipteran } \\
\text { abundance }(\log )\end{array}$ & $\begin{array}{c}\text { Herb cover } \\
\text { (sqrt) }\end{array}$ & $\begin{array}{c}\text { Herb diversity } \\
\left(\mathrm{H}^{\prime}\right)\end{array}$ & $\begin{array}{c}\text { Tree diversity } \\
\left(\mathrm{H}^{\prime}\right)\end{array}$ \\
\hline Dipteran richness & 1.00 & & & & \\
Dipteran abundance (log) & 0.41 & 1.00 & & & \\
Herb cover (sqrt) & 0.63 & 0.42 & 1.00 & & \\
Herb diversity (H') & 0.25 & 0.25 & 0.29 & 1.00 & \\
Tree diversity (H') & 0.20 & 0.02 & 0.08 & 0.27 & \\
Lindig & & & & & \\
Dipteran richness & 1.00 & & & & \\
Dipteran abundance (log) & 0.40 & 1.00 & & & \\
Herb cover (sqrt) & 0.66 & 0.55 & 1.00 & & \\
Herb diversity (H') & 0.45 & 0.61 & 0.41 & & \\
Tree diversity (H') & 0.14 & 0.26 & 0.04 & -0.06 & \\
Thiemsburg & & & & & \\
Dipteran richness & 1.00 & & & & \\
Dipteran abundance (log) & 0.47 & 1.00 & & & \\
Herb cover (sqrt) & 0.31 & 0.29 & 1.00 & & \\
Herb diversity (H') & -0.15 & -0.22 & 0.03 & 1.00 & \\
Tree diversity (H') & 0.02 & -0.33 & -0.03 & 0.58 &
\end{tabular}

\section{Empidoidea}

\begin{tabular}{lccccc}
\hline Overall & $\begin{array}{c}\text { Dipteran } \\
\text { richness }\end{array}$ & $\begin{array}{c}\text { Dipteran } \\
\text { abundance }(\log )\end{array}$ & $\begin{array}{c}\text { Herb cover } \\
\text { (sqrt) }\end{array}$ & $\begin{array}{c}\text { Herb diversity } \\
\left(\mathrm{H}^{\prime}\right)\end{array}$ & $\begin{array}{c}\text { Tree diversity } \\
\left(\mathrm{H}^{\prime}\right)\end{array}$ \\
\hline Dipteran richness & 1.00 & & & & \\
Dipteran abundance (log) & 0.70 & 1.00 & & & \\
Herb cover (sqrt) & 0.51 & 0.39 & 1.00 & & \\
Herb diversity (H') & 0.17 & 0.21 & 0.25 & 1.00 & \\
Tree diversity (H') & 0.20 & 0.05 & 0.02 & 0.24 & \\
Lindig & & & & & \\
Dipteran richness & 1.00 & & & & \\
Dipteran abundance (log) & 0.58 & 1.00 & & & \\
Herb cover (sqrt) & 0.43 & 0.27 & 1.00 & & \\
Herb diversity (H') & 0.29 & 0.38 & 0.42 & & \\
Tree diversity (H') & 0.16 & -0.14 & 0.03 & -0.05 & \\
Thiemsburg & & & & & \\
Dipteran richness & 1.00 & & & & \\
Dipteran abundance (log) & 0.56 & 1.00 & & & \\
Herb cover (sqrt) & 0.15 & 0.20 & 1.00 & & \\
Herb diversity (H') & 0.14 & 0.09 & -0.02 & 1.00 & \\
Tree diversity (H') & 0.15 & 0.04 & -0.17 & 0.53 &
\end{tabular}




\section{Phoridae}

\begin{tabular}{lccccc}
\hline Overall & $\begin{array}{c}\text { Dipteran } \\
\text { richness }\end{array}$ & $\begin{array}{c}\text { Dipteran } \\
\text { abundance }(\log )\end{array}$ & $\begin{array}{c}\text { Herb cover } \\
(\text { sqrt })\end{array}$ & $\begin{array}{c}\text { Herb diversity } \\
\left(\mathrm{H}^{\prime}\right)\end{array}$ & $\begin{array}{c}\text { Tree diversity } \\
\left(\mathrm{H}^{\prime}\right)\end{array}$ \\
\hline Dipteran richness & 1.00 & & & & \\
Dipteran abundance (log) & 0.60 & 1.00 & & & \\
Herb cover (sqrt) & 0.03 & 0.08 & 1.00 & & \\
Herb diversity (H') & -0.10 & 0.04 & 0.28 & 1.00 & \\
Tree diversity (H') & 0.05 & 0.01 & 0.06 & 0.24 & \\
Lindig & & & & & \\
Dipteran richness & 1.00 & & & & \\
Dipteran abundance (log) & 0.69 & 1.00 & & & \\
Herb cover (sqrt) & -0.07 & 0.04 & 1.00 & & \\
Herb diversity (H') & -0.09 & 0.17 & 0.41 & & \\
Tree diversity (H') & 0.19 & 0.19 & 0.04 & -0.09 & \\
Thiemsburg & & & & & \\
Dipteran richness & 1.00 & & & & \\
Dipteran abundance (log) & 0.46 & 1.00 & & & \\
Herb cover (sqrt) & 0.10 & 0.25 & 1.00 & & \\
Herb diversity (H') & -0.07 & -0.13 & 0.07 & 1.00 & \\
Tree diversity (H') & -0.12 & -0.18 & -0.07 & 0.56 &
\end{tabular}

\section{Online Resource 7}

List of Dipteran families collected by pan trapping and suction sampling in the herb layer of the Hainich National Park. $n=$ number of individuals.

\begin{tabular}{lcc}
\hline \multicolumn{1}{c}{ Family } & $n$ & Relative proportion $(\%)$ \\
\hline Agromyzidae & 9 & 0.05 \\
Anisopodidae & 10 & 0.05 \\
Anthomyiidae & 393 & 2.00 \\
Asilidae & 6 & 0.03 \\
Asteiidae & 4 & 0.02 \\
Atelestidae & 27 & 0.14 \\
Calliphoridae & 209 & 1.06 \\
Cecidomyiidae & 2142 & 10.91 \\
Ceratopogonidae & 107 & 0.54 \\
Chironomidae & 331 & 1.69 \\
Chloropidae & 160 & 0.81 \\
Clusiidae & 117 & 0.60 \\
Conopidae & 4 & 0.02 \\
Culicidae & 10 & 0.05 \\
Diadocidiidae & 2 & 0.01 \\
Ditomyiidae & 3 & 0.02 \\
Dolichopodidae & 2109 & 10.74 \\
Drosophilidae & 329 & 1.68 \\
Dryomyzidae & 8 & 0.04 \\
Empididae & 1015 & 5.17 \\
Ephydridae & 6 & 0.03 \\
Fanniidae & 178 & 0.91 \\
& &
\end{tabular}




\begin{tabular}{lcc} 
Heleomyzidae & 10 & 0.05 \\
Hippoboscidae & 3 & 0.02 \\
Hybotidae & 1001 & 5.10 \\
Keroplatidae & 14 & 0.07 \\
Lauxaniidae & 953 & 4.85 \\
Limoniidae & 928 & 4.72 \\
Lonchaeidae & 3 & 0.02 \\
Lonchopteridae & 138 & 0.70 \\
Micropezidae & 3 & 0.02 \\
Microphoridae & 32 & 0.16 \\
Muscidae & 1086 & 5.53 \\
Mycetobiidae & 2 & 0.01 \\
Mycetophilidae & 81 & 0.41 \\
Odiniidae & 1 & 0.01 \\
Oestridae & 1 & 0.01 \\
Opomyzidae & 158 & 0.80 \\
Phaeomyiidae & 7 & 0.04 \\
Phoridae & 4955 & 25.23 \\
Platystomatidae & 16 & 0.08 \\
Pseudomyiidae & 1 & 0.01 \\
Psilidae & 2 & 0.01 \\
Psychodidae & 112 & 0.57 \\
Ptychopteridae & 5 & 0.03 \\
Rhagionidae & 107 & 0.54 \\
Rhinophoridae & 60 & 0.31 \\
Sarcophagidae & 165 & 0.84 \\
Scatophagidae & 4 & 0.02 \\
Scatopsidae & 1 & 0.01 \\
Sciaridae & 1724 & 8.78 \\
Sciomyzidae & 61 & 0.31 \\
Sepsidae & 5 & 0.03 \\
Simuliidae & 8 & 0.04 \\
Sphaeroceridae & 28 & 0.14 \\
Stratiomyiidae & 4 & 0.02 \\
Syrphidae & 384 & 1.96 \\
Tabanidae & 2 & 0.01 \\
Tachinidae & 181 & 0.92 \\
Tipulidae & 200 & 1.02 \\
Ulidiidae & 2 & 0.01 \\
Xylophagidae & 14 & 0.07 \\
\hline & &
\end{tabular}




\section{Online Resource 8}

List of phorid species collected with yellow pan traps in the herb layer of the Hainich National Park. $n=$ number of individuals. Most females of the genera Megaselia and Phora are currently unidentifiable to species level and therefore have been identified to genus only.

\begin{tabular}{|c|c|c|}
\hline Species & $n$ & Rel. Proportion $(\%)$ \\
\hline Anevrina unispinosa (Zetterstedt, 1860) & 1 & 0.04 \\
\hline Chaetopleurophora erythronota (Strobl, 1892) & 43 & 1.73 \\
\hline Conicera floricola Schmitz, 1938 & 11 & 0.44 \\
\hline Diplonevra abbreviata (von Roser, 1840) & 6 & 0.24 \\
\hline Diplonevra florea (Turton, 1801) & 1 & 0.04 \\
\hline Diplonevra nitidula (Meigen, 1830) & 12 & 0.48 \\
\hline Gymnophora arcuata (Meigen, 1830) & 17 & 0.68 \\
\hline Gymnophora integralis Schmitz, 1920 & 59 & 2.38 \\
\hline Gymnophora nigripennis cf. Schmitz, 1926 & 1 & 0.04 \\
\hline Gymnophora quartomollis Schmitz, 1920 & 7 & 0.28 \\
\hline Gymnoptera longicostalis Schmitz, 1933 & 1 & 0.04 \\
\hline Megaselia aculeata (Schmitz, 1919) & 2 & 0.08 \\
\hline Megaselia aequalis (Wood, 1909) & 3 & 0.12 \\
\hline Megaselia affinis (Wood, 1909) & 13 & 0.52 \\
\hline Megaselia albicans (Wood, 1908) & 2 & 0.08 \\
\hline Megaselia altifrons (Wood, 1909) & 3 & 0.12 \\
\hline Megaselia angusta (Wood, 1909) & 5 & 0.20 \\
\hline Megaselia brevicostalis (Wood, 1910) & 2 & 0.08 \\
\hline Megaselia campestris (Wood, 1908) & 1 & 0.04 \\
\hline Megaselia ciliata (Zetterstedt, 1848) & 19 & 0.77 \\
\hline Megaselia citrinella Buck, 2001 & 2 & 0.08 \\
\hline Megaselia conformis (Wood, 1909) & 2 & 0.08 \\
\hline Megaselia consetigera (Schmitz, 1925) & 1 & 0.04 \\
\hline Megaselia correlata (Schmitz, 1918) & 1 & 0.04 \\
\hline Megaselia crassipes (Wood, 1909) & 25 & 1.01 \\
\hline Megaselia diversa (Wood, 1909) & 2 & 0.08 \\
\hline Megaselia drakei Disney, 1984 & 2 & 0.08 \\
\hline Megaselia errata (Wood, 1912) & 1 & 0.04 \\
\hline Megaselia flava (Fallén, 1823) & 8 & 0.32 \\
\hline Megaselia flavicans Schmitz, 1935 & 3 & 0.12 \\
\hline Megaselia fusca (Wood, 1909) & 1 & 0.04 \\
\hline Megaselia fuscinervis (Wood, 1908) & 2 & 0.08 \\
\hline Megaselia fuscovariana Schmitz, 1933 & 9 & 0.36 \\
\hline Megaselia giraudii (Egger, 1862) & 7 & 0.28 \\
\hline Megaselia glabrifrons (Wood, 1909) & 1 & 0.04 \\
\hline Megaselia hirticrus (Schmitz, 1918) & 9 & 0.36 \\
\hline Megaselia hortensis (Wood, 1909) & 2 & 0.08 \\
\hline Megaselia ignobilis (Schmitz, 1919) & 5 & 0.20 \\
\hline Megaselia insons (Lundbeck, 1920) & 5 & 0.20 \\
\hline Megaselia latifrons (Wood, 1910) & 2 & 0.08 \\
\hline Megaselia longicostalis (Wood, 1912) & 4 & 0.16 \\
\hline Megaselia longiseta (Wood, 1909) & 56 & 2.26 \\
\hline Megaselia major (Wood, 1912) & 2 & 0.08 \\
\hline Megaselia malhamensis Disney, 1986 & 1 & 0.04 \\
\hline
\end{tabular}


Megaselia minor (Zetterstedt, 1848)

Megaselia nigripalpis/conformis cf.

Megaselia pleuralis (Wood, 1909)

Megaselia posticata (Strobl, 1898)

0.12

Megaselia propinqua (Wood, 1909)

0.16

Megaselia protarsalis Schmitz, 1927

Megaselia pulicaria-complex (Fallén, 1823)

Megaselia pumila (Meigen, 1830)

Megaselia rufa (Wood, 1908)

0.12

Megaselia ruficornis (Meigen, 1830)

3.91

Megaselia simulans (Wood, 1912)

0.12

Megaselia sp. Rondani, 1856

21.02

Megaselia subfraudulenta Schmitz, 1933

Megaselia subnudipennis (Schmitz, 1919)

0.12

0.08

Megaselia subpleuralis (Wood, 1909)

1.29

Megaselia subtumida (Wood, 1909)

0.04

Megaselia surdifrons (Wood, 1909)

0.08

Megaselia tarsalis (Wood, 1910)

Megaselia tumida (Wood, 1909)

Megaselia vernalis (Wood, 1909)

Metopina braueri (Strobl, 1880)

Metopina galeata (Haliday, 1833)

0.04

0.04

0.04

17.84

35.28

Metopina oligoneura (Mik, 1867)

0.28

0.04

$\begin{array}{lll}\text { Phalacrotophora berolinensis Schmitz, } 1920 & 2 & 0.08 \\ \text { Phora sp. Latreille, } 1796 & 2 & 0.08\end{array}$

Triphleba antricola (Schmitz, 1918)

0.12

Triphleba aprilina (Schmitz, 1918)

0.04

Triphleba distinguenda (Strobl, 1892)

0.85

Triphleba dudai (Schmitz, 1918)

0.12

Triphleba papillata (Wingate, 1906)

0.08

Triphleba sp. Rondani, 1856

0.04

Triphleba trinervis (Becker, 1901)

0.16

Woodiphora retroversa (Wood, 1908)

0.12 


\title{
CHAPTER 4
}

\section{Herbivory, seed production and seed} predation in forest herbs along a tree and herb diversity gradient

\author{
E. A. Vockenhuber, P. Kabouw, T. Tscharntke, C. Scherber
}

(submitted)
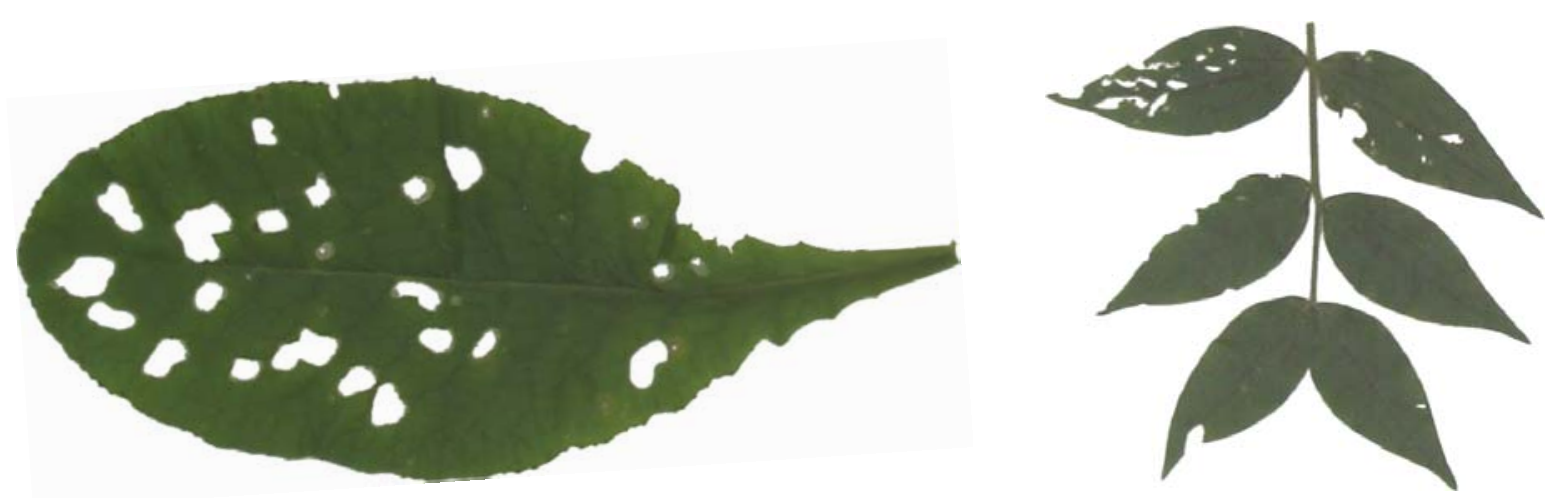


\section{Summary}

1) Plant diversity can influence numerous ecosystem processes, including multitrophic interactions that can in turn affect plant performance. While links between biodiversity and ecosystem functioning have been commonly studied in grasslands, little is known on how trophic interactions in the herb layer of forests respond to changing tree and herb diversity.

2) We simultaneously explored three types of trophic interactions, namely invertebrate herbivory, pollination-dependent seed production and post-dispersal seed predation, along a gradient of tree and herb diversity in a near-natural temperate deciduous forest. Potted individuals of the understorey herbs Lathyrus vernus and Primula elatior were set out on 40 forest plots for 3 months. Thereafter, we assessed invertebrate herbivore damage and pollination-dependent seed production. Half of L. vernus individuals were treated with rootfeeding nematodes before transfer into the forest to test whether the relationship between below- and aboveground herbivory is modified by plant diversity. We also performed a seed removal experiment using different predator exclusion treatments.

3) Foliar herbivore damage decreased with increasing tree diversity in P. elatior. In L. vernus, herbivory only responded to belowground feeding, with higher aboveground herbivory in nematode-treated plants. Seed production was enhanced by tree diversity in L. vernus and decreased with increasing herbivore damage in both species. Herb diversity and abundance of slugs were not related to herbivore damage or seed production.

4) The seed removal rate was positively related to herb diversity for seeds of L. vernus, but not P. elatior. Exclusion treatments showed that both vertebrates and invertebrates act as seed predators of $L$. vernus, while seed removal of $P$. elatior is mainly performed by invertebrates.

5) Synthesis. Tree and herb diversity in forests influenced the performance of understorey plants via changes in plant-invertebrate interactions. However, diversity effects were dependent on plant species identity, with decreasing herbivory, increasing seed production and higher seed removal in only one of the two herb species. From the plant's perspective, higher pollination-dependent seed production in diverse forest stands may be counterbalanced by higher seed predation. Belowground herbivory significantly affected aboveground leaf damage, underlining the importance of linkages between below- and aboveground herbivory under field conditions.

Key-words: biodiversity, ecosystem functioning, foliar damage, Hainich, herbaceous layer, multitrophic interactions, plant - herbivore interactions, pollination, seed dispersal 


\section{Introduction}

Plant diversity can impact ecosystem processes and affect the diversity of higher trophic levels (Haddad et al. 2009; Cardinale et al. 2011). In addition, plant diversity may modify multitrophic interactions that subsequently influence the performance of individual plants (Unsicker et al. 2006; Schuldt et al. 2010). These multitrophic interactions can have negative (e.g. herbivory, seed predation) or positive (e.g. pollination) impacts on plant fitness and consequently on plant population dynamics. Despite the high number of studies on the relationship between biodiversity and ecosystem functioning, little is known on how plant diversity affects several trophic interactions acting simultaneously on plant individuals, in particular in the context of forest tree diversity gradients.

So far, most studies on the role of biodiversity for ecosystem processes have been conducted in grassland ecosystems, while forests have received less attention. When compared to grasslands, forests are characterised by a higher structural complexity due to their greater biovolume and the organization of the plant community into different layers (Leuschner, Jungkunst \& Fleck 2009; Nadrowski, Wirth \& Scherer-Lorenzen 2010). Therefore, relationships between plant diversity and ecosystem processes may not be easily detectable. However, studying a similar set of ecological processes in different ecosystems is crucial for generalization among systems and for testing ecological theories (Belovsky et al. 2004). Previous studies which focused on tree diversity effects on herbivory were mostly limited to comparisons of monocultures with two- or three-species stands (Vehvilainen, Koricheva \& Ruohomaki 2007), while studies using gradients of high tree diversity in old forests are scarce (but see Sobek et al. 2009; Schuldt et al. 2010). To our knowledge, there are no published studies of tree diversity effects on pollination or seed predation in forests. A component of forest vegetation which has been mostly over-looked in biodiversity-ecosystem functioning studies is the herb layer, although this layer generally contains around 80 percent of the total floral diversity in forests (Gilliam 2007). Moreover, herb layer plants play a crucial role in ecosystem processes such as nutrient cycling (Gilliam 2007) and can be strongly affected by plant-insect interactions (Ehrlen 2002; Whigham 2004).

Invertebrate herbivory can substantially lower plant fitness (Crawley 1997). Several studies showed that diversity and abundance of insect herbivores increase with increasing plant diversity (Haddad et al. 2009; Scherber et al. 2010). It has been hypothesized that plants experience less herbivory in diverse systems than in monocultures because host finding is 
hindered (resource concentration hypothesis) and natural enemies are able to build up bigger populations and better control herbivores (enemies hypothesis) (Root 1973; Russell 1989). However, it is questionable if the resource concentration hypothesis, which has been primarily developed for agricultural systems, can be applied to herbivory in natural ecosystem, in particular forests, because it compares monocultures of a given plant species with mixtures and only holds for specialist herbivores. Alternatively, it has been suggested that higher herbivore damage could be expected in more diverse systems because herbivores benefit from a greater variety of niches and from dietary mixing and therefore exert more damage (Prieur-Richard et al. 2002; Unsicker et al. 2008). So far, field studies have yielded contradictory results, with herbivory increasing (Mulder et al. 1999; Schuldt et al. 2010) or decreasing (Unsicker et al. 2006; Sobek et al. 2009) with increasing plant diversity, or showing no response (Scherber et al. 2006).

The total seed production of a plant, an important characteristic of reproductive success, can be affected by plant diversity via changes in pollination success, provided that plants are strongly dependent on insect pollination. Diversity and visitation frequency of pollinators often increase with increasing plant diversity (Hegland \& Boeke 2006; Ebeling et al. 2008), which can lead to a higher pollination success and consequently a higher seed production (Ghazoul 2006). On the other hand, invertebrate herbivores can negatively affect seed production, either by directly consuming fruits or by decreasing plant fitness in such a way that less seeds are produced. Indeed, herbivore damage has been shown to reduce reproductive parameters such as fruit set and total seed number (Mothershead \& Marquis 2000; Garcia \& Ehrlen 2002).

Seed predation is a crucial process in plant population dynamics because of its potential to limit plant regeneration (Hulme \& Benkman 2002). One can distinguish between predispersal and post-dispersal seed predation, the latter of which is mainly performed by generalist seed predators (Hulme \& Benkman 2002). Increases in plant diversity may affect seed predation if seed predator populations are affected by changes in environmental or resource heterogeneity (Taboada et al. 2010; Stevens \& Tello 2011). As different groups of seed predators may be differentially affected by plant diversity, knowing the identity of dominant seed predator taxa (e.g. vertebrates vs. invertebrates) is crucial for understanding the relationship between seed predation and plant diversity.

In this study, we use a pronounced gradient of both tree and herb diversity in a temperate deciduous forest to study biodiversity effects on trophic interactions (herbivory, pollinationdependent seed production and post-dispersal seed predation). In contrast to purely 
observational approaches, we used a gradient in plant diversity that has been selected a priori, a useful approach for biodiversity studies under natural field conditions (Unsicker et al. 2006). To our knowledge, our study is the first to simultaneously examine the relationship between plant diversity and several trophic interactions which act on individual plants in the forest understorey. We set out potted plants of two locally common forest herbs (Lathyrus vernus L. and Primula elatior (L.) Hill) on 40 plots differing in tree and herb diversity to study herbivory and seed production (phytometer approach, see Scherber et al. 2006; Albrecht et al. 2007). Phytometer plants are introduced into a system and experience local processes acting on individual plants. This allows a standardized assessment of plant performance as plants do not differ in their genetic background or in the soil parameters which they experience. The phytometer experiment included an experimental manipulation of belowground herbivory in L. vernus to assess linkages between belowground and aboveground herbivory. In addition, we performed a seed-removal experiment on the same plots using different predator exclusion treatments to study the post-dispersal seed predation rate along the tree and herb diversity gradient. As slugs are important herbivores and seed predators in our study system (Türke et al. 2010), we additionally quantified slug abundance. We hypothesize that higher tree and herb diversity leads to (i) higher herbivore damage, (ii) higher seed production and (iii) a higher rate of seed predation.

\section{Materials and Methods}

Study area and study sites

The study was conducted in the Hainich National Park (Thuringia, Central Germany), near the village of Weberstedt $\left(51^{\circ} 05^{\prime} 28^{\prime}\right.$ ' $\left.\mathrm{N}, 10^{\circ} 31^{\prime} 24^{\prime \prime} \mathrm{O}\right)$. The Hainich forest covers 16,000 ha (7,500 ha have National Park status) and represents Germany's largest remaining continuous area of semi-natural deciduous forest. The climate is sub-Atlantic with continental influence; throughout the study period (2009), the mean daily temperature was $9^{\circ} \mathrm{C}$ and annual precipitation was $773 \mathrm{~mm}$ (Meteomedia, Germany). For more information on the study area, see Leuschner, Jungkunst \& Fleck (2009).

Forest stands in which study plots were located were mature and had been unmanaged for a minimum of 40 years. Dominant tree species were Fagus sylvatica L., Tilia platyphyllos Scop., Tilia cordata Mill., and Fraxinus excelsior L. Other species such as Carpinus betulus L., Acer campestre L., Acer platanoides L., Acer pseudoplatanus L., Prunus avium L., Sorbus 
torminalis (L.) Crantz, Quercus robur L., Quercus petraea Liebl., and Ulmus glabra Huds. were less abundant. The study area is exceptionally suitable for studies on tree diversity effects because differences in historic forest-use practises (mostly coppicing and selective cutting) have created a small-scale mosaic of stands differing in tree diversity, while exhibiting comparable climatic and edaphic conditions (Leuschner, Jungkunst \& Fleck 2009). In spring 2008, one hundred plots were established in the course of a previous study based on a priori combinations of tree species (Leuschner, Jungkunst \& Fleck 2009). For the current study, we selected 40 plots out of these 100 original plots based on own vegetation surveys from 2008 (Vockenhuber et al. 2011). These 40 plots showed both a gradient in tree and herb diversity. An additional requirement was that plots had to have a minimum distance of $50 \mathrm{~m}$. Plots were circular (radius $20 \mathrm{~m}$, area: $1257 \mathrm{~m}^{2}$ ) and selected from two locations (each $N=$ 20), Lindig and Thiemsburg (distance between locations approximately $1.5 \mathrm{~km}$, see Appendix S1 in Supporting Information).

\section{Vegetation measurements}

To assess herb layer diversity on the 40 study plots, vegetation surveys were conducted on two 1 x $1 \mathrm{~m}$ quadrats in the centre of each plot in early May and late June 2009 (for details see Vockenhuber et al. 2011). We estimated percentage cover of each vascular plant species present. All plants with a height $<1 \mathrm{~m}$ were included, as this threshold is commonly used to delimit the herb layer (Gilliam 2007). Data from early May and late June surveys were pooled and the Shannon-Wiener diversity index $\left(\mathrm{H}^{\prime}\right)$ was calculated as a measure of herb diversity. To estimate tree diversity, we recorded all tree species within the plot with a diameter at breast height $(\mathrm{dbh})$ of $>7 \mathrm{~cm}$. Additionally we measured dbh of all trees with circumference tape and calculated the stem area. The Shannon-Wiener diversity index (H') based on stem area was used as a measure of tree diversity. Tilia cordata/ T. platyphyllos and Q. robur/Q. petraea were recorded on genus level as these species could not be reliably distinguished in the field.

\section{Phytometer species}


Lathyrus vernus (Fabaceae) is a rhizome-bearing perennial typical of deciduous woodlands. It flowers at the end of early spring. Though self-compatible, L. vernus lacks mechanisms for self-pollination and is therefore dependent on insect pollinators (Ehrlen 1992). L. vernus experiences herbivory by molluscs, insects, and vertebrate grazers (Ehrlen et al. 1995), as well as pre-dispersal seed predation by bruchid and apionid beetles (Ostergard \& Ehrlen 2005).

Primula elatior (Primulaceae) is a perennial plant typically found in deciduous forests, but also occasionally in more open habitats. Flowering starts in early spring. P. elatior is distylous (having either pin or thrum flowers) and self-incompatible. Herbivory by lepidopteran larvae, molluscs, and deer has been reported (Taylor \& Woodell 2008).

$L$. vernus and P. elatior were chosen as phytometer species because they are pollinated by insects, their leaf shapes allow an easy estimation of herbivory, and because naturally growing plant individuals in the study area showed signs of invertebrate feeding. Both species were reasonably common in the study area, with $L$. vernus already present on $25 \%$ of plots, $P$. elatior on $42 \%$ of plots. Phytometer plants were bought from a commercial supplier (Staudenkulturen Stade, Germany) in early March 2009 before shoot emergence. Plants were transferred into 1.51 pots containing a 1:1 mixture of commercial standard garden soil (Fruhstorfer Erde T25, Hawita Gruppe GmbH, Germany) and soil collected from the study area, with a layer of water-storing polymer (Broadleaf P4, Broadleaf Industries, USA) at the bottom to slow down soil desiccation. Before their transfer to the forest plots, plants were stored outside in large mesh cages to keep out herbivores or pollinators.

\section{Nematode treatment}

To study the impact of belowground herbivory on aboveground foliar herbivory along the tree and herb diversity gradient, we treated individuals of $L$. vernus with the plant parasitic cyst nematode Heterodera schachtii and the root-knot nematode Meloidogyne hapla. Several species of Lathyrus are susceptible to Meloidogyne hapla and Heterodera sp. (Rumbaugh \& Griffin 1992; Sikora, Greco \& Silva 2005). The normal background nematode community sampled from the rhizosphere and soil of five randomly selected L. vernus plants consisted mainly of bacterivorous nematodes $(60 \%$ of the total community for rhizosphere and $75 \%$ for the bulk soil). Heterodera and Meloidogyne were extracted from roots and soil of Savoy cabbage and tomato plants, respectively, according to Kabouw et al. (2011). For both species, the soil and root extracted nematodes were combined and five subsamples were counted to 
determine the density of the nematodes in the resulting solutions (22.7 individuals per $\mathrm{mL}$ for Heterodera and 27.4 individuals per $\mathrm{ml}$ for Melodoigyne). To add about 1000 nematodes per pot, which corresponds to inoculum levels used in prior studies of plant parasitic nematodes on Lathyrus plants (Rumbaugh \& Griffin 1992), $25 \mathrm{~mL}$ (Heterodera solution, 568 individuals) and $18 \mathrm{~mL}$ (Melodoigyne solution, 494 individuals) of the solutions were required. Nematode inoculation of the pots assigned to the nematode treatment took place on 21 March 2009.

\section{Phytometer experiment}

At the beginning of flowering, phytometer plants were transferred to the forest ( $P$. elatior: 24/25 March 2009; L. vernus: 14/15 April 2009). Each plot received three individuals of $L$. vernus and $P$. elatior. The potted plants were placed at the plot centre within a circular deer fence. Pots were buried so that their lips were flush with the ground or the litter layer. To assess the dependency of the two plant species on insect pollinators, one plant of each species was covered with a gauze cage supported by a metal frame (mesh size $0.8 \mathrm{~mm}$, basal area 30 x $30 \mathrm{~cm}$, height $50 \mathrm{~cm}$ ) that excluded flying insects. In addition, one L. vernus plant per plot had been subjected to the nematode treatment (see above). Upon transplantation, the original leaf number of all plants was recorded. Plants were watered every second week.

Between 20 and 23 May 2009, herbivore damage on all phytometers not covered by gauze was assessed by imagining a cylinder around each plant, dividing the cylinder into four sections and randomly choosing one leaf per quarter section. On each leaf, the area $(A)$ damaged by foliar herbivores was measured using a $1 \mathrm{~mm}^{2}$ grid. Also, we recorded maximum length $(l)$ and width $(w)$ of the leaf. The original leaf area was estimated using the formula for the area of an ellipse (Johnston, Olivares \& Bustos 2011), based on $l$ and $w$ (representing the major and minor axes of an ellipse). Percentage herbivory $(p)$ was calculated as:

$p=\frac{A}{(l / 2) *(w / 2) * \pi} * 100 \quad[\%]$

, where the denominator gives the original leaf area. If a large part of the leaf was damaged ( $>$ $10 \%$ ), the damage in percent was directly visually estimated using 5\% steps. For the compound leaves of $L$. vernus, each leaflet was assessed separately. The mean leaf damage of the 4 randomly chosen leaves was taken as a measure of herbivore damage per plant in May. 
Upon ripening of seeds in late June/early July, all mature fruits were collected and seeds were counted. We define "seed production" as the total number of seeds per plant. Between 5 and 15 July 2009, all plants were collected and transferred back to the laboratory. Herbivore damage of all phytometers that had not been enclosed in gauze cages was assessed closely following Unsicker et al. (2006). Briefly, digital photographs of leaves were taken in a standardized procedure and the percentage of leaf area removed by herbivores was estimated using the graphics program ImageJ 1.42 (Rasband 1997-2005).

After the herbivory assessment, all aboveground plant material was oven-dried at $105^{\circ} \mathrm{C}$ for $24 \mathrm{~h}$ and weighed. Dried plant material of $L$. vernus (nematode treated and control plants) was grounded into a powder. Approximately $6 \mathrm{mg}$ of each ground sample were weighed into a tin capsule and analyzed for nitrogen content using an automated $\mathrm{C}$ and $\mathrm{N}$ analyzer (Heraeus Elementar Vario EL, Hanau, Germany). Roots of L. vernus (nematode treated and control plants) were dried at $70^{\circ} \mathrm{C}$ for $72 \mathrm{~h}$ and weighed.

\section{Slug sampling}

As slugs were commonly observed as herbivores on L. vernus and P. elatior, slug abundance on study plots was assessed by cardboard trapping between 22 and 26 June (Hawkins, Lankester \& Nelson 1998). Two sheets of moist corrugated cardboard (50 x $50 \mathrm{~cm})$ were placed on the ground at random locations close to the plot centre shortly before sunset and weighed down with dead wood. The moisture remaining under the cardboards attracts gastropods. During the following morning (14 - 18 hours after exposure of cardboard sheets), we counted all slugs adhering to the upper or lower side of the cardboard sheets or present on the ground beneath the cardboard.

\section{Bumblebee sampling}

Bumblebees, important pollinators of L. vernus and P. elatior (Ehrlen 2002; Taylor \& Woodell 2008), were sampled using pan traps on the 40 study plots in the course of previous investigations in 2008. Prompted by the observation that the number of seeds per plant in $L$. vernus varied with tree diversity (see results section), we used these previously recorded data to test for a possible relationship between bumblebee abundance and tree diversity. It must be noted that bumblebee data were collected in 2008 while the phytometer experiment was conducted in 2009; however, a cautious interpretation of bumblebee abundances along the 
tree diversity gradient might reveal interesting patterns. A blue plastic pan trap ( $5 \mathrm{~cm}$ deep, 15 $\mathrm{cm}$ upper diameter, $8 \mathrm{~cm}$ lower diameter) was mounted on a wooden pole at a height of $50 \mathrm{~cm}$ and placed in the plot centre. The trap was filled with $200 \mathrm{~mL}$ of a $50 \%$ ethylene glycol solution in water and a few drops of unscented dishwashing detergent and set out for one week in May and July 2008.

\section{Seed removal experiment}

To examine the intensity of post-dispersal seed predation in L. vernus and P. elatior along the tree and herb diversity gradient, we conducted a seed removal experiment between 11 and 20 August 2009. Seed depots consisted of compartmented Petri dishes (diameter $\mathrm{x}$ height $=90 \mathrm{x}$ $14 \mathrm{~mm}$ ) that held 50 seeds of each species. Seeds were exposed in the forest for 8 days. Remaining seeds were subsequently counted in the laboratory and the percentage of removed seeds was calculated.

On all study plots, four different exclusion treatments were applied to assess the relative importance of invertebrates and vertebrates as seed predators:

1) Open access: The seed depot was inserted into a white plastic square $(20 \mathrm{x} 20 \mathrm{~cm})$ for greater stability, with the lip of the Petri dish flush with the plastic. Invertebrates and vertebrates could access this treatment.

2) Vertebrate exclusion: Seed depots were installed in the same way as described above, but the installation was covered by a $25 \times 25 \times 8 \mathrm{~cm}$ wire cage (mesh size $12 \mathrm{~mm}$ ). This allowed access for invertebrates only. Cages were firmly fixed with metal pins to the ground.

3) Invertebrate exclusion: The seed depot was glued onto a $5 \mathrm{~cm}$ high plastic cylinder situated in the middle of the white plastic square. Then, the cylinder and the underside of the seed depot were coated with Fluon (Whitford GmbH, Germany), a slippery, Teflon-like material that prevents arthropods from climbing into the seed container (Mittelbach \& Gross 1984). In addition, a $3 \mathrm{~cm}$ wide slug-deterring copper tape (Copper Barrier Tape, Direct Products, UK) was placed around the base of the cylinder and coated with slug repellent (Schneckenabwehrpaste IRKA, R + M Gartenbedarf, Germany) to exclude slugs. The combination of copper and slug paste has proven successful in deterring slugs from seed depots (Türke et al. 2010).

4) Total exclusion: A combination of the vertebrate and invertebrate exclusion treatments was used as a control to measure background seed loss. 
For all treatments, the plastic squares holding the seed depots were on the same level as the ground surface and secured to the ground with one nail on each corner. Each treatment was protected from rain by a plastic roof.

\section{Statistical analysis}

We used mixed-effects models (MEMs) in R 2.12.0 (R Development Core Team 2011) to account for the nesting of phytometer individuals within plots. Linear MEMs (nlme package, Pinheiro \& Bates 2000) were used for analyses of percentage herbivore damage (phytometer experiment) and percentage seed removal (seed predation experiment). For analyses of count data (total seed number per plant), Poisson generalized linear MEMs fit by Penalized QuasiLikelihood were used (MASS library, Venables \& Ripley 2002). A negative binomial generalized linear model was used to test for effects of tree diversity on bumblebee abundances in 2008. Percentage data were arcsine-square root transformed and slug abundance data were log transformed to improve model fit. There was low multicollinearity between explanatory variables (variance inflation factors all $<2$ ).

For the phytometer experiment, separate models were fitted for L. vernus and for P. elatior to analyse herbivore damage and number of seeds per plant. The original leaf number of phytometer plants was used as a covariate in all analyses. First, we fitted a maximal model with plot and date as random effects and the following sequence of fixed effects: Original leaf number + location + date + nematode treatment (only for L. vernus) + herb diversity + tree diversity + slug abundance, plus all two-way interactions with the factors location, date, and nematode treatment. Date was only included when analysing herbivory as it was the only response variable recorded at two points in time. For analyses of number of seeds per plant, herbivore damage at the end of the experiment was included as explanatory variable instead of slug abundance. Each maximal model was further simplified using a modified version of stepAIC (MASS library, Venables \& Ripley 2002) that computes AICc (Akaike's Information Criterion corrected for small sample sizes, Burnham \& Anderson 2002) instead of AIC. Models were considered minimal adequate when AICc reached a global minimum (Burnham \& Anderson 2002). Generalized linear MEMs, for which AICc is not defined, were simplified by sequentially removing non-significant terms, starting with two-way interactions. $\mathrm{P}$ values for parameter estimates were obtained from comparisons with Student's $t$ distribution. 
To test for differences in seed removal between the exclusion treatments of the seed predation experiment, we fitted models with plot as random effects and treatment as fixed effect separately for each plant species. Differences between treatments were inspected further using Tukey HSD post-hoc tests implemented in the multcomp package (Hothorn, Bretz \& Westfall 2008). In addition, we analysed effects of covariates on total seed predation (open treatment) by fitting a model with plot as random effect and location + species + herb diversity + tree diversity + slug abundance plus all two-way interactions with the factors location and species as fixed effects. Models were simplified using the modified version of stepAIC as described above.

For all models, residuals were inspected for normality and homogeneity of variance. Variance functions were used to model remaining heteroscedasticity if this improved the AICc (Pinheiro \& Bates 2000). Averages are presented as arithmetic mean \pm 1 SE. For t-tests, adjusted degrees of freedom based on the Welch approximation are given.

\section{Results}

Local plant and herbivore communities

Herb diversity $\left(\mathrm{H}^{\prime}\right)$ in the plots ranged from $0.25-2.94$. Herb diversity was strongly positively correlated with vegetation cover in summer (Spearman rank correlation $=0.77$ ), but not in spring (Spearman rank correlation $=-0.3$ ). The number of herb layer species per plot ranged from 3 - 32 species. The most common species were A. platanoides, F. excelsior, A. pseudoplatanus and F. sylvatica for tree saplings, Anemone nemorosa L., Lamium galeobdolon (L.) L. s. str., Ranunculus ficaria L. and Viola reichenbachiana Boreau for forbs, and the graminoid Hordelymus europaeus (L.) Harz. Tree diversity in the plots ranged from $0.29-1.88$. We recorded two (nearly monospecific F. sylvatica stands) to nine different broad-leaved tree species per plot.

Sampled slug abundance averaged $7.5 \pm 0.9$ individuals (range: $0-33$ individuals). More than $95 \%$ of all sampled slugs belonged to the genius Arion, while only a few individuals of Limax cinereoniger and Deroceras sp. were found.

Phytometer experiment

Efficiency of nematode treatment 
On transfer to the forest, 4 weeks after nematode inoculation, plants treated with nematodes tended to have slightly fewer leaves than control plants $(19.3 \pm 1.6$ vs. $22.9 \pm 1.3$, Welch's ttest, $t(74.02)=1.7, P=0.09)$. At the end of the phytometer experiment, nematode-treated plants had a lower aboveground biomass $(2.18 \pm 0.19 \mathrm{~g}$ vs. $3.2 \pm 0.24 \mathrm{~g}$, Welch's t-test, $t(67.47)=3.33, P=0.001)$ as well as a lower root mass $(4.6 \pm 0.41 \mathrm{~g}$ vs. $7.86 \pm 0.82 \mathrm{~g}$, Welch's t-test, $t(49.74)=3.56, P<0.001)$, but did not differ in their nitrogen content from control plants $(25.64 \pm 0.63 \mathrm{mg} / \mathrm{g}$ dry weight vs. $26.34 \pm 0.57 \mathrm{mg} / \mathrm{g}$, Welch's t-test, $t(69.72)=$ $0.82, P=0.42)$.

\section{Herbivory}

Inspection of feeding patterns and direct field observations showed that herbivore damage was mainly caused by slugs and leaf-chewing insect herbivores (Curculionidae and lepidopteran larvae). Mining rarely occurred, and no galls were observed.

Herbivore damage on L. vernus was not significantly affected by herb diversity, tree diversity, or slug abundance. Nematode-treated L. vernus plants were significantly more heavily damaged by herbivores than control plants, both in May $(12.1 \pm 1.9 \%$ vs. $6.6 \pm 1.4 \%$, $N=39$ and 40, Table 1, Fig. 1) and in July $(17.2 \pm 1.8 \%$ vs. $11.1 \pm 1.4 \%, N=37$ and 38 , Table 1, Fig. 1).

P. elatior showed low herbivore damage in May $(1.3 \pm 0.3 \%, N=79)$, but average leaf area loss had increased in July $(11.2 \pm 1.4 \%, N=75)$ and was similar to damage recorded for unmanipulated L. vernus plants in July (Fig. 1). Herbivore damage on P. elatior significantly decreased with increasing tree diversity in July, while damage in May did not show a response (Table 1, Fig. 2a). Herb diversity and slug abundance did not significantly affect leaf damage on P. elatior. 


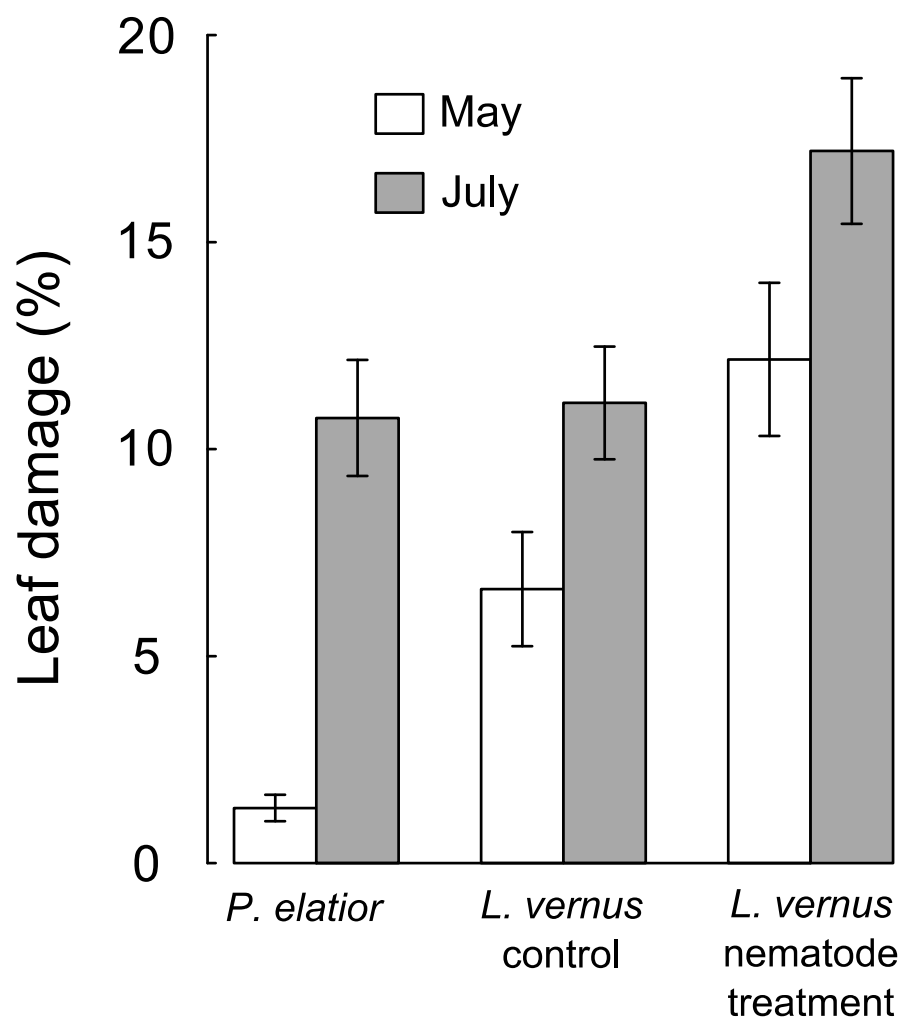

Fig. 1. Leaf damage (\%, mean $\pm 1 \mathrm{SE})$ caused by invertebrate herbivory in the herb layer species Primula elatior and Lathyrus vernus in May and July 2009. P. elatior: $N=79$ (May), $N=75$ (July); L. vernus (control): $N=40$ (May), $N=38$ (July); L. vernus (nematode treatment): $N=39$ (May), $N=37$ (July). 
Table 1. Parameter estimates (Est.), standard errors (SE), degrees of freedom (DF), $t$ and $P$ values of terms included in minimal adequate mixed-effect models predicting herbivory (May and July), seed production, and seed removal rate for the forest herbs Lathyrus vernus and Primula elatior. Parameters are tested marginally, i.e., in presence of all other terms in the model. Differences between the categorical variables treatment (control vs. nematode treatment), location (Lindig vs. Thiemsburg), and species (L. vernus vs. P. elatior) are treatment contrasts, i.e., the intercept represents the mean of the first level of the variable, while the mean of the second level is the difference between the intercept and the parameter estimate indicated in the table. Parameter estimates are on the arcsine square-root scale (for analyses of herbivory and seed removal) or log-scale (for analyses of seed number)

\begin{tabular}{|c|c|c|c|c|c|c|}
\hline Response variable & Explanatory variable & Est. & SE & DF & $t$ & $P$ \\
\hline \multicolumn{7}{|l|}{ Phytometer L. vernus } \\
\hline \multicolumn{7}{|l|}{ Herbivore damage May } \\
\hline & Intercept (control) & 0.33 & 0.03 & 39 & 12.28 & $<0.001$ \\
\hline & Treatment (nematode) & -0.12 & 0.03 & 38 & -3.96 & $<0.001$ \\
\hline \multicolumn{7}{|l|}{ Herbivore damage July } \\
\hline & Intercept (control) & 0.41 & 0.02 & 37 & 18.73 & $<0.001$ \\
\hline & Treatment (nematode) & -0.09 & 0.02 & 36 & -4.85 & $<0.001$ \\
\hline \multicolumn{7}{|l|}{ Seeds per plant } \\
\hline & Intercept (Lindig) & 2.50 & 0.60 & 35 & 4.19 & $<0.001$ \\
\hline & Location (Thiemsburg) & -0.54 & 0.21 & 35 & -2.62 & 0.013 \\
\hline & Original leaf number & 0.03 & 0.01 & 35 & 3.39 & 0.002 \\
\hline & Tree diversity & 0.83 & 0.38 & 35 & 2.18 & 0.036 \\
\hline & Herbivore damage (July) ${ }^{\mathrm{a}}$ & -2.88 & 0.74 & 35 & -3.92 & $<0.001$ \\
\hline \multirow{2}{*}{\multicolumn{7}{|c|}{$\begin{array}{l}\text { Phytometer } \boldsymbol{P} \text {. elatior } \\
\text { Herbivore damage May }\end{array}$}} \\
\hline & & & & & & \\
\hline & Intercept (Lindig) & 0.01 & 0.002 & 39 & 4.85 & $<0.001$ \\
\hline & Location (Thiemsburg) & 0.06 & 0.01 & 38 & 5.81 & $<0.001$ \\
\hline \multicolumn{7}{|l|}{ Herbivore damage July } \\
\hline & Intercept & 0.61 & 0.08 & 37 & 7.73 & $<0.001$ \\
\hline & Tree diversity & -0.24 & 0.06 & 36 & -3.96 & $<0.001$ \\
\hline \multicolumn{7}{|l|}{ Seeds per plant } \\
\hline & Intercept & 6.83 & 0.23 & 36 & 29.14 & $<0.001$ \\
\hline & Herbivore damage (July) ${ }^{\mathrm{a}}$ & -1.58 & 0.77 & 36 & -2.04 & 0.049 \\
\hline \multicolumn{7}{|l|}{ Seed removal experiment } \\
\hline \multirow[t]{4}{*}{ Seed removal open treatment } & Intercept (L. vernus) & -0.01 & 0.18 & 38 & -0.05 & 0.964 \\
\hline & Herb diversity & 0.33 & 0.10 & 38 & 3.40 & 0.002 \\
\hline & Species (P. elatior) & 0.78 & 0.16 & 38 & 4.95 & $<0.001$ \\
\hline & Herb diversity:species & -0.27 & 0.09 & 38 & -3.12 & 0.003 \\
\hline
\end{tabular}

${ }^{\mathrm{a}}$ arcsine square-root transformed 


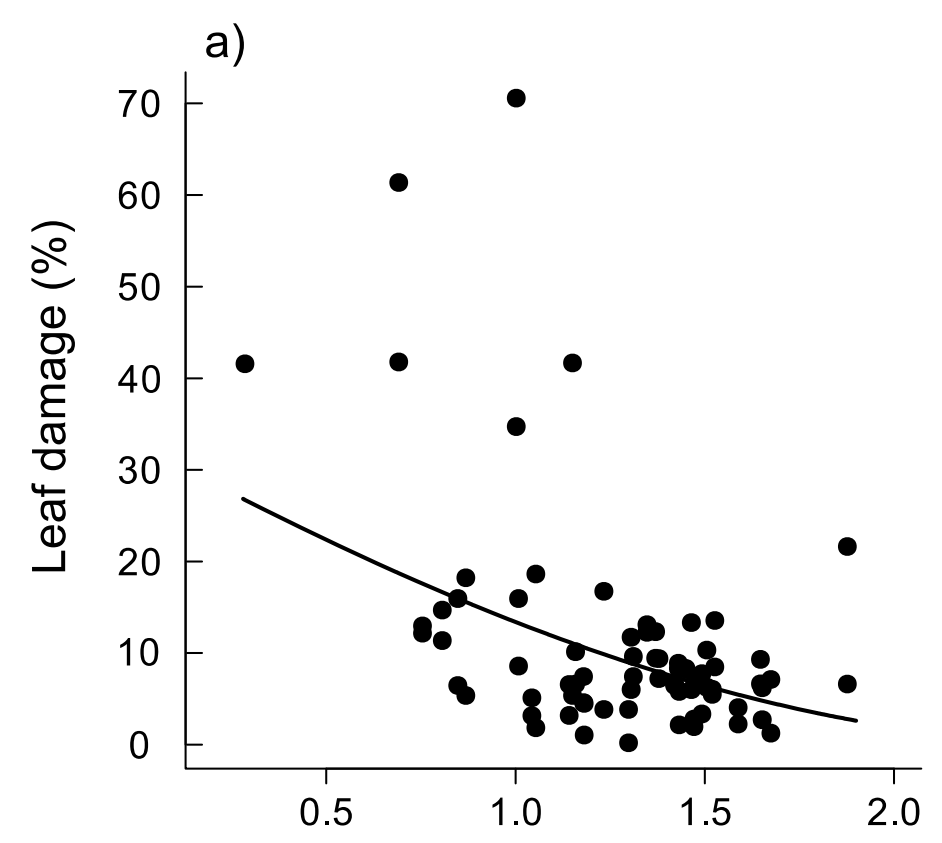

b)

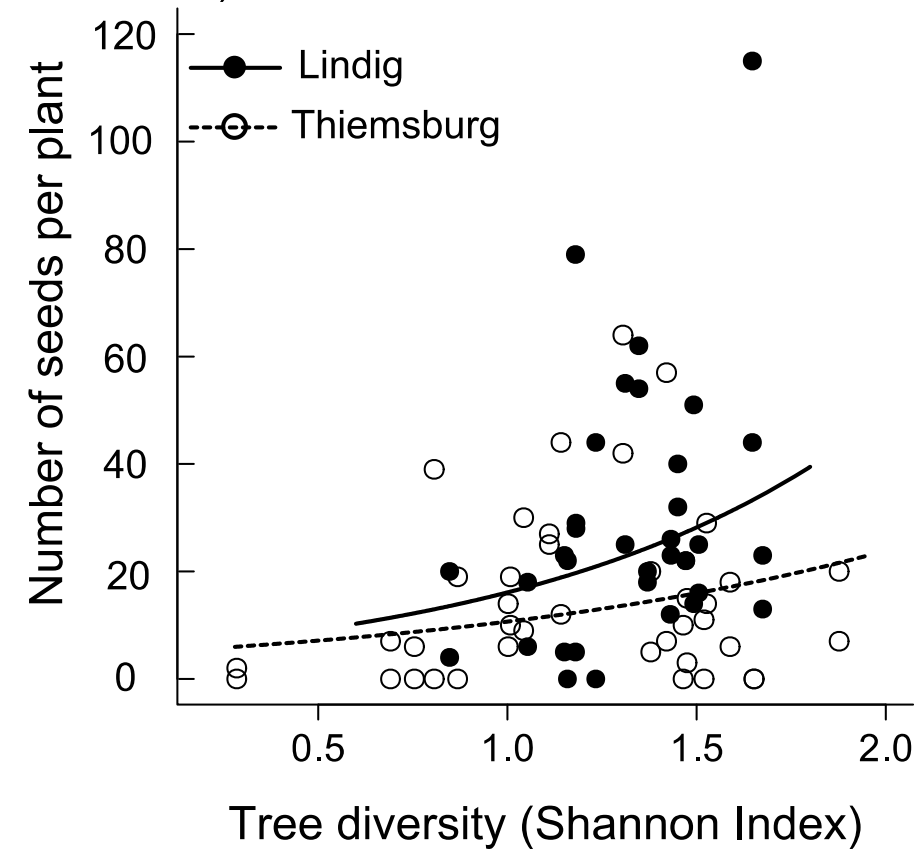

Fig. 2. Relationship between tree diversity (expressed by the Shannon-Wiener diversity index) and a) leaf damage (\%) caused by invertebrate herbivory in Primula elatior and b) number of seeds per plant produced by Lathyrus vernus. $N=75$ (both for a) and b). Curves are based on parameters from fitted minimal adequate mixed-effect models (Table 1). Fitted values for leaf damage were back-transformed for better visualisation. In a), the study locations Lindig and Thiemsburg are shown separately because the number of seeds produced was significantly dependent on the location.

\section{$\underline{\text { Seed production }}$}

L. vernus plants produced on average $21.2 \pm 2.4(N=75)$ intact seeds per plant, with an average of $3.3 \pm 0.1$ seeds per fruit $(N=64$, only plants which produced fruits included). Seed pods of nine L. vernus plants were attacked by the specialist seed predator Oxystoma opeticum (Apionidae), leading to the destruction of $32.2 \pm 7 \%$ of the total seeds per plant ( $N$ $=9$ ). The number of seeds per plant was not significantly affected by the nematode treatment, but significantly increased with increasing tree diversity (Table 1, Fig. 2b). Also, seed production significantly increased with increasing initial leaf number and decreased with 
increasing foliar herbivore damage (Table 1, Fig. S1). The number of seeds per plant was unrelated to bumblebee abundance measured in 2008 .

In $P$. elatior, the number of seeds per plant averaged $574.3 \pm 54.2$ seeds $(N=77)$, with an average of $35.6 \pm 1.6$ seeds per fruit $(N=67$, only plants which produced fruits included). The number of seeds per plant significantly decreased with increasing herbivore damage (July), but did not respond to tree or herb diversity or any other variable (Table 1, Fig. S1).

Plants covered with gauze showed a strongly reduced seed production compared to freely accessible plants (L. vernus: $0.2 \pm 0.1$ vs. $21.2 \pm 2.4$ seeds per plant, Welch's t-test, $t(74.36)=$ 8.7, $P<0.001$; P. elatior: $5.6 \pm 4$ vs. $574.3 \pm 54.2$ seeds per plant, Welch's t-test, $t(76.82)=$ $10.47, P<0.001)$.

Bumblebees (Bombus pascuorum) and bee flies (Bombylius sp.) were observed pollinating $L$. vernus and $P$. elatior phytometers on the study plots. Bumblebee abundance (measured previously in 2008) was positively associated with tree diversity (negative binomial generalized linear model, deviance $=3.84$; d.f. $=1,35 ; P=0.05$; Fig. S2).

\section{Seed predation experiment}

Overall seed removal from the open treatment significantly differed between the two plant species, with $P$. elatior showing a higher removal rate $(56.9 \pm 3.8 \%)$ than $L$. vernus $(29.9 \pm$ $5.9 \%$; Table 1). In addition, overall seed removal significantly increased with increasing herb diversity, with a steeper increase for $L$. vernus than for P. elatior (see main effect and interaction term in Table 1; Fig. 3). Tree diversity did not significantly affect the seed removal rate for either species.

Although mucous trails of slugs were frequently observed on seed depots and several slugs were directly observed in seed depots accessible to invertebrates, slug abundance also did not significantly affect the seed removal rate for either species. Additionally eleven seed depots $(7.4 \%, N=148)$ showed signs of on-site seed consumption by rodents (empty seed cases of $L$. vernus). 


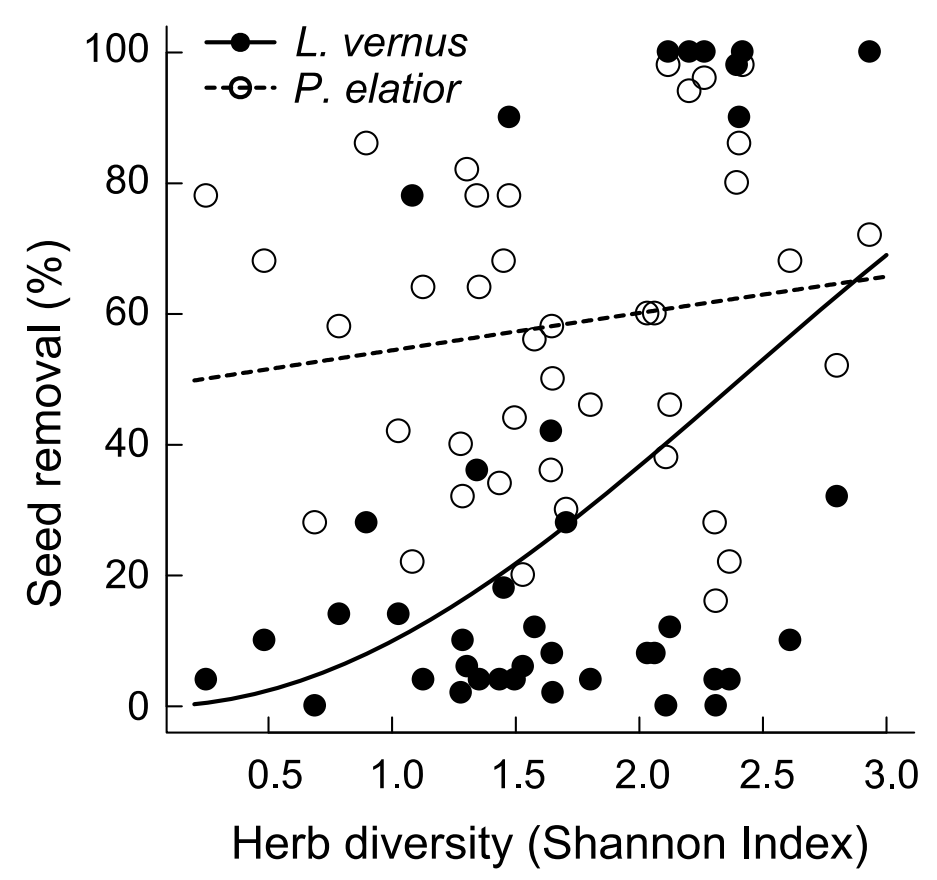

Fig. 3. Relationship between herb diversity (expressed by the Shannon-Wiener diversity index) and seed removal rate (\%) for Lathyrus vernus and Primula elatior. $N=40$ for each species. Curves are based on parameters from fitted minimal adequate mixed-effect models (Table 1). Fitted values were back-transformed for better visualisation.

For L. vernus, both the vertebrate and the invertebrate exclusion treatment reduced the seed removal rate by roughly two-thirds (seed removal from vertebrate exclusion: $10 \pm 1.3 \%$, invertebrate exclusion: $13 \pm 5.5 \%$, Fig. 4). In contrast, the seed removal rate for P. elatior was only weakly reduced by the vertebrate exclusion treatment $(46.6 \pm 4.1 \%$, Fig. 4$)$, while the exclusion of invertebrates led to a significantly lower rate of seed removal $(7.9 \pm 3.2 \%$, Fig. 4). Seed removal from the control treatment (total exclusion) was very low for both plant species (L. vernus: $0.7 \pm 0.3 \%$; P. elatior: $2.6 \pm 0.8 \%$ ).

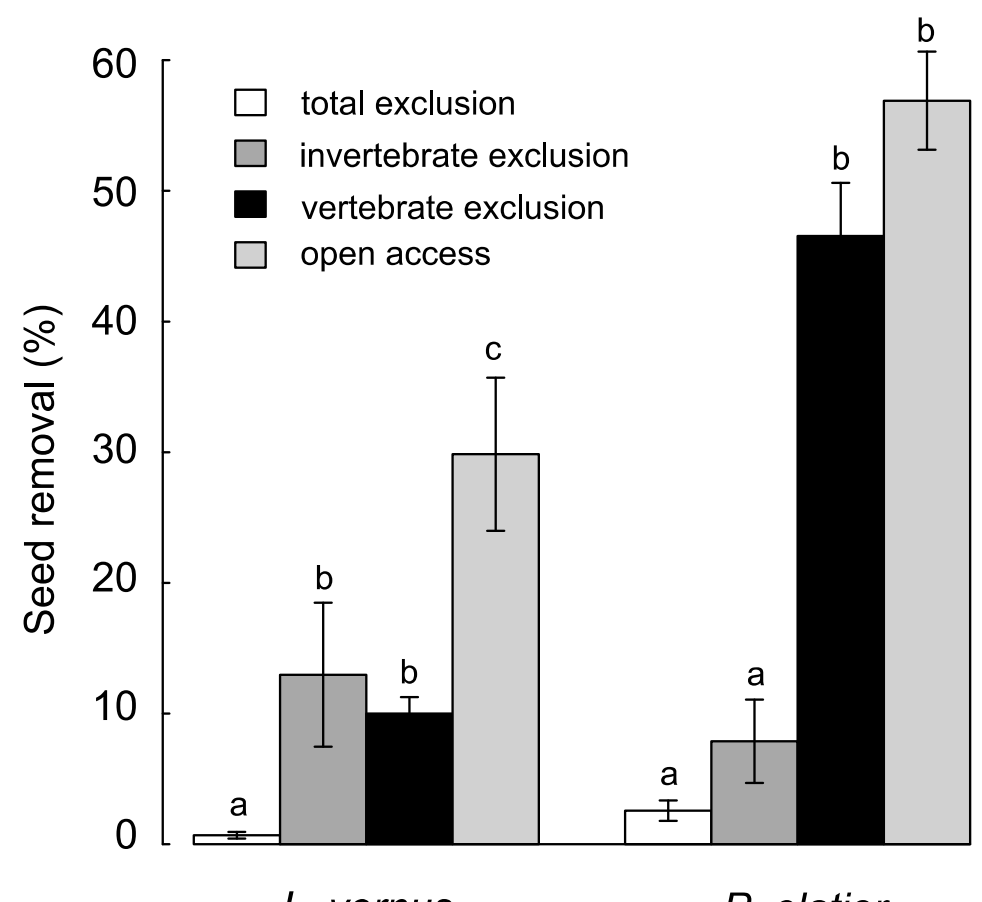

Fig. 4. Seed removal rate $(\%$, mean $\pm 1 \mathrm{SE})$ for seeds of Lathyrus vernus and Primula elatior from different predator exclusion treatments. Exclusion treatments had a significant effect on the seed removal rate $(L$. vernus: $\mathrm{F}_{3,105}=48.57, P<0.001$; $P$. elatior: $\left.F_{3,105}=118.02, P<0.001\right)$. Different letters indicate differences between treatments within the plant species (Tukey HSD posthoc test, $P<0.05$ ). Total exclusion $N=35$, invertebrate exclusion $N=33$, vertebrate exclusion $N=40$, open access $N=40$.

L. vernus

P. elatior

Plant species 


\section{Discussion}

Our study shows clearly that the diversity of the tree and the herb layer in an old-growth, near-natural forest influences several plant-animal interactions that are important for plant reproduction. Tree diversity was negatively associated with herbivory in P. elatior and positively related to seed production in L. vernus. Also, increasing herb diversity led to increased rates of seed predation. Thus, our data suggest that these moderate, but significant linkages between plant diversity and trophic interactions are species-specific, possibly depending on the life histories of the particular plant species. With the understorey of forests receiving little attention in biodiversity - ecosystem functioning research, our study is the first to demonstrate that such linkages affect herbaceous understorey plants. While herbivory and seed predation generally have a negative and pollination a positive impact on plant reproduction, the outcome in terms of population dynamics may be neutral, i.e. L. vernus produces more seeds in diverse forest stands, but also loses more seeds to seed predators.

\section{Herbivory}

Contrary to our expectations, invertebrate leaf damage decreased with increasing tree diversity in $P$. elatior, while it remained unaffected in $L$. vernus. This refutes our expectation that a greater abundance or species richness of herbivores on more diverse plots would exert a stronger herbivory pressure. It is possible that plots with higher tree diversity house a greater abundance of natural enemies that effectively control herbivores (supporting the enemies hypothesis, Russell 1989). Herbivory can reduce potential plant fecundity by removing resources needed for seed production or making the plant less attractive to pollinators (Mothershead \& Marquis 2000). In a closely related Primula species, it has been shown that herbivory negatively impacts future plant performance (Garcia \& Ehrlen 2002). Thus, diversity-related changes in herbivory levels could potentially contribute to altered plant population dynamics in $P$. elatior.

While this is to our knowledge the first study quantifying invertebrate herbivore damage of herbaceous understorey plants along a tree and herb diversity gradient, several studies have explored effects of tree diversity on herbivory on tree sapling in the herb layer. Our results agree with Sobek et al. (2009), who found decreasing leaf damage in saplings of F. sylvatica with increasing tree diversity. Again, as in this study, results were species-specific, with saplings of two Acer species not responding to the tree diversity gradient. In contrast, Schuldt 
et al. (2010) reported a positive association between tree diversity and herbivore damage on saplings of several tree species in a highly diverse subtropical forest in south-east China. Contrasting responses of herbivory to tree diversity might be caused by the different magnitude of the tree diversity gradient in temperate and tropical forests, the diet breadth of dominant herbivores, and by the palatability of the study species (Jactel \& Brockerhoff 2007; Sobek et al. 2009; Schuldt et al. 2010).

Surprisingly, tree diversity rather than herb diversity was related to herbivory in P. elatior, even though the plants were located in the herb layer and one might expect that the diversity of the directly surrounding plant community would be most relevant. However, in forest ecosystems, trees act as ecosystem engineers that strongly shape conditions in the herb layer (Barbier, Gosselin \& Balandier 2008; Vockenhuber et al. 2011). Therefore it is well feasible that the diversity of the canopy layer affects multitrophic interactions occurring closer to the forest floor. The greater variety of food resources available at higher herb layer diversity apparently did not affect herbivore populations in a way that would increase the consumption of our study plants. Indeed, Cardinale et al. (2011) pointed out in their review that there is currently no consistent evidence to suggest that plant diversity influences the amount of plant biomass consumed by herbivores, although individual studies did discover either positive or negative effects.

Our experimental manipulation of belowground nematode feeding significantly affected aboveground leaf damage: L. vernus plants that had been treated with plant parasitic nematodes experienced more foliar herbivory than control plants. Possible explanations for interactions between below- and aboveground herbivores include changes in the nutrient content of leaves due to a stress response caused by root feeding (Masters \& Brown 1997). However, our analyses of plant nitrogen content showed that this is, at least for nitrogen, not a likely explanation. More recently, the role of secondary defence metabolites has been emphasised: Root feeding can either trigger an inducible plant defence response which also leads to less herbivory in aboveground plant parts (Bezemer \& van Dam 2005), or interfere with the production centres of defensive compounds, leading to higher rates of herbivore damage due to a lower concentration of defensive compounds in the leaves (Kaplan, Sardanelli \& Denno 2009). Little is known about defensive compounds in L. vernus whose production could have been affected by nematode feeding. While both positive and negative relationships between below- and aboveground herbivores and herbivory have been convincingly demonstrated in greenhouse studies, evidence from field situations with more natural conditions remains scarce (Vandegehuchte, de la Pena \& Bonte 2010). Our results 
show that increased belowground herbivory can increase the rate of aboveground leaf damage also under realistic field condition. This relationship is consistent for both sampling dates, although study plants had only been exposed to herbivores in the forest for 5 weeks before the first herbivory assessment. As neither herbivory in nematode treated plants nor in control plants of $L$. vernus responded to tree or herb diversity, we conclude that belowground herbivory does not change the relationship between plant diversity and aboveground herbivory.

Frequent observations of mucus trails and faeces as well as slugs feeding on study plants indicated that slugs were important herbivores in the Hainich forest, as has been shown in other forest systems (von Oheimb \& Brunet 2007; Pigot \& Leather 2008). However, we did not find a correlation between slug abundance and herbivore damage. Similarly, Nystrand \& Granstrom (2000) found that slug herbivory on Pinus sylvestris seedlings was unrelated to the activity density of slugs. Possibly the assessment of slug abundance in late June was not indicative of slug abundances in earlier months when much of the herbivore damage occurred. Also, other herbivores, such as lepidopteran larvae and curculionid beetles, which were also observed on study plants, may have been as important herbivores as the more conspicuous slugs.

\section{Seed production}

In L. vernus, the total number of seeds per plant increased with increasing tree diversity, but was not related to herb diversity. This partly confirms our hypothesis that tree and herb diversity would be positively associated with seed production due to a positive effect on insect pollinators. With our gauze exclusion cages we showed that the exclusion of flying insects from our phytometer plants reduced seed production almost to zero. This confirms that seed production in both $L$. vernus and P. elatior strongly depends on insect pollination. In addition, it has been shown that populations of $L$. vernus are sometimes pollen-limited (Ehrlen 1992). As a consequence, potential fecundity of plants might be enhanced by factors beneficial to pollinator communities. Previous studies showed that higher plant diversity, and also more specifically tree diversity, increases the abundance of hymenopteran pollinators (Ebeling et al. 2008; Sobek et al. 2009). In our study area, tree diversity was also positively correlated with the abundance of bumblebees, which are considered as the most important pollinators of L. vernus (Ehrlen 2002). If pollinators benefit from attributes of diverse forest stands, for example a greater availability of nesting and overwintering sites, food resources, 
or more favourable microclimatic conditions, this could lead to enhanced pollination success. Consequently, seed production of plants growing in diverse stands might be higher, which could influence community dynamics of $L$.vernus if seedling recruitment is seed-limited.

In contrast to $L$. vernus, seed production of $P$. elatior did not respond to tree diversity. Possibly P. elatior depends on different pollinators which are less affected by tree diversity. Even though bumblebees are also common visitors of $P$. elatior, bee flies and Meligethes beetles also act as pollinators (Taylor \& Woodell 2008). Moreover, other factors that can contribute to total seed production, for instance the level of floral herbivory, pre-dispersal seed predation or pollen limitation, may be more important than plant diversity for the seed production in P. elatior.

In both study species, plants that experienced higher herbivore damage showed a reduced seed production. This negative effect of herbivory on current reproductive success is a widespread phenomenon in plant communities (Ehrlen 1995; Mothershead \& Marquis 2000; Scherber et al. 2006) and might also affect plant reproduction in the following year, depending on the timing of herbivory (Garcia \& Ehrlen 2002).

\section{Seed predation}

The overall rate of seed removal in L. vernus increased with increasing herb diversity. We had hypothesized that higher tree and/or herb diversity would lead to higher rates of seed predation as seed predators may benefit from greater resource heterogeneity and structural complexity of more diverse forest stands. Apparently, for this trophic interaction the diversity of the herb layer plays a greater role than tree layer diversity. Again, the biodiversity effect was species-specific, with seed removal rates in P. elatior only very weakly increasing with herb diversity. In contrast to P. elatior, rodents contributed to seed removal in L. vernus at about the same rate as invertebrates. The greater variety of available food sources as well as the higher plant cover on plots with a diverse herb layer might enhance rodent abundances and thus increase seed predation rates. Indeed, numerous studies show a positive effect of vegetation cover on rodent seed predation (Mittelbach \& Gross 1984; Manson \& Stiles 1998; Kollmann \& Buschor 2003).

Our seed removal experiment using selectively accessible seed depots showed that invertebrates were the main seed predators of P. elatior, whereas for L. vernus, vertebrates and invertebrates removed approximately the same amount of seeds. It is possible that vertebrates preferred seeds of $L$. vernus due to their greater size (seed mass tenfold higher 
than in P. elatior). Indeed, seed size has been suggested to influence the preference of rodent seed predators (Hulme 1994).

Invertebrate seed removal was approximately five times higher in P. elatior than in L. vernus and accounted for most of the total seed predation in P. elatior. This differing attractiveness of seeds to invertebrates might be explained by differences in nutritional value or by the smaller seed size of $P$. elatior, which could allow easier handling for invertebrates (Honek et al. 2007). Also, small seeds are more likely to adhere to the sticky skin of slugs, possibly increasing passive seed removal. Slugs appeared to be the most important invertebrate seed predators as indicated by the presence of mucous trails as well as frequent direct observations of slugs inside seed depots. Indeed, Türke et al. (2010) found that slugs contributed most to seed removal of forest herbs in our study area, while insects and rodents played a smaller role. Seed predation by slugs has been reported both from agricultural and forest systems, although their impact is probably still underestimated (Kollmann \& Bassin 2001; Türke et al. 2010). Although seed removal in experiments is often seen as a proxy for seed predation, the ultimate fate of the seeds is not known, so it is possible that the apparent seed predation actually constitutes seed dispersal. Rodents frequently move seeds to different locations and store them for later consumption. However, germination success of cached seeds is generally low (Hulme 1998), and feeding traces at seed depots indicated that at least some seeds had been consumed on the spot. For slugs it has been shown that they consume seeds as a whole. After gut passage, seeds are still able to germinate, but are less attractive to rodents, thus passage through the slug gut may even reduce the risk of rodent seed predation (Türke et al. 2010). In addition, seeds which adhere to the slugs' sticky skin may be removed from seed depots without predation occurring.

\section{Conclusions}

We have shown that several trophic interactions in the herb layer of a temperate deciduous forest are modified by plant diversity. Via these effects on plant-invertebrate interactions, vegetation diversity influences the performance of individual herb layer plants and may ultimately affect plant population dynamics. However, the net outcome in terms of plant fitness may be neutral if a higher seed production in diverse forest stands is offset by an increased loss of seeds to seed predators.

The presence of these biodiversity effects appears to be species-dependent. Also, while the trophic interactions herbivory and pollination were related tree layer diversity, herb layer 
diversity was more relevant for seed predation rates. Overall, we found evidence that producer diversity plays a role for ecosystem processes such as herbivory, pollination and seed predation in the understorey of a complex, near-natural forest, a system that has so far received little attention in biodiversity - ecosystem functioning research. Future research monitoring herb layer plant populations over several seasons is needed to determine if observed changes in plant performance will affect long-term plant population dynamics.

\section{Acknowledgements}

This study was funded by the German Research Foundation within the framework of the Research Training Group 'Graduiertenkolleg 1086: The role of biodiversity for biogeochemical cycles and biotic interactions in temperate deciduous forest'. We thank

Tobias Wommelsdorf for providing data on tree layer composition and Emma Dyson and Jasmin Seven for field and laboratory assistance.

\section{References}

Albrecht, M., Duelli, P., Muller, C., Kleijn, D. \& Schmid, B. (2007) The Swiss agrienvironment scheme enhances pollinator diversity and plant reproductive success in nearby intensively managed farmland. Journal of Applied Ecology, 44, 813-822.

Barbier, S., Gosselin, F. \& Balandier, P. (2008) Influence of tree species on understory vegetation diversity and mechanisms involved - A critical review for temperate and boreal forests. Forest Ecology and Management, 254, 1-15.

Belovsky, G.E., Botkin, D.B., Crowl, T.A., Cummins, K.W., Franklin, J.F., Hunter, M.L., Joern, A., Lindenmayer, D.B., MacMahon, J.A., Margules, C.R. \& Scott, J.M. (2004) Ten suggestions to strengthen the science of ecology. Bioscience, 54, 345-351.

Bezemer, T.M. \& van Dam, N.M. (2005) Linking aboveground and belowground interactions via induced plant defenses. Trends in Ecology \& Evolution, 20, 617-624.

Burnham, K.P. \& Anderson, D.R. (2002) Model selection and multimodel inference: $a$ practical information-theoretic approach, 2nd ed edn. Springer, New York, US.

Cardinale, B.J., Matulich, K.L., Hooper, D.U., Byrnes, J.E., Duffy, E., Gamfeldt, L., Balvanera, P., O'Connor, M.I. \& Gonzalez, A. (2011) The functional role of producer diversity in ecosystems. American Journal of Botany, 98, 572-592. 
Crawley, M. (1997) Plant - Herbivore Dynamics. Plant Ecology (ed. M. Crawley), pp. 401474. Blackwell Science, Oxford.

Ebeling, A., Klein, A.M., Schumacher, J., Weisser, W.W. \& Tscharntke, T. (2008) How does plant richness affect pollinator richness and temporal stability of flower visits? Oikos, 117, $1808-1815$.

Ehrlen, J. (1992) Proximate limits to seed production in a herbaceous perennial legume, Lathyrus vernus. Ecology, 73, 1820-1831.

Ehrlen, J. (1995) Demography of the perennial herb Lathyrus vernus .1. Herbivory and individual performance. Journal of Ecology, 83, 287-295.

Ehrlen, J. (2002) Assessing the lifetime consequences of plant-animal interactions for the perennial herb Lathyrus vernus (Fabaceae). Perspectives in Plant Ecology Evolution and Systematics, 5, 145-163.

Garcia, M.B. \& Ehrlen, J. (2002) Reproductive effort and herbivory timing in a perennial herb: Fitness components at the individual and population levels. American Journal of Botany, 89, 1295-1302.

Ghazoul, J. (2006) Floral diversity and the facilitation of pollination. Journal of Ecology, 94, 295-304.

Gilliam, F.S. (2007) The ecological significance of the herbaceous layer in temperate forest ecosystems. Bioscience, 57, 845-858.

Haddad, N.M., Crutsinger, G.M., Gross, K., Haarstad, J., Knops, J.M.H. \& Tilman, D. (2009) Plant species loss decreases arthropod diversity and shifts trophic structure. Ecology Letters, 12, 1029-1039.

Hawkins, J.W., Lankester, M.W. \& Nelson, R.R.A. (1998) Sampling terrestrial gastropods using cardboard sheets. Malacologia, 39, 1-9.

Hegland, S.J. \& Boeke, L. (2006) Relationships between the density and diversity of floral resources and flower visitor activity in a temperate grassland community. Ecological Entomology, 31, 532-538.

Honek, A., Martinkova, Z., Saska, P. \& Pekar, S. (2007) Size and taxonomic constraints determine the seed preferences of Carabidae (Coleoptera). Basic and Applied Ecology, 8, 343-353.

Hothorn, T., Bretz, F. \& Westfall, P. (2008) Simultaneous inference in general parametric models. Biometrical Journal, 50, 346-363.

Hulme, P. (1998) Post-dispersal seed predation: consequences for plant demography and evolution. Perspectives in Plant Ecology, Evolution and Systematics, 1, 32-46. 
Hulme, P.E. (1994) Post-dispersal seed predation in grassland: its magnitude and sources of variation. Journal of Ecology, 82, 645-652.

Hulme, P.E. \& Benkman, C.W. (2002) Granivory. Plant Animal Interactions: An Evolutionary Approach (eds C.M. Herrera \& O. Pellmyr), pp. 132-156. Blackwell Science, Oxford.

Jactel, H. \& Brockerhoff, E.G. (2007) Tree diversity reduces herbivory by forest insects. Ecology Letters, 10, 835-848.

Johnston, M., Olivares, A. \& Bustos, Y. (2011) Vegetative growth of two mulberry species (Morus multicaulis and M. alba) under greenhouse and field conditions. Ciencia E Investigacion Agraria, 38, 41-51.

Kabouw, P., Kos, M., Kleine, S., Vockenhuber, E.A., van Loon, J.J.A., van der Putten, W.H., van Dam, N.M. \& Biere, A. (2011) Effects of soil organisms on aboveground multitrophic interactions are consistent between plant genotypes mediating the interaction. Entomologia Experimentalis et Applicata, 139, 197-206.

Kaplan, I., Sardanelli, S. \& Denno, R.F. (2009) Field evidence for indirect interactions between foliar-feeding insect and root-feeding nematode communities on Nicotiana tabacum. Ecological Entomology, 34, 262-270.

Kollmann, J. \& Bassin, S. (2001) Effects of management on seed predation in wildflower strips in northern Switzerland. Agriculture Ecosystems \& Environment, 83, 285-296.

Kollmann, J. \& Buschor, M. (2003) Edges effects on seed predation by rodents in deciduous forests of northern Switzerland. Plant Ecology, 164, 249-261.

Leuschner, C., Jungkunst, H.F. \& Fleck, S. (2009) Functional role of forest diversity: Pros and cons of synthetic stands and across-site comparisons in established forests. Basic and Applied Ecology, 10, 1-9.

Manson, R.H. \& Stiles, E.W. (1998) Links between microhabitat preferences and seed predation by small mammals in old fields. Oikos, 82, 37-50.

Masters, G.J. \& Brown, V.K. (1997) Host-plant mediated interactions between spatially separated herbivores: effects on community structure. Multitrophic interactions in terrestrial systems (eds A. Gange \& V. Brown), pp. 217-237. Blackwell, Oxford.

Mittelbach, G.G. \& Gross, K.L. (1984) Experimental studies of seed predation in old-fields. Oecologia, 65, 7-13.

Mothershead, K. \& Marquis, R.J. (2000) Fitness impacts of herbivory through indirect effects on plant-pollinator interactions in Oenothera macrocarpa. Ecology, 81, 30-40. 
Mulder, C.P.H., Koricheva, J., Huss-Danell, K., Hogberg, P. \& Joshi, J. (1999) Insects affect relationships between plant species richness and ecosystem processes. Ecology Letters, 2, 237-246.

Nadrowski, K., Wirth, C. \& Scherer-Lorenzen, M. (2010) Is forest diversity driving ecosystem function and service? Current Opinion in Environmental Sustainability, 2, 75-79.

Nystrand, O. \& Granstrom, A. (2000) Predation on Pinus sylvestris seeds and juvenile seedlings in Swedish boreal forest in relation to stand disturbance by logging. Journal of Applied Ecology, 37, 449-463.

Ostergard, H. \& Ehrlen, J. (2005) Among population variation in specialist and generalist seed predation - the importance of host plant distribution, alternative hosts and environmental variation. Oikos, 111, 39-46.

Pigot, A.L. \& Leather, S.R. (2008) Invertebrate predators drive distance-dependent patterns of seedling mortality in a temperate tree Acer pseudoplatanus. Oikos, 117, 521-530.

Pinheiro, J.C. \& Bates, D.M. (2000) Mixed-effects models in S and S-PLUS. Springer, New York, US.

Prieur-Richard, A.H., Lavorel, S., Linhart, Y.B. \& Dos Santos, A. (2002) Plant diversity, herbivory and resistance of a plant community to invasion in Mediterranean annual communities. Oecologia, 130, 96-104.

R Development Core Team (2009) R: a language and environment for statistical computing. R Foundation for Statistical Computing, Vienna, Austria, http://www.R-project.org

Rasband, W. (1997-2005) ImageJ, U. S. National Institutes of Health, Bethesda, Maryland, USA, http://rsb.info.nih.gov/ij/, 1997-2005.

Root, R.B. (1973) Organization of a plant-arthropod association in simple and diverse habitats - fauna of collards (Brassica oleracea). Ecological Monographs, 43, 95-120.

Rumbaugh, M.D. \& Griffin, G.D. (1992) Resistance of Lathyrus species and accessions to the northern root-knot nematode, Meloidogyne hapla. Journal of Nematology, 24, 729734.

Russell, E.P. (1989) Enemies hypothesis - a review of the effect of vegetational diversity on predatory insects and parasitoids. Environmental Entomology, 18, 590-599.

Scherber, C., Eisenhauer, N., Weisser, W.W., Schmid, B., Voigt, W., Fischer, M., Schulze, E.D., Roscher, C., Weigelt, A., Allan, E., Bessler, H., Bonkowski, M., Buchmann, N., Buscot, F., Clement, L.W., Ebeling, A., Engels, C., Halle, S., Kertscher, I., Klein, A.M., Koller, R., Konig, S., Kowalski, E., Kummer, V., Kuu, A., Lange, M., 
Lauterbach, D., Middelhoff, C., Migunova, V.D., Milcu, A., Muller, R., Partsch, S., Petermann, J.S., Renker, C., Rottstock, T., Sabais, A., Scheu, S., Schumacher, J., Temperton, V.M. \& Tscharntke, T. (2010) Bottom-up effects of plant diversity on multitrophic interactions in a biodiversity experiment. Nature, 468, 553-556.

Scherber, C., Milcu, A., Partsch, S., Scheu, S. \& Weisser, W.W. (2006) The effects of plant diversity and insect herbivory on performance of individual plant species in experimental grassland. Journal of Ecology, 94, 922-931.

Schuldt, A., Baruffol, M., Bohnke, M., Bruelheide, H., Hardtle, W., Lang, A.C., Nadrowski, K., von Oheimb, G., Voigt, W., Zhou, H.Z. \& Assmann, T. (2010) Tree diversity promotes insect herbivory in subtropical forests of south-east China. Journal of Ecology, 98, 917-926.

Sikora, R., Greco, N. \& Silva, J. (2005) Nematode parasites of food legumes. Plant Parasitic Nematodes in Subtropical and Tropical Agriculture (eds M. Luc, R. Sikora \& J. Bridge), pp. 259-318. CAB International, Wallingford.

Sobek, S., Scherber, C., Steffan-Dewenter, I. \& Tscharntke, T. (2009) Sapling herbivory, invertebrate herbivores and predators across a natural tree diversity gradient in Germany's largest connected deciduous forest. Oecologia, 160, 279-288.

Stevens, R.D. \& Tello, J.S. (2011) Diversity begets diversity: relative roles of structural and resource heterogeneity in determining rodent community structure. Journal of Mammalogy, 92, 387-395.

Taboada, A., Tarrega, R., Calvo, L., Marcos, E., Marcos, J.A. \& Salgado, J.M. (2010) Plant and carabid beetle species diversity in relation to forest type and structural heterogeneity. European Journal of Forest Research, 129, 31-45.

Taylor, K. \& Woodell, S.R.J. (2008) Biological Flora of the British Isles: Primula elatior (L.) Hill. Journal of Ecology, 96, 1098-1116.

Türke, M., Heinze, E., Andreas, K., Svendsen, S.M., Gossner, M.M. \& Weisser, W.W. (2010) Seed consumption and dispersal of ant-dispersed plants by slugs. Oecologia, 163, 681693.

Unsicker, S.B., Baer, N., Kahmen, A., Wagner, M., Buchmann, N. \& Weisser, W.W. (2006) Invertebrate herbivory along a gradient of plant species diversity in extensively managed grasslands. Oecologia, 150, 233-246.

Unsicker, S.B., Oswald, A., Kohler, G. \& Weisser, W.W. (2008) Complementarity effects through dietary mixing enhance the performance of a generalist insect herbivore. Oecologia, 156, 313-324. 
Vandegehuchte, M.L., de la Pena, E. \& Bonte, D. (2010) Interactions between root and shoot herbivores of Ammophila arenaria in the laboratory do not translate into correlated abundances in the field. Oikos, 119, 1011-1019.

Vehvilainen, H., Koricheva, J. \& Ruohomaki, K. (2007) Tree species diversity influences herbivore abundance and damage: meta-analysis of long-term forest experiments. Oecologia, 152, 287-298.

Venables, W. \& Ripley, B. (2002) Modern applied statistics with S. Springer, New York.

Vockenhuber, E., Scherber, C., Langenbruch, C., Meißner, M., Seidel, D. \& Tscharntke, T. (2011) Tree diversity and environmental context predict herb species richness and cover in Germany's largest connected deciduous forest. Perspectives in Plant Ecology Evolution and Systematics, 13, 111-119.

von Oheimb, G. \& Brunet, J. (2007) Dalby Söderskog revisited: long-term vegetation changes in a south Swedish deciduous forest. Acta Oecologica-International Journal of Ecology, 31, 229-242.

Whigham, D.E. (2004) Ecology of woodland herbs in temperate deciduous forests. Annual Review of Ecology Evolution and Systematics, 35, 583-621. 


\section{Appendix}

\section{Appendix S1.}

The two study locations, Thiemsburg and Lindig (a). Plots are shown as filled blue dots on the detailed map of the (b) Thiemsburg and (c) Lindig location.

(a)

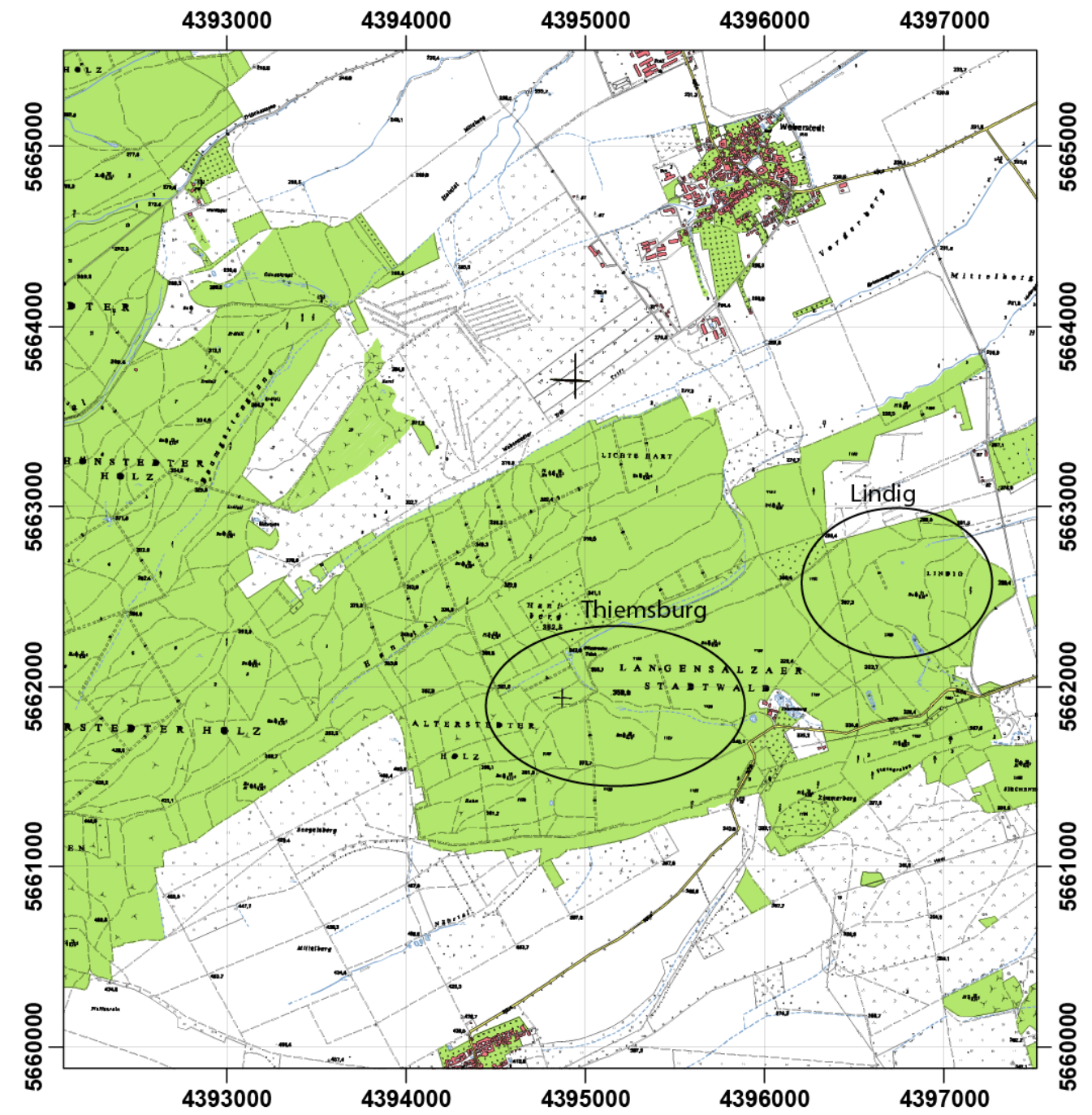


(b) Thiemsburg

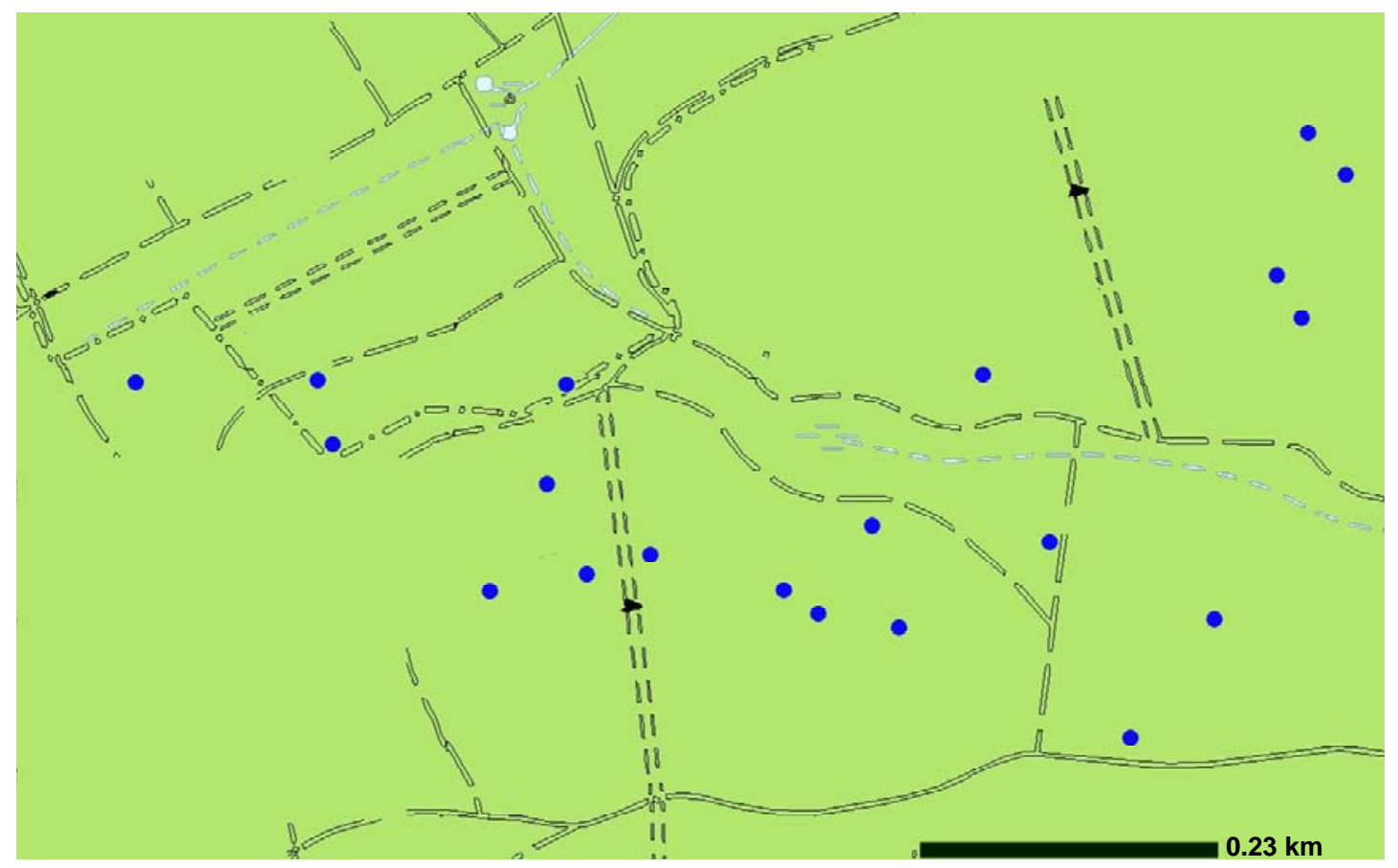

(c) Lindig

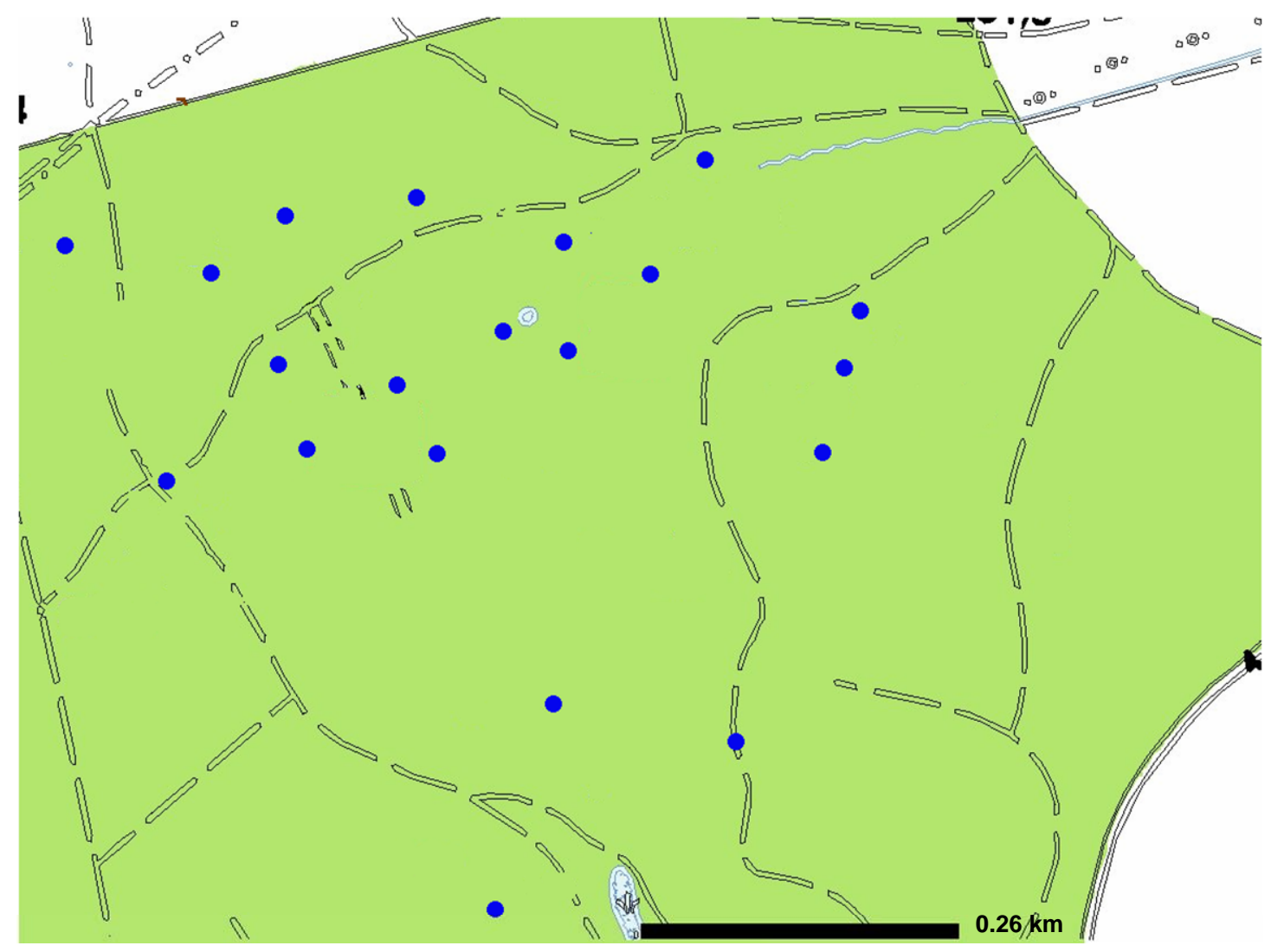



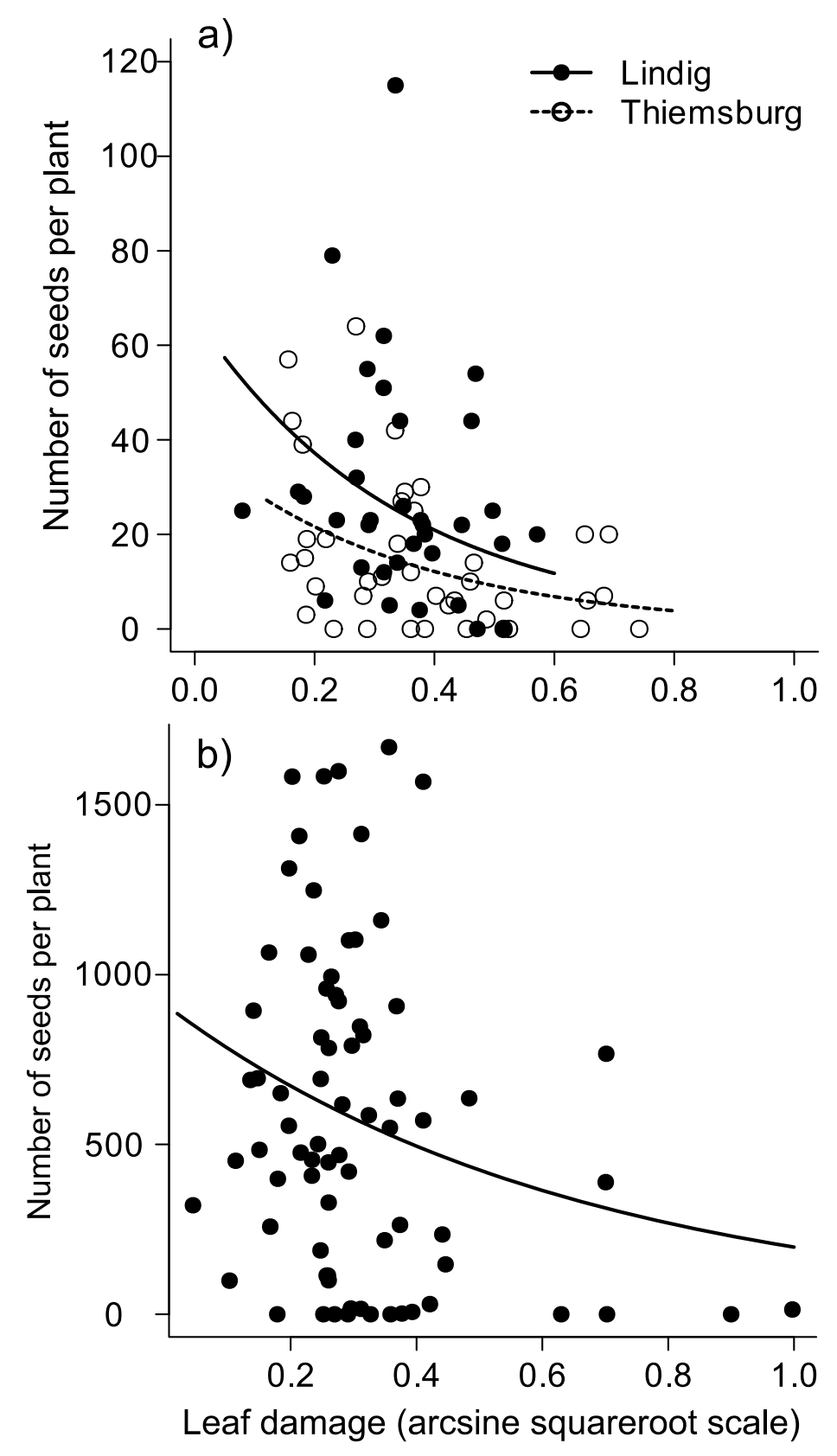

Figure S1. Relationship between percentage of invertebrate leaf damage at harvest (arcsine squareroot scale) and the number of seeds produced per plant for the phytometer species (a) Lathyrus vernus and (b) Primula elatior. $\mathrm{N}=75$. Curves are based on parameters from fitted minimal adequate mixed-effect models (Table 1). In (a), the study locations Lindig and Thiemsburg are shown separately because the factor "location" remained in the minimal adequate model. 


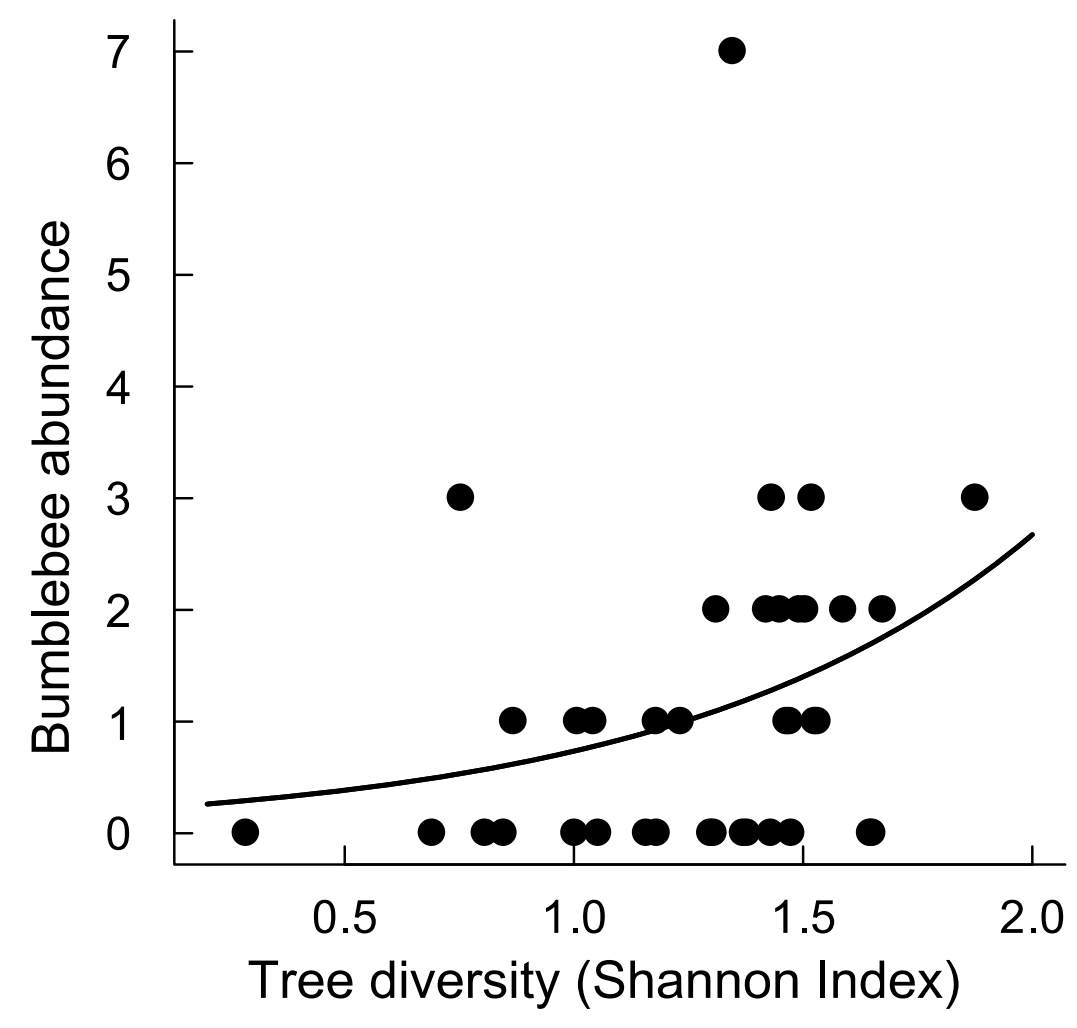

Figure S2. Relationship between tree diversity (Shannon-Wiener diversity index) of forest plots and the abundance of bumblebees (nr. of individuals). Pan trap samples were collected in May and July 2008 in the Hainich National Park. $N=37$. The curve is based on parameters from a fitted negative binomial generalized linear model. 


\section{CHAPTER 5}

Synopsis

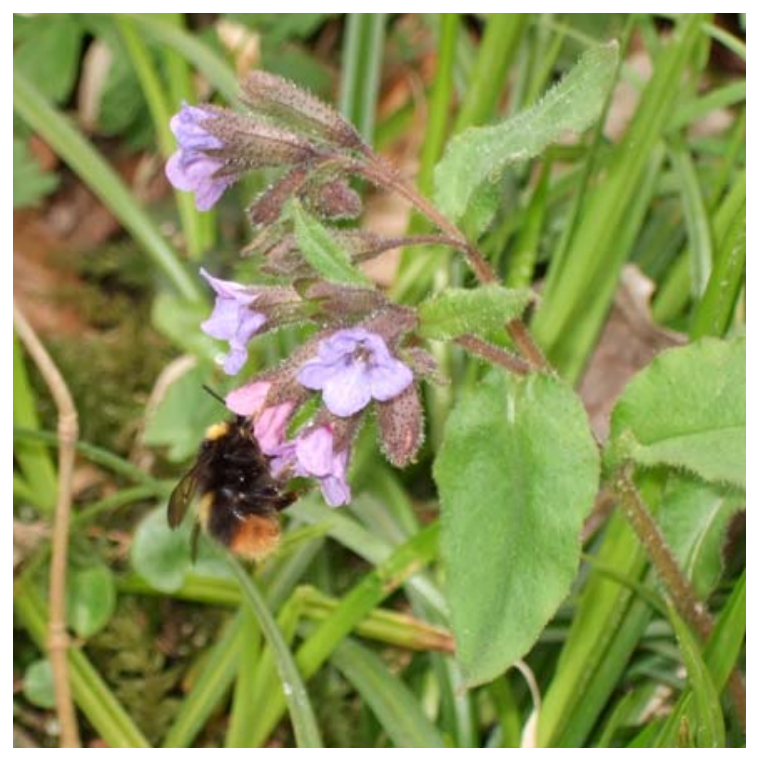




\section{Synopsis}

In this thesis, we showed that tree and herb diversity in a temperate deciduous forest play a role for forest herb communities as well as for flies living in the herb layer. In addition, we demonstrated that several trophic interactions, namely herbivory, pollination-dependent seed production and seed predation, are related to tree or herb layer diversity, although these effects differed between study plant species. The associations between plant diversity and measured variables were generally weak; therefore their importance for the functioning of the herb layer system should be cautiously interpreted as statistical significance does not necessarily translate to biological significance. Nevertheless, based on our data we can say that in the herb layer of a near-natural forest, linkages do exist between plant diversity and ecosystem functions as well as communities of higher trophic level organisms. Very little information is available so far on biodiversity - ecosystem functioning relationships in this lowest forest stratum, despite the high ecological significance of the herb layer (Gilliam 2007). In general, forests have so far received less attention in biodiversity- ecosystem functioning studies than simpler ecosystems such as grasslands or agricultural systems. Thus it is intriguing to find evidence for plant diversity effects in this highly complex system that the forest stands of the Hainich National Park provide, in spite of the great variety of other environmental factors simultaneously acting on herb layer communities.

Indeed, in an observational study such as ours, it is not possible to infer strong causality since apparent associations with plant diversity could actually be caused by a common response to a third, unknown factor. However, we tried to minimise effects of "hidden treatments" by

carefully selecting our study plots within an area with relatively comparable edaphic and climatic conditions (Leuschner et al. 2009). Moreover, we believe that observational studies in established forests are crucial for understanding tree and herb diversity effects because they provide representative conditions of (near) natural, old-growth forest ecosystems. By studying experimental tree plantations, collinearity between tree species diversity and other variables can be reduced, but these artificial stands cannot provide the complexity of environmental conditions and processes occurring in old-growth forests. Therefore, a combination of experimental and observational studies is recommended to elucidate plant diversity effects in forests (Leuschner et al. 2009).

Our study on fly community characteristics in the herb layer showed that plant diversity can also modify the abundance of taxa that do not encompass many herbivores. It was striking though that plant diversity effects were context-dependent and did not allow a clear 
interpretation, while effects of plant cover were much more pronounced and consistent between locations and fly taxa. Vegetation cover is most likely connected to a higher plant biomass, which has been shown to increase insect abundances and diversity (Haddad et al. 2001). In addition, a higher vegetation cover is probably associated with a greater structural complexity of the habitat, which leads to a greater availability of sites that insects can use for sheltering, reproduction and over-wintering, thus benefiting insect communities (Lawton 1983). It would be interesting to investigate in future studies which aspects of the herb layer vegetation are most relevant for insect communities, for instance by harvesting above-ground biomass, measuring structural complexity of the vegetation or looking at identity effects of certain plant species in more detail.

An interesting aspect that came out of our study on linkages between herb and tree diversity is that herb diversity is positively influenced by the distance to the forest edge. This finding is highly relevant as forests in Central Europe suffer from high levels of fragmentation (Harper et al. 2005). As our study was designed to assess tree diversity effects rather than edge effects, plots are not located at regular distances from the forest edge, which makes an evaluation of edge effects more difficult. Future studies in the Hainich National Park that are designed to investigate changes in herb layer and insect community characteristics with increasing distance to the forest edge would be very promising, especially if edge effects in forest stands with high and low tree diversity are compared. In this manner one could test the hypothesis that negative edge effects are dampened in diverse tree stands.

Another worthwhile opportunity for future research could be to study plant diversity effects on multitrophic interactions involving forest herbs over a period of several years. This would show if effects of herbivory and pollination on current plant performance (e.g. seed production) affect future plant reproduction and plant community dynamics. For instance, a reduction in seed production may not lead to reduced plant fitness if seedling recruitment is microsite limited rather than seed limited (Crawley 1997). A good example of extensive studies on the whole life cycle of a forest herb (Lathyrus vernus) is provided by Ehrlen et al. (2002), who showed for instance that the life stage in which a plant experiences herbivory strongly affects future impacts on growth and reproduction. Similar studies that also incorporate the diversity of the surrounding plant community are needed to test if biodiversity-mediated changes in plant-animal interactions affecting plant performance matter for plant community dynamics in the longer term.

In conclusion, tree and herb diversity in a near-natural, deciduous forest are linked, and both are related to community characteristics of flies as well as trophic interactions in the herb 
layer. Therefore, the maintenance of a diverse canopy and understory in the course of forest management can help to conserve the diversity and functioning of plant and insect communities in the herb layer.

\section{References}

Crawley M (1997) Plant Ecology, 2nd edn. Blackwell Science, Oxford

Ehrlen J (2002) Assessing the lifetime consequences of plant-animal interactions for the perennial herb Lathyrus vernus (Fabaceae). Perspectives in Plant Ecology Evolution and Systematics 5:145-163

Gilliam FS (2007) The ecological significance of the herbaceous layer in temperate forest ecosystems. Bioscience 57:845-858

Haddad NM, Tilman D, Haarstad J, Ritchie M, Knops JMH (2001) Contrasting effects of plant richness and composition on insect communities: A field experiment. American Naturalist 158:17-35

Harper KA et al. (2005) Edge influence on forest structure and composition in fragmented landscapes. Conservation Biology 19:768-782

Lawton JH (1983) Plant Architecture and the Diversity of Phytophagous Insects. Annual Review of Entomology 28:23-39

Leuschner C, Jungkunst HF, Fleck S (2009) Functional role of forest diversity: Pros and cons of synthetic stands and across-site comparisons in established forests. Basic and Applied Ecology 10:1-9 


\section{SUMMARY}

The human-induced loss of biodiversity from many ecosystems has led to increased interest in the relationship between biodiversity and ecosystem functioning. Research in this field is mostly focused on the producer level, i.e. the diversity of plants. Plant diversity can positively affect the diversity and abundance of higher trophic level organisms, for example insects. In addition, it has been shown that plant diversity can impact plant-insect interactions such as pollination and herbivory. Most studies on plant diversity effects have been conducted in grasslands, whereas forest ecosystems have received less attention so far. In particular, herbaceous plant communities of the forest understorey and their associated insect communities have rarely been the focus of biodiversity studies.

In this thesis we investigated plant diversity effects in the herb layer of a near-natural temperate deciduous forest. We explored possible linkages between the plant diversity of the tree and the herb layer. In addition, we investigated how the diversity of tree and herb layer influence diversity, abundance and community composition of fly communities in the herb layer. Finally, we studied trophic interactions (herbivory, pollination-dependent seed production, seed predation) in relation to tree and herb diversity.

The study was conducted on 100 plots along a gradient of tree diversity (2-9 species) and herb diversity (2-28 species) in the Hainich National Park (Central Germany). Vegetation surveys of the herb layer were performed in two consecutive years. Flies were sampled with pan traps and suction sampling. To study trophic interactions, potted individuals of the common understorey herbs Lathyrus vernus and Primula elatior were set out on 40 plots for three months in 2009. On these "phytometer" plants, we assessed invertebrate herbivore damage as well as seed production as a proxy for pollination success. Half of the L. vernus individuals had been treated with plant parasitic nematodes to investigate if links between belowground and aboveground herbivory are affected by the diversity of the surrounding plant community. Also in 2009, we performed a seed removal experiment using different predator exclusion treatments to study seed predation in the herb layer.

Species richness and cover of the herb layer increased with increasing tree diversity. In addition, the environmental variables canopy cover and humus layer mass had a negative effect both on herb layer species richness and cover. Herb layer species richness was positively related to increasing soil $\mathrm{pH}$ and the distance to the forest edge. The proportion of forbs increased with increasing tree diversity, whereas the proportion of tree saplings decreased. The proportion of graminoids was not affected. 
Both tree and herb diversity influenced fly abundance, while abundances of the locally common fly taxa Empidoidea and Phoridae responded to herb diversity only. Relationships between fly abundance and tree and herb diversity were positive in the study location dominated by lime (Lindig), but absent or weakly negative in the beech-dominated location (Thiemsburg). Fly family richness and the species richness of Empidoidea and Phoridae were not affected by tree or herb diversity. In contrast, herb cover showed a strong and consistently positive association both with fly richness and abundance. Plots which were similar in their herb and tree layer composition also had more similar fly communities.

In our phytometer experiment, foliar herbivore damage decreased with increasing tree diversity in P. elatior. In L. vernus, foliar herbivore damage only responded to belowground herbivory, with higher aboveground herbivory in nematode treated plants. Seed production per plant increased with increasing tree diversity in $L$. vernus and decreased with increasing herbivore damage in both species.

The seed predation experiment showed that the seed removal rate was positively related to herb diversity for seeds of L. vernus, but only weakly so in the case of $P$. elatior. Predator exclusion treatments revealed that both vertebrates and invertebrates act as seed predators of L. vernus, while seed removal of $P$. elatior is mainly performed by invertebrates. Slugs appeared to be the dominant invertebrate seed predators in our study system.

In conclusion, we found that the diversity of tree and herb layer affects plant and fly communities in the herb layer of Germany's largest connected deciduous forest. In addition, we demonstrated that several types of trophic interactions, namely herbivory, pollinationdependent seed production and seed predation, are related to tree or herb layer diversity. As a consequence, overall forest biodiversity and the functioning of trophic interactions are expected to benefit from forestry practises that promote high tree diversity, which goes along with a diverse and well-developed herb layer. 


\section{ZUSAMMENFASSUNG}

Der zunehmende Verlust an biologischer Vielfalt in vielen Ökosystemen hat in den vergangenen Jahrzehnten zu einer verstärkten Beschäftigung mit den Zusammenhängen zwischen Biodiversität und dem Funktionieren von Ökosystemen geführt. Die Forschung in diesem Gebiet konzentriert sich dabei vor allem auf die Ebene der Primärproduzenten, d.h. die Vielfalt an Pflanzen. Oft steht Pflanzendiversität in einem positiven Zusammenhang mit der Diversität und Abundanz von Organismen aus höheren trophischen Ebenen, zum Beispiel Insekten. Außerdem hat sich gezeigt, dass sich Pflanzendiversität auf Pflanze-InsektInteraktionen wie Bestäubung und Herbivorie auswirken kann. Die meisten Studien zu Effekten von Pflanzendiversität wurden im Grünland durchgeführt, während Waldökosysteme bisher nur selten berücksichtigt wurden. Insbesondere die Pflanzengemeinschaften der Krautschicht in Wäldern und die dort lebenden Insekten standen selten im Mittelpunkt der Biodiversitätsforschung.

In der vorliegenden Arbeit beschäftigten wir uns mit den Effekten von Pflanzenvielfalt in einem naturnahen gemäßigten Laubwald. Zuerst untersuchten wir mögliche Zusammenhänge zwischen der Diversität von Baum- und Krautschicht. Darüber hinaus beschäftigen wir uns mit der Frage, ob sich Baum- und Krautartendiversität auf die Diversität, Abundanz und Artenzusammensetzung von Fliegengemeinschaften in der Krautschicht auswirken. Schließlich untersuchten wir trophische Interaktionen (Herbivorie, bestäubungsabhängige Samenproduktion, Samenprädation) bei unterschiedlichen Levels von Baum- und Krautartendiversität.

Für diese Studie wurden 100 Untersuchungsflächen entlang eines Gradienten an Baumartenvielfalt (2-9 Arten) und Krautartenvielfalt (2-28 Arten) im Hainich Nationalpark (Thüringen, Deutschland) herangezogen. Vegetationsaufnahmen der Krautschicht wurden in zwei aufeinanderfolgenden Jahren durchgeführt. Fliegen wurden mit Hilfe von Farbschalen und Saugproben gefangen. Zur Untersuchung von trophischen Interaktionen wurden auf 40 Untersuchungsflächen getopfte Individuen der häufigen Krautschichtarten Lathyrus vernus (Frühlingsplatterbse) und Primula elatior (Hohe Schlüsselblume) ausgebracht und drei Monate lang im Wald belassen. An diesen „Phytometer“-Pflanzen konnten wir die von Insekten und Schnecken verursachte Herbivorie sowie die Samenproduktion als Maß für den Bestäubungserfolg messen. Die Hälfte aller L. vernus Pflanzen war vor Beginn des Experiments mit pflanzenparasitären Nematoden behandelt worden, um zu untersuchen, ob die Beziehung zwischen unterirdischer und oberirdischer Herbivorie von der Diversität der 
umgebenden Pflanzengemeinschaft abhängt. In einem weiteren Experiment erforschten wir das Ausmaß an Samenprädation an Samen von L. vernus und P. elatior und identifizierten anhand von selektiven Ausschlusskäfigen die wichtigsten Gruppen von Samenprädatoren.

Artenreichtum und Deckung der Krautschicht nahmen mit steigender Baumdiversität zu. Zusätzlich hatten der Deckungsgrad der Krone und die Masse der Humusschicht einen negativen Effekt auf Artenreichtum und Deckung der Krautschicht. Der pH-Wert des Bodens sowie die Entfernung zum Waldrand wirkten sich positiv auf den Artenreichtum der Krautschicht aus. Der Anteil an krautigen Pflanzen nahm mit zunehmender Baumdiversität zu, während der Anteil an Jungbäumen sank. Der Anteil an Gräsern war nicht von der Baumdiversität abhängig.

Sowohl Baum- als auch Krautschichtdiversität beeinflussten die Gesamtabundanz an Fliegen, während die Abundanzen der im Untersuchungsgebiet häufigen Fliegentaxa Empidoidea und Phoridae nur auf die Diversität der Krautschicht reagierten. Der Zusammenhang zwischen Fliegenabundanz und Baum- und Krautschichtdiversität war in dem von Linden dominierten Teilgebiet (Lindig) positiv, während es im stärker buchendominierten Teilgebiet (Thiemsburg) keinen oder einen schwach negativen Zusammenhang gab. Die Anzahl an Fliegenfamilien und der Artenreichtum von Empidoidea und Phoridae wurden nicht von Baum- oder Krautschichtdiversität beeinflusst. Im Gegensatz dazu zeigte die Krautdeckung eine starke und durchwegs positive Assoziation mit der Fliegenvielfalt und -abundanz. Untersuchungsflächen, die sich in ihrer Baum- und Krautartenzusammensetzung ähnlich waren, wiesen auch ähnliche Fliegengemeinschaften auf.

In unserem Phytometer Experiment nahm der Blattfraß an $P$. elatior mit steigender Baumdiversität ab. Das Ausmaß an Blattfraß an L. vernus wurde nur durch das Vorhandensein von unterirdischen Herbivoren beeinflusst: Die Pflanzen, die mit pflanzenparasitären Nematoden behandelt worden waren, verloren mehr oberirdische Blattfläche an Herbivore. Die Gesamtsamenzahl pro Pflanze reagierte bei L. vernus positiv auf steigende Baumdiversität und nahm bei beiden Pflanzenarten mit steigendem Herbivoriegrad ab.

Im Rahmen des Samenprädationsexperiments zeigte sich, dass die Samenprädationsrate bei $L$. vernus mit steigender Krautschichtdiversität deutlich zunahm, während der Effekt bei $P$. elatior nur schwach ausgeprägt war. Sowohl Vertebraten als auch Invertebraten entfernten Samen von L. vernus, während vor allem Invertebraten für die Samenprädation an Samen von P. elatior verantwortlich waren. Nacktschnecken erwiesen sich als wichtige Samenprädatoren in unserem Untersuchungsgebiet. 
Zusammenfassend konnten wir zeigen, dass die Diversität von Baum- und Krautschicht in Deutschlands größtem zusammenhängendem Laubwaldgebiet die Pflanzen- und Fliegengemeinschaften der Krautschicht beeinflusst. Darüber hinaus hat sich herausgestellt, dass verschiedene Typen von trophischen Interaktionen, nämlich Herbivorie, bestäubungsabhängige Samenproduktion und Samenprädation, mit der Baum- und Krautschichtdiversität in Verbindung stehen. In Folge dessen ist zu erwarten, dass Formen der Waldnutzung, die eine hohe Baumdiversität und damit verbunden eine diverse und gut ausgeprägte Krautschicht fördern, der gesamten biologischen Vielfalt im Wald sowie dem ungestörten Ablaufen von trophischen Interaktionen zugute kommen. 


\section{ACKNOWLEDGEMENTS}

Above all I owe special thanks to my supervisors Prof. Dr. Teja Tscharntke and Dr. Christoph Scherber. Thank you for enabling me to work on this great project, for providing many valuable ideas and insights during our scientific discussions, and for always being such positive and supportive supervisors! I am also very grateful to Prof. Dr. Stefan Vidal and Prof. Dr. Stefan Scheu for being part of my thesis and defence committee. Furthermore, I kindly thank Dr. Dirk Gansert for organizing the PhD program "Biological Diversity and Ecology" in which I took part.

Financial support was kindly provided by the DFG (German Research Foundation) within the framework of the Research Training Group 1086. I highly acknowledge Dr. Stefan Fleck, Dr. Mascha Jacob, Dr. Tobias Gebauer and Dr. Michael Köhler for coordinating this research training group and Prof. Dr. Christoph Leuschner and Prof. Dr. Rainer Marggraf for functioning as its Speakers. I am extremely grateful to the members of the Research Training Group 1086 (also known as Grakos, Grakoletten, Grakoiden or Grakoianer) for their help during field work, successful collaborations, countless fun hours in Göttingen, Finland and the Hainich Forest and in general for being great colleagues and friends. I also say thank you to our Finish colleagues from the Finnish-German Graduate School in Forest Ecosystem Studies (ForEco) for allowing us to enjoy such a memorable and pleasant workshop in Finland (the food! The saunas!). Another big ,thank you“ goes to the staff of the Hainich National Park who continuously supported us during our work and who gave permission for this project to take place in this beautiful and very special forest that has recently received the status of a UNESCO Natural World Heritage site.

I thank Mareen Gollnow and Julia Dolezil for their valuable help with sorting and identifying insect samples. Emma Dyson was the best RISE intern I could imagine and I thank her for making field work more fun and manageable and for the admirable task of counting thousands of seeds. I highly acknowledge Dr. Sabine Prescher and Dr. Gisela Weber for identifying great quantities of phorid flies and Dr. Andreas Stark for identifying all my empidoid flies and providing very helpful information about their ecological requirements.

A very big "thank you" goes to the Agroecology Group - you all helped to create a wonderful and welcoming working atmosphere and I will miss you. Particular thanks to Jutta Gilles who was extremely helpful with all administrative matters and always had a friendly word.

Finally, I am extremely thankful to my family for their exceptional support and encouragement and to Patrick for always being there for me! 


\section{CURRICUlum VitaE}

Elke Vockenhuber, born 18.02.1983 in Vienna, Austria

Education:

04/2008 - 08/2011: $\quad \mathrm{PhD}$ thesis "Insect diversity and plant-insect interactions along a tree diversity gradient" Agroecology Group, University of Göttingen, within doctoral thesis programme "Biodiversity and Ecology" Supervised by Prof. Dr. Teja Tscharntke, Dr. Christoph Scherber

03/2007-04/2008: Diploma thesis "Reproductive behaviour and parental care in the glass frog Hyalinobatrachium valerioi" Supervised by Prof. Dr. Walter Hödl Department of Evolutionary Biology, University of Vienna

07/2005 - 12/2005: University of Melbourne, Australia: Exchange semester

10/2002 - 04/2008: $\quad$ Undergraduate studies in ecology, University of Vienna, Austria 09/1993 - 06/2001: $\quad$ Secondary school: Gymnasium BG Perchtoldsdorf

09/1998 - 06/1999: $\quad$ South Medford High School, Medford, Oregon, USA

\section{Volunteer work:}

07/2003:

SCI Volunteer Workcamp in eco-village Solheimar, Iceland

08/2001 - 02/2002: AFS Community Service in Costa Rica: Volunteer work in Parque Nacional Volcán Tenorio 


\section{Publication list}

\section{Journal articles}

Vockenhuber, E.A., Kabouw, P., Tscharntke, T., Scherber, C. (submitted). Herbivory, seed production and seed predation in forest herbs along a tree and herb diversity gradient.

Vockenhuber, E.A., Tscharntke, T., Stark, A., Scherber, C. (in prep.). Richness, abundance, and community composition of flies (Diptera) across a tree and herb diversity gradient.

Vockenhuber, E.A., Scherber, C., Langenbruch, C., Meißner, M., Seidel, D., Tscharntke, T. (2011). Tree diversity and environmental context predict herb species richness and cover in Germany's largest connected deciduous forest. Perspectives in Plant Ecology, Evolution and Systematics 13: 111-119.

Kabouw, P., Kos, M., Kleine, S., Vockenhuber, E.A., van Loon, J.J.A., van der Putten, W.H., van Dam, N.M., Biere, A. (2011). Effects of soil organisms on aboveground multitrophic interactions are consistent between plant genotypes mediating the interaction. Entomologia Experimentalis et Applicata 139: 197-206.

Vockenhuber, E.A., Hödl, W., Amézquita, A. (2009). Glassy fathers do matter: Egg attendance enhances embryonic survivorship in the glass frog Hyalinobatrachium valerioi. Journal of Herpetology 43 (2): 340-344.

\section{Book sections}

Vockenhuber, E.A., Hödl, W., Karpfen, U. (2008).Reproductive behaviour of the glass frog Hyalinobatrachium valerioi (Anura: Centrolenidae) at the tropical stream Quebrada Negra (La Gamba, Costa Rica). Stapfia 88: 335-348.

\section{Conference contributions}

\section{$\underline{\text { Talks }}$}

Vockenhuber, E.A., Tscharntke, T., Scherber, C.: Tree species identity drives responses of Dipteran communities to tree and herb diversity. Netherlands Annual Ecology Meeting, 8.9.2.2011

$\underline{\text { Posters }}$

Vockenhuber, E.A., Tscharntke, T., Scherber, C.: Effects of tree and herb layer diversity on diversity and abundance of flies (Diptera) in Germany's largest cohesive deciduous forest. Student Conference on Conservation Science 2011, Cambridge, 22.-24.3.2011

Vockenhuber, E.A., Scherber, C., Tscharntke, T.: Diversity of Diptera in a deciduous forest: The role of tree and herb diversity. 9th European Congress of Entomology, Budapest, 22.27.8.2010 
Vockenhuber E. A., Kabouw, P., Scherber, C., Tscharntke T.: Effects of plant diversity and belowground herbivory on aboveground herbivory in two forest herbs. Multitrophic Interactions Workshop, Göttingen, 25.-26.3.2010

Vockenhuber, E.A., Scherber, C., Tscharntke, T.: The effect of plant diversity on insect communities in a temperate deciduous forest (poster presentation). $39^{\text {th }}$ Annual Conference of the Ecological Society of Germany, Austria and Switzerland (GFÖ), Bayreuth, 14.-18.9.2009

\section{THESIS DECLARATIONS}

Declaration of the author's own contribution to manuscripts with multiple authors

The chapters 2 to 4 are a series of manuscripts that have or will be submitted to peer-reviewed journals. I am the overall author of all manuscripts presented in this thesis. I have personally collected and analysed the data for all manuscripts, developed the main ideas presented in the manuscripts, written all manuscripts, created tables, figures, and appendices, and contributed significantly to the sampling design. All co-authors contributed to finalising the manuscripts.

\section{Declaration plagiarism}

I hereby confirm that I have written this doctoral thesis independently, that I have not used other sources or facilities other than the ones mentioned, that I have not used unauthorized assistance and that I have not submitted this thesis previously in any form for another degree at any university or institution.

Göttingen, July 2011 